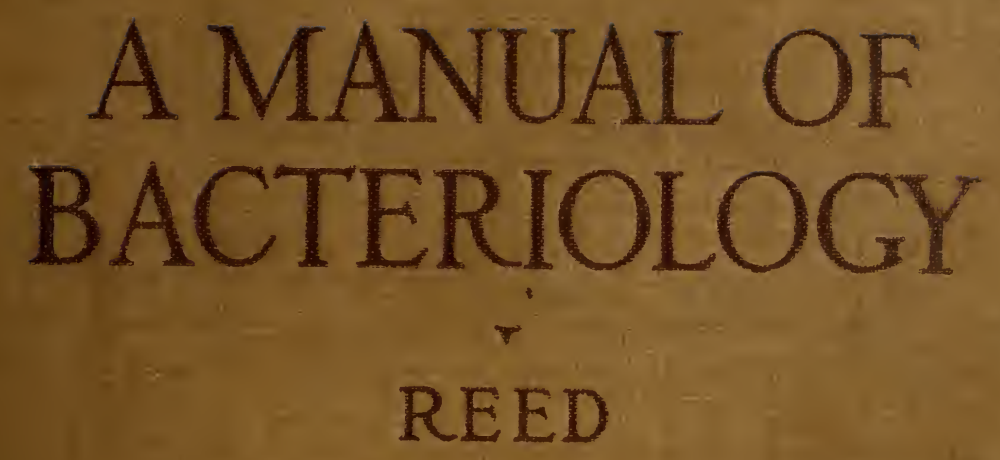

5

$$
3_{3}=4=0
$$


- Cohn Q.MsDonald -

MEDICAR SCHOOZ UIIRARY
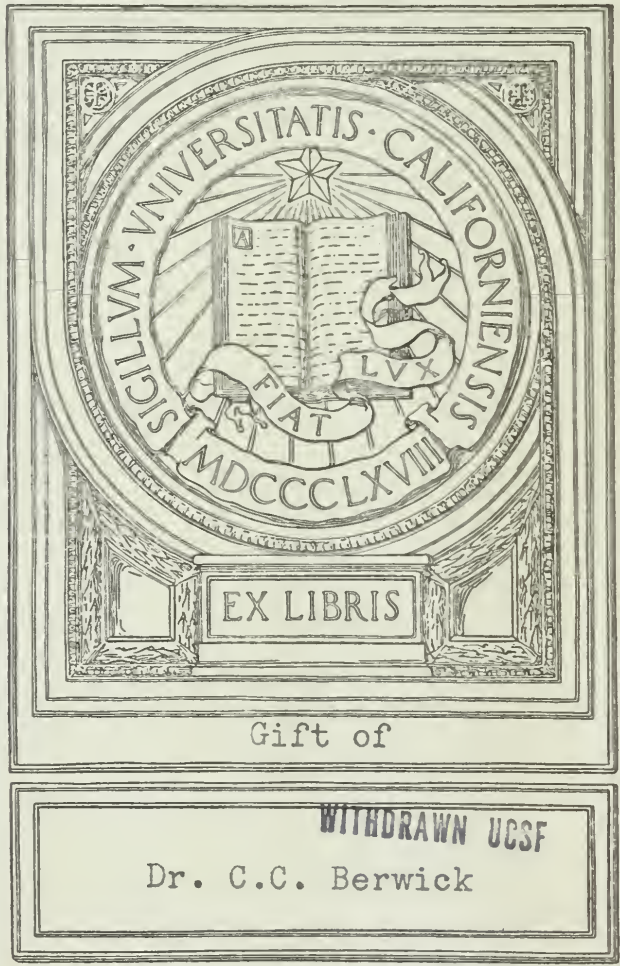
Eas Davis. 
1 


\section{A \\ MANUAL OF BACTERIOLOGY \\ FOR AGRICULTURAL AND GENERAL \\ SCIENCE STUDEN'TS}

BY

HOWARD S. REED, Ph.D.

PROFESSOR OF MYCOLOGY AND BACTERIOLOGY IN THE

VIRGINIA POLYTECHNIC INSTITUTE; PLANT PATHOLOGIST AND BACTERIOLOGIST

IN THE VIRGINIA AGRICULTURAL EXPERIMENT STATION

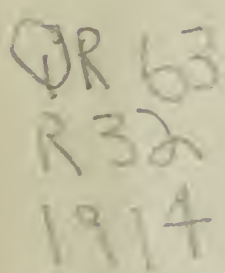

GINN AND COMPANY

BOSTON · NEW YORK · CHICAGO LONDON 
COPYRIGHT, 1914, BY

HOWARD S. REED

ALL RIGHTS RESERVED

614.1

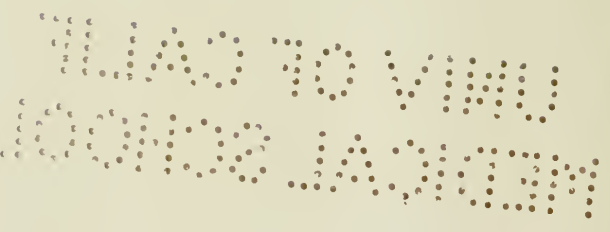

Ebe atbenxum Đress

GINN AND COMPANY . PROPRIETORS - BOSTON - U.S.A. 


\section{PREFACE}

The study of bacteriology in technical schools of all kinds has grown rapidly in the past few years, and especially in the institutions which teach agriculture and allied subjects. The present work is an attempt to outline a profitable course for students in such classes. The Manual is the outgrowth of several years' experience in teaching bacteriology to students of agriculture and engineeiring, and includes some experiments which have not previously appeared in print.

The writer has tried to outline many experiments calling for the simplest kind of equipment, but which should acquaint the student with some fundamental facts concerning bacteria. In the main, however, the Manual is devoted to more extended experiments which call for precise results and need precise apparatus for their performance. Wherever possible the experiments are planned to give quantitative results, to the end that vagueness of statement and uncertain thinking may disappear.

In addition to the outline for the study of bacteria, a section has been added outlining the study of important fermentations caused principally by fungi. In most cases the agricultural student desires to become acquainted with the more fundamental principles of the cultivation of these organisms.

The appendixes are intended to present in a convenient form both new and well-known methods. The section on sterilization is designed to aid the advanced tworker by supplementing the facts given in the body of the Manual. Emphasis is placed upon several facts recently brought out in investigations on sterilization.

References to the literature bearing directly upon the subject of the exercise have been introduced wherever possible. The conspicuous position of these references is designed to stimulate the student to do collateral reading. 
The section on soil bacteria has been read by Dr. J. G. Lipman, Director of the New Jersey Experiment Station. That on the bacteria of milk has been read by Professor E. G. Hastings, of the University of Wisconsin. My colleague, Dr. E. B. Fred, has prepared portions of the appendixes and given many valuable suggestions throughout the work. Mr. C. H. Crabill has aided greatly in the preparation of the illustrations.

In the preparation of the material, frequent use has been made of the manuals of Löhnis, Eyre, Frost, Heinemann, Abel, Russell and Hastings, Muir and Ritchie, and others, to which acknowledgment is due. 


\section{CONTENTS}

SECTION I. THE FORM AND OCCURRENCE OF BACTERIA

EXERCISE

PAGE

1. The Forms of Bacteria . . . . . . . . . . . . . 2

2. Types of Bacteria . . . . . . . . . . . . . 2

3. Spores of Bacteria . . . . . . . . . . . . . . 2

4. Motility of Bacterla . . . . . . . . . . . . . . 4

5. Zoöglea Forms . . . . . . . . . . . . . . . . 4

6. Comparison of the Shapes of Teasts axd dolo Fung with Bacteria . . . . . . . . . . . . . . 5

SECTION II. THE NUTRITION OF BACTERIA

7. Preparation of Nutrient dgar . . . . . . . . . 6

8. Preparation of Bolillon . . . . . . . . . . . . . . 9

9. Preparation of Nutrient Gelatin . . . . . . . . 10

10. Preparation of Potatoes for Cultures . . . . . . 11

\section{SECTION III. STERILIZATION}

11. Sterilization of Culturf Meda with Moist Heat in the ArNold TYPe of Sterilizer . . . . . . . . . . . 12

12. Sterilization of Culture Media with Moist Heat in the: Autoclave . . . . . . . . . . . . . 1:3

13. Results of Fractional Sterilization . . . . . . . 14

14. Sterilization of Dishes and Instrumexts by Dri Heat 1.)

SECTION IV. RELATION OF BACTERLA TO FACTORS OF THE PHYSICAL ENYIRONMENT

15. Relation of Bacteria to Oxygen (Growth) . . . . 16

16. Relation of Bacteria to Oxygex (Mothlitr) . . . . 16

17. Effect of Light rpon Bacteria . . . . . . . . $16^{\circ}$ 
18. Effect of Light of Different Wave Lengtus upon BacTERIAl Growtil . . . . . . . . . . . . . . . . 17

19. Relation of Bacteria to Heat . . . . . . . . 17

20. Relation of Bacteria to Concentration of Medium . 17

21. Effect of Drying upon Bacteria . . . . . . . 18

22. The Effect of Different Disinfectants . . . . . 18

\section{SECTION V. RELATION OF BACTERIA TO BIOLOGICAL FACTORS}

23. Rate of Growtil of Bacteria . . . . . . . . . 19

24. Сhemotaxis . . . . . . . . . . . . . . . . . . 19

25. Arrangement of Bacteria witi Respect to Each Other 20

26. Production of Enzymes . . . . . . . . . . . . . 21

SEGTION VI. FUNDAMENTAL MIETHODS USED IN THE CULTURE OF BACTERIA

27. Inoculation of Cultures on Solid Media . . . . . . 21

28. Ixoculation of Cultures ox liquim Media. . . . . . 23

29. Preparation of Milk for Use as a Cultere Medicm. 23

30. Preparation of Litmus Milk . . . . . . . . . 23

31. Preparation of Litmes Whey . . . . . . . . . . 23

32. Preparation of Witey Agar . . . . . . . . . . . 23

33. Preparation of Sugar Boyllion . . . . . . . . 24

34. Preparation of Sugar Gelatin . . . . . . . . . . 24

- 35. Preparation of Lituus-lactose Gelatin or Agar . . 24

36. Preparation of Glucose-Formate Boullox . . . . . 24

37. Preparation of Dunham's Solution. . . . . . . . . 25

38. Preparation of Phexol Boulllon . . . . . . . . 25

39. Preparation of Lactose Bile for Isolation of Intestinal. Bacteria . . . . . . . . . . . . . . . 25

40. Preparation of Neutral Red Brotil . . . . . . 25

41. Preparation of MacConkey's Bhle Salt Brotil . . . 26

42. Preparation of Monffed Giltay and Amerson's Fleid for Denitrifying Organisms. . . . . . . . . 26

43. Preparation of Iron Boulllon . . . . . . . . . 26

44. Preparation of Lead Bovillon . . . . . . . . . . . 26

45. Preparation of Glycerin Bolillon. . . . . . . . . 27

46. Preparation of yax Deldex's Solutiox . . . . . . 27

47. Preparation of Potato gejatin . . . . . . . . . . 27

48. Preparation of Heyden-ÿurgtof Agar . . . . . 27 
49. Preparation of Ashby's Solution

50. Preparation of Nitrogen-Free Media for Culture of Symbiotic Nitrogen-Fixing Bacteria . . . . . . 28

51. Preparation of Winogradsky and Omelianski's Solution for Cultivating Nitrite-Forming Organisms . . . . 29

52. Preparation of Winogradsky ani Omelianski's Solution for Cultivating Nitrate-Forming Organisms . . : $\quad$. 29

53. Preparation of Negeli's Solution . . . . . . . . . 29

54. Preparation of Czapek's Nutrient Solution for the Cultivation of Fungi . . . . . . . . . . . . . . 30

55. Preparation of Sulphindigotate Bouillon for Detecting Avä̈robic Organisms . . . . . . . . . . 30

56. Methods of Cultivating Anä̈robic Bacteria . . . 30

57. Preparation of Sterile Water Blanis . . . . . . . 32

SECTION VII. FUNDAMENTAL METHODS USED IN THE STAINING AND EXAMINATION OF BACTERIA

58. Preparation of Simple Stains . . . . . . . . . . . 33

59. General Method of Making Stained Preparations . . 34

60. Preparation of Contrast Stains . . . . . . . . . 35

61. Special Stains . . . . . . . . . . . . . . . . 36

62. Differential Staining . . . . . . . . . . . . . 37

SECTION VIII. FUNDAMENTAL METHODS OF ISOLATION

63. Isolation of a Pure Culture . . . . . . . . . . 39

SECTION IX. OUTLINE FOR THE ROUTINE CULTIVATION OF BACTERIA

64. Prelininary Examination . . . . . . . . . . . . 41

65. Study of Bacterial Characters. . . . . . . . . 41

SECTION $\mathrm{X}$. BACTERIA OF THE AIR

66. Relation of Bacteria to Atmospheric Dust . . . . 48

67. Determination of the Number of Bacteria in Air . . 48

68. Study of Micrococcus Candicans . . . . . . . . 50

69. STUdy of SARCINA LUTEA . . . . . . . . . . . . . . 50

70. STUDY OF BACILLUS FLUORESCENS LIQUEFACIENS . . . . . . 50

71. StUdy of BaCILLUS Prodigiosus . . . . . . . . . . . 50

72. Study of Bacille's setbtilis (Hay Bacillus) . . . . . . .0 


\section{SECTION XI. BACTERIA OF WATER AND SEWAGE}

73. Collecting Saiples of Water. . . . . . . . . 51

74. Quantitative Study of Bacteria in Surface Waters . 52

75. Qualitative Study of Bacteria ix Surface Waters . 53

76. Prescaptive Test for Bacilles coli . . . . . . . 54

77. Tests for Fecal Bacteria . . . . . . . . . . 5t

78. Quantitative Examination of Sewage . . . . . . . 55

79. Bacterial Content of Snow and of Rain Water. . . $5 \overline{5}$

80. Study of Streptococci . . . . . . . . . . . 5.

81. IsOlation of BACILLt's COLI . . . . . . . . . . . 56

82. Study of Characters of Bacillus Coli . . . . . . . 57

83. Study of Bacillus protel's V'tlgaris . . . . . . . . . . 57

84. Study of Ä̈robic Organisis Which Decompose Cellulose jo

85. Study of Axa Ërobic Organisus Which Deconpose Chlltlose 58

86. Cellulose Decomposition with Formation of Hyirogex 59

\section{SECTION XII. BACTERIA OF THE SOIL}

87. Obtaining Soll Sampies . . . . . . . . . . . 60

88. Preparing Dilutions ant Pouring Plates . . . . . 61

89. Deternination of tile Number of Syores in Sorl . . . 61

90. Ammonification of Peptone by Soll Bacteria . . : . 62

91. Ammoxification of Nitrogenots Sibstaxces ix soll . 63

92. Nitrite Formation in Solution . . . . . . . . . 64

93. Nitrate Formation in Solution . . . . . . . . . . 64

94. Nitrification in Soll . . . . . . . . . . . . . 6.

95. Reduction of Nitrates by Bacteria. . . . . . . . 66

96. The Redicing Action of Denitrifying; Bacteria roon

Nitrates And Metilylene Ble . . . . . . . . 66

97. Nonsyabiotic Bacteria which Fix Atmospheric Nitrogex.

Isolatiox axd Study of Azotobacter . . . . . . 67

98. Growth of Azotobactir in Pure Cultures . . . . . 67

99. Symbiotic Bacteria wilch Fix Atmosplieric Nitrogen.

BACILLUS RADICICOLA . . . . . . . . . . . . 68

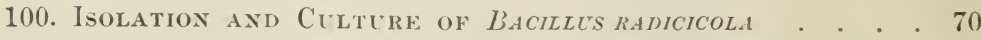

101. The Production of Bacteroids of Bacilles Radicicola

upon Artificial Media . . . . . . . . . 70

102. The Formation of Tubercles upon Roots of Legumes . 71

103. The Reduction of Selphates by Bacteria . . . . . 71

104. The Celtivation of Bacille's amyobacter . . . . . . T2

105. STEDY OF B.ACILLYY MYOIIES. . . . . . . . . . . . T.2 
106. Study of Bacillus Vulgatus. . . . . . . . . . . 72

107. StUdy OF BACILLUS DENITRIfiCANS . . . . . . . . . . 73

108. StUdy of BACILLUS RADTCTCOLA . . . . . . . . . . 73

\section{SECTION XIII. BACTERIA OF MILK}

109. The Contanination of Mrlk with Bacteria from Various Sources . . . . . . . . . . . . 74

110. Quantitative Examination of the Organisms in Milk . 75

111. Determination of the Numbers of Bacteria in Milk by Direct Microscopical Examination . . . . . . 76

112. The Examination of Milk for Body Cells . . . . . 77

113. A Direct Microscopical Method for Determining the Number of Body Cells in Milk . . . . . . . . 78

114. The Germicidal Action of Fresil Milk . . . . . . 78

115. The Catalase of Milk . . . . . . . . . . . . . 79

116. The Relation of Bacteria to the Normal Solvixg of

MrLK . . . . . . . . . . . . 80

117. The Fermentation Test . . . . . . . . . . . . 81

118. Study of Curds Forined by Diffelient Organisms . . 82

119. The Reducing Action of Milik of High axil Low Geri Content . . . . . . . . . . . . . . . . . . 82

120. The Effect of Pasteurization upon Different Bacteria 84

121. Study of BACteriUM LACTIS-ACIDI . . . . . . . . . . 84

122. STUDY OF BACILLUS LACTIS AËROGENES . . . . . . . . . 85

123. Study of Bacilles slbtilis and the Trpe of Fermenta-

tion it Pronuces. . . . . . . . . . . . . . . 8.

124. Study of BACILLUS CYANogents . . . . . . . . . . 86

125. STUDY OF BACILLUS LACTIS VISCOSUS . . . . . . . . . . 86

126. STUDY OF MICROSPIRA TYROGENA . . . . . . . . . . 86

127. STUDY OF OIDIUM (OOSPORA) LACTIS . . . . . . . . . 87

\section{SECTION XIV. BACTERIAL DISEASES OF PLANTS}

128. The Blight of Pone Fruts Cacseid by Bacillés AMYLVORUS . . . . . . . . . . . . . . 88

129. The Wilt of Sweet Corn Caused by Pseldoholas STEWARTII . . . . . . . . . . . . . 89

130. The Black Rot of Cabbage Catslid by Bacildís CaMpestris 89

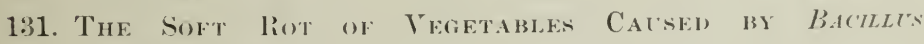

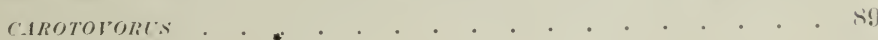




\section{SECTION XV. BACTERIAL DISEASES OF MAN AND ANIMALS}

132. Preparing a Disinfectant . . . . . . . . . . . 92

133. Axtimax (Splexic Fever) . . . . . . . . . . . 92

134. Tuberculosis (Consumption, Phthisis) . ' . . . . . 94

135. Greer Pus . . . . . . . . . . . . . . . . . 95

136. Septiciemia, Ixflanition, etc. Caused by Streptococcus PYOGENES . . . . . . . . . . . . . . . 96

SECTION XVI. SOME ORGANISMS CAUSING IMPORTANT FERMENTATIONS

137. Norphology of Yeast (Saccharomyces) . . . . . 9S

138. Reproduction of Yeast by Budding. . . . . . . . 98

139. Spore Formation in Yeast . . . . . . . . . . . 99

140. Preparation of Pure Clutures of Yeast from Single

Cells . . . . . . . . . . . . . . 100

141. Cultivation of Yeasts . . . . . . . . . . . 100

142. The Intertase of Yeast . . . . . . . . . . . . 101

143. The Zruase of Yeast . . . . . . . . . . 102

144. Tile Preparation of Yeast Jlice . . . . . . . 102

145. The Preparation of an Active Yeast Powder . . 103

146. Tile Estmation of tine Chiff Products of the Fer-

mentation of Sugars . . . . . . . . . . . . : 104

147. The Fermentation of Breai Dolgi . . . . . . 105

148. The Fermentation of Ciner . . . . . . . . . . . 107

149. The Fermentation of Wine . . . . . . . . 107

150. Tile Fermentation of Vinegar . . . . . . . 108

151. Stedy of Mecor . . . . . . . . . . . 108

152. Stedy of Pexicillicil . . . . . . . . . . . . 110

153. StUdy of Aspergillés . . . . . . . . . . . . 111

154. Stedy of Torela . . . . . . . . . . . . . . . 112

155. STUDY OF DEMATIUM PULLCLAAS . . . . . . . . . . . 112

156. Obtaining Mold Celteres from Spores in the Air. . 113

157. Culture of Molns ox Liquid Media . . . . . . 113

158. The Stinulating Action of Weak Polsoxs . . . . 113

159. Demoxstration of the Presence of Arsenic by Means OF PextCILLIUM BREVICACLE . . . . . . . . . . . 114

160. Tile Amylolytic Power of Moldi . . . . . . . 114

161. The Peptoxizing Action of Molim . . . . . . . 11 t 
APPENDIX A. STERILIZATION

Sterilization witi Chemicals . . . . . . . . 115

Sterilization with Heat . . . . . . . . . . 117

Hot-Air sterilization . . . . . . . . . . . 117

Steali sterilization At $100^{\circ}$ C. . . . . . . . . 118

Steali sterilization Under pressure . . . . . . . 119

Partial sterilization - Pasteurization . . . . . 120

Sterilization by Filtration . . . . . . . . . 121

Sterilization by Ligit . . . . . . . . . . . . 124

The Technique of Sterilization for Special Purposes 125

Glassware, pipettes, ANd instruments . . . . . 125

Liquid MEDIA AND OTHER SOLCTIONS. . . . . . 125

Gelatix AND AgAR MEDia . . . . . . . . 126

Sugar-containing Media . . . . . . . . . . . 127

Solid Vegetables . . . . . . . . . . . . . 127

MILK . . . . . . . . . . . . . . . . . 127

BLOOD SERCM . . . . . . . . . . . 128

SoIL . . . . . . . . . . . . . . . . . . 128

SEEDS . . . . . . . . . . . . . . . 131

GrowiNg higiner plants UNIER Sterile conditions • 134

APPENdix B. Handling Stock Clltures . . . . . . 138

appendix C. Making Permanent Preparations . . . . 139

Appendix D. The Inoculating Chamber . . . . . . 141

appendix E. The Titration of Boullon . . . . . . 142

APpendix F. The Determination of Ammonia . . . . 143

APpendix G. The Determinatiox of Nitrate . . . . 146

APPEndix H. The Determination of Nitrite . . . . 148

APPEndix I. The Determination of Nitrites by Tromisdorf's

METHOD . . . . . . . . . . 150

APPendix J. Deternination of Total Nitrogex *. . . 151

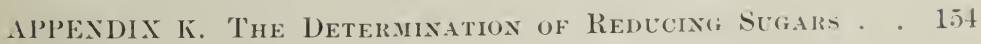


appendix L. Titanicm Trichloride Solution: its PrepaRATION AND STANDARDIZATION . . . . . 159

APpendix M. Measures axd Weights - Conversion Tables 160 Appendix N. Alcohol Table (Modified from Windiscii) a 162 appendix 0. Comparisox of Fahrexheit axd Centigrade Thermometer Scales . . . . . . . . . 164 APpendix P. Chart of the Society of American BacTERIOLOGISTS . . . . . . . . . . . 16 J INDEX . . . . . . . . . . . . . . 175 


\section{A MANUAL OF BACTERIOLOGY}

\section{SECTION I \\ THE FORM AND OCCURRENCE OF BACTERIA}

Bacteria are small and simply organized plants. For the most part they consist of single cells, but some consist of filaments made up of separate individuals and show some tendency toward a physiological division of labor. The bacterial cell is supplied with a definite cell wall which incloses living protoplasmic substance. Bacteria multiply by simple division, usually constricting in the middle and forming two new cells from each mother cell.

The first recorded descriptions of bacteria are those of Leeuwenhoek, a Dutchman, which were written in 1683. Most of our knowledge of bacteria, however, has been obtained since the year 1869 .

We have learned that bacteria are widely distributed in nature. The soil and natural waters contain large numbers of them. The dust particles in the air carry numbers of germs. In thickly populated regions the number of germs in the air is larger than in sparsely settled districts, while the air over the sea and on the tops of high mountains is quite poor in bacteria.

We find that bacterial activities are intimately associated with processes of growth and decay, health and disease, life and death. Although there are certain bacteria which cause diseases, yet the sum total of their activities is beneficial to the human race, and it is certain that life as we know it could not long exist on the earth were it not for their action. The study of these organisms has led to the solution of many of the important problems of human welfare. 


\section{Exercise 1. The Forms of Bacteria}

Using prepared laboratory slides, examine bacteria of different origin. Note that the organisms have been stained artificially. You will need to use a microscope having an oil-immersion lens and an Abbe condenser with an iris diaphragm (Fig. 1). ${ }^{1}$

\section{Exercise 2. Types of Bacteria}

1. Place a small drop of Gram's iodine solution on a glass slide. With a needle transfer a bit of scum from a hay infusion to the drop of iodine solution. Tease it up and put over it a cover glass. Examine with the microscope. Describe the different types of bacteria found.

2. Following the directions given in Exercise 59, stain bacteria from the hay infusion, using methylene blue or carbol-fuchsin. Sketch the types of bacteria seen on the stained preparation.

3. With a clean knife or needle scrape a little of the material attached to your teeth and spread it in a very thin layer on a cover glass. Dry, fix, and stain as before. Sketch the types of bacteria seen on the stained preparation.

\section{Exercise 3. Spores}

Search the stained preparations made in Exercise 2 for rods which contain oval glistening bodies. These bodies are spores which, on account of their resistant walls, did not take the simple stains employed. How many spores do you find in a rod? Examine prepared slides of Clostridia showing rods swollen by the presence of a large spore. Spores are more resistant to unfavorable conditions than the vegetative cell.

${ }^{1}$ A suitable microscope for bacteriological purposes would have both coarse and fine adjustments and the following fittings: 2 oculars, 1 in. $(\times 8)$ and 2 in. $(\times 4)$; 3 objectives, $\frac{2}{3}$ in. $\left(16 \mathrm{~mm}\right.$.), $\frac{1}{6}$ in. $\left(4 \mathrm{~mm}\right.$.), and $\frac{1}{12}$ in. (2 mm.) oil-immersion objective, mounted on a triple revolving nose piece, together with an Abbe condenser in the substage. It is not so important that the image shall be large as that it shall be sharp and clear. When you have finished for the time being with the oil-immersion lens, remove the oil with a piece of Japanese lens paper. If the oil has dried upon the lens, soften it by the addition of more oil and allow it to stand several minutes, when it can usually be removed with the paper. If this method does not succeed, you should call the instructor. 


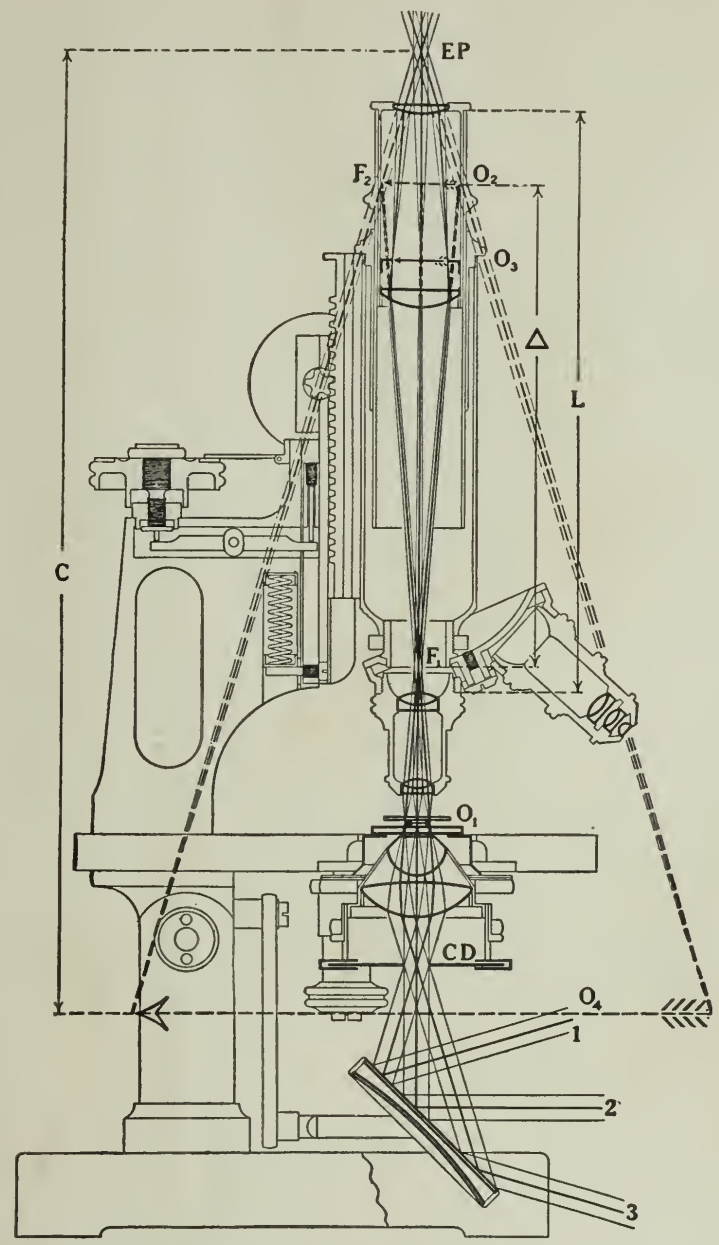

FIg. 1. Diagram to show the parts of the compound microscope. (After Russell and Hastings)

$\mathrm{O}_{1}$, object; $\mathrm{O}_{2}$, real image in $F_{2}$, transposed by the collective lens to $\mathrm{O}_{3}$, real image in eyepiece diaphragm; $\mathrm{O}_{4}$, virtual image formed at the projection distance $C, 250$ inm. from eyepoint $E P$; $C D$, condenser diaphragm; $L$, mechanical tube length (160 mm.) ; 1, 2, 3, three pencils of parallel light coming from different points of the source of illumination. (After Bausch \& Lomb Optical Co.) 


\section{Exercise 4. Motility of Bacteria}

Transfer a small quantity of bacteria from an agar culture twenty-four hours oll, or a drop from a hay infusion, to a clean cover glass. Take care to use a small drop and place it at the

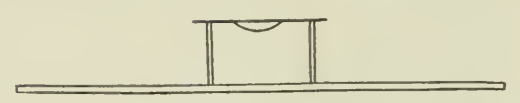

FIg. 2. Van Tieghem cell for work with

The cover glass is supported on the top of the cell hanging drop, as seen in section

center of the cover glass. Place a Van Tieghem cell on a slide and quickly invert the cover glass on the top of the cell (Fig. 2). Examine this with the $\frac{1}{6}$ objective $(4 \mathrm{~mm}$.$) and with the dia-$ phragm nearly closed. It will be very difficult at first to see the bacteria, but by careful focusing they will appear as transparent dots or rods. Examine carefully to see whether they are stationary or motile, distinguishing those as motile which actually move back and forth across the stage, and not those which simply dance back and forth without locomotion (the Brownian movement, exhibited by inanimate particles also). What causes the bacteria to have the power of motion? Are cocci self-motile?

\section{Exercise 5. Zoöglœa Forms}

The cell walls of most bacteria have a gelatinous outer sheath. Examine stained preparations for chains of bacteria. Do the
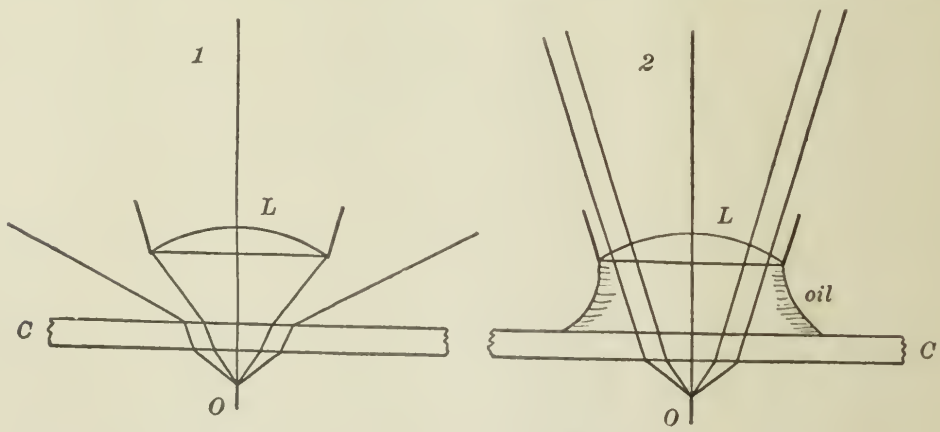

Frg. 3. Optical principles of dry lens and oil-immersion lens compared

1, path of light in a dry-lens system; 2, path of light in an oil-immersion lens system; $O$, object ; $C$, cover glass; $L$, lens of the objective 
indiviclual bacteria touch each other? Is the intervening space always equal? Examine the surface of a hay infusion for a zoöglœa mass.

\section{Exercise 6. Comparison of the Shapes of Yeasts and Mold Fungi with Bacteria}

Put a piece of baker's yeast into a 3 per cent cane-sugar solution, and place the dish for a few hours in a warm place $\left(25^{\circ}-30^{\circ} \mathrm{C}\right.$.). Examine a drop of the solution containing yeast cells, comparing their size, form, and structure with that of the bacteria studied above. Examine microscopically such mold fungi as Mucor, Aspergillus, or Penicillium. How do these organisms compare with bacteria in respect to size and complexity of structure?

\section{SECTION II}

\section{THE NUTRITION OF BACTERIA}

Bacteria require for their nourishment compounds of carbon, nitrogen, hydrogen, sulphur, oxygen, phosphorus, potassium, and magnesium. For some organisms iron and calcium compounds are also needed. A few bacteria may use carbon dioxide in gaseous form, and several use elementary nitrogen, but most bacteria require compounds of the above elements in suitable form. In nature, bacteria are found growing upon more or less complex organic substances. Unlike the chlorophyll-containing plants, most bacteria are unable to lay hold of the atmospheric carbon dioxide, but must derive their carbon compounds from other plants or animals, or from excreta from these organisms.

A proper amount of moisture is required in order that certain of the compounds may be dissolved. If water is too abundant, the food supply will be too dilute to supply the needs of the bacteria; on the other hand, if water is scantily supplied, the concentration of solutes is too high to permit of absorption, if indeed they are dissolved at all.

In making artificial culture media the general principle holds that the medium should approximate as closely as possible that 
on which the organism is found to grow in nature. For the study of pathogenic bacteria investigators make use of meat extracts, blood serum, etc. Beef extract in some form is the basis of nutrient media for many bacteria, since it furnishes carbon and nitrogen in such suitable combinations. By the addition of agar-agar or of gelatin we obtain a solid medium which may be easily liquefied by heat.

Agar-agar is a colloidal substance prepared from seaweeds growing on islands in the Pacific Ocean. Agar is liquefied at about $90^{\circ} \mathrm{C}$. and hardens at about $45^{\circ} \mathrm{C}$.; it can therefore be incubated at $37.5^{\circ} \mathrm{C}$. without rlauger of liquefaction. Agar media are not usually affected by the peptonizing action of bacteria. Few instances have been reported in which agar media, were liquefied by bacteria.

Gelatin is a colloidal substance of animal origin. It consists chiefly of chondrin and gluten and is prepared from bone, tendon, and hide. Gelatin media are liquefied at $35^{\circ} \mathrm{C}$. and harden at about $24^{\circ} \mathrm{C}$.

Gelatin media are better suiter for the growth of many bacteria than agar media, especially for bacteria which are natives of the bodies of warm-blooded animals.

The peptonizing enzymes produced by many bacteria and fungi liquef y gelatin, each in its characteristic manner. 'The type of liquefication caused by bacteria in stab cultures is used as a diagnostic character.

We are indebted to Robert Koch for the introduction of gelatin and agar-agar into bacteriological work.

\section{Exercise 7. Preparation of Nutrient Agar}

1. Place in a clean beaker or granite-ware pitcher the following substances, in the order named. Two students may coöperate to make double the quantity named.

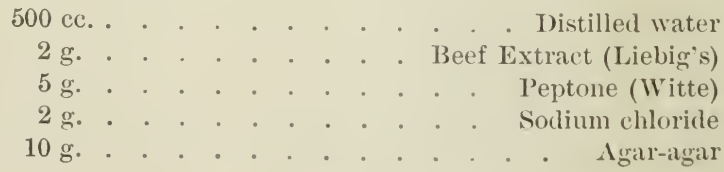


2. Dissolve these ingredients by boiling them over a gas flame with constant stirring. A better method, and one that obviates the danger of burning the material, is to cook it in the autoclave at $10 \mathrm{lb}$. steam pressure (see Exercise 12). After cooking for twenty minutes add $50 \mathrm{cc}$. distilled water to replace that lost by evaporation.

3. Filter immediately through a thin layer of wet absorbent cotton in a funnel. Place the filtered medium in a funnel with delivery tube and pinchcock, as shown in Fig. 5.

4. Fill test tubes to the depth of about $4 \mathrm{~cm}$. with the liquid agar, taking care that none is smeared on the inner surface of the tube near the mouth, as this will cause the cotton to stick to the glass when the plugs are removed.

5. Plug the mouths of the test tubes with cotton. The plugs are rolled from strips of cotton about $5 \mathrm{~cm}$. wide, and should fit firmly enough to allow the tube to be lifted by that part which projects; at the same time they should be loose enough to permit interchange of gases. The plug should extend into the tube for about $3 \mathrm{~cm}$., and should be in contact with the wall throughout this distance. The part of the plug which projects from the mouth of the tube

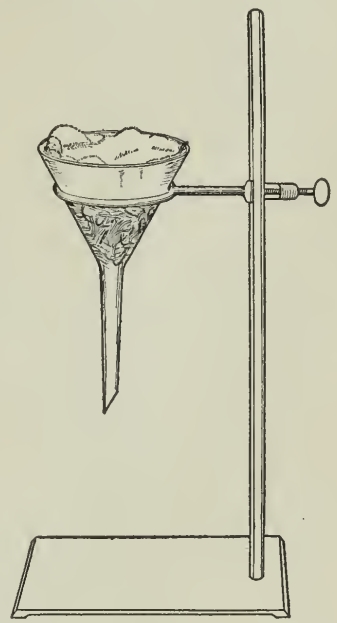

FIG. 4. Funnel arranged for filtering agar media

The layer of absorbent cotton is supported by a wad of excelsior or clean straw should overhang the lip of the tube enough to prevent dust from lodging there (Fig. 6).

6. Sterilize in the autoclave according to directions given in Exercise 12.

7. After sterilization lay the tubes in an oblique position, so that the agar may solidify in the manner shown in Fig. 7. This produces what is known as an agar slant, or agar slope, and is much used because it gives a larger surface for the development of the bacterial colony. 


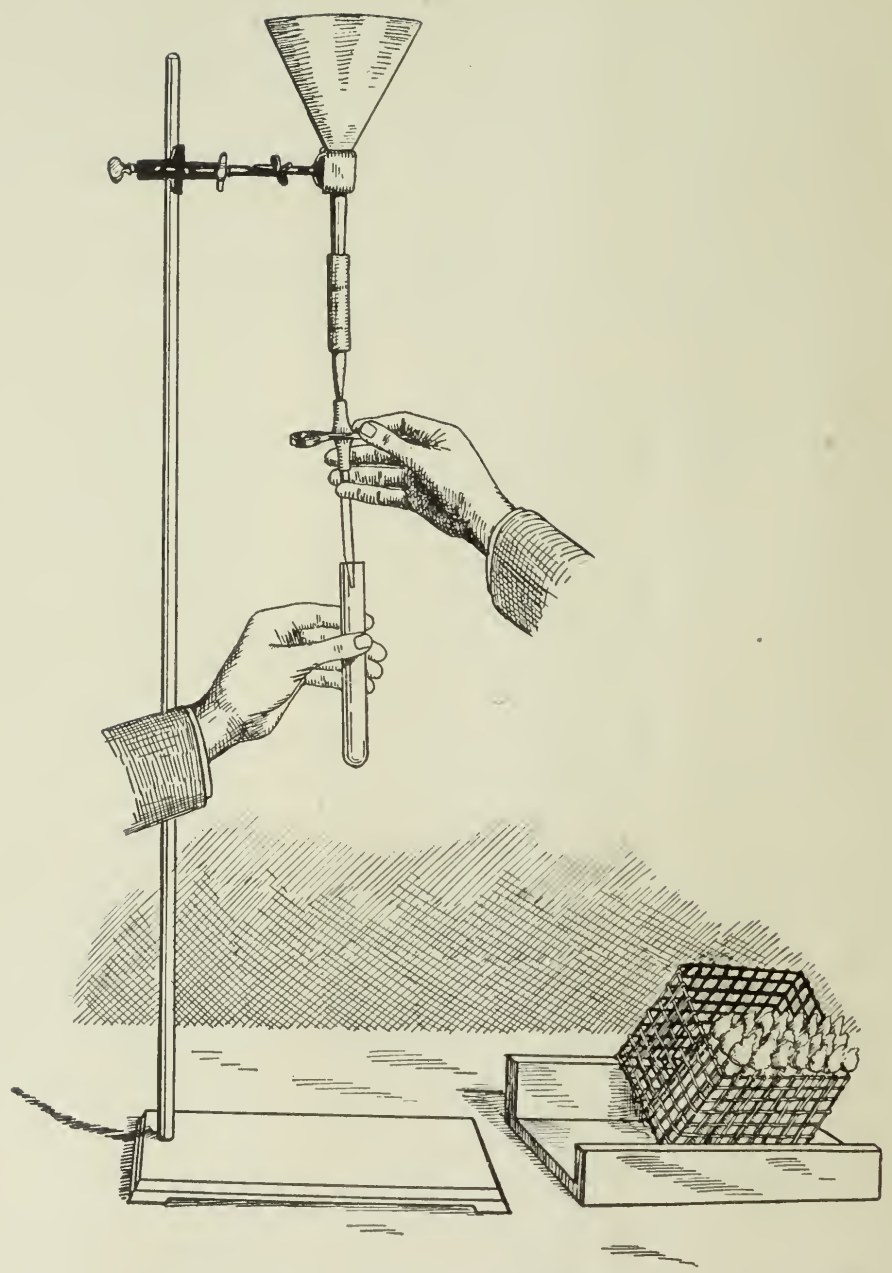

Fig. 5. Method for filling test tubes with liquid media. (After Russell and Hastings)

Hold the tip free from the walls of the tube and avoid smearing the mouth of the tube with the medium 


\section{Exercise 8. Preparation of Bouillon}

Two methods of preparation are used by bacteriologists, but method $B$ is more convenient and hence more generally used. It is open to the following objection: Liebig's Beef Extract (the one commonly used) often contains very resistant bacterial spores. Triple sterilization at $100^{\circ} \mathrm{C}$. sometimes fails to kill these organisms; however, the bouillon can be sterilized by heating to $120^{\circ} \mathrm{C}$. in the autoclave and subsequently used either as a culture medium or as a basis for making up nutrient gelatin, agar, etc.

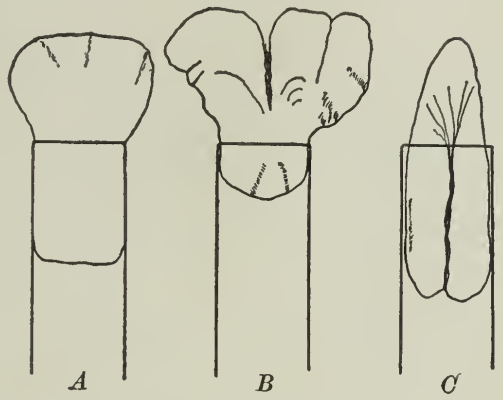

Fig. 6. Cotton plugs

$A$, correctly made plug; $B$, shallow plug which will be easily displaced; $C$, plug which does not protect the tube from the entrance of dust

\section{A}

\section{B}

1. Place 500 g. of lean chopped beef, free from fat, in $1000 \mathrm{cc}$. of distilled water. Stir and set in a refrigerator for twelve to twenty-four hours.

2. Strain the meat water through a piece of clean cheesecloth. Add distilled water to make filtrate up to 1000 ce. Place in a flask or agate-ware kettle for cooking.

3. Add to either of the above $10 \mathrm{~g}$. peptone and $5 \mathrm{~g}$. sodium chloride. Weigh the vessel containing the solution on a balance and record the weight.

4. Cook the bouillon on a steam bath or in the Amold sterilizer fifteen to twenty minutes. Add water to restore to the original weight. 
5. Neutralize. If method $B$ has been used, neutralization is often unnecessary, but the reaction should be tested in every case. For research work the method described in Appendix E is more accurate and should be used. For student work the

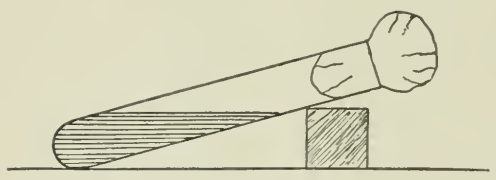

FIG. 7. Method of making an agar slant following method is satisfactory: Add to the hot bouillon a few cubic centimeters of a normal solution of sodium hydrate. Stir thoroughly with a glass rod. Test the reaction by touching the end of the wet stirring rod to a strip of neutral litmus paper. Continue the addition of small quantities of sodium hydrate solution until the litmus paper shows only a faint pink color.

6. Boil for five minutes and restore water lost.

7. Add 0.5-1.5 ec. normal hydrochloric acid solution. For ordinary work 1.0 ce. acid is employed.

8. If the precipitate in the bouillon is mealy, filter through folded, moistened filter paper ; if not, the bỏillon must be cooked again until the precipitate becomes mealy, and then filtered.

9. Place the bouillon in plugged tubes or flasks and sterilize twenty minutes at $120^{\circ} \mathrm{C}$. in the autoclave.

\section{Exercise 9. Preparation of Nutrient Gelatin}

1. Measure 500 ce. sterile bouillon, made according to Exercise 8 , into a clean beaker or pitcher.

2. Arld Gold Label gelatin. In cold weather a quantity equal to 10 per cent of the bouillon used is ample, but in warm weather 15 per cent gelatin should be used.

3. After weighing the ressel and its contents, place it in the Arnold sterilizer or on a steam bath until the gelatin is melterl.

4. Neutralize as in Exercise 8 ; then boil five minutes.

5. Filter through absorbent cotton while hot. Much clearer gelatin may be obtained if the solution, before being filtered, is allowed to cool somewhat and the white of an egg added, then cooked again until the egg white is completely coagulated before filtering. Fill test tubes to a depth of $t_{-i}^{-i} \mathrm{~cm}$. 
6. Plug tubes with cotton and sterilize in the Arnold sterilizer for twenty-five minutes on three consecutive days.

Caution. Long exposure to high temperature may alter the gelatin so that it will not solidify when cool.

\section{Exercise 10. Preparation of Potatoes for Cultures}

Potatoes have been for a long time used in bacteriological work. At the present time they are used chiefly for test-tube cultures, the former use of potato slices for isolating bacteria having been displaced by the use of gelatin or agar media in Petri dishes.

1. Select lạge, ripe potatoes and scrub them in water. Remove the eyes. Cut plugs from the potatoes with the special cutter or with a large cork-borer. The pieces should be dropped at once into cold water and washed several times, if they are to be kept white. Divide the cylinders with a diagonal cut and trim if necessary to fit tubes.

2. The pieces of potato should be put into large test tubes containing a few drops of water. Some device is necessary to keep the potato plugs from standing in the water. Roux test tubes accomplish this by means of a constriction near the bottom. Ordinary test tubes may be used, however, by first
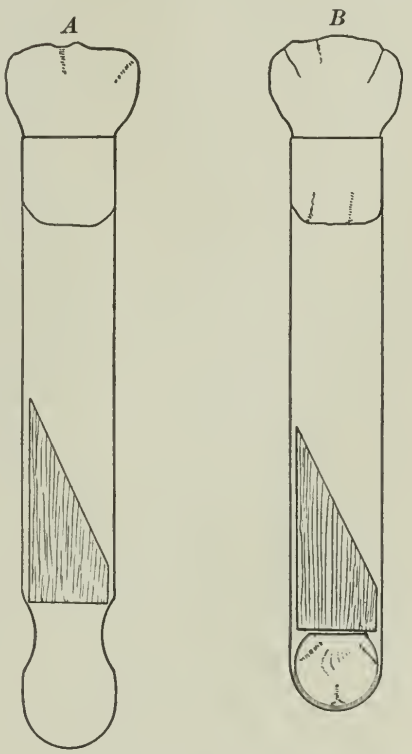

Frg. 8. Potato tubes

1, Roux tube, with coustriction to hold the plug out of the water; $B$, ordinary tube, with cotton wad supporting the plug putting in glass beads or a wad of absorbent cotton (Fig. 8).

3. After plugging the tubes with cotton, sterilize them on four consecutive days in the Arnold sterilizer, or once in the autoclave at $115^{\circ} \mathrm{C}$. The potato bacillus (Bacillus mesentericus vulgatus: is often very difficult to kill, and the potato media should be watched for a week to make sure that they are sterile. 


\section{SECTION III}

\section{STERILIZATION}

The air in few places is free from bacteria. At times the number of germs in the air is quite large; if they fall upon suitable media, they soon begin to grow and to cause more or less extensive changes in the composition of the media. Therefore some method of preserving the media from change is necessary. Moreover, for exact work it is generally imperative that we have none other than the desired species under cultivation, that is, a pure culture.

Hence the necessity arises that the culture medium should not only be cleared of all germ life before using, but that foreign germs should be prevented from entering after the sterile condition is once attained. The operations of sterilization are directed to this end. Heat is the best and most generally applicable method we have for sterilizing culture media. Dry heat and moist heat are both employed, but these differ somewhat in efficiency.

\section{Exercise 11. Sterilization of Culture Media with Moist Heat in the Arnold Type of Sterilizer}

The most efficient type of sterilizer for work at the temperature of boiling water is the Arnold sterilizer, which has super-

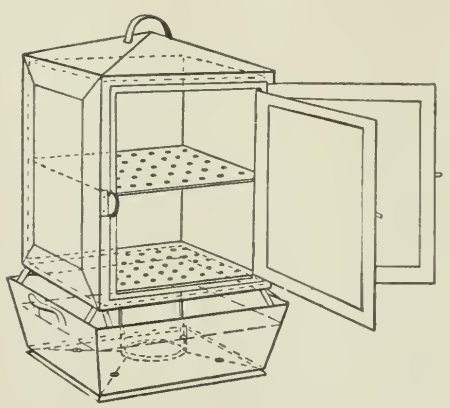

Fıc. 9. Arnold sterilizer

The false bottom holds only a thin layol. of water, which can be quickly boilecl seded the old Koch steam chest. The Arnold type of sterilizer is so constructed that only the water in the false bottom needs to be boiled to furnish steam, and the steam circulates in the sterilizing chamber (Fig. 9). The steam which escapes from the top of the chamber is condensed between the two walls and drips back into the pan. There should be a thermometer in the roof of the sterilizing 
chamber. Plenty of water should always be supplied to the lower pan before heat is applied.

Culture media should be steamed for twenty minutes, beginning to count the time when the thermometer records $100^{\circ} \mathrm{C}$. The media should be steamed on three successive days. Why? Between steamings the media should be kept at temperatures favorable for spore germination. Why? This is known as Tyndall's method of fractional sterilization, or as Tyndallization.

\section{Exercise 12. Sterilization of Cul- ture Media with Moist Heat in the Autoclave}

Both spores and bacteria are killed within half an hour when exposed to moist heat at temperatures of $110^{\circ}-120^{\circ} \mathrm{C}$. In practice these temperatures are usually obtained by sterilization in a strong, tightly closed chamber. The autoclave is the form generally used (Fig. 10).

The autoclave is first supplied with a small quantity of water, the culture media are put in, and the lid screwed on tightly. Heat is applied to the bottom to boil the water supplied. The stopcock at the top of the cham-

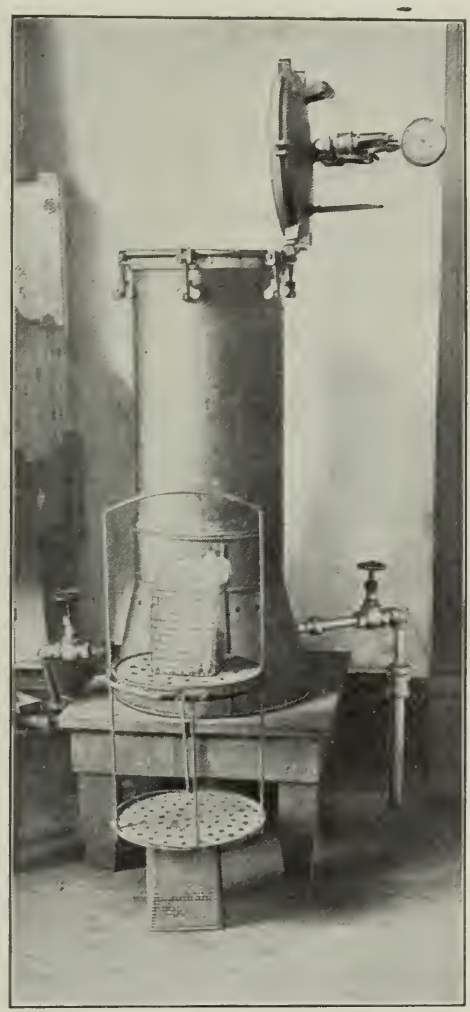

Fig. 10. Autoclave fitted with steam connections

This type can also be heated by a large gas burner ber is kept open until all the air is expelled and steam escapes from the opening. The chamber may then be assumed to be at a temperature of $100^{\circ} \mathrm{C}$. and to be nearly if not entirely free from air. The stopenck is then closerl and pressure developed up to $15 \mathrm{lb}$. The autoclare is 
usually supplied also with a safety valve. The following table gives the temperatures corresponding to the pressure shown on the gauge.

TEMPERATURE CORRESPONDING TO STEAM PRESSURES

\begin{tabular}{c|c|c||c|c|c}
\hline \hline \multicolumn{2}{c|}{ Temperatures } & Steam pressures & \multicolumn{2}{|c|}{ Temperatures } & Steam pressures \\
\cline { 1 - 3 } \cline { 3 - 5 } Fahr. & C. & Pounds & Fahr. & C. & Pounds \\
212 & 100.0 & 0 & 251 & 121.5 & 15 \\
228 & 109.0 & 5 & 260 & 126.5 & 20 \\
240 & 115.5 & 10 & 287 & 141.5 & 40 \\
\hline \hline
\end{tabular}

An exposure of twenty minutes with a temperature of $120^{\circ} \mathrm{C}$. is sufficient to kill all germ life. After cutting off the heat the stopcock is opened and the steam allowed to escape slowly, else the culture media may boil up and force the plugs out.

\section{Exercise 13. Results of Fractional Sterilization}

Select eight tubes of sterile nutrient agar and give successive numbers. Melt the agar and cool until the tubes can be held in the palm of the hand. Inoculate all the tubes from a hay infusion. Pour tubes 1 and 2 immediately into sterile Petri dishes. Place the remainder in the Arnold sterilizer and steam them twenty-five minutes at $100^{\circ} \mathrm{C}$.; remove and immediately pour 3 and $t$ into sterile Petri dishes, setting away the remainder. 'The following day heat the remaining tubes as before and pour 5 and 6 . On the following day repeat with 7 and 8. Count the colonies on each plate the third day after pouring, and average the duplicates. Why were not all germs killed after the first heating? What explanation does this experiment give for the old theory of spontaneous generation?

\begin{tabular}{l|c|c|c|c}
\hline \hline $\begin{array}{c}\text { Colonies developing in } \\
\text { forty-eight hours }\end{array}$ & $\begin{array}{c}\text { Agar not } \\
\text { heated }\end{array}$ & $\begin{array}{c}\text { Agar once } \\
\text { heated }\end{array}$ & $\begin{array}{c}\text { Agar twice } \\
\text { heated }\end{array}$ & $\begin{array}{c}\text { Agar three } \\
\text { times heated }\end{array}$ \\
\hline & & & \\
\hline
\end{tabular}


Exercise 14. Sterilization of Dishes and Instruments by Dry Heat

The hot-air sterilizer is a double-ivalled oven constructed of sheet iron or copper and usually covered with asbestos. It is heated by a gas flame. Objects should be sterilized in this oven for one hour at a temperature of $140^{\circ}-150^{\circ} \mathrm{C}$. After the temperature of the oven f has fallen below $40^{\circ} \mathrm{C}$. the objects may be taken out of the sterilizer and used.

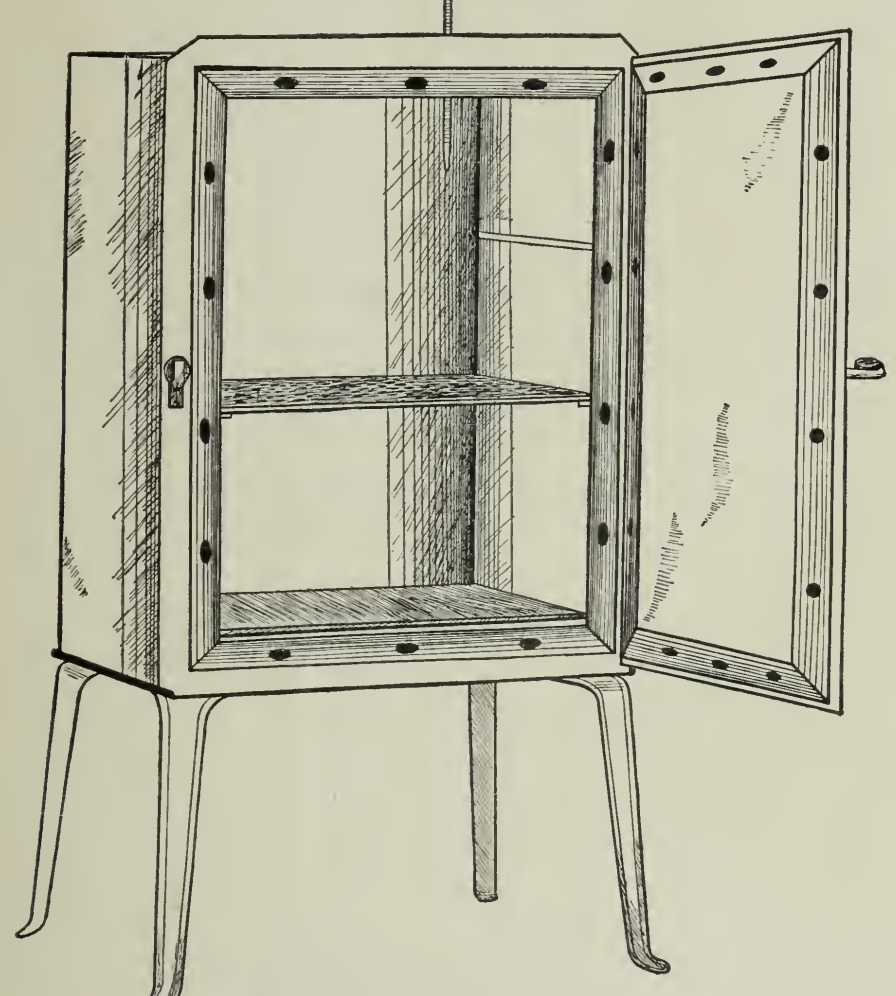

FIc. 11. An oven for dry sterilizing

Objects to be dry sterilized should be clean, clry, and free from dust. Volumetric pipettes should be put into a sheet-iron box for sterilization. Petri dishes which are to be kept for a time before using, may be separately wrapped in manila paper. 


\section{SECTION IV}

\section{RELATION OF BACTERIA TO FACTORS OF THE PHYSICAL ENVIRONMENT}

\section{Exercise 15. Relation of Bacteria to Oxygen (Growth)}

1. Pour a tube of melted agar into a sterile Petri dish. Keep the dish level until the agar has hardened.

2. Inoculate the plate in three parallel lines about $5 \mathrm{~mm}$. distant from each other. Use the straight platinum wire charged

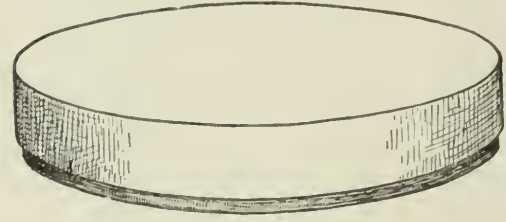

FIf;. 12. $\Lambda$ Petri dish with B. subtilis.

3. Sterilize a plate of mica or a cover glass in the Bunsen flame, wait a few seconds for it to cool, then lay it over the lines of inoculation. Press it down in firm contact with the agar to exclude the air.

4. After three clays examine the plate for bacterial growth. Sketch the plate, showing the location of bacterial growth.

5. Make a duplicate plate, using an anaërobie germ.

\section{Exercise 16. Relation of Bacteria to Oxygen (Motility)}

Examine water in which seeds have been boiled and allowed to putrefy for motile bacteria. 'Transfer a llop containing bacteria to a slicle, adrl a few filaments of green alga, and seal the edge of the cover glass with vaseline. Clamp the slicle to the microscope stage and set the preparation in the dark until the bacteria have ceased to move. Why do they cease to move? Then set the preparation near a window and look for the restoration of movement. Where does it first take place? What function does the alga filament play? Why?

\section{Exercise 17. Effect of Light upon Bacteria}

1. Inoculate a tube of melted agar with B. prodigiosus. Mix well and transfer three loopfuls to a sereond molted tube. Pour this second tube into a sterile l'etri dish. 
2. When the agar is solidified, invert the Petri dish and cover half the bottom with black paper.

3. Expose this dish, paper side up, to direct sunlight for half a day, or, better still, place it on a table and adjust a 40 -candlepower incandescent electric light about $50 \mathrm{~cm}$. above it while the colonies are developing.

4. Record the differences in the number and size of the colonies on both the illuminated and the darkened side of the dish.

\section{Exercise 18. Effect of Light of Different Wave Lengths upon Bacterial Growth}

To test the effect of primary colors upon bacterial growth:

1-2. Same as in the preceding exercise.

3. Coat the exposed half of the dish with photographic collodion which contains 2 per cent of one of the following aniline dyes : Chrysoidine (for red); Aurantia (for orange); Naples yellow (for yellow); Malachite green (for green); Eosin, bluish (for blue); Methyl violet (for violet). Different students may employ different dyes.

4. Expose the plates thus prepared to strong diffused light (not direct sunlight) for several days.

5. Take notes upon the growth of colonies on both sides of the dish. Observe the results where lights of different colors are used.

\section{Exercise 19. Relation of Bacteria to Heat}

Make four agar streak cultures of $B$. coli and four of $B$. megatherium. Incubate one of each at the following temperatures: $7^{\circ} \mathrm{C}$. (ice chest), $20^{\circ} \mathrm{C}$. (room), $28^{\circ} \mathrm{C}$. (incubator), $37.5^{\circ} \mathrm{C}$. (incubator).

Keep careful notes on the amount and rate of growth of cultures, and determine the optimum temperature of these organisms.

\section{Exercise 20. Relation of Bacteria to Concentration of Medium}

Place about $3 \mathrm{cc}$. of Liebig's Extract of Beef in each of two large test tubes. Add to one tube $20 \mathrm{cc}$. of water. Inoculate both with $B$. fluorescens liquefaciens. In which tube do bacteria develop? Why? 


\section{Exercise 21. Effect of Drying upon Bacteria}

1. Prepare five clean .corer glasses and sterilize by quickly passing them several times through a flame.

2. Heavily inoculate 10 ce. of distilled water with $B$. subtilis and mix by shaking thoroughly.

3. With the sterile platinum loop place an approximately equal quantity of this bacterial suspension on each cover glass.

t. Place the cover glasses in a sterile Petri dish and dry them in the incubator at a temperature not higher than $28^{\circ} \mathrm{C}$.

5. On the next day and every twenty-four hours later transfer one cover glass with sterile pincers to a sterile Petri dish and flood it with a tube of melted agar. Rock the dish gently to distribute the bacteria before the agar hardens.

6. Determine the effect of drying upon this organism by counting the colonies as they develop on the agar plates.

7. Duplicate the experiment, using B. coli.

8. To what difference between these two organisms can you refer the difference of results?

\section{Exercise 22. The Effect of Different Disinfectants}

Pour beef bouillon into a series of test tubes, filling each about one third full. Inoculate all tubes from a hay infusion. To the different tubes add the following: $a$, nothing; $b, \frac{1}{4} \mathrm{~g} . \mathrm{NaCl}$; c, $1 \mathrm{~g}$. $\mathrm{NaCl} ; d, 2 \mathrm{~g}$. sugar; e, $5 \mathrm{~g}$. sugar ; $f, 1$ drop mercuric bichloride solution (1:1000): \%. 6 drops mercuric bichloride solution; $h, 1$ drop formalin; $i, 3$ drops formalin; $j, 1$ drop carbolic acid solution $(1: 20) ; k, 10$ drops carbolic acid solution; $l, 150 \mathrm{mg}$. borax ; $m, 300 \mathrm{mg}$. borax. Tubes $h, i, j$, and $k$ should be corked. Why? Place all test tubes in the incubator and examine at intervals to see which of them undergo putrefaction and which are thoroughly disinfected. Note how very much more efficient some disinfectants are than others. How do you explain the results of $b, c, d$. and $e$ ? Which proves to be the most efficient? For a discussion of the relative value of these and other disinfectants the student is referred to the Appendix. 


\section{SECTION V}

\section{RELATION OF BACTERIA TO BIOLOGICAL FACTORS}

\section{Exercise 23. Rate of Growth of Bacteria}

This question will be studied by noting the rate of growth of B. coli in a flask of beef broth inoculated by the instructor. A schedule will be made, assigning students to draw and plate samples at hourly intervals from the moment of inoculation. Students will take samples from the flask, according to directions, and put them into sterile Petri dishes, adding immediately a tube of melted agar. Mix the contents of the Petri dish by tilting it back and forth, allow to cool in a horizontal position, and place in the incubator. Each student will compute the number of organisms per cubic centimeter in his samples and report the number to the instructor for the composite result. Take notes on the entire experiment and draw a graph to illustrate the rate of increase. Where does the graph rise most rapidly? Why?

\section{Exercise 24. Chemotaxis}

Free-swimming organisms, such as motile bacteria, show a response to the presence of chemicals commonly serving as nutrients. This response can be conveniently studied by placing the chemicals to be tested in small capillary tubes and observing the behavior of organisms near the open ends of the tubes.

Proceed as follows: 1 . Heat a small glass tube in a flame until soft, withdraw from the flame, and quickly draw it out to a slender filament. Break up the thinnest part of the filament into pieces $8-10 \mathrm{~mm}$. long and fuse up one end of each in the flame. Place these tubẹs in a small dish of beef bouillon and exhaust the air under the receiver of an air pump.

2. A culture of motile bacteria may be obtained by boiling a few kernels of corn or peas for a minute, to kill them, and allowing them to putrefy in an open dish. Mount a drop of this culture on a slide; taking one of the capillary tubes in a pair of 
forceps, rinse it quickly in water and lay the tube with the open end near the center of the drop. Put on the cover glass and examine with the $\frac{1}{6}(t \mathrm{~mm}$.) objective.

3. Note the subsequent movements of the free-swimming organisms as they enter the area where the bouillon is diffusing from the open end of the tube. Study the reactions which ultimately bring them into the tube. How do you explain them?

\section{Exercise 25. Arrangement of Bacteria with Respect to Each Other}

1. Make bouillon cultures of the following organisms: Micrococcus (any species), Sarcina lutea, B. moctigiosus, B. subtilis, Microspira (any species), Spirillum rubrum.

2. Make stains and hanging-(lrop preparations after thirty-six hours.

3. Examine with the oil-immersion objective and classify the organisms in the following table:

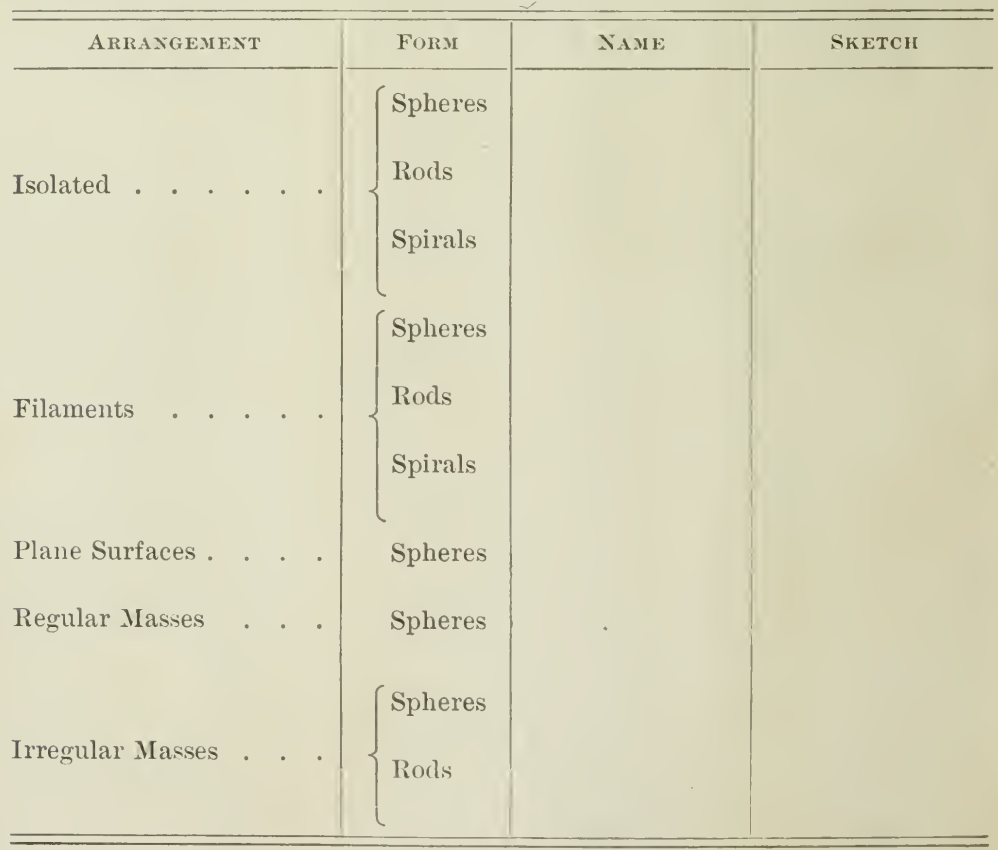




\section{Exercise 26. Production of Enzymes}

Jordax. General Bacteriology, p. 91. Philadelphia, 1908.

Make two gelatin stab cultures of $B$. prodigiosus. Incubate them below $22^{\circ} \mathrm{C}$. until the bacteria have liquefied nearly all of the gelatin. Add $1 \mathrm{cc}$. of toluol or 3 cc. of chloroform, shake well, and filter after it has stood for fifteen minutes. Pour one culture into a tube of sterile gelatin and the other into a tube of milk, and note changes after three to five days. Why is the disinfectant used instead of heat to kill the bacteria? Record the results of adding these solutions to the gelatin and milk tubes.

\section{SECTION VI}

\section{FUNDAMENTAL METHODS USED IN THE CULTURE OF BACTERIA ${ }^{1}$}

\section{Exercise 27. Inoculation of Cultures on Solid Media}

Platinum needles mounted in glass rods are generally used for inoculating cultures of bacteria. A straight needle is used for stab and streak cultures, while a needle with a small loop

O
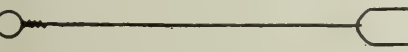

FIG. 13. Inoculating needles

Pieces of platinum wire set in glass rods

(diameter $2 \mathrm{~mm}$.) at the extremity is used for liquid cultures (Fig. 13). These needles are sterilized by putting them into a gas flame and heating to redness just before and just after

1 This section is intended to be a summary of methods most likely to be useful to the undergraduate student or for a student beginning independent investigation. It is not intended to be exhaustive. For more ample treatment of these subjects the student is referred to Muir and Ritchie, Manual of Bacteriology ; Abbott, Principles of Bacteriology ; Eyre, Bacteriological Technique ; Abel, Bakteriologisches Taschenbuch; Lafar, Technische Mykologie; and other special works. 
using. When the cotton plugs are removed from sterile tubes, the tubes should be held horizontal or sloping slightly downward. The plugs should be held between the fingers in such a way that the portions entering the tubes will not come in contact with each other nor with other objects (Fig. 1t).

Stab cultures are made by thrusting the straight wire down the center of the cylinder of the culture medium. Streak cultures are made by drawing the wire once over the flat surface of the medium (agar or potato).

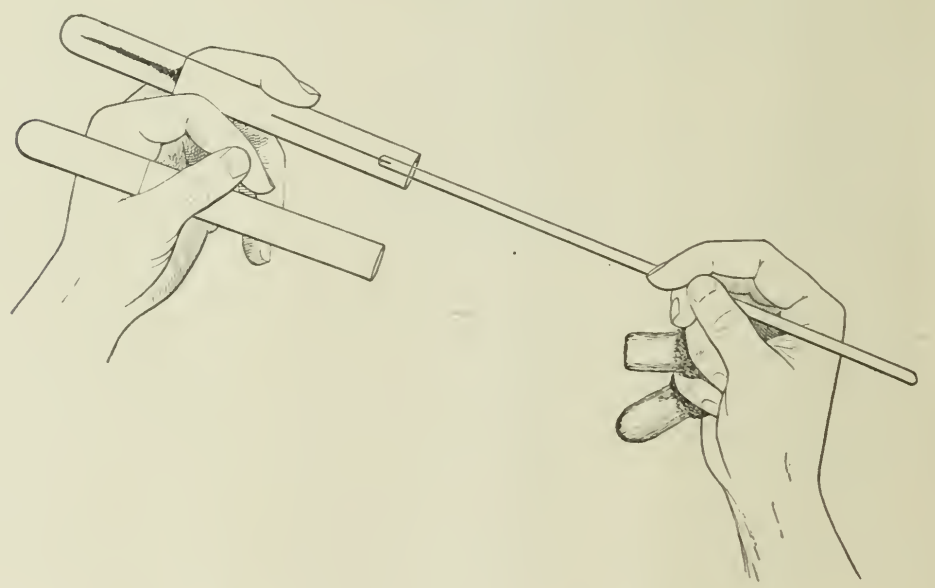

Fig. 11. Method of inoculating tubes of solid media

After inoculation, tube cultures should be placed in some receptacle which will keep them upright, and set in a place where they will not be exposed to strong light. Experimental cultures can be storerl in incubators at required temperatures. Stock cultures should be kept in a room of even temperature, preferably not too high, and should be transferred to new media once in six or eight weeks. Before removing the cotton plugs from old cultures it is well to burn over the surface of the cotton, to kill germs which may have settled in it. The plugs may be protected from dust by caps of paper, tin foil, or rubber. 


\section{Exercise 28. Inoculation of Cultures on Liquid Media}

Bouillon, milk, and the various liquid media are inoculated by introducing the inoculum upon a platinum needle. Transfers from one liquid to another are made with the platinum loop. The liquid media may be used in test tubes or in small flasks of about 250 ce. capacity.

\section{Exercise 29. Preparation of Milk for Use as a Culture Medium}

Strictly fresh milk must be procured. The cream should be removed either by a centrifugal separator or by shaking out with ether. The milk is placed in test tubes or flasks, as desired, and sterilized in the Arnold sterilizer. Prolonged heating should be avoided, else the proteins will be wholly coagulated. It is well to heat for fifteen minutes on four successive days, then discard such tubes as show, after a three-day incubation, any sign of bacterial growth.

\section{Exercise 30. Preparation of Litmus Milk}

This useful medium is prepared by adding aqueous litmus solution to fresh milk. Soak $50 \mathrm{~g}$. of clry litmus cubes for twentyfour hours in $250 \mathrm{cc}$. of distilled water. After filtration through filter paper, enough of this solution is added to the fresh milk to give it a strong lavender color. Sterilize as directed for milk cultures.

\section{Exercise 31. Preparation of Litmus Whey}

1. Precipitate the casein of fresh milk by rennet extract. Neutralize the filtered whey with 4 per cent citric acid and heat on the steam bath for thirty minutes.

2. Filter and add litmus solution until a strong lavender color is obtained. Sterilize.

\section{Exercise 32. Preparation of Whey Agar}

1. Precipitate the casein of fresh milk by adding a few drops of acetic acid to boiling milk. Filter.

2. Neutrailize the whey with sodium hydroxide or bring to 1 per cent acid if desired. 
3. Idd to the whey 1 per cent peptone, 2 per cent dextrose. and 1.5 per cent agar. Cook, filter, and sterilize in the Arnold sterilizer.

\section{Exercise 33. Preparation of Sugar Bouillon}

This is ordinary beef bouillon to which dextrose, lactose, or saccharose lias been added. It is prepared by adding to the ordinary bouillon (Exercise 8) 1 per cent by weight of one of the above sugars. If lactose or saccharose bouillon is prepared, the original bouillon should be free from inosite. This can be tested by inoculating a fermentation tube containing the plain bouillon with a gas-producing organism like $B$. coli. If no gas is formed, the bouillon is free from inosite. Triple sterilization in the Arnold sterilizer is best for sugar bouillon, since the heat of the autoclave sometimes darkens the sugar.

\section{Exercise 34. Preparation of Sugar Gelatin}

To the sugar bouillon, prepared as in Exercise 33, add 12 per cent gelatin. Cook, neutralize, and filter as in Exercise 9. Adjust the acidity and sterilize in the Armold sterilizer.

\section{Exercise 35. Preparation of Litmus-Lactose Gelatin or Agar}

To ordinary nutrient gelatin, prepared as in Exercise 9, add 1 per cent of lactose by weight and enough litmus solution to give a good blue color (see Exercise 30 for the preparation of the litmus solution). It is better to add 15 per cent gelatin instead of the usual 12 per cent. Tube the medium as usual and sterilize in the Amold sterilizer. Litmus-lactose agar may be prepared by using ? per cent agar instead of the gelatin in the above.

\section{Exercise 36. Preparation of Glucose-Formate Bouillon (Kitasato)}

Add to a liter of beef bouillon $20 \mathrm{~g}$. glucose and $4 \mathrm{~g}$. sodium formate. After they have dissolved, give triple sterilization in the Arnold sterilizer. Solid media may be prepared by the addition of gelatin or agar. This medium is useful in testing the fermentative power of organisms. 
Exercise 37. Preparation of Dunham's Solution (for Indol Tests)

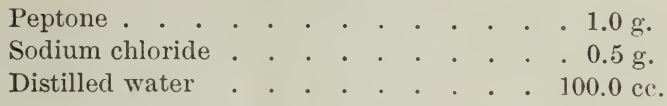

Dissolve, place in test tubes, and sterilize as usual. Ten days after inoculation, test for indol as follows: add $1 \mathrm{cc}$. of 0.01 per cent solution potassium nitrite and a few drops of concentrated sulphuric acid. Warm gently by putting tubes in warm water. A pink color inclicates the presence of indol. The action of an excess of sulphuric acid on peptone causes a brown color in the solution.

\section{Exercise 38. Preparation of Phenol Bouillon}

Add 1 g. of phenol (carbolic acirl) crystals to 1 liter of beef bouillon prepared as directed in Exercise 8. This medium is more frequently used for the cultivation or isolation of $B$. coli. A solid medium may be had by the addition of gelatin or agar.

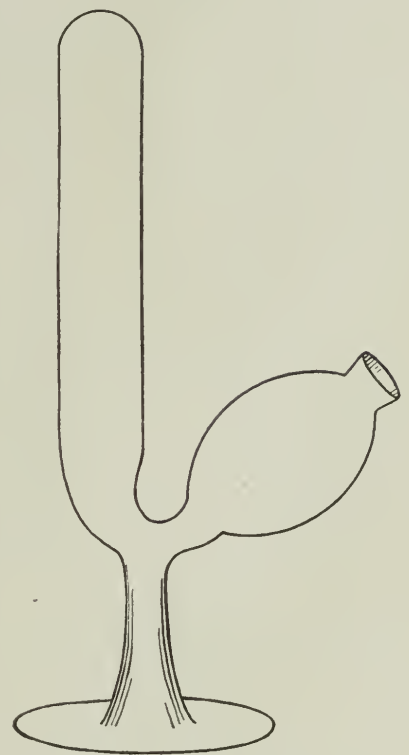

Fig. 15. A fermentation tube

\section{Exercise 39. Preparation of Lactose Bile for Isolation of Intestinal Bacteria}

1. Procure from the slaughterhouse an ox gall bladder. Empty the bile into a graduated cylinder and add 1 per cent of lactose.

2. Fill fermentation tubes and sterilize them in the Arnold sterilizer.

\section{Exercise 40. Preparation of Neutral Red Broth}

Prepare beef bouillon in the regular way, adding 1 per cent lactose, and to each 100 cc. of bouillon add 5 cc. of a 1 per cent solution of neutral red (Grübler's Neutral Roth nach P. Ehrlich).

Tube and sterilize in the Arnold sterilizer. 


\section{Exercise 41. Preparation of MacConkey's Bile Salt Broth for Isolating Intestinal Bacteria}

1. Place $20 \mathrm{~g}$. Witte's peptone in $200 \mathrm{cc}$. distilled water previously warmed to $60^{\circ} \mathrm{C}$. Stir until the peptone is in suspension.

2. Wreigh out $\tilde{j} \mathrm{~g}$. sodium taurocholate (commercial) and $5 \mathrm{~g}$. glucose and dissolve in the peptone water.

3. Wash the peptone water into a flask with distilled water and make the volume up to 1 liter. Cook the solution in the steamer for twenty minutes at $100^{\circ} \mathrm{C}$. Filter through paper into a flask.

4. Add either (a) sterile litmus solution sufficient to give the medium a deep purple or (b) 亏 ce. of a freshly prepared 1 per cent solution of neutral red.

5. Fill fermentation tubes, plug, and sterilize in the Arnold sterilizer.

Exercise 42. Preparation of Modified Giltay and Aberson's Fluid for Denitrifying Organisms

\begin{tabular}{|c|c|c|c|c|c|c|c|}
\hline Distilled water . & & & & & & & \\
\hline Potassium nitrate & & . & & & & 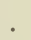 & \\
\hline Magnesium sulphate & - & & & & & . & \\
\hline acid. . . & & & & & & . & \\
\hline Dipotassium phosphate & & & & & & . & \\
\hline Calciu & & & & & & . & \\
\hline hydrous sollium car & & & & & & & \\
\hline
\end{tabular}

The solution should be nentralizerl by the ardition of potassium hydrate if, after boiling, it shows any acidity.

Exercise 43. Preparation of Iron Bouillon for Detecting the Presence of Hydrogen Sulphide

Add $1 \mathrm{~g}$. ferric tartrate (or lactate) to 1 liter beef bouillon. Sterilize in Arnold sterilizer.

Exercise 44. Preparation of Lead Bouillon for Detecting the Presence of Hydrogen Sulphide

Add $1 \mathrm{~g}$. lead acetate to 1 liter beef bouillon. Sterilize in the Arnold sterilizer. 


\section{Exercise 45. Preparation of Glycerin Bouillon}

Add 6 or 8 per cent glycerin to beef bouillon after filtration. This medium is espeeially used for the cultivation of $B$. tuberculosis, but may be used for other organisms with good results. A solid medium is usually prepared by the addition of agar.

\section{Exercise 46. Preparation of van Delden's Solution for Cultivation of Sulphate-Reducing Bacteria}

\begin{tabular}{|c|c|c|c|}
\hline Dipotassium phosp & phat & & \\
\hline Sodium lactate. & 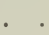 & & \\
\hline Magnesium sulpha & ate & & \\
\hline Asparagine. . & . & & \\
\hline Ferrous sulphate. & . & . & \\
\hline Tap water. . & . & & \\
\hline
\end{tabular}

\section{Exercise 47. Preparation of Potato Gelatin (Elsner)}

1. Grate finely about $1 \mathrm{~kg}$. of clean peeled potatoes. Weigh the grated potato and add $1 \mathrm{cc}$. of clistilled water for every gram of potato. Place the mixture in a 2-liter flask and let it stand in the ice chest for twelve hours.

2. Strain through cheesecloth; then filter through swedish filter paper into a grarluated cylinder.

3. Add 15 per cent gelatin to the potato rlecoction and heat in the Arnold sterilizer for sixty minutes.

t. Estimate the reaction and render the final reaction plus 2.5.

5. Cool the medium to below $60^{\circ} \mathrm{C}$. and clarify with eggwhite.

6. Add 1 per cent potassium iodicle to the medium.

7. Filter through papier Chardin.

8. Tube and give triple sterilization in the Arnold sterilizer.

\section{Exercise 48. Preparation of Heyden-Nahrstoff Agar}

1. Place $10 \mathrm{~g}$. Heyden-Nährstoff in a flask containing $300 \mathrm{cc}$. distilled water. Stir the powder until a good suspension is obtained and allow the flask to stand overnight. Place $20 \mathrm{~g}$. agar shreds in $500 \mathrm{cc}$. water and allow it to stand overnight.

2. Heat the Nährstoff suspension in the Armold sterilizer for one to two hours, and filter while hot through paper. Drain the 
agar through a clear cloth, wash briefly, and put into a flask or earthenware pitcher. Add to it the filtered Nährstoff solution, and make up to a volume of 1 liter with distilled water.

3. Melt the agar in the autoclave or over a flame, as described in Exercise 7. Filter through absorbent cotton and tube. Sterilize in the autoclave.

\section{Exercise 49. Preparation of Ashby's Solution for Isolating Azotobacter from Soil}

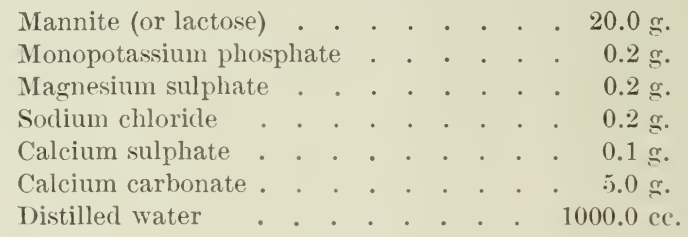

Dissolve the monopotassium phosphate separately in a little water and neutralize it with potassium hydroxide solution before adding it to the other ingredients.

\section{Exercise 50. Preparation of Nitrogen-Free Media for Culture of Symbiotic Nitrogen-Fixing Bacteria}

1. Dextrose solution.

\begin{tabular}{|c|c|c|c|c|c|c|c|}
\hline Potassium biphosph & & & & & & & \\
\hline Magnesium chloride & & & & & & & \\
\hline Sodium chloride & & & & & & & \\
\hline Ferrous sulphate & & & & & & & \\
\hline Manganese sulphate & & & & & & & \\
\hline Dextrose . . & & & & & & & \\
\hline Distilled water . & & & & & & & \\
\hline
\end{tabular}

To prepare a solid medium add $20 \mathrm{~g}$. of agar to this solution.

2. Mannite solution.

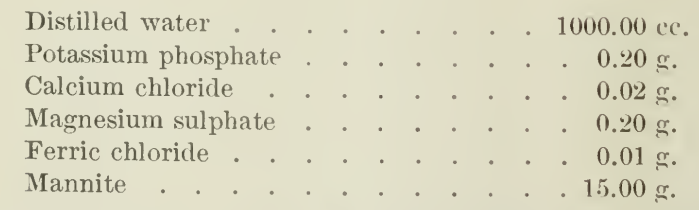

Neutralize if necessary with $\mathrm{NaOH}$, using phenolphthalein as indicator. 
3. Soil extract medium Löhnis. ${ }^{1}$

Prepare a soil extract by heating $1 \mathrm{~kg}$. of soil with 1 liter of water in an autoclave for half an hour at $15 \mathrm{lb}$. pressure, or heat $1 \mathrm{~kg}$. of soil with 2 liters of water over an open flame for two hours. Filter the hot solution through paper and use as directed in the following formula:

Soil extract . . . . . . . . $1000 \mathrm{cc}$.

Potassium phosphate . . . . . . . $5 \mathrm{~g}$.

Mannite or dextrose . . . . . . . . $10 \mathrm{~g}$.

Agar . . . . . . . . . . $15 \mathrm{~g}$.

Exercise 51. Preparation of Winogradsky and Omelianski's Solution for Cultivating Nitrite-Forming Organisms

Ammonium sulphate . . . . . . . $1.0 \mathrm{~g}$.

Potassium biphosphate . . . . . . $1.0 \mathrm{~g}$.

Magnesium sulphate . . . . . . $0.5 \mathrm{~g}$.

Sodium chloride . . . . . . . . $2.0 \mathrm{~g}$.

Ferrous sulphate . . . . . . . . . $0.4 \mathrm{~g}$.

Basic magnesium carbonate . . . . . Excess

Distilled water . . . . . . . . 1000.0 cc.

Exercise 52. Preparation of Winogradsky and Omelianski's Solution for Cultivating Nitrate-Forming Organisms

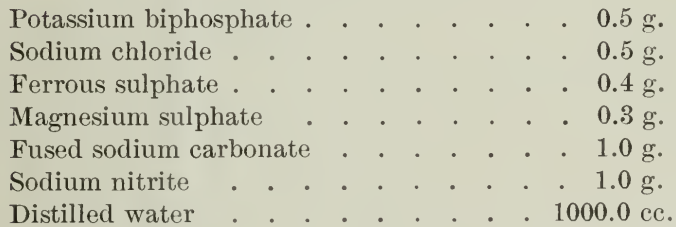

Exercise 53. Preparation of Nægeli's Solution

This solution has been found to be well suited for the culture of yeast and of many other fungi.

Calcium chloride . . . . . . . . $0.1 \mathrm{~g}$.

Magnesium sulphate . . . . . . $0.2 \mathrm{~g}$.

Dipotassium phosphate. . . . . . . $1.0 \mathrm{~g}$.

Ammonium tartrate . . . . . . . $10.0 \mathrm{~g}$.

Distilled water . . . . . . . . $1000.0 \mathrm{cc}$.

1 Centíalbl. f. Bakt., 2te Abt., 14 : 590. 1905. 
Exercise 54. Preparation of Czapek's Nutrient Solution for the Cultivation of Fungi

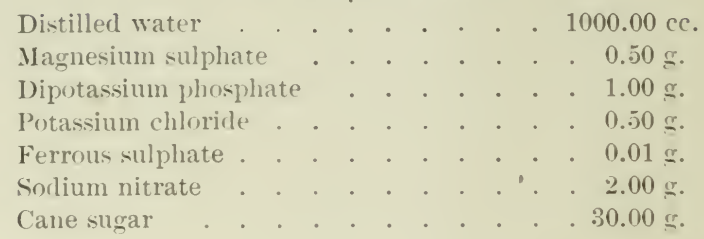

Exercise 55. Preparation of Sulphindigotate Bouillon (Weyl) for Detecting Anaërobic Organisms

To' 1 liter of regular beef boullom arld $20 \mathrm{~g}$. of glucose and $1 \mathrm{~g}$. of sodimm sulphindigotate. After sterilization, which should

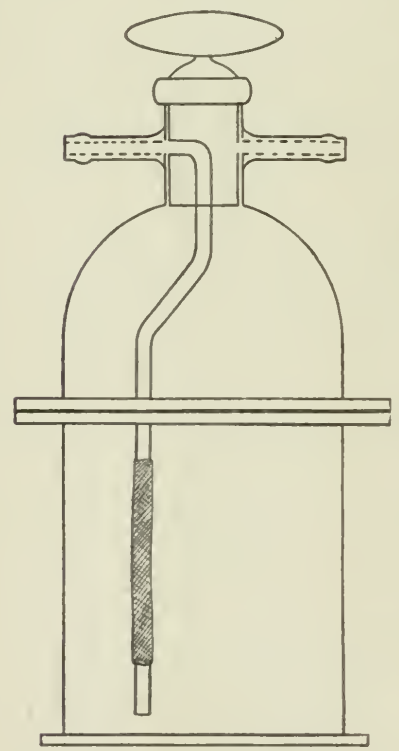

Fig. 16. Novy jar for anä̈robic cultures

The jar is sealed by turning the stopper in the top lated. Wright's modification of Buchuer's method. given on the following page, is very anvenient. medium should be blue. The growth of anaërobic organ isms turns it yellow. folid media may be had by the ardition of gelatin or agar.

\section{Exercise 56. Methods of Cultivating Anaërobic Bacteria}

These bacteria grow in an atmosphere devoid of oxygen, obtaining the oxygen necessary for their metabolism from carbohydrates and other rompounds in the medium which they break down. Any methosl of eulture is successful which either absorbs the gaseous oxygen present or replaces the air with a nonpoisonoms gas.

1. Test-tule cultures. The cultures should be made in dextrose beef agar or gelatin, which should be freshly prepared and always boiled to expel air immediately before being inocu-

be done in the Amold sterilizer, the 
After inoculating the eulture medium, burn over the cotton stoppers and, with foreps sterilized in the flame, push the stop)pers into the test tubes for a distance of 2 or 3 cm. It is gen-

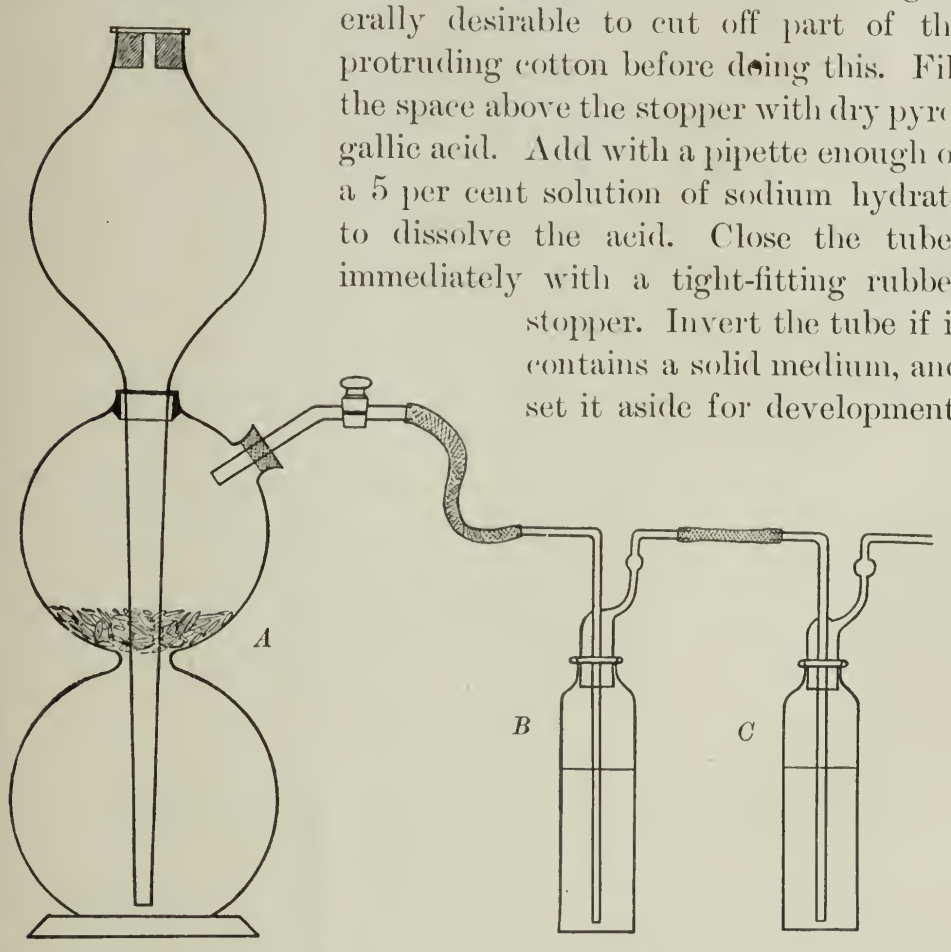

Fis. 17. Kipp apparatus arranged for generating hydrogen

$A$, generator ; $B$, wash bottle containing lead nitrate solution; $C$, wash bottle containing silver nitrate solution

2. Plates and miscellaneous multures. Place the cultures in a Novy jar (Fig. 16) connected with a hydrogen generator. Pass the hychrogen from the Kipp generator through two wash bottles, one of which contains lead nitrate solution, the other a solution of silver nitrate. It is well to add another wash bottle containing potassium permanganate. From time to time collect a test tube full of gas from the outlet. Test by holding a burning mateh at the month of the tube. As long as explesion oceurs, 
there is air mixed with the hydrogen, and the gas must be kept flowing. When the escaping liydrogen is pure, close the Nory jar by turning the stopper. Shut off the flow of gas from the generator. Disconnect the apparatus and put the Nory jar in the culture room.

\section{Exercise 57. Preparation of Sterile Water Blanks}

Water blanks are used for diluting cultures containing large numbers of bacteria. Physiological salt solution (0.6 per cent $\mathrm{NaCl}$ ) or distilled water may be used.

Water blanks usually contain 10 cc., 100 cc., 200 cc., or 500 ce. The liquid should be measured with a burette or accurate pipette into vessels of approximately twice the volume of the solution to be used. Large test tubes or bottles are generally used. The mouths of the vessels should be rather tightly plugged with cotton and should be sterilized in the autoclave. During sterilization there is slight evaporation, which, however, is usually corrected when 1 cc. of the test solution is added.

\section{SECTION VII}

\section{FUNDAMENTAL METHODS USED IN THE STAINING AND EXAMINATION OF BACTERIA}

The general forms of bacteria may be studied in a living condition, as has already been done in Section I. Howerer, if the exact shape and structure of the bacteria are to be studied, they should be stained. In some instances the results of staining are valuable as diagnostic characters. Most of the stains commonly employed in bacteriological laboratories are solutions of aniline dyes.

Solutions of stains should not usually be kept long before being used, although in a few cases their staining powers improve with age.

$\mathrm{By}$ the use of certain chemical agents called mordants the staining power of the aniline dyes is increased. Various metallic salts and organic acids are used as mordants - for example, 
ferrous sulphate, tannic acid, carbolic acid, etc. These chemical agents seem to have great powers of penetration into the cells, carrying the stains through the membranes with them.

Aniline oil water is also used as a mordant. It is prepared by shaking a small amount of aniline oil in distilled water for fifteen minutes or longer and then filtering. The aniline oil water so obtained is mixed with the dye to be used. It is not stable for a long time.

\section{Exercise 58. Preparation of Simple Stains}

1. Fuchsin (basic).

a. Saturated aqueous solution.

Basic fuchsin . . . . . . . . . $1.5 \mathrm{~g}$.

Distilled water . . . . . . . . $100.0 \mathrm{cc}$.

b. Saturated alcoholic solution.

Basic fuchsin . . . . . . . . . $3.5 \mathrm{~g}$.

95 per cent alcohol . . . . . . . $100.0 \mathrm{ce}$.

Place in a stoppered bottle, shake well at frequent intervals, and filter after two hours.

c. Carbol fuchsin (Ziehl).

Saturated alcoholic solution fuchsin . . . $10 \mathrm{cc}$.

Carbolic acid (cryst.) . . . . . . . . $5 \mathrm{~g}$.

Distilled water . . . . . . . . $100 \mathrm{cc}$.

Filter before using. This solution improves with age.

2. Methylene blue.

a. Saturated aqueous solution.

Methylene blue . . . . . . . $1.5 \mathrm{~g}$.

Distilled water . . . . . . . . $100.0 \mathrm{cc}$.

b. Saturated alcoholic solution.

Methylene blue . . . . . . . 1.5 g.

95 per cent alcohol . . . . . . $100.0 \mathrm{cc}$.

Place in a stoppered bottle, shake well at frequent intervals, and filter after two hours.

c. Alkaline methylene blue (Löffler).

Saturated alcoholic solution methylene blue . $30 \mathrm{cc}$.

0.1 per cent aqueous solution $\mathrm{KOH}$. . . $100 \mathrm{cc}$.

Filter before using. 
3. Gentian violet.

a. Saturated aqueous solution.

Gentian violet . . . . . . . . $2 \mathrm{~g}$.

Distilled water . . . . . . . $100 \mathrm{cc}$

b. Saturated alcoholic solution.

Gentian violet. . . . . . . . . $5 \mathrm{~g}$.

95 per cent alcohol . . . . . . . . 100 cc.

Place in a stoppered bottle, shake frequently, and filter after two hours.

\section{Exercise 59. General Method of Making Stained Preparations}

1. Clean a cover glass, holding it only by the edges. Remove all greasy material, using alcohol or other solvents for the purpose. After cleaning the cover glass, place it in the cover-glass forceps (Fig. 18) and pass it rapiclly several times through a

Bunsen flame.

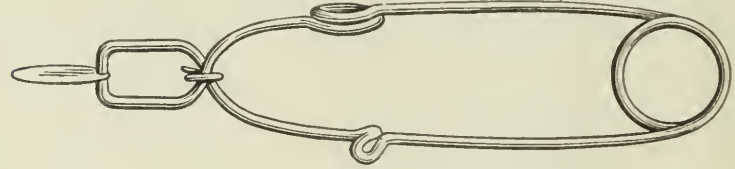

Fic. 18. Cover-glass forceps

('ireular cover glasses $18 \mathrm{~mm}$. in diameter are most suitable for bacteriological work.

2. With the platinum loop place a small drop (about the size of a pinhead) of distilled water upon the center of the cover glass. 'Transfer the bacteria to be examined with a sterile platinum needle to the drop on the cover glass. Mix the bacteria thoroughly with the drop and spread it as evenly as possible over the cover glass, within $2 \mathrm{~mm}$. of the edge. If the drop does not spread well, the cover glass has not been suceessfully cleanerl. When the bacteria to be examined are taken from liquid media, the platinum loop will be used and a drop of water on the cover glass is unnecessary.

It is difficult, especially for beginners, to get few enough bacteria to make a good preparation. It is well to make a second - mount from the first by transferring a part of a rather large drop to a second cover glass. 
3. Dry the film. If the drop used is sufficiently small, the film will dry readily at room temperature. The drying process may be hastened by holding the cover glass in the fingers, high over the flame. If the wet film is overheated, the preparation will be spoiled.

4. Fix the bacteria to the cover glass by passing it three times through the flame, holding the cover glass, film side up, in the cover-glass forceps. This process coagulates the albuminous substances and causes the bacteria to adhere firmly to the glass through subsequent operations.

5. Stain the preparation, keeping it still in the forceps. Place on the film a few drops of the staining solution to be used. Allow it to act five or ten minutes, the time depending somewhat on the species of bacteria and the stain employed.

Instead of placing the stain upon the film, the cover glass - may be immersed in a small glass dish containing the stain. Special cover-glass forceps are made for this purpose. If heat is required to hasten or intensify the process, a watch glass holding the stain is placed on the steam bath and in it the cover glass; or the cover glass with the stain upon it may be held over the Bunsen flame, the stain being replenished as it is evaporated.

6. Wash the cover glass in a weak stream of water.

7. Put the wet cover glass, film side downward, on a slide. Blot with filter paper and examine with the microscope.

8. If it is desired to make a permanent preparation, the cover glass should be dried in the air or gently over a flame, and then mounted on a slide with Canarla balsam.

9. Label the slide, stating name of organism, stain employed, date, and owner's name or initials.

\section{Exercise 60. Preparation of Contrast Stains}

1. Aqueous eosin.

Eosin (water soluble) . . . . . . . . $1 \mathrm{~g}$.

Distilled water . . . . . . . . $100 \mathrm{cc}$.

Dissolve and add absolute alcohol . . . $5 \mathrm{cc}$.

2. Bismarck brown (Vesuvin).

Bismarck brown . . . . . . . $0.5 \mathrm{~g}$.

Distilled water . . . . . . . . . $100.0 \mathrm{cc}$. 


\section{Exercise 61. Special Stains}

1. Capsule stain (Welch).

a. Prepare and fix the film in the usual manner.

b. Flood the slide with 2 per cent acetic acid,.leaving it in contact for two minutes. This swells and fixes the capsule so it will take the stain.

c. Blow off the acetic acid by the aid of a pipette.

d. Immerse in aniline-gentian-violet for five to thirty seconds.

e. Wash in water, dry, and mount.

2. Flagella stain.

a. Make an agar streak of the organism to be stained.

b. After eighteen to twenty-four hours, by means of the platinum needle remove a portion of the growth (being careful to aroid the culture medium) to a large drop of tap water on a * clean cover glass. Allow this to stand five minutes rather than spread, as there is less danger of breaking off the flagella.

c. Spread carefully two or three loopfuls of this drop on each of several clean cover glasses and dry at room temperature.

d. Fix by passing through the flame, the cover glass being held in the hand.

e. Flood the cover glass thus prepared with the following solution (mordant): liquor ferri sesquichloridi diluted with distilled water 1:20, one part; saturated aqueous solution tannic acid, three parts. This mixture improves with age but should be filtered before using. Allow to act one minute.

$f$. Wash the cover glass in water and dry by blotting it between strips of filter paper.

y. Stain with hot carbol-fuchsin for about one minute.

$h$. Wash in water, dry, and mount in balsam.

3. Spore stain.

a. Prepare and fix film in usual way.

$b$. Cover the film with hot carbol-fuchsin and hold above a small flame or lay the cover glass in a watch glass full of stain on a hot steam bath. Replace the stain as it evaporates. Keep the film covered with hot carbol-fuchsin for twenty or twentyfive minutes. (Both spores and bacteria are now stained.) 
c. Wash with water and decolorize with acetic alcohol (95 per cent alcohol, two parts, 1 per cent acetic acid, one part) until only a faint pink color remains. Finally wash thoroughly with water.

d. Mount the cover glass in water and examine microscopically with the $\frac{1}{6}$ objective. The spores should be red and the rest of the film colorless or a very faint pink. If satisfactory, pass on to section $e$; if not, repeat steps $b$ to $d$ inclusive.

$e$. Stain with weak methylene blue.

$f$. Wash in water, dry, and examine under the microscope. The spores should be red, the cells blue. Young spores are more readily decolorized than older ones.

\section{Exercise 62. Differential Staining}

1. Gram's method. This method depends upon the fact that the protoplasm of some bacteria permits aniline-gentian-violet and Gram's iodine solution, when consecutively used, to enter into chemical combination, resulting in the formation of a blueblack pigment which is practically insoluble in alcohol. Such organisms are said to be Gram positive; if the color is not held, they are said to be Gram negative.

a. Prepare aniline-gentian-violet as follows:

Saturated alcoholic solution of gentian violet $11 \mathrm{cc}$.

Absolute alcohol . . . . . . . . $10 \mathrm{cc}$.

Aniline water ${ }^{1}$. . . . . . . . . $100 \mathrm{cc}$.

This solution does not keep well.

b. Prepare Gram's iodine solution as follows:

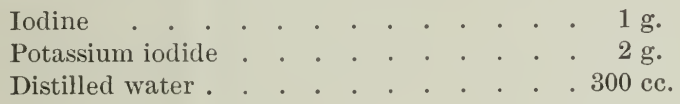

c. Prepare a cover-glass film and fix in the usual way.

d. Stain with aniline-gentian-violet for three to five minutes.

$e$. Drain off excess of stain and, without washing, cover the film with Gram's iodine solution; allow it to remain for one to three minutes. The cover glass looks black at this point.

1 Made by shaking together 5-6 cc. of aniline oil in $100 \mathrm{cc}$. of distilled water, with subsequent filtering. 
$f$. Wash with 60 per cent alcohol until only a light brown shade remains (as if the glass were smeared with dry blood).

g. Rinse off alcohol with water. Dry and mount, or contrast stain with eosin or Bismarck brown. If the bacteria are Gram positive, they will appear a deep blue under the microscope.

2. Ziehl-Neelson method of demonstrating B. tuberculosis and other acil-fast organisms.

a. Spread a thin film on the cover glass; dry and fix as usual.

b. Stain with hot carbol-fuchsin five to ten minutes (entire film stained).

c. Decolorize with 25 per cent sulphuric acid or 30 per cent nitric acid. (Removes stain from everything but acid-fast organisms.)

d. Wash thoroughly with water.

e. Counterstain the film with weak methylene blue. (Stains non-acid-fast organisms, leucocytes, epithelial cells, etc.)

$f$. Wash in water, dry, and mount.

\section{SECTION VIII}

\section{FUNDAMENTAL METHODS OF ISOLATION}

In nature single species of bacteria do not often grow alone. Even in those cases where they do exist it is not always possible to get them into artificial culture without contamination with other species. Yet the student of bacteriology must have pure cultures of a single species in order to learn anything definite about them. This was one of the greatest handicaps from which the earlier workers suffered. After the introduction of agar and gelatin media the problem of isolating species was greatly simplified, since it was then possible to get colonies sufficiently separated from each other, on plates, to obtain bacteria which were the descendants of a single organism, and therefore of the same species. For special methods of isolation in cases where this procedure is not successful, the student is referred to Eyre, Bacteriological Technique, Chapter XIII; Muir and Ritchie, Manual of Bacteriology, page 51; or Abel, Bacteriologisches Taschenbuch. 


\section{Exercise 63. Isolation of a Pure Culture}

In order to get a pure culture from a mixture of bacteria such as may be had in water, sewage, or commercial milk, proceed as follows : Three tubes of sterile nutrient agar or gelatin are melted in hot water and cooled to about $42^{\circ} \mathrm{C}$. Label the tubes $A, B$, and $C$. Select a platinum inoculating needle which has a loop $2 \mathrm{~mm}$. in diameter at the extremity. Sterilize the needle by heating to redness in the gas flame and, after allowing a few seconds for it to cool, dip the loop of the wire into the liquid containing bacteria. A film of liquid is held in the loop at the encl of the wire. Inoculate tube $A$ with three loopfuls of the liquid. Sterilize the wire and place it in the holder. Thoroughly mix the contents of tube $A$. This must be done without wetting the cotton stopper. 'The result can best be accomplished by rolling the tube between the palms of the hands, while slanting it alternately right

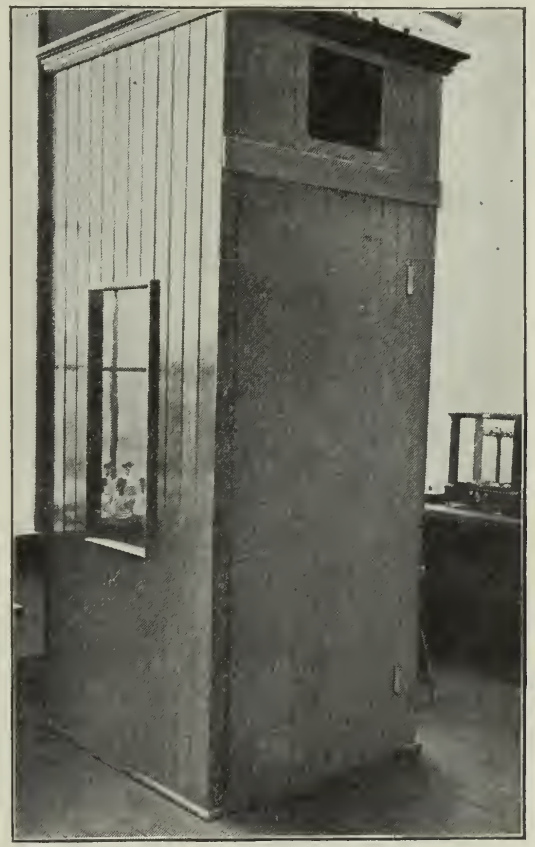

FIG. 19. An inoculating room

The interior walls are lined with linoleum and can easily be washed with a weak solution of bichloride. If inoculations are made in such a room, the danger of contaminations is greatly minimized and left. Tube $A$ is called the First Dilution. After mixing, transfer three loopfuls of tube $A$ into tube $B$, using the same procedure as before. Tube $B$ is the Second Dilution. In the same way transfer three loopfuls of $B$ in to $C$, constituting the Third Dilution. The Third Dilution usually contains few enough bacteria for the purpose of isolation, but the Second Dilution should also be poured. 
Place two sterile Petri dishes on the table and label them Second Dilution and Third Dilution. Remove the plug from the mouth of tube $B$ and flame the mouth of the tube; slightly raise the cover of the Second Dilution dish and pour in the melted medium (Fig. 20). Take care that none of the liquid medium rises over the edge of the Petri dish. If the medium fails to cover the entire surface of the plate, gently tilt the dish back and forth until the fault is rectified. Keep the Petri dishes level until the medium has hardened; then they may be placed in the culture chamber.

After twenty-four to forty-eight hours, depending upon the temperature, the plates will be dotted with colonies, each of

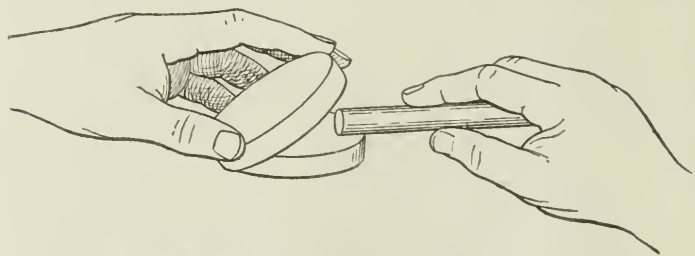

Frg. 20. Method of pouring melted media into Petri clishes which is supposed to consist of the descendants of a single organism. Study the colonies by placing the inverted Petri dish on the stage of the microscope and using the $\frac{2}{3}$ objective with weak light from the substage. Sterilize a straight platinum neerle in the flame and, after allowing it to cool a few seconds, dip the tip of it into one of the colonies. Inoculate both an agar slant and a gelatin stab with bacteria obtained in this manner. Label the tube, giving it a number, and make a record in a notebook stating the kind of colony from which the bacteria were taken and the original source of the Petri dish. Place the inoculated tubes in the culture chamber.

If the bacteria used for these inoculations were the descendants of a single organism, these tubes will contain pure cultures. The bacteria may be used for other subcultures, for stained preparations, etc. It often happens, however, that the first isolations are not pure cultures. In that case another series of plates must be poured, using the growth in the test-tube culture as the source. In fact, it is always safer to observe this precaution. 


\section{SECTION IX}

\section{OUTLINE FOR THE ROUTINE CULTIVATION OF BACTERIA}

In bacteriology the basis for all work is the pure culture. All possible care must be taken to obtain pure cultures and to keep them from contamination. The characters of most organisms can only be studied to a slight extent with specimens under the microscope; the majority of their characters are determined by their behavior in pure cultures on various media. The scheme given below calls for cultures sufficient to determine or demonstrate the characters of most organisms called for in this manual, except where special directions are given.

The student should consult the Descriptive Chart adopted by the Society of American Bacteriologists (Appendix P).

\section{Exercise 64. Preliminary Examination}

1. Inoculate an agar-slant tube from each pure culture furnished by the instructor or isolated from mixed infections. Place the inoculated tubes in the incubator for twenty-four hours.

2. After twenty-four hours examine the tubes for growth.

a. Describe the growth along the stroke of the needle (see Exercise 65).

b. Make a Gram-stained preparation.

c. Make a simple stain with carbol-fuchsin, methylene blue, or gentian violet.

3. Inoculate the following media from the agar slant: gelatin, potato, litmus milk, beef broth, and agar plate. All cultures except gelatin are to be kept in the incubator.

4. After twenty-four to forty-eight hours describe and make sketches of these cultures as directed in Exercise 65.

\section{Exercise 65. Study of Bacterial Characters}

A. Morphology.

1. Form and arrangement: coccus, single and grouped; cliplococeus: streptororens: : sereina; rorls, single and in chains ; spivals. 
2. Size. Measurements in terms of the micron.

3. Reaction to stains :

a. Simple stains: stains easily or with difficulty.

b. Differential stains: Gram's stain, Ziehl-Neelson stain, etc.
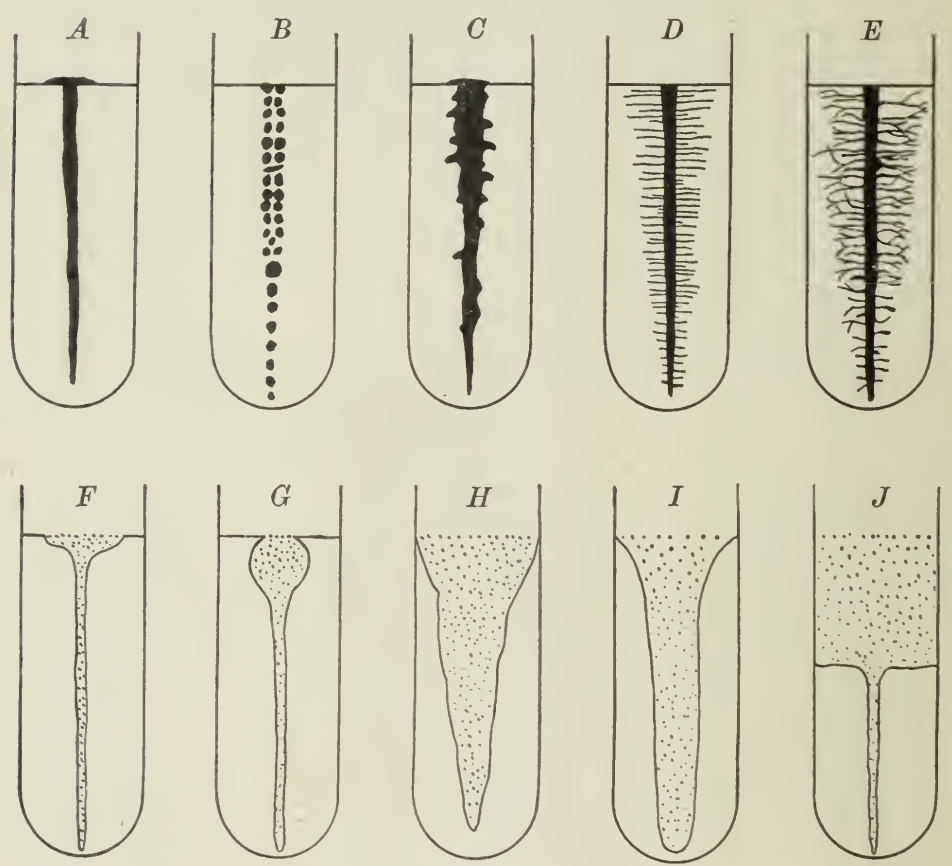

Fig. 21. Types of growth of bacteria in stab cultures

$A$ to $E$, nonliquefying: $F^{\prime}$ to $J$, liquefying. $A$, filiform ; $B$, beaded: $C$, echinulate ; $D$, villous: $E$, arborescent : $F$, crateriform; $F_{r}$, napiform: $I I$, infundibuliform; $I$, saccate; $J$, stratiform

4. Spores: time required for formation, media, position in cell.

5. Special characters:
a. Flagella.
b. Capsule.
c. Vacuoles.
d. C'rrstals or granules.
$e$. Involution forms. 
B. Cultural characters.

1. Gelatin stab.

I. Nonliquefying.

a. Line of puncture: filiform, uniform needle-shaped growth (Fig. 21, A); beaded, succession of small, disjointed colonies (Fig. 21, B); echinulate, prickly
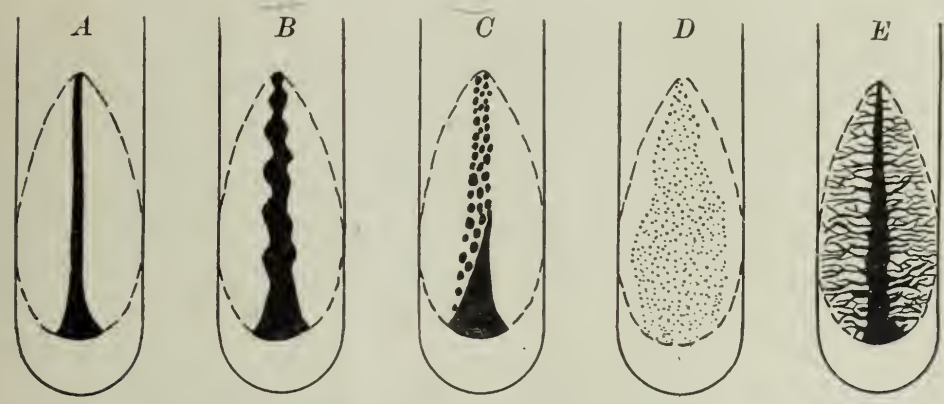

FIci, 22. Types" growth of bacteria on streak cultures

$A$, filiform ; $B$, echinulate ; $C$, bearlerl ; $D$, effuse ; $E$, arborescent

(Fig. 21, C): rillous, beset with unbrancherl hairlike extensions (Fig. 21, D); plumose, a feathery growth; arborescent, beset with rootlike extensions (Fig. 21, E).

b. Surface growtl. Same as for colonies on plate cultures.

II. Liquefying.

a. Type of liquefaction: crateriform, saucer-shaped (Fig. 21, $F$ ) ; napiform, turnip-shaped (Fig. 21, ( $\dot{*}$ ); infundibuliform, funnel-shaped (Fig. 21, II); surcat?. sac-shaped (Fig. 21, I) ; strutiform, the liquefaction descending in a horizontal plane (Fig. 21, J).

b. Character of the fluid: clear, cloudy, flocmlent, arrenular.

2. Streak cultures (agar or potato).

1. Growth: invisible, scanty, moderate, abundant.

1. For'm: filiform. a narrow line (Fig. 22. A) : erchimulate. growth along line of inoculation with tootherl or 
pointed margins (Fig. 22, B); beaded, a succession of small, disjointed colonies (Fig, 22, C); effused, spreading (Fig. 22,D); villous, plumose, arborescent (Fig. 22, E).

c. Luster: glistening, dull, cretaceous.

d. Optical characters: opaque, transhucent, opalescent, iridescent.

e. Odor: absent, decided.

$f$. Elevation of growth

g. Topography same as for plate cultures.

h. Consistency : stimy; butyrous, of a consistency like butter; viscid, growth follows the needle when touched and withdrawn; coriaceous, growth tough, leathery; brittle. growth dry, friable under the needle.

$i$. Medium discolored.

3. Beef-broth cultures.

a. Condition of fluid: rlear, rloudy.

b. Surface membrane: when formed, color, consistency:

c. Sediment: amount, compact, floculent, gramular, viscid.

d. Reaction to litmus.

e. Odor.

4. Milk cultures.

I. Curd formed.

a. Time required to curdle.

7. Character of curd : hured or soft, solid or perforated, changed or not, when twiled.

c. Whey: amount, dear or turbid.

d. Reaction to litmus.

e. Digestion of curd: time required, reaction to litmus, solution rloudy or clear.

f. Gas bubbles.

\%. Odor.

II. Digestion without formation of curd.

III. No visible change even after boiling. 
5. Plate cultures.

$\alpha$. Surface colonies.

I. Naked-eye appearance.

a. Form: punctiform, too small to be defined by the naked eye; circular; oval; spindle-shaped; conglomerate, an aggregate of similar colonies (Fig. 23, A); amoeboid, very irregular(Fig. 23, B); rhizoid, branched,
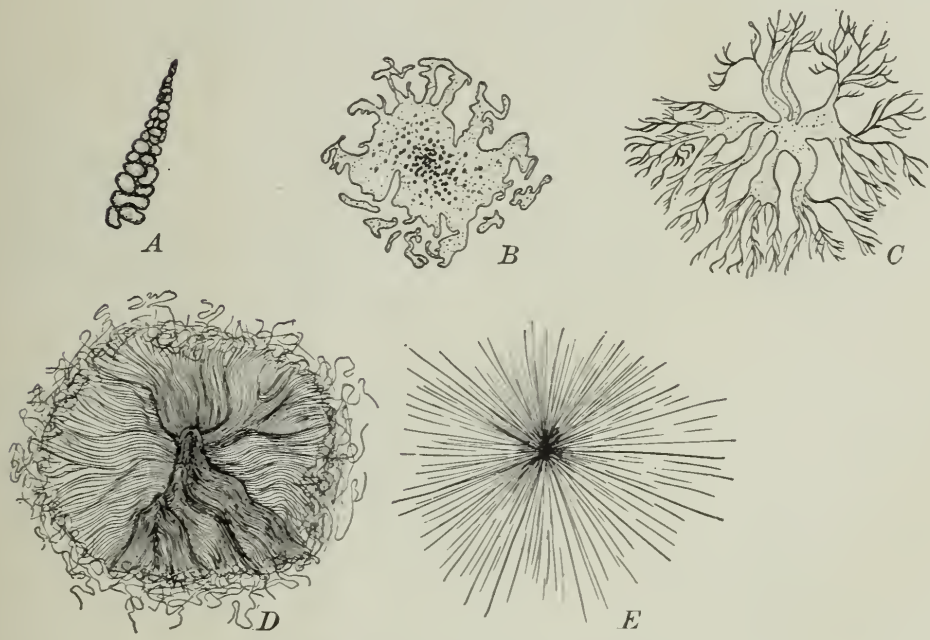

Fig. 23. Types of bacterial colonies

$A$, conglomerate ; $B$, amœboid ; $C$, rhizoid ; $D$, curled ; $E$, myceloid

rootlike structure (Fig. 23, C); curled, filaments in strands like curly hair (Fig. $23, D)$; myceloid, filamentous with the character of a mold (Fig. 23, E).

b. Size, approximately expressed in millimeter's.

c. Surface elevation: flat (Fig. 24, A); spreading; raised (Fig. 2t, B); convex (Fig. 2t, C); pulvinate, surface a segment of a circle (Fig. 24,D); capitate, surface a semisphere (Fig. 2t, E) : umbitimate. depressed in the center (Fig. 2t, F); umlumut". elevated at the center (Fig. 2t, G). 
d. Topography of surface: smooth; contoured, smoothly undulating, like the surface of a relief map; rugose, short, irregular folds due to shrinkage; verrucose, growth wartlike, with wartlike prominences.

II. Microscopic appearance.

a. Edge of colony: entire (Fig. 25, A); undulate, wavy (Fig. 25, B); repand (Fig. 25, C); lobate (Fig. 25, D);

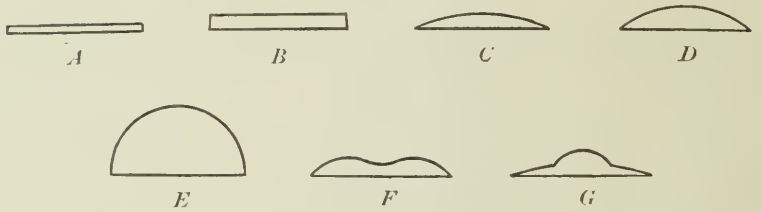

Fig. 24. Types of surface elevation of bacterial colonies $A$, tlat; $B$, raised ; $C$, convex; $D$, pulvinate ; $E$, capitate; $F$, umbilicate ; $G$, umbonate

anticulate (Fig. 25, E); lucerate, irregularly cleft (Fig. 25, F) ; fimbricate, fringed (Fig. 25, $G$ ); ciliate (Fig. 25, $H$ ) ; erose, irregularly toothed (Fig. 25, $I$ ).

b. Internal structure: amorphous, no definite structure; finely granular; coursely gramular; grumose, appears

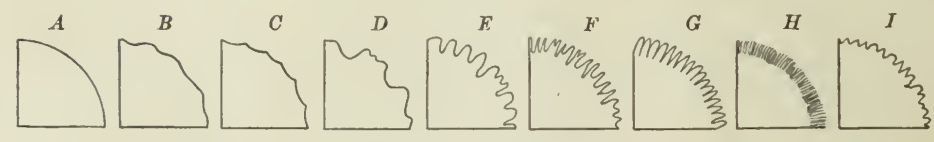

FIG. 25. Types of margin of bacterial colonies

$A$, entire; $B$, undulate; $C$, repand ; $D$, lobate; $F$, aurienlate: $F$, lacerate: $G$, fimbricate; $I I$, ciliate; $I$, erose

clotted (Fig. 26, B); yyrose, showing chinks or cracks (Fig. 26, E) ; reticulate, netted (Fig. 26, G); filamentons: floceose.

B. Deep colonies.

a. Color.

b. Shape: menctiform, lanceolute, oval, circular, spindle

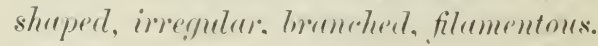

r. Translucency. 
C. Physiology.

1. Relation to oxygen.

2. Relation to light, desiccation, etc.

3. Pigment production.

4. Gas production.

a. In shake culture.

b. In fermentation tube: growth in open arm; growth in closed arm.

c. Ratio of $\mathrm{H}: \mathrm{CO}_{2}$.
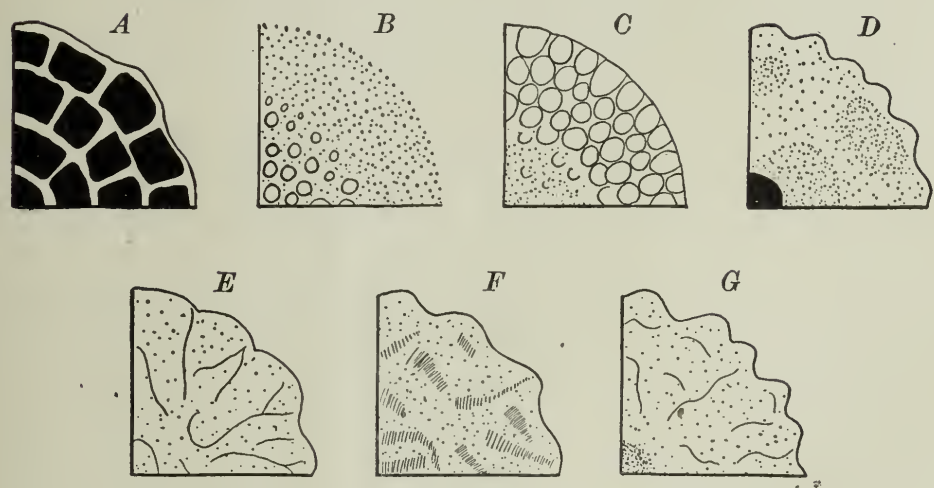

Fig. 26. Types of internal structure of colonies

$A$, areolate; $B$, grumose ; $C$, moruloid ; $D$, clouded ; $E$, gyrose ; $F$, marmorated ; $G$, reticulate

5. Acid or alkali production.

a. Litmus milk.

6. Reduction of nitrates to nitrites, to ammonia, or to free nitrogen.

7. Indol production.

8. Habitat. 


\section{SEGTION $\mathrm{X}$}

\section{BACTERIA OF THE AIR}

In a strict sense there are perhaps no bacteria of the air, since in that medium there is small chance for bacterial development, yet there are species of bacteria commonly carried in air currents. These species are common on dead organic matter, and are among those which cause contamination of culture media in the laboratory. The greater part of the bacteria in the atmosphere probably are carried on particles of dust. Other things being equal, therefore, the more dust in the air, the more bacteria.

\section{Exercise 66. Relation of Bacteria to Atmospheric Dust}

Melt nine tubes of agar and pour each into a sterile Petri dish. Replace the covers and allow the agar to harden. Label one dish $A$ and place it in the incubator for a control. Give the other dishes consecutive labels and expose one in each of the following named locations by removing the cover for exactly ten minutes: $B$, laboratory; $C$, out of doors, at least $50 \mathrm{ft}$. from any building; $D$, basement ; $E$, room before being swept ; $F$, room immediately after being swept with a dry broom; $G$, room immediately after being swept with a damp broom; $H$, barn; $I$, barn after hay has been thrown down. Do not invert the covers while making the exposure. Several students may coöperate in this exercise. After the results are posterl, each sturlent will take notes on the entire series. It will be noted that the results obtained by this method are comparative, not absolute.

\section{Exercise 67. Determination of the Number of Bacteria in Air}

Fraxklaxd, P. F. Phil. Trans. Roy. Soc. 178 B. : 113-152. 1887.

Report of Committee on Standard Methods for the Examination of Air, Amer. Jour. Pub. Hyg. 20 : 346. 1910.

Rettger, L. F. Jour. Exp. Med. 22 : 461. 1910.

'The following method, while not as exact as some, is simpler' and more likely to yield good results in the hands of students beginning the subject. 
Two students working together should prepare the following simple apparatus: Place $100 \mathrm{cc}$. of physiological salt solution (6 g. $\mathrm{NaCl}$ in $1000 \mathrm{cc}$. water) in a 500 -cc. Erlenmeyer flask. Close the flask with a tight-fitting rubber stopper through which two bent glass tubes are passed. One of the tubes ends about $2 \mathrm{~mm}$. from the bottom of the flask. The ends of the tubes are plugged with cotton and the flask is sterilized in the autoclave. Place 5 liters of water in a large bottle and mark the level of

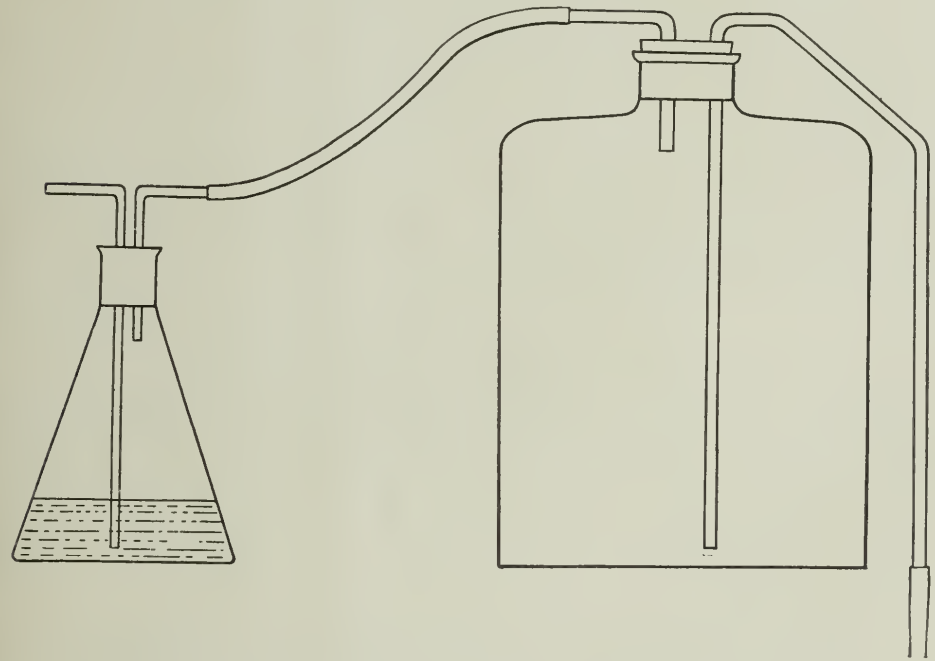

FIG. 27. Aspirator and flask for determination of bacteria in air

the water surface. Adjust a siphon with a shut-off and a suction tube. After the Erlenmeyer flask and contents have cooled, the end of the short tube is connected with the aspirator by means of rubber tubing. The cotton plug is removed from the open end of the long tube and the aspirator started (Fig. 27).

When 5 liters of water have run out, a similar volume of air has been drawn through the flask. The apparatus is then disconnected and the contents of the flask well shaken. Two 1-cc. samples are drawn with a sterile pipette and plated - one in agar and one in gelatin. The count multiplied by 100 represents the number of organisms in 5 liters of air. 


\section{Exercise 68. Study of Micrococcus candicans}

Make cultures on agar and gelatin. Study the microscopic and cultural features.

\section{Exercise 69. Study of Sarcina lutea}

Make cultures on gelatin, agar, and potato. Study the microscopic characters and compare with $M$. candicans.

\section{Exercise 70. Study of Bacillus fluorescens liquefaciens}

This organism is common in air and in water. It is one of those commonly present in decaying albuminous compounds.

Uncler the microscope note the small rods. In liquids the rods are actively motile. Make cultures on gelatin, agar, and potato. Note the fluorescence developed. Is it imparted to the agar or is it confined to the colony of bacteria?

\section{Exercise 71. Study of Bacillus prodigiosus}

This bacillus was formerly classed as a micrococcus. It is quite common and was one of the first to be noticed, because of the conspicnous red pigment it produces on starchy media.

Under the microscope note the small rorls. Make cultures on gelatin, agar, and potato.

\section{Exercise 72. Study of Bacillus subtilis (Hay Bacillus)}

This is one of the most widely distributed of bacteria. It not only occurs in air but also in water, soil, and all sorts of putrefying liquids if oxygen be present. It is abundant in hay infusions. It grows rapidly and forms spores abundantly. Under the microscope study the individual rods and the chains. Make special spore stain, using bacteria from an old culture. One way of obtaining cultures of this organism is to cover finely cut hay with distilled water and boil for a quarter of an hour. Set aside with a loose cover for forty-eight hours. A thick scum will show itself on the surface, composed of $B$. subtilis whose spores have survived the heat. Make cultures on gelatin, agar, and potato tubes; also gelatin and agar plates. 


\section{SECTION XI \\ BACTERIA OF WATER AND SEWAGE}

Nearly all bodies of natural waters contain varying numbers of bacteria. Many bacteria are introduced from the atmosphere or from organic substances coming into the water, but the larger number are washed in from the soil. Those bacteria survive and multiply which are best suited to the physical environment of the water into which they are brought. There comes to be a characteristic group of organisms in water, which may be regarled as "normal" bacteria.

The bacteriology of waters is of importance from the standpoint of sanitary living, and has received much study. A chemical determination of the chlorides, nitrates, nitrites, albuminoid ammonia, and the hardness of the water is required for complete investigation of the water sample.

Horrocks. The Bacteriological Examination of Water. London, 1901.

Kinsiccti, Winslow, and Pratr. Sewage Disposal. New York, 1910.

Prescott and Winslow. Elements of Water Bacteriology. New York, 1908.

Mason. Examination of Water. New York, 1909.

\section{Exercise 73. Collecting Samples of Water}

1. Tie pieces of filter paper or tin foil over five glass-stoppered bottles of 150-250 cc. capacity. The bottles, which should be perfectly clean, are sterilized in the dry sterilizer at $140^{\circ} \mathrm{C}$. for two hours.

2. At the time of taking samples from surface waters, remove the paper cap, then withdraw the stopper, touching only the top of it with the fingers. Hold the bottle by the base in the other hand and plunge it mouth downward into the water. When about $12 \mathrm{in}$. beneath the surface, turn the bottle mouth upwards and allow it to fill. Whenever any current exists, the mouth of the bottle should be directed against it, in order to carry away any bacteria from the fingers. If there is no current, a similar effect can be produced by turning the bottle under water and giving it a quick forward motion. Remove the bottle 
from the water and replace the stopper, wipe the exterior of the bottle dry, and replace the paper cap. Instead of this bottle an Esmarch or other type of sampler may be employed.

3. Samples for bacteriological examination should be used as soon as possible. If they are to be kept more than an hour, they should be packed in ice.

4. Samples from pumps should be collected after fifteen minutes of continuous pumping. Samples from a faucet should be taken only after the water has run freely for five to ten minutes.

\section{Exercise 74. Quantitative Study of the Bacteria in Surface Waters}

1. Obtain samples of water from three different sources, following directions given in Exercise 73.

2. After shaking the sample at least 25 times, remove $1 \mathrm{cc}$. of water with a sterile pipette and place it in the bottom of a sterilized Petri dish. If the sample is suspected of being highly infected, the water should be diluted $1: 10$ or $1: 100$, using sterile water blanks for the purpose. Plates ought not to contain over 200 colonies.

3. Pour into each dish a tube of melted gelatin (not warmer than $43^{\circ} \mathrm{C}$.). Tilt the plate gently to mix the water and gelatin. Place on a level until the gelatin has solidified, and incubate at a temperature of $22^{\circ} \mathrm{C}$. or lower.

4. In the same way make plates, using beef-peptone agar and Heyden-Nährstoff agar. These plates may be incubater at temperatures up to $37^{\circ} \mathrm{C}$.

5. Count the colonies on plates incubated at $22^{\circ}$ after seventytwo hours, and on plates incubated at $37^{\circ}$ after forty-eight hours, using a counting plate. If possible to do so, all the colonies on the plate should be counted. If there are more than 400 , it is easier and fully as accurate to comnt a fractional part of the plate and estimate from it the total number. It is customary in practice to make plates in cluplicate or triplicate, thus affording a check for one's own work. In the best of hands the limit of experimental error is large. With very careful work a variation of 10 per cent may be obtained, but a smaller variation is not to be expected. 


\section{Exercise 75. Qualitative Study of Bacteria in Surface Waters}

1-2. Same as in the preceding exercise.

3. Pour plates, using litmus-lactose agar, and incubate them at $37^{\circ} \mathrm{C}$. for three days.

t. Make differential counts of acid-forming colonies (recognized by the reddening of the litmus) and the non-acid-forming colonies.

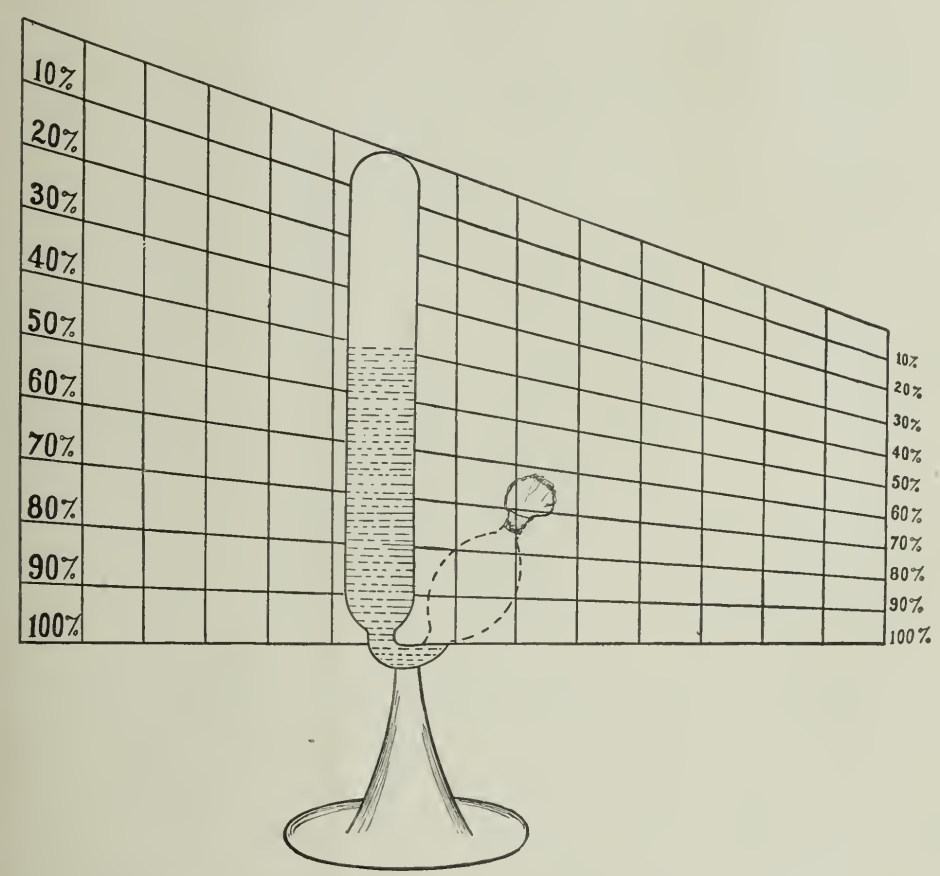

Fig. 28. Fermentation tube and gasometric chart for reading the quantity of gas evolved

The student may copy the chart on cardboard for use as indicated

The small, compact red colonies usually represent streptococci ; verify by making a simple stain. Estimate the proportion of streptococci to the total number of colonies.

5. Examine gelatin plates made in Exercise $7 t$, to determine the number of liquefying and nonliquefying colonies. The latter are assumed to come from decaying organic matter. 


\section{Exercise 76. Presumptive Test for Bacillus coli}

The presumptive test is designed to give a fairly accurate idea of the existence of pollution without the time-consuming operation of isolating $B$. coli. Several such tests are in use. Inder diverse conditions diverse results are obtained.

1. Lactose-bile bouillon. Adi 1 per cent of lactose to fresh ox bile, place in fermentation tubes, and sterilize in the Arnold sterilizer. Inoculate with samples of suspected water or sewage and incubate at $37.5^{\circ} \mathrm{C}$. for forty-eight to seventy-two hours. 'Tubes showing 25 per cent or more of gas are regarded as positive.

2. Dextrose-beef bouillon. Inoculate fermentation tubes of sterile dextrose-beef broth with 1 ec. samples of the vater to be tested. Incubate at $37.5^{\circ} \mathrm{C}$. Test for gas after forty-eight to seventy-two hours. If the gas is approximately one third carbon dioxide and two thirds hydrogen, the test is regarded as positive.

3. Litmus-lactose agar. Although less delieate than the fermentation tests, this method is of considerable value. With suitable dilutions pour Petri dishes, using this agar. Count the rolonies which redilen the agar. A large number of acid-forming rolonies is regarderl with suspicion.

\section{Exercise 77. Tests for Fecal Bacteria (Bacillus coli and Others)}

The tests here given are those (ommonlÿ used. None of them meets the approval of all bacteriologists. They are to be regarded as presumptive rather than as absolute.

A. Lactose-bile bonillon.

1. Inoculate six or more fermentation tubes of sterile lactose bile with at least 1 ce of the sample to be investigated. Incubate at $37^{\circ}($.

2. Measure the amount of gas presęnt in the closed arm after twenty-four and after forty-eight hours.

3. Make stains from each tube and use Grams stain to determine the presence of streptococci.

B. Lactose-beef bouillon.

Repeat A, using lactose-beef bonillon. 
C. Neutral Red bouillon.

Add 1 ce. of the water under examination to tubes containing Neutral Red bouillon. Fecal bacteria transfor'm the red color to a canary yellow accompanied by green fluorescence. Make stains for $B$. coli.

D. Phenol bouillon.

Repeat C, using phenol bouillon.

\section{Exercise 78. Quantitative Examination of Sewage}

1. Procure samples as directed for water in Exercise 73.

2. In making plates and fermentation tube tests use dilutions of $1: 1000,1: 10,000,1: 100,000$, or even greater.

3. Make plates of beef gelatin, beef agar, Heyden-Nährstoff agar, and litmus-lactose agar.

4. Incubate part of the agar plates at $37^{\circ} \mathrm{C}$. and others below $22^{\circ} \mathrm{C}$. Count the former after forty-eight hours and the latter after seventy-two hours. ('ompare the results.

\section{Exercise 79. Bacterial Content of Snow and of Rain Water}

If opportunity presents itself, make bacterial counts of snow. Collect samples in sterilized glass-stoppered bottles, as in case of water. Bring the bottles to the laboratory, allow the snow to melt, draw samples with sterile pipettes before all of the snow has melted. Collect samples of freshly fallen snow and after intervals of twenty-four, forty-eight, and seventy-two hours.

Collect samples of rain water by uncovering sterile glass jars while rain is falling. Make plate cultures within one hour from the time the jars are set out.

Compare the number of organisms per cubic centimeter with that obtained in surface waters.

\section{Exercise 80. Study of Streptococci}

The term "Sewage Streptococci" is applied to a poorly defined group including cocci which may or may not form well-defined chains. Under the microscope they appear to occur in pairs, short chains, or irregular groups. They grow well on sugar 
media, and ferment dextrose and lactose, forming acid but no gas. On the litmus-lactose-agar plate, made from a polluted water, the streptococcus colonies may be distinguished from other acid-forming colonies by their small size, compact structure, and permanent deep red color. The organisms grow feebly on the surface of beef agar, but flourish better under partial anaërobic conditions, such as those prevailing in the lower part of the stab canal.

While it seems entirely reasonable to look upon the streptococci as evidence of pollution, still there is no such wellestablished connection with sewage as in the case of the colon bacteria.

Houston regards streptococci as indicative of recent and objectionable pollution. Horrocks, however, found that B. coli gradually disappeared from jars of sewage kept in the dark for three months, and that those forms which survived were mainly varieties of streptococci and staphylococci. He believes that streptococci indicate pollution with old sewage which is not necessarily langerous.

1. Transfer from colonies of streptococei to tubes of sterile media. Cultivate on beef gelatin, beef agar, and dextrose bouillon.

2. Make stained preparations from bouillon cultures.

\section{Exercise 81. Isolation of Bacillus coli}

Much remains to be clesired in the way of methods for isolating the colon bacillus. With the most careful work it is not possible to isolate this germ from all samples of polluted water's.

1. Prepare an "enriching culture" by inoculating fermentation tubes of sterile dextrose bouillon each with $1 \mathrm{cc}$. of the sample under investigation. Nix by tilting the tubes. Incubate at $37.5^{\circ} \mathrm{C}$. for ten to twenty-four hours. W' Watch the tubes ancl, upon the first appearance of gas, plate out the organisms on litmus-lactose agar.

2. Watch the plates for acid-forming colonies. Transfer from them to agar-slope cultures. If the culture resembles $B$. coli, 
numerous subcultures are made from it. The following gives those which will be of diagnostic value:

3. Gelatin. B. coli grows well without liquefying the medium.

4. Milk. In milk it produces acid and forms a curd in twelve to twenty-four hours at $37.5^{\circ} \mathrm{C}$.

5. Nitrate solution. When grown on Giltay and Aberson's or other nitrate solution it reduces nitrates to nitrites. The solutions are kept twelve to twenty-four hours at $37.5^{\circ} \mathrm{C}$.

6. Sugar bouillon. In sugar bouillon gas is evolverl. Analysis shows the ratio $\mathrm{H}: \mathrm{CO}_{2}:: 2: 1$. Incubate twelve to twenty-four hours at $37.5^{\circ} \mathrm{C}$.

7. Dunham's solution. Indol is produced when B. coli grows on Dunham's solution (Exercise 37). Incubate tubes three or four clays at $37.5^{\circ} \mathrm{C}$. ; then test for indol.

\section{Exercise 82. Study of Characters of Bacillus coli}

If the precerling exercise has been omitted, make studies of pure cultures of $B$. coli on the various media there described. Make stained preparations with carbol-fuchsin and determine its reaction to Gram's stain.

\section{Exercise 83. Study of Bacillus proteus vulgaris}

Members of the so-called proteus group of bacteria are commonly found in putrefying substances. Their decomposing action is marked by a very foul odor and an alkaline reaction. Their presence in water does not always indicate sewage pollution, but pollution is very probable if they occur in conjunction with the colon bacillus.

Make cultures on agar slope, gelatin stab, milk, and potato. Study the "swarming islands" with a magnification of $60 \times$ in colonies in gelatin plates. Make stained preparations with carbolfuchsin and determine the relation of this organism to Gram's stain.

Study the fermenting, activity in shake cultures of dextrose agar and in fermentation tubes of clextrose bouillon.

Examine cultures on Dunham's solution for indol. 
Exercise 84. Study of Aërobic Organisms which Decompose Cellulose

A study of these organisms, even in mixed cultures, is instructive in demonstrating how cellulose substances are liquefied in sewage, manure, soil, and other media.

1. Prepare the following medium and fill Erlenmeyer flasks to a depth of $0.5^{-1} \mathrm{~cm}$.

$$
\begin{aligned}
& \text { Filter paper (in strips) . . . . . . . . } 2.00 \mathrm{~g} \text {. } \\
& \mathrm{NH}_{4} \mathrm{Cl} \text {. . . . . . . . . . . } 0.10 \mathrm{~g} \text {. } \\
& \mathrm{K}_{2} \mathrm{HP}_{4} \mathrm{O}_{4} \text {. . . . . . . . . . . . } 0.05 \mathrm{~g} \text {. } \\
& \mathrm{CaCO}_{3} \text { (chalk) . . . . . . . . . } 2.00 \mathrm{~g} \text {. } \\
& \text { IVater . . . . . . . . . } 100.00 \text { cc. }
\end{aligned}
$$

2. Inoculate the flasks with fresh horse manure or with slimy mud from the bottom of a pond or river. Incubate the flasks for three or four weeks at a temperature of $30^{\circ}-34^{\circ} \mathrm{C}$.

3. Transfers should be made with a platinum loop to other flasks of sterile solution after a month. In this way the growth of the cellulose-decomposing organisms is increased. It may require two or three transfers to get really active decomposition.

4. The cellulose first becomes brown in color, then perforated with holes. A brown color is usually imparterl to the solution.

5. Make cover-glass stains of bacteria taken from a flask in

\begin{tabular}{|c|c|c|c|c|c|c|c|c|c|}
\hline Filter paper & . & . & & & & & & & $20.00 \mathrm{~g}$. \\
\hline $\mathrm{CaCO}_{3}$ (chalk) & . & - & - & . & & & & & $2.00 \mathrm{~g}$. \\
\hline $\mathrm{K}_{2} \mathrm{HPO}_{4} \ldots$ & . & . & - & - & - & & & & $0.10 \mathrm{~s}$. \\
\hline $\mathrm{MgSO}_{4}$ & & . & - & - & • & & & & $0.50 \mathrm{~g}$. \\
\hline$\left(\mathrm{NH}_{4}\right)_{2} \mathrm{~S}()_{4}(\mathrm{or}$ & $\left.P()_{4}\right)$ & . & . & . & - & & & & $1.00 \underline{\simeq}$. \\
\hline $\mathrm{NaCl}$ & - & . & . & . & . & & . & & . trace \\
\hline Water & . & . & • & . & . & & . & & $1000.00 \mathrm{cc}$. \\
\hline
\end{tabular}
which cellulose decomposition is progressing.

Exercise 85. Study of Anaërobic Organisms which Decompose Cellulose

1. Proceed to fill Erlenmeyer flasks to the stopper (rubber) with the following solution:

2. Inoculate with fresh horse manure or slimy mud. If horse manure is to be used, the filter paper may be omitted.

3. Incubate at $30^{\circ}-34^{\circ} \mathrm{C}$. for a month and make transfers as in Exercise 84. 


\section{Exercise 86. Cellulose Decomposition with Formation of Hydrogen}

In the foregoing experiments methane $\left(\mathrm{CH}_{4}\right)$ is the principal gas formed from the decomposition of cellulose. If the culture made by one of the first transfers be heated after inoculation to $75^{\circ} \mathrm{C}$. for fifteen minutes and then cooled, the production of methane will be replacerl by that of hytrogen. The organisms causing the hydrogenic fermentation of cellulose appear to be spore-formers which can withstand the temperature of $75^{\circ} \mathrm{C}$.

\section{SECTION XII}

\section{BACTERIA OF THE SOIL}

Of all the varied activities of bacteria in nature, none compares in importance with the work of the soil bacteria. They not only determine the fertility of the soil, but they serve as the connecting link between the world of the living and the world of the dead. 'They are the great scavenging agents which tear' down the dead bodies of animals and plants and restore the carbon, nitrogen, sulphur, and other elements of the tissue to the round of nature. The processes of nature are such that the same material is repeatedly used, passing in endless cycle from plant to plant or from plant to animal, and back again to plant, but always with the intervention of bacteria. Withont their action dead bodies would accumulate and cover the surface of the earth; the kingdom of the living would be replaced by the kingdom of the dearl; and the world's supply of carbon and nitrogen would be locked up in a form useless to most forms of life.

The soil may be regarrled as the greatest field of bacterial activity we know. The surface layers of the soil are usually inhabited by many thousands of germs per gram. The soil furnishes many of the germs found in lakes and streams, most of those found in air, and some of those concerned in animal diseases. Bacteria appear to be most numerous in the surface layers of the soil and to diminish at increasing deptlis. Below 
a depth of four to six feet bacteria are rarely found except in places where local drainage currents carry them downward. $V$ arious factors, such as temperature and moisture, influence the number and activities of the soil organisms, but it is probable that they are active cluring the greater part of the year.

Again, the bacteria of the soil are of various species, and no one species has uncontended sway in the field. Those which are best suited to the environment thrive; those which are not so well suited are crowded out and diminish in numbers or die.

In other words, the soil bacteria, like other organisms, have a definite problem of existence which must be solver in the main under the conditions which they find in arable soils. At times one species of bacteria predominates in numbers and activity; at other times, under changed conditions, other species predominate. When the bacteria which set up certain activities predominate, the productiveness of the soil is enhanced ; when other classes predominate, the reverse is true.

An enumeration of the number of hacteria in soil does not mean much in itself. However, if soil conditions are sufficiently well controlled, a quantitative determination may shed light on the effects of various factors upon microörganic life in soil. Only comparative results can be obtainerl, even under the best conditions, since many soil organisms do not grow upon the media available for counting bacterial colonies.

\section{Exercise 87. Obtaining Soil Samples}

1. Sterilize in the dry oven several trowels or steel spatulas, previously wrapped in Manila paper. Also sterilize three widemouthed, glass-stoppered bottles.

2. In the field scrape off the top layer of soil; then, using a fresh sterile spatula, loosen about $10 \mathrm{~cm}$. of the soil, stir it thoroughly, and transfer $25-50 \mathrm{~g}$. to a sterile bottle. 'The surface soil varies widely in bacterial content, owing to seasonal extremes of moisture, the inhibiting action of light, accidental contamination, and other causes.

3. Carry the samples to the laboratory within an hour after collecting them. 


\section{Exercise 88. Preparing Dilutions and Pouring Plates}

1. Weigh 1-g. samples of soil into 99-ce. water blanks. Stir with a sterile glass rod until all lumps are broken up.

2. Draw $1 \mathrm{cc}$. of the muddy water with a sterile pipette and transfer to another 99-cc. water blank. These water blanks should be contained in narrow-necked flasks or bottles of $200 \mathrm{cc}$. capacity, to permit of agitation without loss of their contents. Agitate for two minutes; then transfer $1 \mathrm{cc}$. with a sterile pipette to a sterile Petri dish and add a tube of melted agar which has cooled to $43^{\circ} \mathrm{C}$. Mix the contents by tilting the dish. When cool, incubate at a temperature between $18^{\circ}$ and $23^{\circ} \mathrm{C}$.

For making these plates agar media are preferable to gelatin, on account of the higher nitrogen content of the latter. Beefpeptone agar may be used, although the Heyden-Nährstoff agar will give higher counts. Lipman ${ }^{1}$ reports good results from the use of a synthetic agar.

3. Count the colonies as they develop and estimate the number of bacteria per gram.

4. Many of the bacteria of the soil are anaërobic and can only be grown in the absence of oxygen. For method see Exercise 56.

\section{Exercise 89. Determination of the Number of Spores in Soil}

1. Make a soil suspension in a dilution of $1: 1000$. Add $1 \mathrm{cc}$. to a tube of sterile melted gelatin.

2. Heat the tube in a water bath to a temperature of $80^{\circ} \mathrm{C}$. for ten minutes.

3. Pour the melted gelatin into a sterile Petri dish. Incubate at room temperature and count the colonies after four days. Estimate the number of spores in $1 \mathrm{~g}$. of the soil sample.

1 Lipman and Brown. Centralbl. f. Bakt., 2te Abt., 25 : 447. 1910.

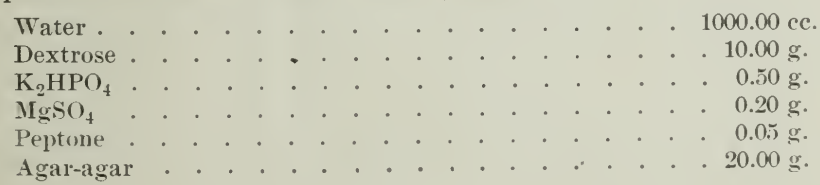




\section{SOIL BACTERIA IN RELATION TO NITROGEN COMPOUNDS}

The relations of soil bacteria to compounds of nitrogen have been more extensively studied than their relations to other soil constituents, although there is reason to believe that their relations to sulphates and phosphates are also of great importance. In many soils, however, the amount and form of nitrogen present seems to be the chief chemical factor governing plant production. Bacteria have been found to play an important part in the transformations of soil nitrogen, to say nothing of the ability of some races of bacteria to add considerable stores of nitrogen to the soil.

Although there are many unsettled problems, and our knowledge of these bacteria is far from complete, there is reason to believe that we may control to some extent the addition of nitrogen to cultivated soils, and its subsequent transformations.

For a more complete discussion of these and allied questions the student is referred to

Coxx. Agricultural Bacteriology, Seconł Edition. Philadelphia, 1909.

Lipusx. Bacteria in Relation to Comtiry Life. New York, 1908.

Voorness and Lipuax. Review of Investigations in Soil Bacteriology, Bulletin

No. 194. Office of Experiment Stations, I .s. I)epartment of Agriculture, 1907 .

Marshall. Microbiology. Philadelphia, 1911.

LAfar. Handbuch der technischen Mykologie, Bu. III. .Jena, 1905.

Löнsis. Handbuch d. landw. Bakteriologie. Berlin, 1911.

Numerous papers in journals and agricultural literature.

In many of the experiments which follow, analyses are to be made which involve more or less chemical work. The chemical methods given in appendixes F, G, H, and I are the simplest which will give anything approximating accurate results in the hands of undergrarluate students. They are mainly qualitative. The research worker who has more apparatus and who desires more accurate quantitative results, is referred to works on standard analysis of waters and soils.

\section{Exercise 90. Ammonification of Peptone by Soil Bacteria}

1. Prepare $400 \mathrm{cc}$. of Dumham's solution (see Exercise 37). Place 200 cc. in each of two flasks of 500 ce. capacity.

2. Sterilize the flasks in the autoclave. 
3. Keep one flask for a control and inoculate the other with a few grams of fresh garden soil. Incubate the flasks at $30^{\circ}-37^{\circ} \mathrm{C}$. for a week.

4. Moisten strips of clean filter paper with Nessler's reagent and pour upon them a few drops from each of the flasks. A reddish-yellow color indicates the presence of ammonia. Another method is to remove a portion, say $50 \mathrm{cc}$, make alkaline with $\mathrm{NaOH}$, and boil it in a small flask, holding a strip of Nessler paper at the mouth of the flask.

\section{Exercise 91. Ammonification of Nitrogenous Substances in Soil}

1. Place $100 \mathrm{~g}$. samples of freshly gathered soil in each of four tumblers or beakers. Add $5 \mathrm{~g}$. of cottonseed meal or dried blood to two tumblers, leaving the others for controls. Stir with a sterile spatula.

2. Add water to give optimum moisture content as nearly as possible. Cover the tumblers loosely with a glass plate. Incubate at room temperature for one week.

3. At the end of the incubation period transfer the soil to a flask, preferably a copper flask. Add a little paraffin and some magnesium oxide and distill off the ammonia.

4. For a qualitative test a piece of filter paper moistened with Nessler reagent may be held at the mouth of the flask as in Ex ercise 90. For quantitative work a condenser is attached and the distillate is collected in standard acid and titrated against standard alkali.

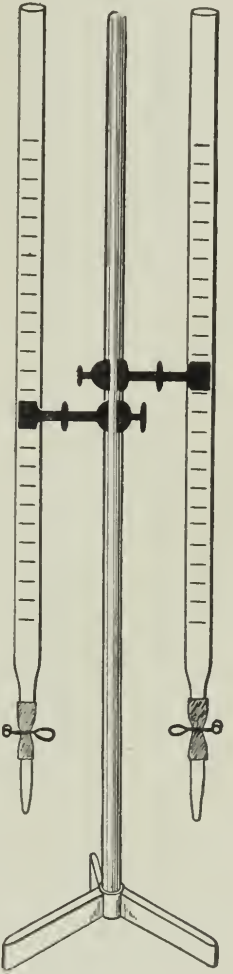

Fic. 29. Burettes arranged for titration

5. Compare the amount of ammonia liberated in the control and in the experimental tumblers. What part do bacteria play in this process? 


\section{Exercise 92. Nitrite Formation in Solution}

1. Prepare Winogradsky and. Omelianski's solution for nitriteforming organisms (see Exercise 51).

2. Divicle the solution equally among fire Erlenmeyer flasks of 500 cc. capacity. Number the flasks consecutively.

3. Inoculate flask No. 1 with 1-2 g. of fresh soil collected about $10 \mathrm{~cm}$. beneath the surface. Incubate the flasks at $25^{\circ}$ $30^{\circ} \mathrm{C}$.

t. As soon as growth is evident (usually in four or five days), inoculate flask No. 2 from flask No. 1, using the platinum loop. Continue the serial inbculation from flask to flask.

5. Examine the bacteria in a drop of Gram is ioline solution and with simple stains. 'Test the solutions for nitrites with the Griess-Ilosvay reagent, or with Trommsilorf reagent.

\section{Exercise 93. Nitrate Formation in Solution}

1. Prepare 1 liter of Winogradsky and Omelianski’s solution (see Exercise 52). Divicle the solution equally among five Erlenmeyer flasks of 500 'c. capacity. Sterilization is of no advantage in this case, since none except nitrifying bacteria can develop in this solution.

2. Inoculate one flask with $1 \mathrm{~g}$. of a soil sample collected about $10 \mathrm{~cm}$. from the surface.

3. Watch the flask for evidence of bacterial growth. At the first indications of growth inoculate the second flask with three loopfuls of solution taken from the first. Carry through the inoculation in this way from flask to flask, leaving one flask uninoculated, to serve as a control. 'This methorl of serial transfers gradually eliminates all bacteria except those fitted to develop in this solution, that is, principally nitrifying bacteria. At the end one obtains a nearly pure culture of these organisms.

4. Make cover-slip stains from the flasks and examine the organisnus microscopically. Stain with warm carbol-fuchsin and wash with acidulated alcohol, or stain with Löffler's alkaline methylene blue. At the expiration of ten days test the solutions for nitrates with phenol-sulphonic acirl. 


\section{Exercise 94. Nitrification in Soil}

For some reasons it is more satisfactory to study the process of nitrification in soils than in solutions. Where comparisons are desired between the capacity of different soils for nitrification, only soils can be used. Moreover, Stevens and Withers (Centralbl. f. Bakt., 2te Abt., 23: 35j. 1909) have shown that soils which show capacity for nitrification often give no result when their suspensions are used as inocula in solutions. The capacity of a soil for nitrification is not, however, a simple proposition depending only upon the number and vigor of the necessary bacteria; it is profoundly influenced by soil conditions-for example, quantity and quality of organic matter, reaction of soil, moisture content, porosity, etc. - as well as by other factor's less readily recognized.

1. With a sterile trowel procure soil samples about $10 \mathrm{~cm}$. below the surface.

2. Put $100 \mathrm{~g}$. of the freshly collected soils into glass tumblers. Reserve one or more tumblers of soil for controls. Add to the others 5 ce. of a 2 per cent solution of sterile ammonium sulphate (equivalent to $.100 \mathrm{~g}$. $\left.\left(\mathrm{NH}_{4}\right)_{2} \mathrm{SO}_{4}\right)$. Add 5 cc. of sterile distilled water to the control tumblers. Weigh each tumbler and record the weight; cover the tumblers with glass plates. Once each week weigh the tumblers and add sterile distilled water to bring the weights back to their original value. Incubate the tumblers at $30^{\circ}-35^{\circ} \mathrm{C}$. for four to six weeks.

3. At the end of the experiment transfer the soil from the tumblers to agate-ware pitchers or to large, wide-mouthed glass bottles. Use 1000 cc. of distilled water for the transfer of each sample. Give thorough agitation for five minutes; then allow the soil to settle for thirty minutes. Filter off the supernatant extract. Filtration may be accomplished with a Pasteur-Chamberland bougie, using the apparatus described in Bulletin No.31, Bureau of Soils, U.S. Department of Agriculture (see Appendix), or, since only a portion is required for analysis, the extract may be decanted through a folded filter paper. The filtration through paper may be hastened by adding $5^{-10} \mathrm{~g}$. of alum (potassium 
aluminum sulphate) per liter to the soil suspension before filtering, as directed above.

4. Draw samples of $50 \mathrm{cc}$. or larger, as soon as possible, to avoid the danger of denitrification. Determine nitrate qualitatively, or quantitatively by the phenol-sulphonic colorimetric method. Each $10 \mathrm{cc}$. of the extract represents $1 \mathrm{~g}$. of the fresh soil sample. By determining the water content of the soil sample at the outset of the experiment, it will be possible to reduce the nitrate determinations to a moisture-free basis.

5. Compute the amount of nitrate formed in the samples to which ammonium sulphate was added. If soils from a variety of sources under a variety of conditions were. included in the plan of the experiment, draw conclusions as to the effect of these conditions upon nitrification.

ХотЕ. The isolation of nitrite and nitrate organisms from soils involves the preparation of silica-jelly media. The work is rather difficult for the beginning student. Directions for procedure will be found in the following works and others.

Hersemaxx. Laboratory Guide in Bacteriology.

LAfar. Handbuch der technischen Mykologie 3 : 155.

Sмıтн. Bacteria in Relation to I'lant Diseases 1 : 36.

\section{Exercise 95. Reduction of Nitrates by Bacteria}

1. Prepare Giltay and Aberson's solution and fill several fermentation tubes and test tubes. Sterilize.

2. Inoculate some of the tubes with a small quantity of fresh horse manure. Inoculate others with B. denitrificans, B. Hartlebii, B. pyocyaneus, or B. fluorescens liquefaciens. Keep the tubes in the incubator for ten to fifteen days.

3. Examine the fermentation tubes for free gases. Examine the contents of the test tubes for nitrites and ammonia compounds.

\section{Exercise 96. The Reducing Action of Denitrifying Bacteria upon Nitrates and Methylene Blue}

Fred. Centralbl. f. Bakt., 2te Abt., 32 : 421. 1912.

Since denitrification is essentially a reducing process in which oxygen is removed from its combination with nitrogen, the action may well be demonstrated by adding a reducible dyestuff 
to the solutions. Methylene blue serves well because it is nonpoisonous to bacteria and is easily reduced to the colorless leuco compound.

1. Add $20 \mathrm{cc}$. of standard methylene blue solution (1:1000) to each 100 cc. of Giltay and Aberson's solution. Fill several fest tubes and fermentation tubes. Sterilize.

2. Inoculate the tubes with B. denitrificans, B. Hartlebii, B. pyocyaneus, and $B$. fuorescens liquefaciens. In order to exclucle oxygen pour in paraffin oil to a depth of about $2 \mathrm{~cm}$. in the test tubes. Keep the tubes in the incubator for three to seven days, or until the solutions become colorless. So long as nitrates are present the bacteria do not attack the methylene blue to any great extent.

3. When a tube has lost its color, test for nitrates; shake the solution or pass air through it. IVhat happens? Explain.

\section{Exercise 97. Nonsymbiotic Bacteria which Fix Atmospheric Nitrogen. Isolation and Study of Azotobacter}

1. Prepare Ashby's solution (see Exercise 49).

2. Clean three small flasks or salt-mouthed bottles. Put into each 25 cc. of Ashby's solution and sterilize in the Arnold sterilizer.

3. Inoculate each with $1 \mathrm{~g}$. of soil. It will be well to use soil samples collected from different places, for Azotobacter is not necessarily most abundant in the most productive soils. Incubate the flasks at $30^{\circ} \mathrm{C}$. for three days; at the end of that time pick out flasks which have a greasy film on the surface of the liquicl.

4. Transfer small flecks of this surface film to a slide. Examine with the microscope. Add a drop of Gram's iodine solution to the preparation. Azotobacter cells are stained golden yellow.

5. Make a cover-glass preparation and stain with aqueous methylene blue.

\section{Exercise 98. Growth of Azotobacter in Pure Cultures}

Hoffuan and Hammer. Centralbl. f. Bakt., 2te Abt., 24 : 181. 1909.

1. Prepare nutrient agar by adding 2 per cent of agar to Ashby's solution. Sterilize in the Arnold sterilizer. 
2. Plate out Azotobacter from the flasks prepared in Exercise 97. Examine and transfer from colonies to tubes of Ashby's agar.

3. The most successful method of cultivating Azotobacter is upon large surfaces. Put 50 cc. of melted agar into an Erlenmeyer flask of 1 liter capacity. After sterilization allow the agar to harden, or pour sterile Ashby's agar into Petri dishes with a diameter of $20 \mathrm{~cm}$. or more. Inoculate with a suspension of Azotobacter in sterile clistilled water. Tilt the culture once or twice daily. The result is usually a thick film of growth upon the agar. In this way enough material may be collected for analytical work, but it should be remored within a week from the time of inoculation.

\section{Exercise 99. Symbiotic Bacteria which Fix Atmospheric Nitrogen. Bacillus radicicola}

Beijepixck. Botanische Zeitung $46: 723.1888$.

Hellriegel. Zeitschr. Rübenzuckerind, deuts. Reichs. 1886.

Kосн. In Lafar's Technische Mykologie, Bd. III. Jena, 190:)

Lönxis. Handbuch landw. Bakteriologie. Berlin, 1911.

Marsiall. Microbiology. Philadelphia, 1911.

Peirce. Proc. Calif. Acad. Sci. (3d ser.) 2 : 295-328. 1902.

Sмiтн. Bacteria in Relation to Plant I)iseases, Vol. 11. Washington, 1911.

The student in regular class work can get no more than an introduction to the bacterial side of this problem, because most experiments in this line require more time than is usually available in laboratory classes. Yet it is possible to gain an intelligent idea of the subject by making a few simple experiments. A casual examination of the literature shows that upon some important questions uncertainty still prevails. For more extended work the student is directed to the researches cited above and to others.

1. Secure the roots of a leguminous plant which shows numerous tubercles. Sketch a root, showing the shape and arrangement of tubercles. Do they seem to have any regular arrangement?

2. Secure young roots of peas or vetch plants. Holding a root with a young tubercle in pith, cut razor sections embracing the tubercle and root tissue at right angles to the long axis of the 
root. Stain the sections in 1 per cent acetic acid in which are clissolved equal portions of fuchsin and methyl violet. Wash the sections briefly with water and make microscopic examination.

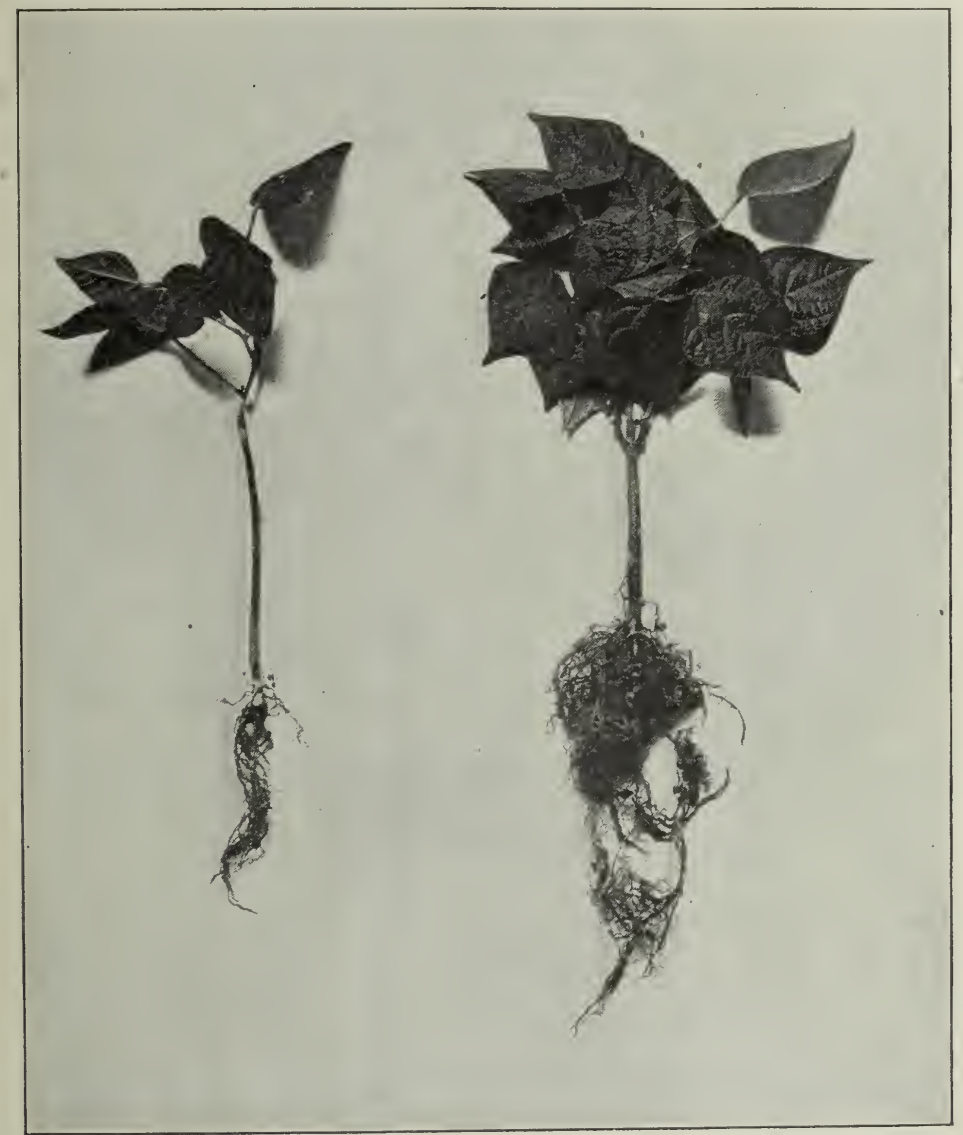

FIG. 30. Increased growth of beans due to inoculation with $B$. radicicola Plant on the left grown in uninoculated soil; plant on the right grown in inoculated soil. (After Ferguson)

Look especially for the "infection threads" extending through the cortical cells of the root. The protoplasm of the root cells and tubercle cells should appear blue, and the bacteria red. 
3. Crush a well-washed tubercle between two glass slides. Transfer a clrop of water from the crushed tubercle to a cover glass and stain in the usual manner. Examine the preparation for the rod-shaped B. radicicola and for branched rods - bacteroids.

\section{Exercise 100. Isolation and Culture of Bacillus radicicola}

Buchaxix, R. E. Centralbl. f. Bakt., 2te Abt., 23 : 59. 1909.

P'каzмошкк. Landw. Vei's.-Stat. 37: 199. 1890.

Harrisox and Barlow. Centralbl. f. Bakt., 2te Abt., 19: 426. 1907. Also works cited under Exercise 99.

1. Obtain several young tubercles from the roots of clover or other legume. Wash thoroughly in tap water.

2. Immerse the tubereles for several minutes in $1: 1000$ solution of mereuric ehloride. Transfer with sterile forceps through several changes of sterile distilled water.

3. Crush the tubercles with a sterile spatula in a sterile Petri dish and make plates from the contents of the nodule. Use the synthetic agar described in Exercise 88.

4. Watch the plates for small, white, moist colonies. Transfer' from them to ordinary laboratory merlia (see Exercise 108).

5. Pour plates also from commercial cultures of B. racticicolu.

\section{Exercise 101. The Production of Bacteroids of Bacillus radicicola upon} Artificial Media

Until recently the branched roul, or bacteroid, of B. roldicionle has been found only in the nodule of the legume. Zipfel has shown, however, that these forms may be produced in cultures in the laboratory (Centralbl. f. Bakt., -2te \bt., 32: 97. 1911) by the following method:

1. Extract $100 \mathrm{~g}$. of bean or fea meal with 100 ce. of normal KOH and 5 liters of water for twenty-four hours. Siphon off the clear liquid and neutralize with phosphoric acil. Nake the volume up to 5 liters. Prepare a medium by taking

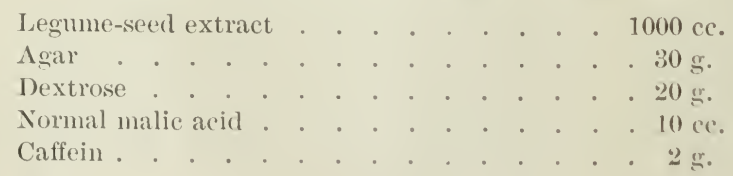


2. Fill tubes, plug, and sterilize in the Arnold sterilizer.

3. Inoculate with different strains of $B$. radicicola. At first growth will be slow, but between the fourth and tenth days many bacteroids may be found.

\section{Exercise 102. The Formation of Tubercles upon Roots of Legumes}

If time permits, this experiment may be performed by the class, different legumes being assigned to different students.

1. Obtain new flowerpots, or sterilize old pots at $150^{\circ} \mathrm{C}$. for an hour. Fill the flowerpots with sand which has been baked at a temperature of $150^{\circ} \mathrm{C}$. for one to two hours.

2. Plant seeds of various legumes in the sand. Inoculate half the pots by adding a suspension of $B$. radicicola obtained either from a pure culture or from soil in which the legume has previously been grown. Water the sand as needed with the following solution :

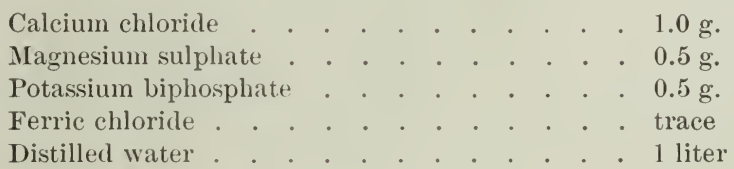

3. Watch the plants for differences in growth. When the differences are marked, pull out the plants and examine the roots of inoculated and uninoculated plants for tubercles.

\section{Exercise 103. The Reduction of Sulphates by Bacteria}

When grown under anaërobic conditions, certains bacteria are able to reduce sulphates. In water-logged swamps ferrous sulphate may be reduced and give rise to deposits of bog iron.

1. Prepare Van Delden's solution for the cultivation of sulphate-reducing bacteria (see Exercise 46).

2. Fill six small flasks nearly full of the solution. Plug and sterilize the flasks in the autoclave.

3. Set aside two flasks for controls; inoculate two with a few grams of garden soil and two with a few cubic centimeters of sewage or ditch water.

4. Incubate for one to two weeks at room temperature. 
5. Partial reduction is indicated by the formation of a dark color due to the formation of ferrous sulphide. Pour a portion of a culture into a test tube and test for sulphates with barium chloride. Test the controls for the relative amount of sulphates.

\section{Exercise 104. The Cultivation of Bacillus amylobacter}

The group of organisms represented by $B$. amylobacter lives upon starchy material and effects its decomposition.

1. Cut slices of beets and place them in wide-mouthed bottles or flasks of $50 \mathrm{cc}$. eapacity. Pour in tap water until the flasks are full and close them with rubber stoppers. If beets are not obtainable, a substitute may be had in thick starch prepared as follows: Boil $100 \mathrm{cc}$. of distilled water until air is expelled; remove the flame and stir in coarsely ground rice until the paste is thick enough to support a spoon in a vertical position; add a few grams of wheat starch ancl stir it in.

2. Keep the material at $35^{\circ}-37^{\circ} \mathrm{C}$. for twelve to forty-eight hours.

3. After fermentation is apparent, transfer a drop of paste to a drop of Gram's iodine solution.

4. Examine the preparation for spindle-shaped bacteria containing granules.

\section{Exercise 105. Study of Bacillus mycoides}

This organism represents those soil organisms which play an important part in ammonification.

Make stains of B. mycoides, using carbol-fuchsin and Gram's method. Using material from an old culture, make a spore stain. Make cultures on agar plates, agar slope, gelatin stab, and potato. Grow the organism on ordinary bouillon or on Dunham's solution, and test for ammonia.

\section{Exercise 106. Study of Bacillus vulgatus (Bacillus mesentericus vulgatus Fliggge)}

This is the organism commonly known as potato bacillus. It is common in soils and hence is a frequent contamination of our potato cultures. In incompletely sterilized milk it sometimes causes slow curdling. Later the curd is digested, with the formation of bitter substances. 
Make stains from pure cultures, using carbol-fuchsin and Gram's method. Examine for spores. Make and describe cultures on agar plate, agar slope, gelatin stab, and potato.

\section{Exercise 107. Study of Bacillus denitrificans}

This organism shows the ability to reduce nitrates, usually with the production of more or less 'free nitrogen. Studies of this organism should be made in pure cultures on gelatin stab, agar slope, potato, and Giltay and Aberson's solution in fermentation tubes. After two weeks the solutions should be tested for nitrites and ammonia.

Comparison of the denitrifying power of $B$. pyocyaneus, B. Hartlebii, and B. fuorescens liquefaciens should also be made (compare Exercise 95).

\section{Exercise 108. Study of Bacillus radicicola}

Continue the study of this organism, begun in exercises 99 and 100 , by making stained preparations from pure cultures. Use carbol-fuchsin, methylene blue, and Gram's stain. Study the growth of the organisms in pure culture on gelatin stab, agar slope, potato, and nitrogen-free media. After three weeks test the cultures on nitrogen-free media for nitrogen as nitrites or nitrates.

\section{SECTI()N XIII}

\section{BACTERIA OF MILK}

Milk is a favorable medium for the growth of many microorganisms. It contains sugar (a food constituent for many bacteria), proteins represented by casein and lactalbumin (which furnish organic nitrogen in suitable combination), potassium and calcium largely as phosphates, and fats which may be used by various mold fungi. These substances are in solution and at a dilution suitable for nourishing bacteria.

The bacteria in their growth processes bring about more or less extensive changes in the character of the milk, and soon alter' its value for human (onsmmption. 'These changes are almost 
inevitable, since commercial milk is exposed to more or less contamination with bacteria before it reaches the consumer.

One of the methods of determining the quality of milk is by bacteriological examination. To determine the exact character of the milk, physical and chemical exammations should also be made. In general the bacterial content of milk depends upon three factors: (a) the number and kinds of organisms gaining access to the fresh milk; (b) the temperature at which the milk has been kept; (c) the age of the milk at the time samples are drawn for analysis.

The student may consult the following works, among others:

Barthel. Methoden zur Untersuchung von Milch und Molkereiprodukten, 2te Aufl. Leipzig, 1911.

Coxw. Bacteria in Milk. New York, 1907.

Fleischusx. The Book of the Dairy. Transl. by Aikman and Wright. London, 1896.

Jexsex. Essentials of Milk Hygiene. Transl. by Pearson. Philadelphia, 1907. Lafar. Handbuch der technischen Mykologie. Jena, 1905-1908.

Löнsis. Handbuch d. landw. Bakteriologie. Berlin, 1911.

Marshall. Microbiology. Philadelphia, 1911.

Milk and its Relation to Public Health (by various anthors), Bulletin No. 41,

Hygienic Laboratory, U.S. Public Health and Marine Hospital Service, 1909.

Russell and Hastixgs. Experimental Dairy Bacteriology. New York, 1909. Swithisixk and Newмx. Bacteriology of Milk. London, 1903.

Weiguax. Mykologie der Milch. Leipzig, 1911.

\section{Exercise 109. The Contamination of Milk with Bacteria from Various Sources}

1. From atmospheric Inst. The relation of bacteria to dust has already been demonstrated in Exercise 60. Parts of this experiment may, howerer, be repeated under different conditions in the barn or in the milk rooms.

2. From the coat of the ron". Carry four plates of sterile agar to the barn. IVet the inner surface of a milk pail and place an uncovered plate of agar in the bottom of the pail. Hold the pail in position for milking and manipulate the cow's udder as in milking for thirty seconds.

Expose the other two plates under eows whose uclers and flanks have been thoronghly moistened with a clean moist cloth. Incubate the plates in the laboratory for two days at $30^{\circ}($. 


\section{Exercise 110. Quantitative Examination of the Organisms in Milk}

The enumeration of bacteria in milk, while in many respects a simple undertaking, is full of difficulties if one attempts to obtain accurate results. In freshly drawn milk the bacteria are unevenly distributed, larger numbers being found in the froth, on hairs, on fragments of manure, in crevices of the vessels, etc. Even when the milk is thoroughly shaken, the distribution of the bacteria is not usually uniform enough to give good counts. In older milk, numbers of the bacteria are carried to the surface layer's as the fat globules rise. The lactic-acid-forming bacteria begin to predominate as the acid which they produce kills off their competitors. Then again the temperature employed and the merlia commonly used for making plate cultures are not suited for the development of all organisms in milk.

In spite of these objections the bacteriological examination of milk gives a fairly accurate picture of the conditions under which the milk has been produced or handled, and continues to be used as one of the important standards for the inspection of commercial milk samples.

1. Procure samples of freshly clrawn milk, of raw market milk, of pasteurized market milk, and of cream, having first thoroughly shaken the ressel from which the sample is to be drawn.

2. Dilute samples about as follows, with sterile physiological salt solution, using the method employed for diluting water samples (Exercise 74):

Freshly drawn milk, $1: 100$.

Raw market milk, $1: 1000$ and $1: 10,000$.

Pasteurized milk, $1: 100$.

Cream, $1: 100,000$.

3. Make plates with beef gelatin, Heyclen-Nährstoff agar, dextrose-litmus agar, and whey agar.

4. Determine the total number of colonies and the proportion of acid-forming colonies.

Note. This experiment may be varied ad libitum by counting colonies on milk drawn from different sources, by different methods, and handled in various way.y. 


\section{Exercise 111. Determination of the Numbers of Bacteria in Milk by Direct Microscopical Examination}

The difficulties of enumerating bacteria by the poured-plate method which were mentioned above have been partially overcome by the introduction of methods involving a direct microscopical examination. Such methods are desirable if for no other reason, because time is not lost in waiting for colonies to grow upon the plates.

The following procedure is substantially that outlined by Breed. See

Winslow. Journ. Infect. Dis., Suppl. No, 1, p. 209. 1905.

Prescott and Breed. Journ. Infect. Dis. 7 : 632-640. 1910.

Breed. Centralbl. f. Bakt., 2te Abt., 30 : 337. 1911.

1. Shake thoroughly the sample of milk to be examined. Draw $0.01 \mathrm{cc}$. by means of a capillary pipette.

2. Spread the required quantity of milk over an area of 1 sq. cm. on an ordinary glass slide.

This can be done by placing the slide on a paper or glass on which an area of this size is ruled. Circular areas are better than square areas. Make duplicate smears on each slide.

3. Dry the milk with gentle heat; treat the film with xylol or

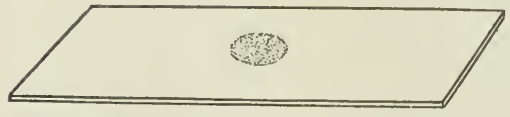

Fig. 31. Glass slide with etched circle

The circle has an area of $1 \mathrm{sq} . \mathrm{cm}$. chloroform to dissolve out the fat; when dry, immerse the slide in 95 per cent alcohol for three to five minutes, to fix the film on the slicle. I)ry the slicle again and stain with methylene blue or other simple stain. Aroid alkaline stains and all others which would attack the casein and loosen the film.

t. When the slides have dried from washing, they are ready to examine. Place the slides under the oil-immersion lens. Move the draw tube until the field of the immersion lens is equivalent to $0.16 \mathrm{~mm}$; then each field of the microscope covers approximately one five-thousandth $(0.0002)$ of a square centimeter. On this basis each bacterium seen in a field taken at random 
represents 500,000 per cubic centimeter if the bacteria are evenly distributed. As a matter of fact they are not uniformly distributed, and it is necessary to count a number of fields for accurate results. The total number of bacteria found in ten fields, multiplied by 50,000, or the total number in 100 fields, multiplied by 5000 , gives the total number of bacteria per cubic centimeter.

\section{Exercise 112. The Examination of Mifk for Body Cells}

The microscopical examination of milk sediment often reveals the presence of leucocytes in greater or less numbers. The presence of these cells has been regarded as important, because it was assumed that they showed the presence of inflammation and pus formation in the cow's udder. Later work, however, has cast considerable doubt upon this assumption. As a matter of fact our methods do not enable us to distinguish between leucocytes and pus cells in the milk. In some cities milk may not be sold which contains more than 500,000 cells per cubic centimeter.

1. Fill 10-ce. centrifuge

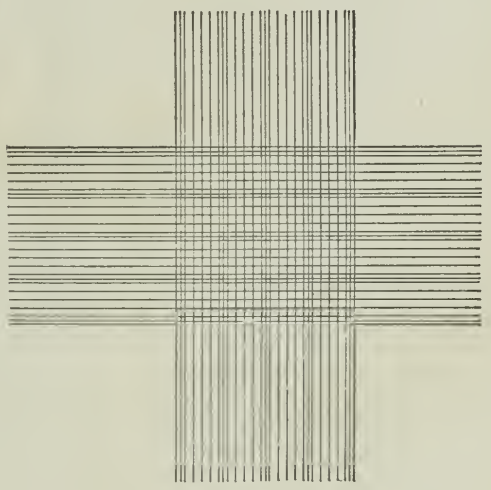

Fig. 32. Field of the Thoma-Zeiss blood counter

The area of all the squares is $1 \mathrm{sq} . \mathrm{mm}$. Each of the 400 squares represents a volume of $\frac{17}{4000} \mathrm{cu} . \mathrm{mm}$. tubes with milk and heat to $70^{\circ}-75^{\circ} \mathrm{C}$. for ten minutes. Shake well to break up aggregates of fat globules.

2. Centrifuge the tubes at high speed for ten minutes. Remove the upper layers of cream and milk with a pipette and refill the tubes with distilled water. Centrifuge again for three or four minutes.

3. Draw off all except $\frac{1}{2}$ cc. of liquid in the point of the rentrifuge tube. Wipe out the upper part of the tube with a bit of absorbent cotfon fastened to a glass rod with a rubber band. 
Mix thoroughly the remaining sediment and liquid with the rounded end of the glass rod.

4. Obtain a clean Thoma-Zeiss blood corpuscle counting cell. The cell represents a volume of $0.1 \mathrm{cu}$. mm., and each square represents $\frac{1}{400} \mathrm{cu}$. mm. With a rod transfer a drop of thoroughly mixed milk and sediment to the counting cell and cover with a clean cover glass. Place the cell under a $\frac{1}{6}$ objective of good working distance.

If the number of leucocytes is low, the entire area of the cell may be counted, using a mechanical stage to move the slicle. If their number is large, five or six small squares may be counted and averaged. The average number per small square, multiplied by 200,000 , gives the number of leucocytes per cubic centimeter in the original milk.

\section{Exercise 113. A Direct Microscopical Method for Determining the Number of Body Cells in Milk}

Recent work has cast some doubt upon the arcuracy of the method using the sediment from centrifuge tubes (see P'rescott and Breed. Jour. Infect. Dis. $7: 632$. 1910).

The direct method is the same as that employed for counting of bacteria describerl in Exercise 111, except that the film should be somewhat overstained with methylene blue and decolorized with alcohol.

\section{Exercise 114. The Germicidal Action of Fresh Milk}

The freshly drawn milk of some, if not of all, cows shows a distinct decrease in the total germ content during the first few hours. Part of the decrease in number's may be due to the fact that many bacteria fall into milk which are not able to live there. and so perish and pass out of sight. Well-controlled inoculation experiments, however, have shown that milk may have distinct germicidal power for seven to eighteen hours after it is drawn (see Löhnis, Iandbuch ıl. landw. Bakteriologie, p. 144. Berlin, 1911), but this is not always easy to demonstrate.

1. Procure in sterile flasks samples of freshly drawn milk from several ('ows. Keep) the milk samples at $20^{\circ}$ ('. 
2. Make plates on gelatin each hour up to twelve hours after the milk was drawn.

3. Determine the increase or decrease of bacteria as indicated by the number of colonies on the plates.

\section{Exercise 115. The Catalase of Milk}

Milk catalase is an enzyme which arises in part from the leucocytes, but in large part from the microörganisms, of the milk. This enzyme may be demonstrated by its ability to liberate oxygen from hydrogen peroxide, by an action which may be represented by the following formula :

$$
2 \mathrm{H}_{2} \mathrm{O}_{2}=2 \mathrm{H}_{2} \mathrm{O}+\mathrm{O}_{2} \text {. }
$$

The value of the test is, according to Gerber, $(a)$ to determine the health of the animals, (b) to reveal inflammation of the udder, $(c)$ to detect abnormal milk, $(d)$ to determine the age of milk and the relative number of bacteria present, (e) to detect colostrum.

Bırthel. Methoden zur Untersuchung von Milch und Molkereiprodukten, 2te Aufl. Leipzig, 1911.

Jexsex. Centralbl. f. Bakt., 2te Abt., 18: 211. 1906.

Lовеск. Molkerei-Zeitung, Hildesheim, Nr. 5, 1910.

Russelu. Bulletin No. 18, Wisconsin Agr. Exp. Sta., 1889.

Weigmaxx. Mykologie der Milch. Leipzig, 1911.

1. The student may use the GerberLobeck Recluctase apparatus (Fig. 33) or the simple arrangement of test tubes shown in Fig. 34.

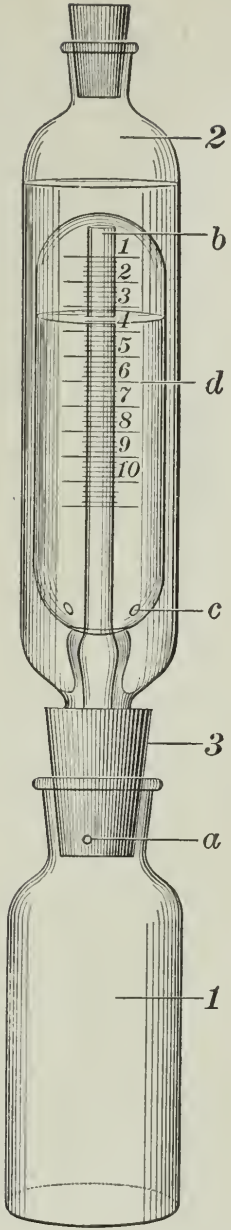

Fig. 39. Gerber-Lobeck Reductase apparatus

1 , flask ; 2 , gas-measuring tube ; 3 , stopper; $a$, perforation to allow escape of air compressed by insertion of the stopper; $b$, narrow tube through which evolved gases rise and displace water through the openings, $c$, and allow it to rise in outer chamber; $d$, scale showing amount of gas erolved 
2. Mix in the apparatus 15 cc. of milk and 5 cc. of dilute hydrogen peroxide. The dilute hydrogen peroxide should con-

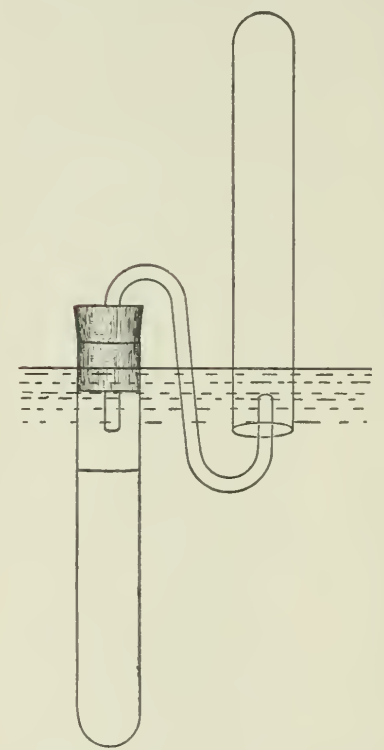

Fig. 34. Apparatus to demonstrate catalase

The corked test tube, containing milk and hydrogen peroxide, stands in water tain one part $\mathrm{H}_{2} \mathrm{O}_{2}$ in 100 parts of water. Shake the apparatus to insure thorough mixing, and place it in a water bath having a temperature of $22^{\circ} \mathrm{C}$. After two to twelve hours read off the amount of gas evolved.

3. Repeat, using separator slime, colostral milk, and boiled milk.

\section{Exercise 116. Relation of Bacteria to the Normal Souring of Milk}

1. Secure six samples of milk, three of raw milk and three of pasteurized milk. Place a sample of each in (a) refrigerator, (b) laboratory cupboard (near the floor if possible), and (c) incubator (temperature $37^{\circ} \mathrm{C}$.).

2. On the day of installation and on each succeeding day pour litmus-lactoseagar plates from each of the samples. Record differential counts of both acidforming and nom-acid-forming colonies as far as possible.

3. As the number of bacteria increases make determinations of the increasing aciclity of the milk. Remove 5 ce. of milk from each sample with a sterile pipette. Arld a few drops of phenolphthalein and titrate with $\mathrm{N} / 20 \mathrm{Na}) \mathrm{II}$. Continue the determinations until there is no further increase in acidity.

4. Express results by plotting curves to show (a) increase in acirlity, (b) increase in acir-forming bacteria, (c) total increase in bacteria, for each kind of milk used.

The percentage of acidity may be computed by the following formula :

$$
\text { Per cent acidity }=\frac{\text { ce. alkali userl } \times .0045}{\text { ce. of milk testerl }} \times 100 \text {. }
$$


If $\mathrm{N} / 10 \mathrm{NaOH}$ were used, the factor in the numerator would be .009 instead of .0045 .

5. Does the acidity eventually decline? Why?

6. Procure commercial tablets of lactic-acid-forming bacteria and inoculate pasteurized milk. Carefully compare the odor and taste of samples inoculated with different strains.

\section{Exercise 117. Fermentation Test}

This is a convenient method of showing whether bacteria of the putrefying or the Coli-Aërogenes groups are present in milk in excess.

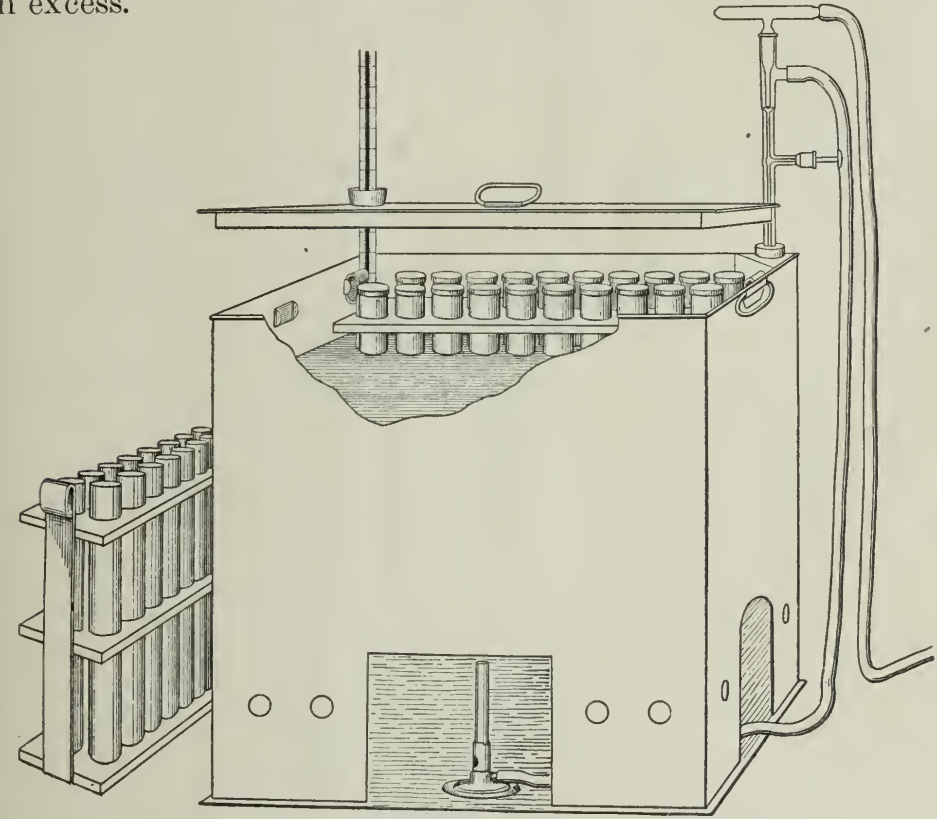

FIG. 35. Constant-temperature water bath for making fermentation and other tests

1. Procure samples of milk from different sources and of different degrees of purity. Put $25 \mathrm{cc}$. of each sample into a large test tube which has been carefully cleaned and sterilized. Plug the tubes with cotton and put them into a rack which fits a water bath (Fig. 35). 
2. The rack full of tubes is then immersed in a water bath kept at a temperature between $37^{\circ} \mathrm{C}$. and $40^{\circ} \mathrm{C}$.

3. Take out the rack and examine the tubes at the expiration of six hours. Note the appearance, odor, and taste of each sample. Replace the rack in the water bath and continue for another six hours, when the condition of the milk in each tube is again noted.

According to Gerber ("Die praktische Milchprïung") good milk properly handled should not coagulate in less than twelve hours when kept under the conditions described.

Peter interprets the five types of curds as follows:

I. Fluid (slight coagulation): germ content low, with cocei predominating; bacteria of the lactic-acid, Coli, and Aërogenes types few.

II. Gelatinous: lactic-acid bacteria predominating; few Aërogenes and Coli varieties. Cocei and Fluorescent bacteria may be present. Gas bubbles indicate presence of Coli and Aërogenes groups.

III. Granular: lactic-acid, Coli, and Aërogenes types of bacteria present; sometimes cocci numerous.

IV. Cheesy-curdy: lactic-acid bacteria along with cocci, Coli, and Aërogenes; sometimes only the latter are active.

V. Gassy: Coli and Aërogenes types predominating, along with lactic-acid bacteria, cocci, and $B$. mesentericus.

\section{Exercise 118. Study of Curds Formed by Different Organisms}

Prepare and fill with milk a number of small bottles or flasks holding about $150 \mathrm{cc}$. Sterilize fractionally and inoculate different bottles with Bact. lactis-acidi, B. coli, B. lactis aërogenes, Streptococcus lacticus, Oidium lactis, a good dairy starter, and some separator slime. Incubate at $30^{\circ} \mathrm{C}$. and examine the curds formed in each case. What does a gassy curd indicate?

\section{Exercise 119. The Reducing Action of Milk of High and Low Germ Content}

Milk in which bacterial development has occurred has a greater or less reducing action upon methylene blue. This action is due to the development of bacteria and not to some substance present in the milk at the time it is drawn. Oxygen must be excluded 
from the milk, otherwise the leuco-methylene blue quickly goes back to the methylene blue.

This action should not be confused with the ability of milk to decompose hydrogen peroxide or to reduce "Schardinger's Reagent" ( 5 cc. sat. alc. solution methylene blue plus 5 ec. formalin plus $190 \mathrm{cc}$. distilled water) at the time of milking. This reducing substance is designated aldehyde-reductase, or simply reductase. This reductase is destroyed if milk be heated to $80^{\circ} \mathrm{C}$. or higher - a fact upon which the Storch test for heated milk depends.

The reduction of methylene blue free from formaldehyde is due to the development of bacteria and not to the reductase, which works only when aldehyde is present. This power is quite closely proportionate to the number of bacteria present, and hence may be used as a rapid and simple method of determining the bacterial content of milk. There are two methods for determining the reducing power: the first consists in recording the length of time necessary for disappearance of the blue color; the second consists in determining the amount of methylene blue remaining unchanged at the end of two to four hours by titrating it with titanium chloride.

Barthel. Zeitschr. Nähr. u. Genussmit. 15 : 385. 1908.

Wichers. Zeitschr. physiol. Chem. 57: 365. 1908.

JEx-Ex. Rev, gen. du lait 7: 308. 1909.

Freid. Centralbl. f. Bakt., 2te Abt., 35 : 391. 1912.

Löıxıs. Handbuch d. landw. Bakteriologie, p. 170. Berlin, 1911.

1. Prepare a standard solution of methylene blue by dissolving one part of methylene blue in 1000 parts of water.

2. Procure several milk samples of various ages and of various grades of cleanliness. Nake plates on whey agar for counting the number of organisms, as directed in Exercise 110.

3. Place in test tubes $10 \mathrm{cc}$. of each sample of milk to be tested, and add to each tube $0.5 \mathrm{cc}$. of standard methylene blue solution; shake until mixed, then cover the liquid in the tube with a layer of paraffin oil $2 \mathrm{~cm}$. deep. The oil layer excludes atmospheric oxygen. If whole milk be used, the rising cream will exclude atmospheric oxygen, and the oil is unnecessary. 
t. Hold the tubes at a temperature of $37^{\circ} \mathrm{C}$. and record the length of time required for the tubes to become white in a water bath (Fig. 35). Compare the periods required for complete reduction with the bacterial count.

According to Barthel, milk may be classified as follows:

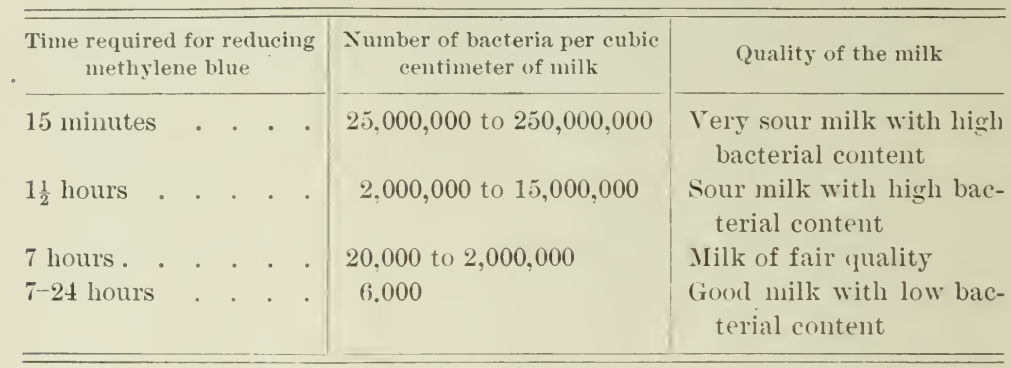

5. Instearl of recording the time necessary for reduction, all tubes which retain color at the end of three or four hours may be titrated with titanium ohloride and the amount of reduction estimated directly. Directions for this titration may be found in Appendix L.

\section{Exercise 120. Effect of Pasteurization upon Different Bacteria}

1. Inoculate two tubes of sterile milk with each of the following organisms: Bact. luctis-acidi, B. coli, Streptococcus lacticus, B. subtilis, B. proteus vulyaris, and B. mycoides.

2. Immerse one tube of each organism in a water bath. Pasteurize them by raising the temperature to $65^{\circ} \mathrm{C}$., or $150^{\circ} \mathrm{F}$. Hold at this temperature fifteen minutes; then cool quickly.

3. Put both sets of tubes in the incubator. Examine at the end of three days, and again after five days, for growth. Which bacteria are killed by pasteurization? Why?

\section{Exercise 121. Study of Bacterium lactis-acidi}

This is the lactic-acid organism. It occurs widely clistributed in nature and finds its way into stored milk. At first it grows slowly in milk. It breaks up the milk sugar, with the formation of lactic acid. As the amount of lactic acid increases, 
other bacteria cease to develop and the lactic-acid organisms increase rapidly, causing the milk to become sour.

Make a study of the characters of the organism on gelatin, agar slope, litmus-lactose agar, milk, and litmus milk. Stain with carbol-fuchsin and Gram's stain.

Demonstrate the presence of acid-forming bacteria by means of calcium-carbonate agar. Proceed as follows :

1. Sterilize in the dry oven three Petri dishes and a test tube half full of calcium carbonate.

2. When cool introduce about $1 / 10$ cc. of calcium carbonate into each Petri dish.

3. Melt three tubes of whey agar, and when cooled to $45^{\circ} \mathrm{C}$. inoculate with a very dilute culture of Bact. lactis-acidi or with a diluted sample of milk.

4. Pour the liquid agar into the Petri dishes. The plates should appear turbid, but not white, if the right amount of calcium carbonate was added.

5. Set the plates in the incubator at $37^{\circ} \mathrm{C}$. As the acid-forming colonies develop they dissolve the calcium carbonate in their vicinity and appear surrounded by a clear zone in the turbid agar.

\section{Exercise 122. Study of Bacillus lactis aërogenes}

This organism forms acid and gas in milk. It is sometimes the cause of "gassy" cheese and also injures the cheese by producing undesirable flavors.

Make a study of its cultural characters on agar slope, gelatin, litmus-lactose agar, dextrose broth in fermentation tubes, and milk.

\section{Exercise 123. Study of Bacillus subtilis and the Type of Fermentation it Produces}

It has already been shown in Exercise 120 that the sporeforming organisms may survive the heat of pasteurization. Although such milk may not turn sour, it generally spoils as the result of the growth of spore-forming bacteria. In normal souring of milk most of this class of bacteria are prevented from growing by the lactic acid produced by other bacteria. 
1. Fill a test tube one-third full of raw fresh milk. Set it for fifteen minutes in boiling water which rises higher than the level of the milk in the tube. Cool and place the tube in the incubator. Note whether the milk shows curdling. What is the reaction of the curd? Test with litmus paper.

2. Inoculate tubes of sterile milk and litmus milk with $B$. subtilis. Set in the incubator. Note whether the milk curdles. What happens to the litmus? Is it acid?

3. Make stains of the bacteria in the pure cultures of $B$. subtilis and in the heated milk, using carbol-fuchsin and Grams stain. How do the bacteria in the two cultures compare?

\section{Exercise 124. Study of Bacillus cyanogenus}

This organism sometimes occurs in the dairy. It is the cause of "blue milk." Its growth is quickly inhibited if lactic-acid bacteria are also present, since it is quite sensitive to the presence of lactic acid.

Make cultures and study the growth of the organism on gelatin stab, agar slope, milk, and litmus milk. Make stains with carbol-fuchsin and Gram's stain.

\section{Exercise 125. Study of Bacillus lactis viscosus}

Ropy milk may be produced by a group of organisms of which this is perhaps the most common. These organisms are so resistant to heat that they often survive the ordinary methods of cleansing dairy utensils.

Make cultures on agar slope and in flasks of sterile milk. Test the viscosity of the milk from time to time with a glass rool.

\section{Exercise 126. Study of Microspira tyrogena}

This organism, accorling to Chester, is sometimes found in cheese. It has been previously noted as a type of spiral bacteria.

Make cultures and study the growth on gelatin stab, agar slope, potato, milk, and litmus milk. Make cover-glass preparations stained with carbol-fuchsin and Gram's stain. 


\section{Exercise 127. Study of Oidium (Oospora) lactis}

This fungus is frequently found in milk or milk products and is believed to be of some importance in cheese manufacture.

It forms chains of barrel-shaped cells which readily break up.

It may usually be obtained from old flasks of sour milk, where it forms a superficial pellicle. From these places pure cultures may be obtained.

1. Put raw skim milk to a depth of $3 \mathrm{~cm}$. into each of two 1-liter flasks. Plug them with cotton. Heat one of the flasks to $75^{\circ} \mathrm{C}$. for ten to fifteen minutes.

2. Keep both flasks at room temperature for three or four weeks, noting the changes which occur in the milk. Note the changes in acid content. Note the sequence of organisms which grow in the flasks.

3. Obtain 0 . lactis from the velvety pellicle on the surface of the raw milk.

t. Make cultures on gelatin stab, agar slope, potato, milk, and litmus milk.

5. Make stains with dilute methylene blue and gentian violet.

\section{SECTION XIV}

\section{BACTERIAL DISEASES OF PLANTS}

A relatively small number of bacteria are known to produce diseases in plants. As further investigations are made the number will no doubt be increaserl. Some plant diseases due to bacteria are important because of their destructiveness and the great difficulty experienced in attempting to control them.

Several distinct types of disease are produced by organisms belonging to this group: The blights are represented by the destructive pear blight, caused by $B$. amylovorus; galls and tumors by the crown gall of nursery trees, caused by Bact. tumefaciens; leaf spots by the bacterial leaf spot of stone fruits, caused by Bact. pruni; wilts by the wilt of sweet corn, caused by Pseudomonas stev'artii; and rots by the black rot of cabbage, caused by $B$. campestris. 
Remedial measures against bacterial diseases are generally unsuccessful. Crop sanitation and the use of immune or resistant varieties are the only practices which have as yet afforded any relief. The student should consult

Surti. Bacteria in Relation to Plant Diseases, Publ. 27. Carnegie Inst. of Washington, 1905-1911.

Vax Hall. Bijdragen tot de kennis der Bakterieele Plantenziekten. Amsterdam, 1902 .

Marshall. Microbiology. Philaclelphia, 1911.

JorDan. General Bacteriology. Philadelphia, 1910.

DugGar. Fungous Diseases of P'lants. Boston, 1909.

Chester. A Manual of Determinative Bacteriology. New York, 1901.

\section{Exercise 128. The Blight of Pome Fruits Caused by Bacillus amylovorus}

1. Note the general condition of pear or apple trees in various stages of blight. What parts of the trees are worst attacked? Look also for cankers on the bark of the trunk and larger limbs. How does the appearance of the bark indicate the progress of the disease? If the weather is moist in spring or early summer, look for brown, sticky bearls on the twigs or blighted fruits. If the weather is dry, the only evidence of the beads may be a dry, glistening spot. Place such material in a moist chamber with the ends of the twigs in water. What is the consistency of these beads?

2. With a sharp knife cut through diseased twigs. In what tissue is the destructive action of bacteria most prominent? What evidence is there that bacteria are transferred by pruning instruments or by insects?

3. Cut some vigorous twigs from the tree and carry them to the laboratory. Cut the ends under water and stand them in a small jar of water. Prick through the bark of the new growth with a steel needle previously sterilized and dipped into a bead on a diseased twig (or a pure culture of the organisms). Watch subsequently for infection. Collect some immature fruits, inoculate as above, and keep under a bell jar.

4. Study the growth of the bacillus on agar slope, gelatin stab, bouillon, milk, and sterilized pear twigs. Make stains with carbol-fuchsin and Gram's stain. 
Exercise 129. The Wilt of Sweet Corn Caused by Pseudomonas Stewartii

In some market-gardening sections this disease may be found, but it is not widely distributed. It attacks only sweet corn, not field corn nor pop corn.

1. Note the wilted appearance of an affected plant.

2. Make razor sections of stalks of diseased plants and examine the fibrovascular bundles. Note the slimy yellow material which oozes from the fibrovascular bundles. Examine a drop of this substance for bacteria. How would you explain the pathological symptoms noted in the plants?

3. Make a study of the organism growing in gelatin, stab, agar slope, and potato. Make stains with carbol-fuchsin and Gram's stain.

\section{Exercise 130. The Black Rot of Cabbage Caused by Bacillus campestris}

1. Examine cruciferous plants which may be affected with this disease. Notice particularly the effect on leaf and stem.

2. Cut stems and leaf petioles transversely. Examine the fibrovascular bundles. Do the organisms ooze from the cut bundles?

3. Make razor or paraffin sections and examine minutely with the microscope. What effect does the organism exert upon the walls of fibrovascular elements?

4. Study the growth of the organism on gelatin stab, agar slope, litmus milk, potato, and bouillon. Make stains with carbolfuchsin and Gram's stain.

5. Inoculate young cabbage or turnip plants growing in the greenhouse by puncturing their leaves with a needle bearing bacteria taken from one of your cultures. Make notes and sketches illustrating the progress of the disease.

\section{Exercise 131. The Soft Rot of Vegetables Caused by Bacillus carotovorus} Joxes. Thirteenth Rept. Vermont Agr. Exp. Sta., 1901.

Potter. Centralbl. f. Bakt., 2te Abt., 7 : 282, 353. 1901.

Joxes, Harding, and Morse. Bulletin No. 147, Vermont Agr. Exp. Sta., 1910.

1. Examine a carrot or other vegetable infected with the organism in question. Note the size and shape of diseased areas. 
Is there a sharply defined line between infected and noninfected tissues or do they gradually merge into each other?

2. Cut slices about $1 \mathrm{~cm}$. thick from a sound carrot, using a Hamerl knife. Place them on a piece of moist filter paper in a Petri dish. Inoculate by scratching them with a needle bearing the organism from a pure culture. Scratch other pieces with the
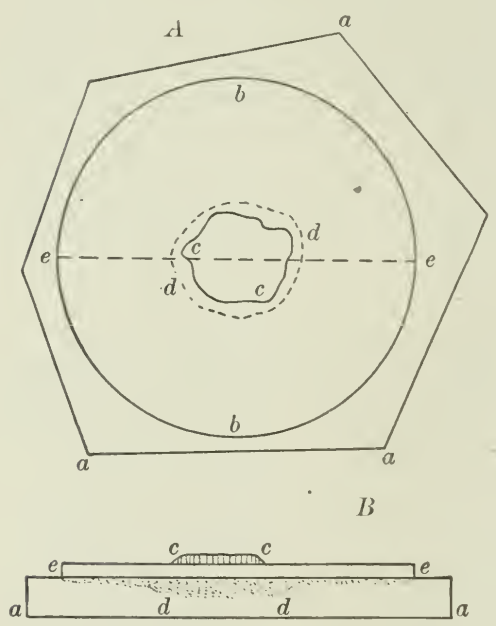

Fı.. 36. Nethod for showing diffusibility of enzymes through agar. (After Jones) $A$, surface view; $B$, vertical section along dotted line e-e; $\quad(-a$, sterile slice of living turnip root: $b-b$, layer of nutrient a gar bearing the bacterial colony $c-c: \mid l-1$, region of most active enzyme action same needle after sterilization in the flame. Keep the Petri dish in your rlesk and make examination after three to five days.

3. By reference to the literature above cited acquaint vourself with the characters of pectinase, the cytolytic enzyme which this organism produces. The following method, described by Jones, is a conrenient one for demonstrating this enzyme.

Pour a tuhe of melted agar into a sterile Petri dish to a depth of $3 \mathrm{mmm}$. Allow this to become hard, then inoculate an area of 2 or $3 \mathrm{~mm}$. in the center of the dish. using the platinum loop, with (are that the layer of agar is not punctured. Keep the dish in the incubator until you have a surface rolony about $1 \mathrm{~cm}$. in rliameter.

With a flamed knife cut a slice from a fresh turnip root and place it at once in a sterile Petri dish. Carefully remove the agar layer bearing the bacterial colony and transfer with sterile instruments to the surfare of the turnip slice. Cover at once to prevent contamination. Prepare a control by covering another turnip slice with a layer of agar bearing no bacteria (Fig. 36). 
After twenty-four to thirty-six hours lift the layer of agar and determine whether the tissues of the turnip have undergone any softening. If so, how does the softened area correspond with the size and shape of the superimposed bacterial colony?

Transfer bits of the softened tissue by means of a sterilizerl needle to tubes of sterile media. If no organisms develop in these tubes, what do you conclude as to the diffusibility of the enzyme? Make a microscopic examination of the softened tissue.

t. Study the characters of the organisms on gelatin stab, agar slope, potato, milk, and Dunham's solution. 'Test the effect of desiccation and exposure to strong light.

\section{SECTION XV}

\section{BACTERIAL DISEASES OF MAN AND ANIMALS}

The first great adrance of bacteriology was in the study and treatment of disease in the animal borly. Its importance to medicine and to civilization can hardly be orerestimated. The proof that a given clisease is caused by bacteria depends upon the fulfilment of four postulates laid down by Robert Kioch. They are as follows: (1) the organism must be clemonstrated in the circulation or tissues of the diseased animal; (2) this organism must be isolated and grown in pure culture for successire generations; (3) the pure culture of the organism, when introcluced into the body of a healthy, susceptible animal, must produce the disease in question ; (4) the organism must be found and reisolated from the circulation or tissues of the inoculated animal.

It is not assumer that the following exercises give an extensive survey of the subject of animal diseases; they are merely intended to be illustrative. An extensive survey of the subject is to be had from works on medical or veterinary bacteriology, among which the following may be mentioned:

Jordax. General Bacteriology. Philadelphia, 1910.

Frost. Laboratory Bacteriology. New York, 1903.

Stervierg. Manual of Bacteriology. New York. 1901.

Brсндкıx. Veterinary Bacteriology. Philadelphia, 1911.

Herzog. Veterinary Micro-organisms. Philadelphia, 1912. 


\section{Exercise 132. Preparing a Disinfectant}

In all work where pathogenic bacteria are employed great care must be used to avoid infection. Apparatus and media should be promptly and thoroughly sterilized after having been used.

The clisinfectant of greatest utility is mercuric bichloride, or corrosive sublimate, in a solution of 1:1000. Prepare 2 liters of a 1:1000 solution of mercuric bichloricle and place it in a jar on your table. The solution is reaclily made by dissolving $20 \mathrm{~g}$. of mercuric bichloride in $100 \mathrm{cc}$. of commercial hychrochloric acid. 5 ce. of this acil solution in 1 liter of water makes a $1: 1000$ solution.

As soon as cliscarcled all cultures should be placed in this jar. Be careful to see that the test-tube cultures sink, drop in the used cotton plugs, open Petri dishes and drop them carefully in. The following day remove the dishes and wash them.

Carefully wipe up the table top with a towel soaker in $1: 1000$ solution from the siphon bottle on the general table. If cultures or infectious material are spilled on the floor, wipe them up in the same way. Wash the hands first with 1:1000 bichloride and then with soap and water.

When sterilizing the platinum neerlles which have infectious material upon them hold high above the flame until the material is dry before bringing it into the flame. This prevents sputtering, which may throw the material off before the germs are killed. Some bacteriologists employ metal tubes into which the needles are thrust for heating.

\section{Exercise 133. Anthrax (Splenic Fever)}

This is one of the best-known and longest-studied of bacterial diseases. It is pathogenic for man and domestic animals. For many year's it was known as Wool Sorter's Disease, because of its prevalence among those who handle wool.

The first proof that a disease may be caused solely by a bacillus was obtained, in the case of anthrax, by Robert Koch in 1876 , although others had previously seen microscopical rods in the blood of cliseased animals. 
Koch's achievement was due to his success in cultivating the anthrax bacillus outside the body in a pure culture, apart from any fluids or tissues of the diseased animal, and in being able to produce the disease by introducing these germs into the bodies of healthy animals.

The spores, likewise discovered by Koch, have been the subject of much biological study. Spores are only procluced in the presence of free oxygen and at temperatures between $14^{\circ}$ and $40^{\circ} \mathrm{C}$. They are extremely resistant to drying, it having been shown experimentally that they may retain their vitality for eighteen years, and then produce the disease when inoculated into susceptible animals. The spores are not so resistant to heat as those of some saprophytic forms, but they are quite resistant to disinfectants.

Vaccination with cultures attenuated by heat is now largely used to protect animals against anthrax and is quite successful. Immune sera are used on human subjects.

1. Observe the instructor inoculate a guinea pig with a pure culture of $B$. anthracis. At the next laboratory period make a post-mortem examination of the animal. Note the condition of the various internal organs.

2. Inoculate tubes of bouillon from the spleen and tubes of agar from the heart blood.

3. Make smear preparations from the spleen. Hold the tissue with sterile forceps and rub it over a clean slide. Dry, fix, and stain with Gram's stain.

4. Place a small drop of blood on a cover glass, add a drop of sterile physiological salt solution, mix, and dry. Stain with methylene blue.

5. Examine and draw a field from each slide.

6. From your observations, how do you explain the death of the animal infected with anthrax?

7. Make stained preparations from the tubes made in 2.

8. When spores appear, make a spore stain according to directions in Exercise 61.

9. Make and describe cultures upon gelatin stab and gelatin plate. 


\section{Exercise 134. Tuberculosis (Consumption, Phthisis)}

This disease is the greatest scourge of the human race. In 1900 about one ninth of all deaths from known causes in the United States were due to this disease. Small nodules, or tubercles, are so uniformly observed in all adranced stages of the clisease in animals that their presence has given the name to the clisease. The tubercle eventually breaks down, the central portion becomes necrotic, caseation sets in, and then the caseous mass softens, probably due to the toxic action of bacterial products. In many cases a deposit of calcium salts finally takes placee in the tubercle, and it is converted into a hard, dry, friable body which may be entirely walled off from the neighboring tissue.

Besides man the disease attacks cattle, swine, birds, and other animals. Among these animals the ravages of the disease are at times very severe.

Tuberculosis may attack almost any tissue or organ in the body. The lungs constitute the seat of the most common infection, but the intestines, the mesenterie glands, the lymph glands of the head and neck, the portal glands and liver, the skin, the bones, and the urogenital system are frequently attacked. Besides the lesions on important organs, the tuberculosis organism produces a slow toxemia which works injury to the whole of the infected borly.

The ways of infection are usually four: (1) the respiratory tract: (2) the alimentary tract: (3) inoculation (rare): (4) prenatal infection. The first two are more (*ommon, so far as we know.

Tuberculin is a mixture of the toxins produced by $B$. tuberculosis in artificial cultures. I glycerin-broth culture of the organism is sterilized in steam, then concentrated by evaporation on a water bath, then filtered through paper and a Berkefeld filter. If it is to be kept, a preservative is adderl. Tuberculin is of use in making a diagnosis. Its injection into man or animals is followed within two to ten hours by a rise in temperature, which continues for a few hours and then disappears. Many modifications of the original method of preparing tuberculin are now employed. 
1. Examine and make descriptions of cultures of B. tubermlosis on the general table. Compare cultures of bovine and human tuberculosis.

2. Examine and describe the museum preparations of pathological material on the general table.

3. Observe the post-mortem conditions of a tuberculous guinea pig. In what parts of the borly are tubercles most abundant?

t. Select one of the small tubercles or a portion of a cliseaserl organ. Grasping it with the dissecting forceps, cut it off. Smear the freshly cut surface over the central portion of a glass slide. Dry and fix as usual. Stain by the Ziehl-Neelson methor and counterstain with methylene blue. Do not put a cover glass over the smear. Wait until the water has evaporated; then put immersion oil on it and examine directly with the oil-immersion objective. The tuberculosis organisms should appear as slender rods stained red; the body cells are stained blue. If the preparation is not satisfactory, repeat until a good one is obtained.

5. Draw a field showing the relation of the B. tuberculosis to the cells and tissues.

6. Rearl and become familiar with the modern principles of treating tuberculosis in man. Has tuberculin any remedial value in treating the disease?

\section{Exercise 135. Green Pus}

Green or blue-green pus is formed sometimes on surgical dressings, due to the development of $B$. pyoryomens. In many of its characters this organism closely resembles $B$. fuorescen. liquefaciens, but it has been shown unquestionably to be pathological both in pure and in mixed infections.

The deep-blue pigment, pyocyanin, has been isolated and studied chemically. It is not toxic to animals. The toxin is very resistant to heat. The virulence of the organism may be inferred from the statement, made by Jordan, that one tenth of a loop of a fresh agar culture will kill a guinea pig in twenty-four hours. 
1. Shake old broth cultures of B. pyocyaneus with chloroform in a separatory funnel until a goodly quantity of pigment is extracted. Evaporate the chloroform from a watch glass.

2. Study the characters of the organisms grown on gelatin stab, agar slant, milk, and potato.

3. Make stains with carbol-fuchsin and Gram's stain.

\section{Exercise 136. Septicæmia, Inflammation, etc. Caused by Streptococcus pyogenes}

This organism may show its pathological effects upon the body in various ways. It may cause suppurative inflammation, erysipelas, septicæmia, puerperal fever, pneumonia, or other diseases. It frequently invades organs alrearly attacked by other bacteria and causes great injury. In the last stages of pulmonary tuberculosis it is likely to invade healthy tissues adjacent to those affected with tuberculosis, and thus predispose the patient to hemorrhage. "Blood-poisoning" is usually due to an infection of streptococci or staphylococci, or both.

The virulence of different strains of organisms appears to vary widely. The toxin may be obtained from cultures killed with chloroform or filtered through unglazed porcelain filters.

Streptococci are always present on the outside of the body, and appear to be capable of causing trouble if they gain entrance when the bodily resistance is low. This emphasizes the necessity of the prompt and thorough disinfection of all wounds.

1. Make cultures of Streptococeus pyogenes on lactose bouillon, gelatin stab, agar slant, potato, and litmus milk.

2. After forty-eight to sixty hours shake up the culture in lactose bouillon and make a stained preparation from the granular sediment formed by the bacteria. Also make a stain from the agar slant. Does it stain with Gram 's stain?

3. Draw and describe the stained preparations with the oilimmersion objective. What is the form and arrangement of the organisms? How do staphylococei differ?

4. Describe all cultures after three days. On which is there 110 growth? 


\section{SECTION XVI}

\section{SOME ORGANISMS CAUSING IMPORTANT FERMENTATIONS}

In the preceding sections the activities of bacteria were the chief topic of study. 'This section will principally treat of the activities of another group of plants, namely, the yeasts and mold fungi. These organisms, though somewhat more complex, resemble in many ways the bacteria; they are devoid of chlorophyll, grow upon organic substances, and reproduce rapidly by small spores, which, when liberated, may be carried long distances in the air. They are thus distributed as widely as bacteria.

The physiological activities of these fungi, on account of their great importance in the arts and industries, have been extensively studied. It is as producers of fermentation that they are of interest in agricultural and industrial technology.

In the modem sense the term fermentation is a very broad one. As defined by Lafar, "Fermentation is a decomposition or transformation of substances of various kinds brought about by the vital activity of fungi." In the older and more common use of the term fermentation it designates the formation of alcohol and carbon dioxide from a carbohydrate - for example, the fermentation of wine from must. It is perhaps needless to say that these phenomena were observed and used in the arts centuries before the scientific basis of the process was demonstrated.

The literature upon fermentation and the organisms which cause it is voluminous. References to a few of the more general treatises are given herewith:

LAFAR. Handbuch d. techn. Mykologie. Jena, 1905-1908.

Jörgexsex. Micro-organisms and fermentation. Transl. by Davies. Philadelphia, 1901.

KLöcкеr. Die Gärungsorganismen. Stuttgart, 1900.

HARDEN. Alcoholic Fermentation. New York, 1911.

Marshall. Microbiology. Philadelphia, 1911.

DeBArY. Comparative Morphology and Biology of the Fungi, Mycetozoa, and Bacteria. Oxford.

Coxs. Agricultural Bacteriology, 2d ed. Philadelphia, 1909. 
Fowlek. Introduction to Bacteriological and Enzyme Chemistry. New York and London, 1911.

Cosx. Bacteria, Yeasts, and Molds in the Home. Boston, 1909.

Pasteur. Studies on Fermentation. New York, 1879.

Haxsm. Practical Studies on Fermentation. Transl. by Miller. London, 1896.

\section{Exercise 137. Morphology of Yeast (Saccharomyces)}

Yeast plants are unicellular organisms which reproduce principally by budding. Inder certain conditions - for example, a sudden diminution in food supply - they produce endogenous spores, usually two to six in each cell. This condition is strpposed to ally the yeasts with the Ascomycetes, and the sporangia are regarded as asci.

1. Mix a piece of compressed yeast with water, mount a drop of the mixture, and examine with both low and high powers.

2. Note the shape of a single cell. Are all cells the same shape? What is the size of single cells? Compare with other organisms studied.

3. Study the finer structure of the yeast cell. Note

a. Color, homogeneity, and transparency. Momnt some yeast cells in Schultze's iodline solution. This solution turns normal cellulose blue, fungus cellulose yellowish-brown. Of which is the yeast cell composed?

b. The protoplasm, a semitransparent, gramular substance filling more or less of the cell cavity. The protoplasm often contains small oil drops, recognizable by their powers of refraction. Are they equally abundant in all cells?

c. Vacuoles, spherical cavities in the protoplasm filled with cell sap. How many vacuoles in each cell?

d. The nucleus, a small spherical body which can only be distinguished by the use of special stains.

\section{Exercise 138. Reproduction of Yeast by Budding}

1. Mount a chrop of yeast culture which has grown for twentyfour hours in liquid wort medium or on wort agar.

2. Note the presence of cells which have former small outgrowths, or buds. Do cells ever form more than one bud? Are all buds of the same size? 
3. Make hanging-drop cultures of very dilute cultures (one or two cells in the hanging drop) and studly the process of budding. Make observations once or twice daily for three days.

4. Make a set of drawings to illustrate the stages in the formation of the bud.

\section{Exercise 139. Spore Formation in Yeast}

The essential conditions for spore formation are abundance of oxygen and paucity of food substances.

1. Prepare gypsum blocks. Mix gypsum (plaster of Paris) with half its volume of water, stir thoroughly, and pour into a paper cylinder mold to harden. The block should be about $4 \mathrm{~cm}$. in diameter and $2 \mathrm{~cm}$. high. When dry, remove the paper and place the block in a stender dish covered with a loose glass cover or a Hansen flask (Fig. 37). Sterilize the block, covererl as described above, in the dry sterilizer for about an hour and a half at a temperature no higher than $120^{\circ} \mathrm{C}$.

2. Inoculate a flask of sterilized wort with a small quantity of good yeast. Incubate at $25^{\circ} \mathrm{C}$. for twenty-four hours. At the expiration of that time there should be a good layer of yeast at the bottom of the flask.

3. Draw off the supernatant liquid with

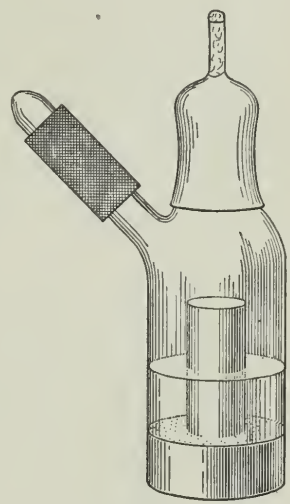

Fig. 37. Gypsum block in a Hansen flask a pipette. Transfer a small quantity of the yeast sediment to the dry surface of a gypsum block. It is essential that the layer of yeast on the gypsum block be very thin. Pour sterile distilled water into the dish so that the gypsum block stancls in water two thirds of its height. Incubate at $25^{\circ} \mathrm{C}$.

4. Examine yeast from the gypsum block after eight to fourteen days. Look for small globular ascospores in the cells. How much of the cell do they occupy? What is their arrangement? Does each spore have a cell wall of its, own?

5. Make staing de preparations using gentian violet or carbolfuchsin. 
Exercise 140. Preparation of Pure Cultures of Yeast from Single Cells

1. Sterilize several .01 cc.-capillary pipettes by using 50 per cent alcohol and warming then until the alcohol is evaporated.

2. Draw .01 ce. of a yeast culture from liquid wort and examine under the microscope. Dilute the culture with sterile wort until .01 ce. contains an average of one cell. (Instead of the pipette a 2 mm.-platinum wire loop may be used.)

3. Inoculate 10-20 tubes of sterile wort with .01 ce. of solution containing one yeast cell. Incubate at $25^{\circ} \mathrm{C}$. Where growth appears, it is a culture developed from one cell.

\section{Exercise 141. Cultivation of Yeasts}

For much of the student's work yeast may be successfully cultivated on various carbohychate media, such as Naegeli's solution (Exercise 53), wine must, apple must, and beer wort. These

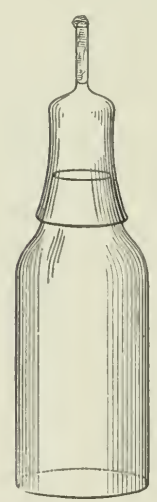

Fig. 38. Freudenreich flask

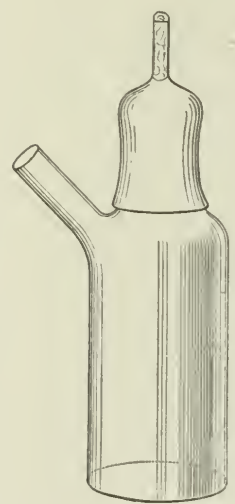

Fig. 39. Hansen flask media may be sterilized in large test tubes or flasks, with or without the adclition of agar or gelatin. In laboratories where cultures are to be kept for some time, specially constructed flasks are used for yeast culture. 'These flasks are provided with narrow apertures, and consequently evaporation of the culture solution is diminished. The Freudenreich type has a cap which terminates in a narrow, cotton-filled tube (Fig. 38).

The Hansen flask has a cotton stopper in the wide opening, over which a cap is fitted which terminates in a narrow tube which also contains a tuft of cotton. It also has a side delivery tube for transfer of the culture media to other flasks. This side

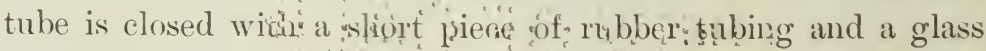
rod (Fig. 39). 


\section{Exercise 142. The Invertase of Yeast}

Invertase is one of the important enzymes produced by yeast. Its specific action is the hydrolytic splitting of disaccharides to monosaccharides, such as dextrose and levulose (invert sugar), by an action represented by the equation

$$
\mathrm{C}_{12} \mathrm{H}_{22} \mathrm{O}_{11}+\mathrm{H}_{2} \mathrm{O}=\mathrm{C}_{6} \mathrm{H}_{12} \mathrm{O}_{6}+\mathrm{C}_{6} \mathrm{H}_{12} \mathrm{O}_{6} \text {. }
$$

Invertase passes out of the yeast cell by exosmosis into the surrounding merlium.

A. A simple and convenient method of demonstrating this is the following :

1. Prepare a 2 per cent solution of pure cane sugar. Make certain that it has no reducing action on Fehling's solution. Put the solution into several large test tubes or small flasks.

2. Add to each tube yeast from a yeast cake or from a pure culture. Keep the tubes in a warm place $\left(25^{\circ} \mathrm{C}\right.$. $)$ for twenty-four hours.

3. Test the contents of the inoculated tubes for invert sugar by the use of Fehling's solution. Write the equation for the chemical change in the sugar.

$B$. By the use of another method the invertase may be obtained free from living yeast cells.

1. Wash $10 \mathrm{~g}$. of brewer's or compressed yeast thoroughly with water and filter with suction.

2. Mix the moist yeast with 100 cc. of distilled water and 5 cc. of chloroform. The chloroform prevents the yeast from growing but does not destroy the enzymic action. Keep the solution for three hours at a temperature of $25^{\circ}-30^{\circ} \mathrm{C}$.; then filter.

3. To test the inverting action of this solution, add 5 cc. to 25 cc. of a 3 per cent cane-sugar solution and keep at $30^{\circ} \mathrm{C}$. for an hour or more. Boil the solution to drive off the chloroform, which would otherwise interfere with the test with Fehling's solution. Add distilled water to restore the boiled solution to its original volume and determine the amount of invert sugar quantitatively by Fehling's solution or by the polariscope. 


\section{Exercise 143. The Zymase of Yeast}

Zymase is the enzyme of yeast which accomplishes the alcoholic fermentation of sugars, but it is only capable of fermenting hexose sugars, chiefly d-glucose, d-fructose, d-mannose, and d-galactose. The action may be represented by the equation

$$
\mathrm{C}_{6} \mathrm{H}_{12} \mathrm{O}_{6}=2 \mathrm{C}_{2} \mathrm{H}_{5} \mathrm{OH}+2 \mathrm{CO}_{2} \text {. }
$$

Zymase is classed as an endoenzyme, because it occurs only in the living cell and does not exosmose into the surrounding merlium. The isolation of the enzyme from yeast cells is described in exercises 144 and 145 , but its action may be demonstrated by the following simpler method:

1. Prepare a $t$ per cent solution of dextrose in tap water and fill three flasks about one-third full; also fill several fermentation tubes. Sterilize all in the Amold sterilizer.

‥ Inoculate two of the flasks and all of the tubes with active yeast. Weigh the flasks and record the exact weight of each. Keep the cultures in the incubator at $25^{\circ} \mathrm{C}$. Is fermentation progresses, note the changes in weight of the flasks in comparison with the control. 'To what are the changes due? After' a week compare the specific gravity of the fermented solution with that of the control.

3. Examine the fermentation tubes at the end of twenty-four hours. When the closed arm of the tube is about half full of gas, test it with 10 per cent $\mathrm{NaOH}$. How much of the gas is carbon dioxide?

4. For further studies of the action of zymase see exercises $146,147,148$, and 149 .

5. State as exactly as possible the characters of invertase and zymase. What is the relation of one to another in causing fermentations?

\section{Exercise 144. The Preparation of Yeast Juice}

In 1897 Buchner succeeded in mechanically breaking down the yeast cell and obtaining a yeast-free extract containing zymase which would cause alcoholic fermentation in sugar solutions. The 
enzyme was separated from the broken cells by filtration under great pressure. The drastic methods which Buchner employed are somewhat beyond the facilities of the average student; nevertheless they should be noted and carried out if possible.

1. Mix a kilo of brewer's yeast with an equal weight of clean quartz sand and $250 \mathrm{~g}$. of infusorial earth. Put all into a mortar and grind together until plastic and moist. Add $100 \mathrm{ec}$. of distilled water and transfer the material to a press cloth.

2. Put the material into a filter press and sulject to a pressure of 400 or 500 atmospheres. Remove the cake, grind it, add another 100 cc. of water, and press again. Clarify the filtrate obtained by shaking it with fresh infusorial earth and filtering.

3. Mix 25 cc. of the juice with an equal volume of 10 per cent dextrose solution. Put the solutions into fermentation tubes, with a few drops of toluol added to inhibit bacterial action. 'Test also cane sugar, levulose, maltose, and lactose. Compare with the results obtained in Exercise 143.

\section{Exercise 145. The Preparation of an Active Yeast Powder}

Buchner's yeast juice does not long retain its ability to ferment sugar solutions. A proteolytic enzyme appears to ligest not only the protein present but the zymase also. Owing to this fact, as well as to the difficulty of preparation, the yeast juice is not so feasible to study in the ordinary laboratory as the permanent yeast powder (Dauerhefe), or zymin. The preparation of zymin is as follows:

1. Rub up $500 \mathrm{~g}$. of brewer's yeast, pressed free from most of its water.

2. Put this yeast into 3 liters of acetone and stir for ten minutes. Filter off the acetone, using suction if necessary.

3. Mix the material with 1 liter of fresh acetone, stir for two minutes, and filter.

4. Rub up the material with 250 cc. of ether for three minutes, and filter.

5. Spread the residue on filter papèr or porous plates to dry. Keep it at a temperature of $35^{\circ}-45^{\circ} \mathrm{C}$. for twenty-four hours, to drive off ether and acetone. 
6. Grind up the dry powder and store it in a clean glassstoppered bottle.

7. Prepare 2 per cent solutions of cane sugar, dextrose, levulose, maltose, and lactose. Put them into fermentation tubes and add to each as much yeast powcler as will lie on the point of a penknife. Examine the tubes for gas at the end of ten to eighteen hours. Compare the results with those obtained with the same sugars in Exercise 143.

\section{Exercise 146. The Estimation of the Chief Products of the Fermentation of Sugars}

The chief products of the fermentation of an invert sugar are carbon dioxide and alcohol. In addition, small amounts of glycerin and succinic acid are produced, together with smaller quantities of other compounds, such as aldehydes, fusel oil, and furfural. This exercise demonstrates methods of estimating the carbon dioxide and alcohol.

1. Prepare about a liter of apple- or grape-juice must. Instead of must, other saccharine solutions may be used - for example, 4 per cent dextrose, or molasses diluted with two volumes of water. Determine quantitatively the sugar content of the must. To do this, make 20 (e. of Fehling's solution by mixing 10 ce. of each of the two stock solutions (see Appendix) in a casserole, and boil. Above the casserole arljust a burette containing 50 cc. of must and add, drop by drop, until the blue color of the Fehling's solution disappears.

1 cc. normal Fehling's solution $=4.94 \mathrm{mg}$. invert sugar.

1 cc. normal Fehling's solution $=4.53 \mathrm{mg}$. dextrose.

For example, 20 cc. of Fehling's solution required 16.2 cc. of must to reduce the copper.

20 cc. Fehling's solution $=.0988 \mathrm{~g}$. invert sugar.

Then

$$
16.2: .0988:: 100: x \text {; }
$$

therefore $x=.60988$ per cent invert sugar in the must.

2. Select three Erlenmeyer flasks of 500 cc. capacity. Put into each 150 cc. of must and sterilize fractionally in the Arnold 
sterilizer. After sterilization add 5 cc. of 95 per cent alcohol to flask No. 1; to flask No. 2, enough dextrose to make the sugar content up to four per cent. Add to each of the three flasks about 3 cc. of a fresh, active yeast culture and fit them with fermentation stoppers. Incubate at $25^{\circ} \mathrm{C}$. Weigh the flasks every two days until the weight is constant, and estimate the grams of carbon dioxide given off. When the flasks reach constant weight, attach a condenser and distill off the alcohol from each separately. Determine its specific gravity either by a pycnometer or by a hydrometer. From this compute the percentage and the exact amount of alcohol formed from the sugar. Determine the amount of sugar remaining in the flask by the method given above.

Write the result, giving formulæ with balanced equations.

\section{Exercise 147. The Fermentation of Bread Dough}

A dough of flour, water, and yeast will rise if kept in a warm place. The flour contains starch and a small amount of diastase, an enzyme which forms sugars from starch. The yeast ferments the sugars thus formed into alcohol and carbon dioxide. The bubbles of gaseous carbon dioxide give the dough a porous structure which is not destroyed when baked. The porous structure makes the bread easier to masticate and hence easier to digest.

A dough of flour and water only will rise if kept in a warm place. The action is due to the production of carbon dioxide by organisms occurring naturally in the flour and water. But the rising will be mucli more rapid and certain if at the beginning a quantity of yeast (leaven) is incorporated with the dough. The leaven may be a piece of dough kept from a previous baking, or it may be a yeast cake. The commercial yeast cake contains an admixture of more or less bacteria, which are sometimes responsible for flavors in the bread. Relatively pure cultures of yeast are used by bakers who wish a rapid rising with little danger of irregularities due to bacterial action.

1. Soak a cake of compresserl yeast for an hour in distilled water and examine the organisms it contains. Both yeasts and 
bacteria will be found. Certain of the bacteria have the power to transform starch into sugar and to dissolve gluten; others form lactic and acetic acids. The amount of acid formed is not usually perceptible unless the lough stands too long before baking or is kept too warm, in which case sour bread is obtained. B. mesentericus vulgatus Flügge is sometimes the cause of viscid bread.

2. Soak a dry yeast cake in distilled water which has been boiled and cooled to $40^{\circ} \mathrm{C}$. After six to eight hours make

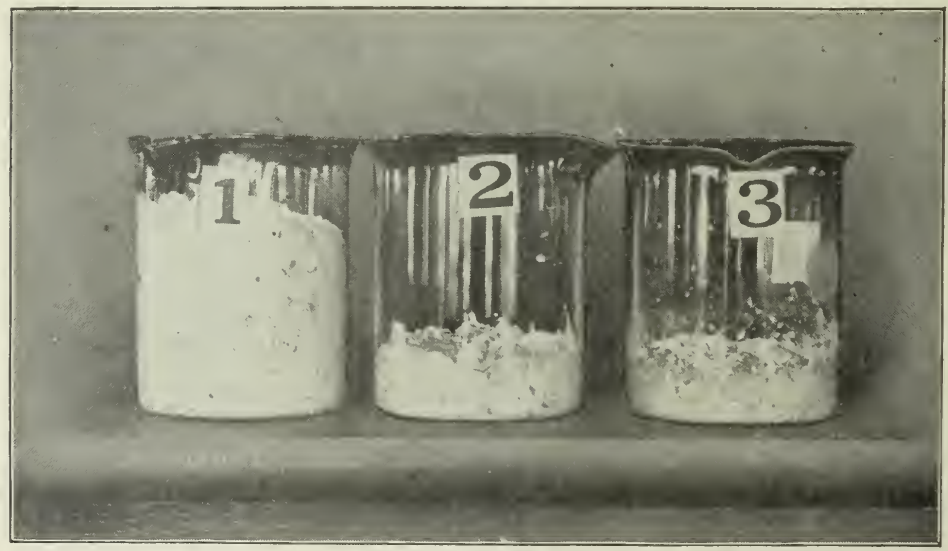

F1G. 40. Bread dough raised with yeast from different sources

Each beaker ( $400 \mathrm{ce}$. capacity) received $75 \mathrm{~g}$. of flour and enough yeast culture to make a stiff dough. The yeast in No. 1 came from a compressed yeast cake; in No. 2, from a dried yeast cake; in No. 3, from a wild yeast culture

microscopic examination for the organisms present. Is the greater number of bacteria in the compressed yeast or in the dry yeast cake?

3. Make a culture of wild yeast as follows: Cook $200 \mathrm{~g}$. of potato in a tin or granite-rrare ressel until it can be mashed. Add $5 \mathrm{~g}$. of sugar and $5 \mathrm{~g}$. of ammonium tartrate. Stir in enough water to make a thin paste. Keep the culture at 2:5 $\mathrm{C}$. until fermentation is evirlent. Examine microscopically for bacteria and yeasts.

4. Weigh off $100 \mathrm{~g}$. of wheat flour into each of three beakers. stir into each a yeast culture made as directed in paragraphs 1, 2, 
and 3 , until a firm daugh is made. Cover the beakers with a plate of glass and place in the incubator. Examine each dough every three hours, to determine which rises most rapidly. Note the texture, viscosity, and odor in each case.

\section{Exercise 148. The Fermentation of Cider}

1. Grind a few ripe apples in a meat cutter. Press the pulp through a cloth and then filter through paper.

2. Fill six fermentation tubes with juice. Place four of them in the Arnold sterilizer and steam them for half an hour. Inoculate two of the sterilized tubes with yeast. Keep the six tubes in the incubator for twenty-four hours.

3. Examine the tubes for fermentation. In which tube is the most gas present? When the arm of the tube is about half full of gas, test it with 10 per cent $\mathrm{NaOH}$. How much of the gas is carbon dioxide? What caused fermentation in the unsterilized tubes?

\section{Exercise 149. The Fermentation of Wine}

IVine is usually defined as the fermented juice of some berry or grape. The grape is the fruit most commonly used, because the juice is rich in sugar and is easily pressed from the crushed fruit as a clear liquid. Among the microörganisms which arthere to the skin of the grape there are always numerous yeasts. The reasts start fermentation in the saccharine juice presserl from the grape. These wild yeasts are sufficient to start the process of fermentation, although better results could undoubtedly be obtained from the use of cultures of selected yeasts.

If practically all the sugar has been fermented (only about 0.1 per cent remaining), the wine is classified as dry; the wine is sureet if the fermentation is checked at an early stage by the addition of alcohol or brandy: the wine is still if the carbon dioxide produced by the fermentation has been allowed to escape before bottling.

The principles of the fermentation of wine have been demonstrated by Exercise 146 and need not be repeated here. 


\section{Exercise 150. The Fermentation of Vinegar}

This fermentation takes place in some weak alcoholic solution, such as cider or wine. The process is carried out by several species of bacteria which are common in the air. Inoculation of the liquids is not, therefore, required for vinegar manufacture. The brown gelatinous mass found in vinegar barrels, known as "mother of vinegar," is the zoöglœum formed by these bacteria.

The process of fermentation involved is one of oxidation, which is most simply expressed by the equation

$$
\mathrm{CH}_{3} \cdot \mathrm{CH}_{2} \mathrm{OH}+\mathrm{O}_{2}=\mathrm{CH}_{3} \cdot \mathrm{COOH}+\mathrm{H}_{2} \mathrm{O} \text {. }
$$

In reality, however, the oxidation process is more complex than the above equation would inclicate.

1. Obtain the film from the surface of some old vinegar and inoculate several water blanks.

2. Plate out the organisms in the water blanks, using wort agar. Incubate the plates at $25^{\circ} \mathrm{C}$.

3. When colonies appear, transfer organisms from them to tubes of wort agar. Incubate tubes at room temperature and at $37^{\circ} \mathrm{C}$.

4. Prepare liquid cultures in flasks containing $50 \mathrm{cc}$. of liquid wort plus 1 per cent alcohol. Inoculate them from the films obtained in 1 . Incubate one flask at $15^{\circ}-20^{\circ} \mathrm{C}$., one at $30^{\circ} \mathrm{C}$., and one at $40^{\circ} \mathrm{C}$. Leave two flasks uninoculated for controls.

5. Examine the flasks daily and note the formation of films. Remove organisms with the sterilized platinum loop, stain with carbol-fuchsin, and examine with the microscope. Use the method described in Exercise 61 to demonstrate the gelatinous capsule. What differences in morphology at rlifferent temperatures?

6. On every second or third day add a small quantity of alcohol. At the end of the experiment, filter the solutions and titrate them with $\frac{1}{20} \mathrm{~N} \mathrm{NaOH}$ to determine acidity.

\section{Exercise 151. Study of Mucor}

Mucor is one of the molds common everywhere, especially upon starchy substances. It is especially common upon bread. cooked potatoes, and bananas. It forms a floccose, aërial layer of 
sporangiophores 1-5 cm. in height. At first the growth is creamy white; later, as the sporangia mature, it becomes dark brown or black. The purely vegetative structure, the mycelium, develops mainly in the substratum.

Mucor is a fungus belonging to the class Phycomycetes, or Alga-like fungi. Mucor mucedo may grow in saccharine solutions and cause therein a weak alcoholic fermentation.

The salient features of the fungus are brought out by the following outline :

1. Examine a culture of Mucor and note

$a$. The general appearance of the whole mass.

$b$. The position and direction of the threads with reference to the supporting substratum.

$c$. The aërial hyphæ (sporangiophores) upon which the black tips (sporangia) have formerl.

2. Examine microscopically a bit of agar from a Petri dish inoculated with. Mucor at the previous laboratory period. Note a. The mycelium, consisting of branched hyphæ.

b. The granular protoplasm in the hyphæ may be found in motion. Is the movement of the protoplasm uniform? Is it ever reversed? Do you find vacuoles present? Are cross walls present? Draw a young branched hypha.

3. In suitable material distinguish upright hyphr which have a swollen tip containing an abundance of granular protoplasm. Is the swollen tip separated from the hypha by a transverse wall? The tip is the beginning of the sporangium.

4. In older material distinguish the spores forming in the sporangia. Find also mature sporangia with ripe spores. Note

a. The sporangium wall.

b. The ripe spores.

c. The swollen tip of the sporangiophore (columella).

5. Draw a young and a mature sporangium.

6. Sexually formed spores (zygospores) are rarely found in Mucor. For details of the process the student is referred to Campbell's "University Textbook of Botany," page 160. 


\section{Exercise 152. Study of Penicillium}

The common green mold, Penicillium, is one of the most cosmopolitan of the fungi. Its spores are found nearly everywhere, and it grows upon anything from lemons to old boots.

Penicillium is a fungus genus belonging to the Ascomycetes. The perithecia are, however, quite rare in the more common species. The spores formed are therefore mostly of the conidial type.

The green Penicillium is usually abundant in portions of the home where food is kept, and causes the loss of much stored food. In the fruit business serious losses are caused by Penicillia, which attack oranges, lemons, apples, cherries, peaches, etc., especially if shipments are made orer long distances in warm, muggy weather. In breweries Penicillium may cause great damage to the malt, as well as to the finished beer.

Grapes on which this mold is abundant make defective wines. The mold not only destroys the necessary sugars, but forms waste products which are deleterious to the subsequent growth of the yeasts.

Some species of Penicillium, like P. C'amemberti, play a useful rôle in the ripening of cheeses.

1. Examine a culture of Penicillium and note a. The general appearance of the whole mass.

$b$. The position and direction of the threads with reference to the supjorting substratum. Remove a small tuft of these aërial hyphre, place them in a llop of 50 per cent alcohol on a slide, tease apart carefully, and examine with both low and high powers.

2. The conidiophores are the straight aërial branches, each of which ends in a tuft of spore-bearing branches. Are cross walls present? Do all the branches reach to about the same level? How many series of branches are present? At the distal end note the sterigmata, or club-shaperl cells, which bear the spores.

3. The spores arise in basipetal order from the sterigmata. Are spores relatively few or abundant? What is their shape? color? Is the spore wall thickened? 1)o the spores contain protoplasm? oil? racioles? 
4. Draw a conidiophore and spores.

5. Lift out pieces of agar on which Penicillium has been sown for two days. Study the mycelium it contains. Have the hyphæ cross walls? Do they branch extensively? Draw a bit of mycelium.

\section{Exercise 153. Study of Aspergillus}

This mold fungus is also of wide distribution, usually developing at rather high temperatures.

Morphologically it is quite similar to Penicillium, and likewise, the conidial spore form is abundant, while the ascospore is comparatively rare. Aspergillus niger is more or less common as a black mold on organic substances. It forms oxalic acid in considerable quantities when grown upon media containing sugars. The fungus produces diastase, maltase, invertase, and emulsin.

Aspergillus oryzae is of considerable interest on account of its pronounced diastatic action. It is, in fact, an important source of diastase, the takadiastase of commerce. This fungus is used in the preparation of rice beer, or sake, a favorite beverage in Japan. The Aspergillus is used to convert the rice starch into sugar; then the sugar is fermented by yeasts which find their way into the mass.

1. Examine a culture of Aspergillus and note

a. The general appearance of the whole mass.

$b$. The position and direction of the threads with reference to the supporting substratum.

Remove a small tuft of these aërial liyphæ, place them in a drop of 50 per cent alcohol on a slide, tease apart carefully, and examine with botli high and low powers.

2. The conidiophores are the aërial branches, each of which ends in an enlargement. The surface of this swollen tip gives rise to numerous sterigmata, or stalk cells, which bear the spores. In some species sterigmata are not formerl.

3. The spores arise in basipetal order from the sterigmata. Are the spores relatively few or abundant? What is their shape? color? Is the spore wall thickenel? Do the spores contain protoplasm? oil? racuoles? 
4. Draw a conidiophore and spores.

5. Remove from a Petri dish a bit of agar on which Aspergillus has been sown two days. Study under the microscope the mycelium it contains. Have the hyphæ cross walls? Do they branch extensively? Draw a bit of mycelium.

6. Add some starch to liquid wort and inoculate with Aspergillus oryzae. Test the solution from time to time for sugars with Fehling's solution.

\section{Exercise 154. Study of Torula}

The genus Torula resembles in most respects that of Saccharomyces, except that it does not produce spores. 'The Torulæ are widely distributed in nature. They have the power of setting up alcoholic fermentation, but most of them produce by-products which give the solution undesirable odors or flavors. After a time they may cause slimy must.

1. Expose Petri dishes of sterile wort agar to the air. Incubate them at $25^{\circ} \mathrm{C}$. for two days.

2. Transfer Torulie from pure cultures or from the Petri dishes to tubes of wort agar, to fermentation tubes of lactose, to tubes of beef broth, and to gypsum blocks.

3. Make stains and write descriptions of the organisms : note the differences and similarities between Torulie and yeasts. Some Torule produce gas from lactose, but the true yeasts do not.

\section{Exercise 155. Study of Dematium pullulans}

This fungus is widely distributer in nature, especially upon fruits, and occurs in damp situations in breweries. It is a deleterious organism in brewing, because it is not only incapable of causing fermentation, but also produces films of growth in the wort and darkens the wort of light-colored beers.

1. Inoculate tubes of wort agar and flasks of liquid wort with pure cultures of Dematium mullulans.

2. Find two methods of producing conidia from the hyphr. Find gemmr, or chlamydospores, in the older cultures. Do the conidia resemble yeast in any way?

3. Make drawings to illustrate the different phases found. 
Exercise 156. Obtaining Mold Cultures from Spores in the Air

1. Put some slices of bread on a plate and steam them for ten minutes in the Arnold sterilizer.

2. Remove and place the plate on a laborator'y table for fifteen minutes, then cover with a bell jar.

3. Under another bell jar place slices of lemon or pieces of cheese.

4. Examine the cultures day by day until they show spores. The material may be used for study, or pure cultures may be prepared by using the isolation methods described in Exercise 63 .

\section{Exercise 157. Culture of Molds on Liquid Media}

Mold fungi are usually capable of culture upon the surface of liquid media. The mycelium of Aspergillus or Penicillium forms a disk which floats upon the surface of the liquid. Spores will develop upon the upper surface of the disk of mycelium.

1. Prepare $100 \mathrm{cc}$. of the synthetic solution described in Exercise 54; divide it between two Erlenmeyer flasks of 200 cc. capacity.

2. Make a series of other solutions in which substitutions are so made that one essential element is lacking in turn from some solution in the set.

3. Sterilize the flasks in the Arnold sterilizer. Inoculate with Aspergillus or Penicillium and make records of the amount of mycelium and spore formation in each.

\section{Exercise 158. The Stimulating Action of Weak Poisons}

The physiological action of small amounts of poison may be well demonstrated by the culture of fungi on liquid media. In the weak dilutions there will be stimulation, while at higher concentration there is toxic action.

1. Prepare a liter of the synthetic solution as in the foregoing exercise.

2. Measure off $50 \mathrm{cc}$. portions which can be put into 200-cc. flasks. 
3. Add to the different Hasks amounts of zinc sulphate to make the following concentrations of the toxic agent: 1.0, 0.25, $0.12,0.06,0.03,0.015,0.007,0.0035,0.00$ per cent.

4. Sterilize in the Arnold sterilizer and inoculate with Aspergillus.

5. Watch the cultures and make records of the amount of mycelium and spore development.

\section{Exercise 159. Demonstration of the Presence of Arsenic by Means of Penicillium brevicaule}

1. Mix the materials to be examined with bread crumbs (preferably brown or graham bread) and neutralize if necessary.

2. Sterilize in steam and inoculate when cool with Penicillium brevicaule. Close the flasks with tight-fitting plugs. Incubate at $37^{\circ} \mathrm{C}$.

3. Twenty-four to forty-eight hours after the mass becomes thoroughly overgrown with Penicillium, open the flasks and examine for odor. An odor of garlic is inclicative of the presence of arsenic.

\section{Exercise 160. The Amylolytic Power of Molds}

1. Measure off $50 \mathrm{ce}$. of liquid wort into a flask of $200 \mathrm{cc}$. capacity and add $1 \mathrm{~g}$. of starch. Sterilize in the Arnold sterilizer.

2. Inoculate with Aspergillus oryzae. After growth is evident, test the solution for reducing sugars with Fehling's solution.

\section{Exercise 161. The Peptonizing Action of Molds}

1. Melt several tubes of beef-peptone gelatin and pour into sterile Petri dishes.

2. When the gelatin has hardened, inoculate the center of each plate with spores of Penicillium.

3 . Keep the plates at $20^{\circ} \mathrm{C}$. and note the progress of liquefaction as the colony spreads over the gelatin.

4. Another method consists in growing the Penicillium in a tube of beef broth until spores are formed, then filtering off the medium. Add several drops of toluol and pour the liquid into a tube containing sterile gelatin. Follow the liquefaction of the solid gelatin from day to day by marks on the wall of the tube. 


\section{APPENDIX A}

\section{STERILIZATION}

Many of the student's difficulties begin and end with the sterilization of the culture media. Wherever accurate work is to be done, much attention must be given to the process of sterilization. Modern bacteriological work rests upon the pure culture. So long as contamination is suspected or known, uncertainty and doubt concerning the results will prevail. The first requisite for the vigorous growth of a pure culture is, therefore, successful sterilization.

The principal agents of sterilization are three - chemicals, heat, and filtration. Each finds its application for special purposes.

\section{STERILIZATION WITH CHEMICALS}

The efficiency of various chemicals as germicides has been investigated by numerous biologists. One class of germicides are used in surgery and contact disinfection work, while another class of more or less volatile compounds are used in laboratories, where toxin and enzyme work is carried on. In choosing a germicide for surgical work it is desirable to have one which shall be highly toxic to the bacteria and shall not at the same time impair its efficiency by forming insoluble compounds with the body fluids which may be present in the wounds.

Certain salts of the heavy metals have shown strong germicidal properties; among them mercuric bichloride (corrosive sublimate) stands first in efficiency and applicability. The concentration of bichloride generally used for disinfection and surgical work is one part to a thousand of water. Since this substance is slowly soluble in water, a hydrochloric acid solution may be first prepared and further dilutions made as required. Thus, $200 \mathrm{~g}$. of mercuric bichloride dissolved in a liter of hydrochloric acid makes a 20 per cent stock solution. If $5 \mathrm{cc}$. of this solution be diluted to $1000 \mathrm{cc}$., it makes a $1: 1000$ solution of bichloride. In the laboratory the stock solution may be conveniently kept in siphon bottles upon the stock table. 
Salts of silver, lead, and copper have also found more or less use at times as disinfectants, but their efficiency is not in proportion to the cost of materials and the labor of preparation.

Potassium permanganate is a readily soluble salt which is used to some extent in surgery. Its value is impaired by the fact that it is easily reduced by organic substances with which it. comes in - contact.

Potassium bichromate is less easily reduced than the permanganate and is sometimes used for sterilizing seeds. There are no instances, however, in which mercuric bichloride would not do the same work as, well or better.

Iodine in solution, especially in a solution of potassium iodide, is toxic to bacteria and may have limited use as a disinfectant.

All acids are more or less fatal to microörganisms, although there are certain microörganisms that will resist some of them. The more highly dissociated acids are the most toxic to bacteria.

Phenol (carbolic acid) has wide use as a germicide and for contact disinfection. It mixes readily with water in all proportions and does not readily enter into combination with organic substances. It is not as toxic to microörganisms as mercuric bichloride, and is more irritating to the skin. It is usually employed in a concentration of $1: 20$ (5 per cent).

Lysol and tricresol are cresol products widely used as contact disinfectants. 'They possess efficiency without irritating the skin or' mucous membrane. Lysol, which contains about 50 per cent cresylic acid, is generally used in solutions ranging from 1 to 3 per cent. Tricresol has greater germicidal power than phenol, but is not as toxic. It does not lose its germicidal powér in the presence of albumins, nor discolor metal instruments. It is used in solutions of 0.5 to 1.0 per cent.

Thymol, salicylic acid, and benzoic acid are weak germicides. They may be used in special cases, but cannot be relied upon to give perfect sterilization. They are to be regarded as agents for retarding bacterial activity rather than as sterilizing agents.

Calcium hypochlorite and chlorine have found extensive use for treating water and sewage. At the concentrations used it is seldom that complete sterilization is accomplished, but it is possible to reduce the number of organisms to a negligible quantity and to annihilate bacteria of the colon-typhoid type. Ozone has in some cases given complete sterility when applied to milk and waters, but 
in other cases it has not proved certain. Hydrogen peroxide is a weak germicide but is useful in some cases.

The volatile group of antiseptics consists of a few organic compounds, which are more or less toxic to microörganisms.

Formaldehyde, either as a gas or in a strong solution (known as formalin.), is an efficient and economical germicide. In a 4 per cent solution it quickly kills all organisms with which it is in contact. It is quite irritating to the skin, however, and must be employed with care. The gas is readily liberated from the solution by the use either of heat or of potassium permanganate.

Chloroform, acetone, and carbon bisulphide have more or less extensive use in sterilizing liquid media, where it is not practical to use heat, but it will not do to assume too quickly that chloroform or carbon - bisulphide has sterilized a solution; the solution should be incubated and observed after several days, to make sure that no growth occurs.

Alcohol and ether have somewhat limited use as sterilizing agents. Alcohol of 60 or 70 per cent strength may be used for quick treatment of glassware when time or location forbids the use of other agents. For sterilizing pipettes or tubing used for taking samples in the field a brief washing with alcohol just previous to the time of using serves very well. After draining off the alcohol, the tubes should be rinsed with the solution to be sampled.

\section{STERILIZATION WITII IEAT}

Heat is the sterilizing agent most useful for general bacteriological work. If properly applied, it produces no detrimental conditions in the culture media, and at the same time it is efficient in killing microörganisms.

Dry or moist heat may be used, according to the nature of the object to be sterilized and the purpose for which it is to be used.

Hot-air sterilization. Dry sterilization is accomplished by placing the objects in a hot-air sterilizer, which is a gas-heated oren constructed of sheet iron or other metal. The ovens constructed for this purpose have double walls so arranged that the hot air circulates through the chamber. The outer walls are covered with asbestos and provided with an opening for the insertion of a thermometer. The Lautenschläger oven is one of the best for dry sterilization. If a simple, cheap oven is to be used, careful tests should be made, to ascertain the relative temperature in its various parts. 
Experience has shown that objects must be exposed to dry heat for a longer time than to moist heat. In practice it is necessary to maintain a temperature of $140^{\circ}-150^{\circ} \mathrm{C}$. for one hour, or of $125^{\circ} \mathrm{C}$. for two hour's. Objects placed in the hot-air sterilizer should be perfectly clean and dry. After the heat is turned off, the door should be kept closed until the temperature of the oven has fallen to near the temperature of the room.

The Lautenschläger oven is heated by a tubular gas burner extending around three sides of the base. If possible, the burner should connect directly with the pipe supplying the gas, and entirely avoid connections of rubber tubing. The special handling of various objects in the hot-air sterilizer is described below. Needles, forcep tips, and scalpel blades may be sterilized directly in the Bunsen flame.

Steam sterilization at $100^{\circ} \mathrm{C}$. Moist heat in the form of steam is, the most efficient sterilizing agent for the culture media usually employed.

At the temperature of boiling water most forms of germ life are killed, although, as previously stated, numerous spores may successfully resist this temperature. Sterilization may thus be effected in a boiler orer an ordinary water bath. For economical and effective work, however, the Arnold type of sterilizer is preferred and, in some form, is in use in most laboratories.

The type of sterilizer which is heated over a gas burner is provided with a double botton. 'The lower bottom contains only a thin layer of water, which consequently boils quickly and the steam passes up through a short (himmey into the chamber of the sterilizer. Water enters the lower bottom through small holes from the reservoir above, which will hold a supply sufficient for several hours.

The chamber of the Arnold sterilizer has double walls, which are so arranged that the condensed stean drips back into the reservoir. The chamber of the sterilizer is fitted with one or more shelves upon which media may be placed.

If the laboratory is supplied with steam, it will be found more economical and satisfactory to install a sterilizer fitted for steam.

The Arnold sterilizer and all other steam sterilizer's should be installed, if possible, in a room separate from the main laboratory, and should stand under a hood which will carry off escaping steam.

The sterilizer should always be provided with a thermometer whose bulb extends about $5 \mathrm{~cm}$. into the chamber: otherwise it is difficult to know the exact time at which the contents reach the 
temperature of $100^{\circ} \mathrm{C}$. The time required for the chamber to heat up depends upon the amount of material which it contains.

When media in test tubes are to be sterilized, the tubes should always be held in wire baskets which permit the easy entrance of steam. If tin cups or beakers are used, it seems to be almost impossible to dislodge a layer of cooler air from the bottom of the cup, and consequently sterilization is only partial.

When the steam first enters the chamber of the sterilizer, condensation takes place, and enough water often drops from the roof to soak the cotton plugs. To guard against this, one may wait until the interior of the sterilizer has reached a temperature of $100^{\circ}$ before introducing the objects to be sterilized, or the cotton plugs may be covered by tying manila or parchment paper over the top of the wire baskets. When flasks of media are being sterilized, small beakers may be inverted over the cotton plugs. Such cotton plugs as are found water-soaked when the media are removed from the sterilizer should be replaced by new plugs and the vessels resterilized.

Circulating steam at $100^{\circ} \mathrm{C}$. will kill the regetative forms of microörganisms in fifteen to twenty minutes, but spores will survive much longer heating. The success of discontinuous, or fractional, sterilization was demonstrated by Tyndall. In general practice, the media are sterilized for twenty to thirty minutes on three successive days. In the intervals between sterilizations the media should be kept at temperatures favoral,le for bacterial growth, in order that the resting spores may germinate and pass into the vegetative stage, and thus be killed at the next sterilization. Even with this treatment the spores of anaërobic bacteria in the superficial layers of the media may not develop, owing to the access of oxygen, and so may survive the process of sterilization.

Steam sterilization under pressure. The autoclave is a strong-walled steam chest which may be tightly closed. In it the steam is used under pressure, and temperatures above $100^{\circ} \mathrm{C}$. are obtained. By this means both the vegetative forms and the bacterial spores are killed, and the necessity for discontinuous sterilization disappears.

The type of autoclave in most common use is a heavy-walled copper cylinder set in a frame above a large gas burner. The upper end has a close-fitting lid which clamps on with six turnscrews. The cover is provided with a steam-pressure gauge, a thermometer, a stopcock, and a safety valve. A rack which fits the inside of the autoclave provides one or two shelves for holding the vessels of media. 
Before using the autoclave sufficient clean water is poured in to cover the bottom to a depth of $\tilde{\mathrm{cm}}$. It is best to use distilled water and to renew it frequently. If the water is dirty or contains media escaping from broken vessels, it is liable to foam up and wet the cotton plugs.

The lid is securely clamped after the media are put in and the gas burners lighted. The stopcock must remain open for the escape of air, since the requisite temperature may not be attained unless the autoclave contains nothing but steam. When the thermometer registers $100^{\circ} \mathrm{C}$. and steam issues rapidly from the stopcock, it may be assumed that the air has been displaced, and the stopcock may then be closed. The gas supply may then be reduced somewhat and pressure allowed to run up to 10 or 15 pounds. The contents of the sterilizer are held at this pressure for twenty to thirty minutes. The gas is then shut off and the sterilizer allowed to cool. The stopcock may be gradually opened as the pressure falls, but caution should be used, because, if the pressure is too suddenly reduced, the superheated media may boil over and dislodge the plugs. If direct steam is used instead of a gas burner, much time and expense will be saved.

The corresponding pressures and temperatures are shown in the following table:

\begin{tabular}{|c|c|c|c|c|c|}
\hline \multirow{2}{*}{$\begin{array}{l}\text { Steam Pressure } \\
\text { Pounds }\end{array}$} & \multicolumn{2}{|c|}{ Temperature } & \multirow{3}{*}{$\begin{array}{c}\text { Steam Pressure } \\
\text { pounds } \\
15\end{array}$} & \multicolumn{2}{|c|}{ Temperature } \\
\hline & Faldrenheit & Centigrade & & Fahrenheit & Centigrade \\
\hline 0 & 212 & 100 & & 2.51 & 121.5 \\
\hline 5 & 28 & 109 & 20 & 260 & 126.5 \\
\hline 10 & 240 & 115.5) & 40 & 287 & 141..5 \\
\hline
\end{tabular}

Partial sterilization-Pasteurization. For many industrial purposess it is not necessary to obtain complete sterilization, provided certain forms can be killed. This is readily accomplished by the use of temperatures somewhat below the boiling point of water. The process is named for Pasteur, who first suggested its use in the treatment of grape must to overcome wine faults.

In this country Pasteurization is extensively used in commercial dairy work. In different estahlishments different temperatures are used. As a usual thing the milk is heated to $60^{\circ}-65^{\circ} \mathrm{C}$. for twenty minutes. In what is known as the continuous process the milk is subjected to a momentary heating of $85^{\circ} \mathrm{C}^{\prime}$, and is then quickly cooled. 
The criterion employed for the Pasteurizing temperature is the temperature necessary to kill such pathogenic organisms as the typhoid and tuberculosis bacteria, and also the majority, if not all, of the lactic-acid bacteria. If the time allowed for heating be short, then the temperature must be higher, and vice versa, within certain limits.

The principle of Pasteurization is somewhat similar to that of fractional sterilization; that is, non-spore-forming bacteria are killed by the temperatures employed. The process is to be regarded as one which retards germ development rather than as one which prevents it.

Pasteurization is also extensively used in the production of beer. The beer, in bottles or jugs, is submerged for half an hour in water at a temperature of $60^{\circ}-65^{\circ} \mathrm{C}$.

\section{STERILIZATION BY MEANS OF FILTRATION}

Liquids which cannot be treated with chemicals or with heat may be sterilized by filtration. In the preparation of enzymes and toxins this method of treatment is extensively employed.

The filters used are cylindrical vessels, closed at one end like a test tube, which are called bougies. The Chamberland filters are made of porous porcelain, hard-burned and unglazed. The Berkefeld filters are made of kieselguhr, a fine, diatomaceous earth. The Chamberland has the finer pores; the Berkefeld filters are quicker; with either one, however, it is necessary to use aspiration or pressure to hasten the filtration.

The simplest way to use such a filter, when a small quantity of liquid is to be filtered, is to place the liquid inside the filter and force it out by means of compressed air. Wrap the nipple end of the bougie with a firm band of absorbent cotton about $7-10 \mathrm{~cm}$. wide. Invert the bougie in a glass cylinder $5-10 \mathrm{~cm}$. longer than the bougie, so that only the nipple end projects from the mouth of the cylinder. The cotton wrapping should fit rather firmly in the mouth of the cylinder, and the nipple of the bougie should be wired to prevent its slipping down into the cylinder. Wrap this apparatus in manila paper and sterilize it in the dry oven for two hours at $140^{\circ} \mathrm{C}$.

After the apparatus is cool, insert a small funnel in the nipple of the bougie and pour in the liquid to be filtered, taking care not to wet the cotton surrounding the upper end of the bougie. Comnect the bougie nipple with an air pump by means of heavy-walled 


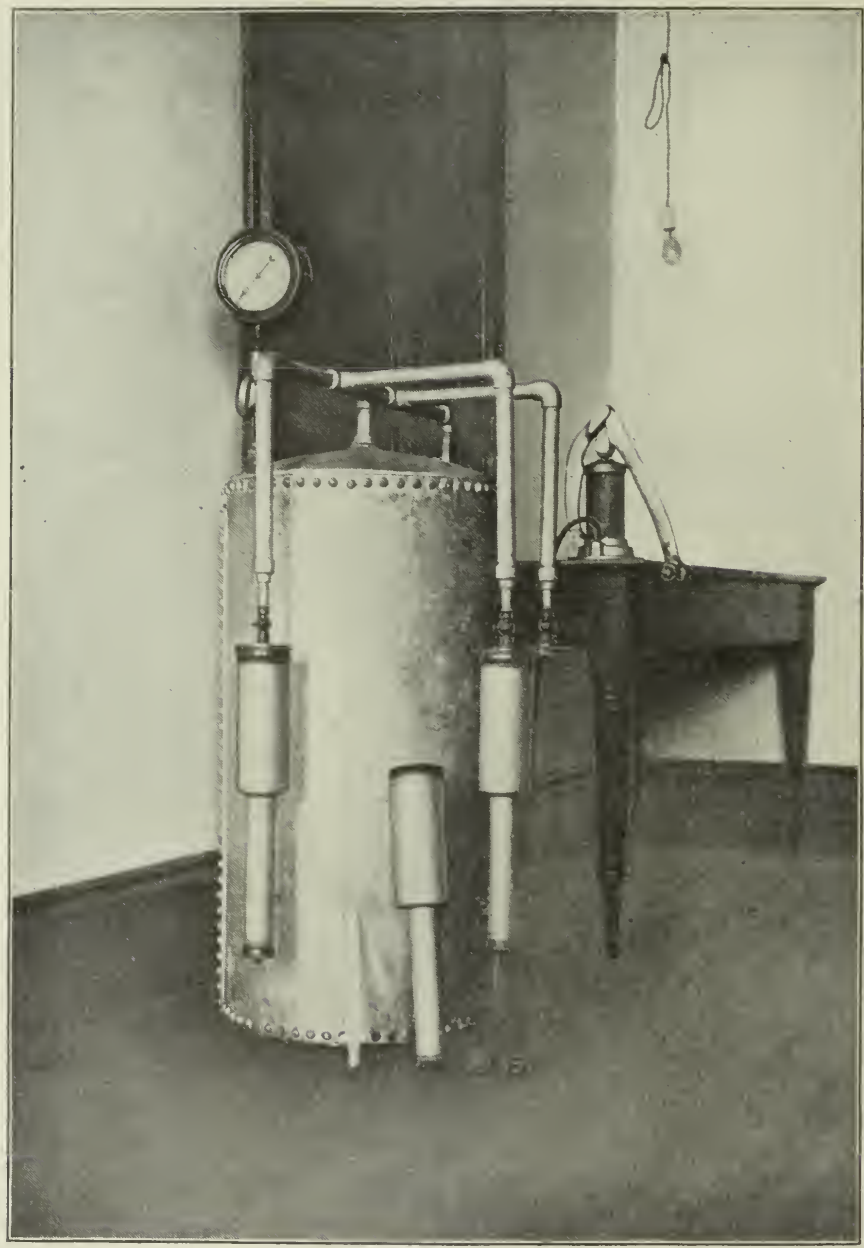

FIc, 41. Filtering apparatus

Air is pmuped into the tank and furnishes pressure to force the solution through the filters

rubber tubing, which should be wired on. Turn on the air slowly until a pressure of $15-20$ pounds is exerted. The liquid should drip rapidly from the bougie, but an excess of pressure should be avoided, because small organisms might be forced through the wall of the filter. 
Aside from the limited capacity afforded by the use of the above method, it is open to another objection : namely, the residuum accumulates upon the inside of the bougie and is hard to remove.

An extremely satisfactory filtering apparatus is that shown in Fig. 41, which was made for the author after the filters used in the Bureau of Soils of the United States Department of Agriculture and described by Schreiner and Failyer in Bulletin No.s1 of that bureau. The metal oylinder which contains the bougie is large enough to hold $500 \mathrm{cc}$. or more of solution and to take a bougie of any length. This last feature is not without value, since it is at times impossible to obtain bougies short enough to fit the apparatus of European manufacturers. The metal filtering cylinders are lined with porcelain enamel and are thus entirely nontoxic - an advantage over the older brass cylinders or those which were silver-plated inside.

The construction of the metal filtering cylinder is evident from the accompanying illustration (Fig. 42). Both ends are accurately threaded and receive screw caps. The lower end has a rubber gasket which fits on the nipple of the bougie. This gasket goes into the lower end of the cylinder and is held in place by the nipple plate and screw collar. The upper end of the cylinder is closed with a cylinder head and a screw collar. A good rubber washer lies between the cylinder and the cylinder head. The cylinder head has a flanged opening at the center, which is threaded to fit the pipe from the air tank and usually needs a rubber washer.

The air pressure needed for filtering, which is from 1 to 2 atmospheres, is supplied by any convenient form of pump. The air tank, which should hold from 10 to 20 gal., serves to store compressed air and to equalize the pressure for filtration. The opening on

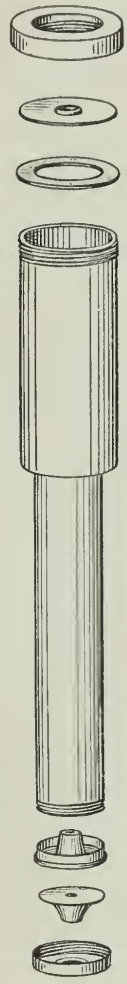

Fig. 42. Cylinder for the Chamberland Filter (after Schreiner and Failyer) the side of the tank is fitted with a stopeock and a bicycle valve, so as to hold the pressure in the tank. The bougie is wrapped in manila paper and sterilized in the hot-air sterilizer. A plug of cotton should be inserted in the nipple end and the whole carefully wrapped in manila paper. When sterilized and cool, the bougie is put into 
place in the filtering cylinder. The solution to be filtered is poured into the large end of the cylinder, which is connected with the air tank. A piece of glass tubing with a rubber-tubing connection is slipped on the nipple end of the bougie. This tubing should previously be sterilized in $1: 1000$ bichloride solution or in 70 per cent alcohol, and rinsed with sterile distilled water.

A cotton-plugged Erlemmeyer flask which was previously dry sterilized is placed to receive the filtrate. The cotton forms a packing around the glass tubing. The time of filtration varies with the pressure and the nature of the solution to be filtered. With a pressure of 1 atmosphere the filtration will usually be rapid.

The bougie can easily be removed for cleaning by unscrewing the cap at the bottom of the cylinder. The scum on the exterior can be removed by washing in water, using a small brush with stiff bristles. Care should be taken to prevent wash water from entering the mouth of the bougie. After washing, rinse in distilled water and dry it for resterilization. A Chamberland bougie may be used continuously for two or three days before resterilization is necessary. Continued use should be aroided, since colonies of microörganisms may grow through the wall of the filter bougie.

When the bougie has been used for some time, its efficiency is impaired and the filtration goes very slowly. The difficulty is due to the clogging of the pores of the filter with organic matter. The bougie should be dried and heated to redness above a Bunsen flame for half an hour. This can be done by hanging the bougie with the nipple upward in a cylinder of sheet iron corered with asbestos and partially covered at the top and bottom with asbestos rings. A single Bunsen burner placed at the bottom will heat the tube to redness in a short time.

After cooling, place the bougie in the filtering cylinder and run distilled water through it, to wash out the charred organic matter. This treatment of the bougies restores them to their former efficiency.

\section{STERILIZATION BY MEANS OF LIGHT}

It is almost universally admitted that sunlight is one of the best and cheapest of germicides, but for rapid work light is not economical. Recent work by Henri and his associates shows that the ultra-violet light of a quartz-tube mereury lamp may give complete sterilization of water and sewage without producing any chemical 
change in the liquids thus treated. In milk the bacteria are likewise killed, but there is a complete or partial destruction of the enzymes of normal milk. Other workers, like Schwarz and Aumann, have found that complete sterilization is frequently not obtained, although the bacterial content is greatly reduced.

The process of sterilization by this means seems promising for laboratory work and, when better developed, ought to be of great assistance to the bacteriologist. Whether it will be of equal value to the engineer remains to be seen.

\section{THE TECHNIQLE OF STERILIZATION FOR SPECIAL PLRPOSES}

1. Glassware, pipettes, and instruments. The most effective method of sterilizing these articles is in the hot-air sterilizer. Objects to be sterilized should be perfectly clean, dry, and free from dust. Flasks should be plugged with cotton, and the plugs may be covered with paper caps. Petri dishes, unless they are to be used immediately, should be wrapped in manila paper or inclosed in the sheet-iron cases made for the purpose. Pipettes should have the large end plugged with absorbent cotton and should be sterilized in sheet-iron boxes or wrapped in paper. Knives, scrapers, scalpels, forceps, needles, and spatulas may be sterilized, at the time of using them, in a gas flame. If they cannot be used while hot, they should be sterilized in a sheet-iron box, as pipettes, or in large test tubes plugged with cotton.

Where time or facilities will not permit of hot-air sterilization, the articles mentioned above may be sterilized with chemicals. Pipettes may be sterilized by drawing up alcohol of 50-70 per cent strength and rinsing the pipette with sterile distilled water or with the solution to be employed. Flasks may be rinsed with alcohol or mercuric bichloride solution and rinsed with sterile water or the test solution. Instruments may be washed with a 1 per cent solution of lysol or tricresol and dried on sterile surgeon's gauze. Wherever possible, however, sterilization by heat is to be preferred.

2. Liquid media and other solutions. For general work solutions are most easily and thoroughly sterilized in the Arnold sterilizer or in the autoclave. They may also be sterilized by heat on a steam bath or, if organic compounds be absent, by boiling over a flame, although in the latter case it is difficult to avoid steaming the cotton plugs. 
3. Gelatin and agar media. Media which contain gelatin should not be heated at high temperatures in the autoclave nor for longer periods than absolutely necessary. in the Arnold sterilizer. An excess of heat breaks down the gelatin so that it will not harden when cool. Flasks and tubes of gelatin media should be chilled as quickly as possible after removal from the stetilizer. After the gelatin has hardened, the vessels may be put into the locker at room temperature, to await the next sterilization. The temperature at which it is kept should be high enough to permit the germination of such resistant spores as may have survived heating. When three successive sterilizations are given at twenty-four-hour intervals, the first heating may be twenty minutes, the second fifteen minutes, and the third ten minutes. After the last heating the media may be put into the locker and held for a few days, during which time they are closely watched for colonies. Such tubes as show colonies should then be discarded. Gelatin media may be sterilized in the autoclave for fifteen minutes, provided the pressure does not rise higher than five pounds and the vessels containing them, when removerl, are plunged at once into cold water.

One source of diffieulty in sterilizing media eontaining gelatin comes from the spores of microörganisms which may have developed during the preparation of the gelatin itself while in the vats or drying house of the manufacturer. Only the best grade of gelatin should be used for bacteriologieal work. Another frequent cause of failure in sterilizing media is due to the presence of resistant spores in beef extract. These spores develop in the meat juice during the process of preparation and evaporation. It is better, when making gelatin media, to make the meat extract yourself, according to directions given in Exereise 8. If, however, it is necessary to use commercial beef extract, make the bouillon first and sterilize it in the autoclave; then add the gelatin and carry on subsequent operations in the Armold sterilizer.

Agar media are not likely to present much difficulty in the way of sterilization so far as the agar itself is concerned, although it is not advisable to use more heat than necessary. If agar media fail to harden after eooling, it is probably due to an excess of sugar or of acid. In making media from fruit decoctions this is an important precaution. If it is found that the acidity of the agar medium is excessive, the medium should be divided into two equal parts. Bring one portion to approximate neutrality with sodium-hydrate solution; then recombine the two portions and heat for a short time, with 
stirring, on the steam bath. If this fails to reduce the acidity sufficiently, then the process may be repeated. An excess of alkali, however slight, must be avoided, because it will seriously discolor media made from plant extracts.

4. Sugar-containing media. All organic chemists are aware of the changes wrought by the artion of heat upon sugars. I)ry heat converts part of the sugar into furfuraldehyde. The moist heat of the autoclave converts sugars into humuslike bodies and other substances unfavorable to the growth of microörganisms. Henderson has found that at a temperature so low as that of $37.5^{\circ} \mathrm{C}$. a glucose solution will, in the course of several days, lose its optical activity.

An excess of heat should always be avoided in sterilizing culture media containing either monosaccharides or disaccharides. The media should be intermittently sterilized in the Arnold sterilizer by heating for twenty minutes the first day, fifteen minutes the second day, and ten minutes the third day.

5. Solid vegetables. In plant-pathological investigations much use is made of sterilized pieces of potatoes, beets, carrots, turnips, rice, corn meal, and other vegetable substances. Nuch difficulty is encountered at times in sterilizing potatoes and beets, because they carry spores of very resistant soil organisms. When preparing tubers or roots for culture media it is well to scrub them thoroughly with a stiff brush, then wash in a 1:1000 bichloride solution, and finally rinse with distilled water before cutting plugs or slices.

There is some possibility that the heat of sterilization, acting upon these carbohydrate substances, may produce compounds toxic to microörganisms, as has been pointed out by L. R. Jones. It is therefore well to use as little heat as possible for sterilization, although the autoclave must generally be used in order to successfully sterilize potato plugs.

6. Milk. Sterilization will be much more successful if fresh, clean milk is obtained. In cities one should obtain certified milk. Whereever possible, the milk should be obtained directly from the dairy. Market milk often contains a large number of organisms, and trouble arises from the heat-resistant types. The cream should be removed by centrifuging and the milk placed in tubes or flasks for sterilization.

Here again an excess of heat brings about undesirable changes in the medium. Prolonged heating coagulates the casein more or less completely and mav transform the sugars into compounds less favorable for bacterial growth. 
Nilk may be steamed at $100^{\circ} \mathrm{C}$. for fifteen minutes on four or five consecutive days. It should then be incubated at $30^{\circ} \mathrm{C}$. for three days, and all tubes which show.signs of microbial activity can be thrown away. It is better to discard a few tubes in which growth occurs than to lose all on account of orerheating.

7. Blood serum. If the slaughter of the animal can be supervised, it is well to have the region of the wound and the knife previously sterilized. Collect the blood from the sheep or ox in a sterile glass jar in a sterile cylinder. Allow the vessel to stand long enough to form a clot before leaving the slaughterhouse. At the laboratory detach the clot from the sides of the jar by means of a sterile glass rod and place the cylinder in the ice chest for forty-eight hour's. The clear serum is drawn out with sterile pipettes and placed in sterile, cotton-plugged tubes.

The tubes of serum are sterilized by heating them to $56^{\circ} \mathrm{C}$. in a water bath for half an hour on each of three consecutive days. On the fourth day the tubes are placed in a sloping position in a serum inspissator and heated to $72^{\circ} \mathrm{C}$. until coagulation occurs. The tubes are then transferred to an incubator at $37^{\circ} \mathrm{C}$. for forty-eight hours. Those which show indications of infections are then discarded.

8. Soil. For many experiments with bacteria and phytopathological fungi sterilized soil is recquired. I'nfortunately, successful sterilization of soil is difficult to accomplish. If all germ life is destroyed, so high a degree of heat is required that profound changes in the constitution of the soil are brought about. The air held in the soil is very difficult to remove and acts as a heat insulator. This condition may prevent the soil in the center of a large pot from receiving enough heat to kill all germ life.

Attention may be called to three methods of soil sterilization which have been used by investigators: dry heat, moist heat, and volatile antiseptics.

Richter ${ }^{1}$ found that exposure to a dry heat of $100^{\circ} \mathrm{C}$. for six hours on three consecutive days increased its absorptive power for water, the amount of nitrogenous material soluble in water or dilute hydrochloric acid, and the amount of water-soluble organic matter.

Seaver, ${ }^{2}$ and Seaver and Clark, ${ }^{3}$ have studied the effect of dry heat upon soil with relation to the growth of pyrophilous fungi and green plants. They have shown that heat alters the soil beneficially

${ }^{1}$ Landw. Versuchsst. 47: 269.18:4;

2 Mycologia $1: 1: 31$. 1909).

3 Mycologia 2: 109. 1910. Biochemical Bulletin No. 1: 41:3. 1912. 
for the development of the fungus Pyronema. The growth of oats was slightly accelerated in soils heated at low temperatures $\left(90^{\circ}-120^{\circ} \mathrm{C}\right.$. $)$, but above this temperature growth was retarded, the retardation increasing with the temperature to which the soils had been heated.

The water extract of soil heated to $120^{\circ} \mathrm{C}$. was yellow in color, due largely to charred organic material. The color was deeper in extracts of soil which had been heated to still higher temperatures. Both the inorganic and the organic extractions were increased about ninefold by heating soil to $170^{\circ} \mathrm{C}$. for two hours. Soils that were heated until they were unfavorable for the growth of oats were nevertheless very favorable for the growth of Pyronema.

Moist heat produces much the same effect upon soils as dry heat, provided the temperature goes high enough.

By steam heating, the physical, chemical, and physiological properties of soils are more or less altered. The chemical changes consist mainly in an increase in soluble matter in the heated soils. This is partly of an inorganic nature, but the largest increase is in the organic matter rendered soluble. Ammonia may be formed from the reduction of nitrates to nitrites and ammonia, but it is especially formed from the decomposition of organic compounds. Large amounts of nitrogenous matter are made soluble and apparently more available for plant use. Carbon dioxide is also produced in large quantities.

Pfeiffer and Francke ${ }^{1}$ steamed soil at 1 atmosphere pressure for three hours and found a consequent increase in dry weight of plant growth and nitrogen content over the unheated. Deherain and De Moussy ${ }^{2}$ prevented nitrification in soils by heating them at $120^{\circ} \mathrm{C}$. in an autoclare, although the sterilized soil, when inoculated with a portion of the unsterilized soil, produced more nitric nitrogen than the unsterilized soil.

Students of this problem sooner or later find that an improvement due to heating soils is often preceded by a marked injury to plant growth. The heat, although it increases the quantity of watersoluble plant nutrients, seems to produce substances which are poisonous to plants. According to the amount of this poison and the sensitiveness of the plants to it, a positive or a negative acceleration of plant growth is produced. The results appear to vary in different soils. The addition of calcium carbonate to the soil before sterilization prevents, almost if not entirely, the formation of poisonous substances.

${ }^{1}$ Landw. Versuchsst. 46 : 117. 1896.

2 Ann. Agron. 22 : 305. 1896. 
The first to notice this unfarorable effect of soil sterilization was Dietrich, ${ }^{1}$ who concluded that some poison was generated by the action of heat upon the organic matter of the soil. Schulze ${ }^{2}$ found that the immediate effect of heat was injurious to bacteria as well as to the higher plants.

Koch and Lüken ${ }^{3}$ found that the application of heat produced immediate injurious effects in soils, even though fertilizers were applied in each case. The injurious effects were found to be unimportant if the plants were started in summer instead of early spring.

Lyon and Bizzell." who also noted the immediate harmful effect of heat, found that, upon standing, the quantity of soluble matter decreased, especially the tótal soluble nitrogen. The soluble organic and inorganic matter decreased in about the same ratio. The growth of wheat plants on steamed soil seemed to hasten its recorery from the injurious effects of heating. The time required for the various soils to recover from these effects was, with one exception, in the order of their relative productiveness.

The experiment of I'ickering ${ }^{5}$ dealt with the effects of heated soils upon seed germination and upon tree growth. He interpreted his results to mean that the heat produced in the soil a nitrogenous compound which was inhibitory to the germination of seeds. This compound was sufficiently stable in solution for the extract of a heated soil to affect a normal soil when adiled to the latter.

The first suceessful attempt to show the ehemieal nature of the changes in organic matter eaused by heating soils is that of Schreiner and Lathrop. ${ }^{6}$ Heating the soils in the autoclare for three hours at about $135^{\circ} \mathrm{C}$. produced an increase in water-soluble constituents and an increase in acidity. At the same time ammonia and amines were formed. By the process of heating, all the constituents isolated from the unheated soil, except nucleic acid, were increased, and, when not previously existing, xanthine, hypoxanthine, guanine, cytosine, and arginine were formed. These compounds are decomposition products of nucleie acid and protein material, and all are beneficial to plant growth.

1 Jahresber. Landw. Versuchs. Marburg, 1901-1902. Bied. Centralbl. 32 : 6\$. 1903.

2 Jahresber. angew. Bot. 1 : :37. 1!(13. Centralbl. f. Bakt., 2te Abt., 2 : 716. 1:03.

${ }^{3}$ Jour. Landw. 55: 161. 1907.

${ }^{4}$ Bulletin No. 275. Cornell Exp. Sta., 1910.

5 Jour. Agr. Sei. 2 : 411. 190s. Ibid. 3 : 32. 1908.

${ }^{6}$ Bulletin No. 8\%. Bur. of Soils. U. S. Dept. Agr., 1912. 
A substance toxic to plants - dihydroxystearic acid - was also formed by the heating process. If already present in the soil, the quantity of dihydroxystearic acid was increased; it appeared, however, even when lacking in the unheated soil.

Schreiner and Lathrop point out that, although the majority of compounds formed when soils were heated must be classed as beneficial, the harmful compound formed at the same time more than counteracts their effects. If this harmful compound can be eliminated or diminished, the full beneficial effects of heating will become apparent. Such changes in the constitution of harmful substances take place if a heated soil is allowed to stand in contact with the air, and are probably due to oxidation.

Soils may also be sterilized by the use of volatile antiseptics like chloroform and carbon bisulphide. One or two per cent of the liquid antiseptic is usually added to the soil and mixed. After allowing one day for the antiseptic to act, the soil is spread out to allow it to pass off into the air. This method gives only partial sterilization, yet its use is usually followed by a large increment in ammonia and bacterial activity, followed by improvement in plant growth.

There are several theories concerning this beneficial action of volatile antiseptics. Hiltner and Stormer ${ }^{1}$ propose a "Selective" action, through which the equilibrium of microörganic life in the soil is disturbed in such a way that ammonifying and other beneficial bacteria become predominant.

Russell and Hutchinson ${ }^{2}$ hold a somewhat similar view. They believe that the effect of partial sterilization is to kill off the larger phagocytic organisms which devour the beneficial bacteria.

Koch ${ }^{3}$ and his associates believe that the small quantities of antiseptics remaining in the soil exert a stimulating action upon bacteria and green plants alike.

Grieg-Smith ${ }^{4}$ holds that soils, especially poor soils, contain a bacteriotoxine which retards growth, and that the result of partial sterilization with carbon bisulphide or by heat is a destruction of these bacteriotoxines.

The subject of partial sterilization by volatile antiseptics is in need of thorough investigation from the standpoint of the organic chemist.

Methods of sterilizing seed. In order to secure vigorous seedlings, free from all microörganisms, great care must be exercised in sterilizing

1 Jahresber. angew. Bot. 5 : 214. 1907. 3 Centralbl. f. Bakt., 2te Abt., 31 : 185.1911.

2 Jour. Agr. Sci. 3: 111. 1909.

${ }_{4}$ Centralbl.f. Bakt, , 2te Abt., 30 : 15t. 1910. 
the seed. Purely physical sterilization is impossible, because the bacteria are even more resistant than the seed. Chemical agents have been found to give the best results. The ordinary antiseptics, such as alcohol, ether, chloroform, and toluol, have proved unsuitable for this purpose. The substances commonly employed for sterilizing seed are corrosive sublimate, silver nitrate, bichromate of potash, copper sulphate, bromine, and many of the mineral acids. The disinfecting power of these substances depends largely upon four factors - strength of solution, time of action, temperature, and pressure.

The ordinary procedure of soaking the seeds in mercuric chloride solution does not always gire satisfactory results, because of the persistance with which occasional air bubbles remain on or inside the seeds, and thus prevent complete sterilization.

Very good results have been obtained in sterilizing the seeds of corn, wheat, and peas by a modification of the method first described by Hutchinson and Miller, ${ }^{1}$ which consists in sterilizing the seeds in a mercuric chloride solution in vacumm. In the first place, well-dried seeds of even size are necessary. These should be thoroughly washed and cleaned in flowing water and perhaps 50 per cent alcohol before beginning sterilization. Transfer the seeds to a sterile bottle and, after adding mercuric chloride, remove the air bubbles with a vacuum pump. The apparatus for this purpose consists of the following (Fig. 43):

Five stout-walled glass flasks, wide at the mouth (capacity about 500-800 cc.), carrying steam-proof rubber stoppers with two holes in each for glass tubes, which are connected by rubber tubing, as seen in the diagram. Flask $B$ is connected to flask $A$ on one side, and on the other, by means of a three-way tube, to two glass bottles, $C$ and $D$. These, in turn, are connected to flask $E$. Fill flask (' with a 0.25 per cent solution of mercuric chloride, $D$ with distilled water, and $E$, which is smaller than the other flasks, about half full of 50 per cent sulphuric acid. This bottle has a drawnout tube passing down through the cork almost to the bottom and serves to purify the air.

After connecting the whole apparatus, place screw clamps on the rubber tubing between all flasks, in order to prevent the liquid from flowing from one bottle into another; then sterilize in the autoclave at $125^{\circ} \mathrm{C}$. for half an hour, or three times by fractional steam. Cool to $40^{\circ} \mathrm{C}$. and connect flask $A$ to a vacuum pump; place

1.Journal of Agricultural Science 3 : 2, 185. 1908. 
the seeds in flask $B$ by means of a fumnel, to prevent contact between the seeds and the neck of the flask. With the vacuun: pump draw the mercuric chloride from $C$ into $B$; then close with a screw clip and exhaust $B$ until the solution begins to boil. By this means the disinfectant comes into direct contact with and is able to act on all portions of the seeds. Allow sterilization to go on for four to six minutes, then invert $B$ and withdraw, by means of the puinp, the mercuric chloride; after this allow sterilized water to flow from $D$ into $B$, and wash the seeds well two or three times with this water. The seeds may then be transferred to Petri dishes and a sterilized layer of 1.25 per cent solution of beef-peptone agar poured over them, or they may be carried to dextrose-beef bouillon, one seed in each

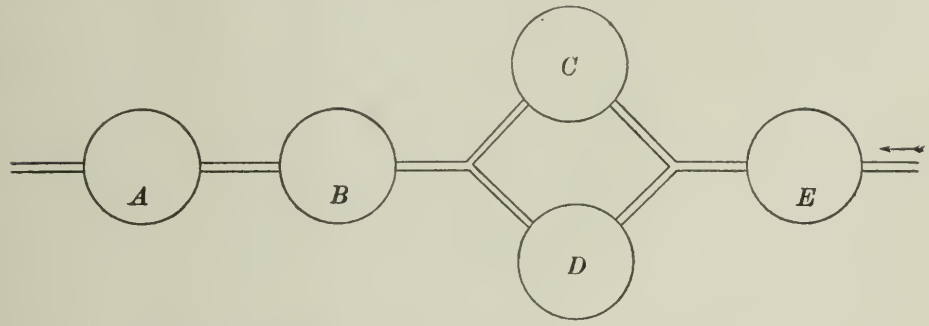

Fig. 43. Arrangement of bottles for seed sterilization

For explanation see text

tube. If the bouillon remains clear until the eighth day when kept in an incubator at $25^{\circ} \mathrm{C}$., it indicates that all bacteria were killed. When agar is used, allow the plates to solidify, invert, and place in incubator at $20^{\circ}-25^{\circ} \mathrm{C}$. At the end of three or four days the majority of the seeds will germinate and form roots $1-1 \frac{1}{2} \mathrm{in}$. long. If these are free from molds and bacteria, they may be carried to sterile wide glass test tubes containing about $10 \mathrm{cc}$. of Tollen's medium or distilled water, over which cotton plugs have been placed. On the cotton plugs the seedlings will grow several inches long, and if no subsequent infection is noted, they may be carried over to culture bottles. There is less danger of infection, however, when the seedlings are carried direct to the culture medium or soil in which they are intended to grow.

Schroeder ${ }^{1}$ recommends a very simple method for sterilizing seed. He found that the seed coats of the Graminex - for example,

1 Centralbl. f. Bakt., '2te Abt., 28 : 492-50.5. 1910. 
barley and wheat - are easily penetrated by such agents as sublimate, iodine, alcohol, ether, chloroform, and acetic acid, while silver nitrate, copper sulphate, sodium fluoride, and barium chloride penetrate very slowly. Taking these results as a basis, he recommends the following method for the sterilization of seed :

Wash the seeds thoroughly and allow them to soak for twelve to twenty-four hours in a 5 per cent solution of silver nitrate. Follow this with four washings in sodium-chloride water and then allow the seeds to stand for twenty-four hours in a dilute solution of sodium chloride. After this, drop the seeds into sterile bouillon and test them for the presence of molds and bacteria as described above.

In sterilizing corn Schulow reports good results from the use of 1 per cent bromine solution for twenty minutes.

Methods for growing higher plants under sterile conditions. In order to grow plants in a medium free from infection, ressels of careful construction are necessary. The weak point with nearly all pots built for this purpose is the method of watering and of packing cotton around the stem of the plant. Because of the long time required for plant growth there is always danger of infecting the culture medium if cotton is wrapped around the stem of the plant. To guard against this it is well to conduct this experiment in a clean room, as free as possible from all outside contamination. A large variety of vessels have been recommended, but many of them are so complicated as to be of little practical values Most of them are prepared either from metal or from glass; the latter have given the hest results. Vessels of metal - for example, the schulze ${ }^{1}$ pot - have many disadvantages: first, it is almost impossible to regulate the water supply; second, in sterilization there is danger of the metal's forming compounds poisonous to plant growth.

Schulow ${ }^{2}$ claims to have grown corn plants free from all infection in glass cylinders thoroughly packed with absorbent cotton.

The culture vessel (Fig. 44,1) is a Woulff's flask with three openings. The ressel used for water is a 2 - or 3 -liter flask of Jena glass (Fig. 44, 2) which carries a stopper with two openings. All stoppers and connecting tubes must be made out of the best Para rubber. The entire apparatus is made from glass and is much easier to prepare than the Schulze metal pot. The large Woulff flask should hold about 3-4 liters and should be made from a good quality of glass.

${ }^{1}$ Landw. Jahrbïcher $30: 219.1906$.

2 Bericht. d. Deutsch. Bot. Gesell. 29 : 504. 1911. 
$U$ tubes, $A$ and $A^{\prime}$, filled with sulphuric acid, are used to purify the air. $B$ is a long, hard-glass tube enlarged at one end for sterile cotton and stopper. $A$ and $B$ are for use in the aëration of the soil (if liquid culture media are used, these may be omitted). Tubes I), E, and $A$ serve for watering; the sterile air is passed through $A$, and $E$ then carries the water in flask 2 over into culture vessel 1 .

The large opening, $C$, in flask 1 carries a cylinder constructed as shown by Fig. 45 .

A wire net is fastened to the sides of $C^{\prime}$ and passes down to the soil in flask 1 . An outer glass cylinder $4-5 \mathrm{~cm}$. in diameter and

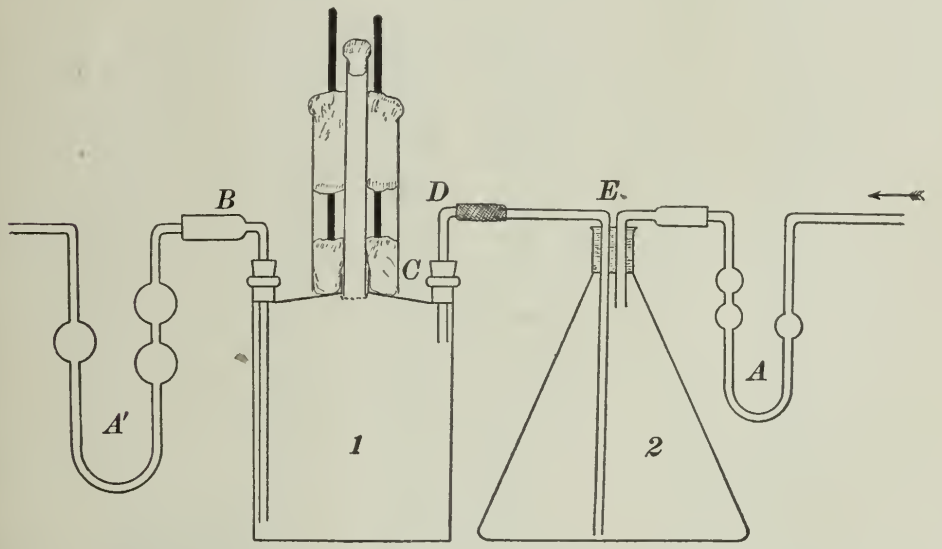

FIG. 44. Complete apparatus for growing seedlings under sterile conditions. (After Fred)

1, Woulff flask containing soil ; 2, Erlenmeyer flask containing sterile distilled water

$15 \mathrm{~cm}$. in length fits very loosely around $C$, in order to allow space for cotton between $C$ and the cylinder. Within $C$ there is an inner tube, about $1 \frac{1}{4}-1 \frac{1}{2} \mathrm{~cm}$. in diameter and $20 \mathrm{~cm}$. long, which reaches to the wire net (see Fig. 45). In the top of this tube there is a cotton plug. Between these two tubes cotton packing and three glass rods about $0.4 \mathrm{~cm}$. in diameter and $15 \mathrm{~cm}$. long are placed. The cotton must be packed loosely, with one open space, as seen in Fig. 45, 1.

If soil is to be used, cover the bottom of flask 1 (Fig. 44) with gravel, and fill this vessel with soil. Raise the water content of the soil to 15 or 20 per cent, according to the type of soil. Now join flask 2, which has been previously filled with distilled water. Fasten a screw clip between $D$ and $E$, in order to prevent the water in 
flask 2 from flowing over into flask 1 while sterilization is going on. Wrap flask 1 with paper and place the entire apparatus, including cylinders for seed, in the autoclave and sterilize for two hours
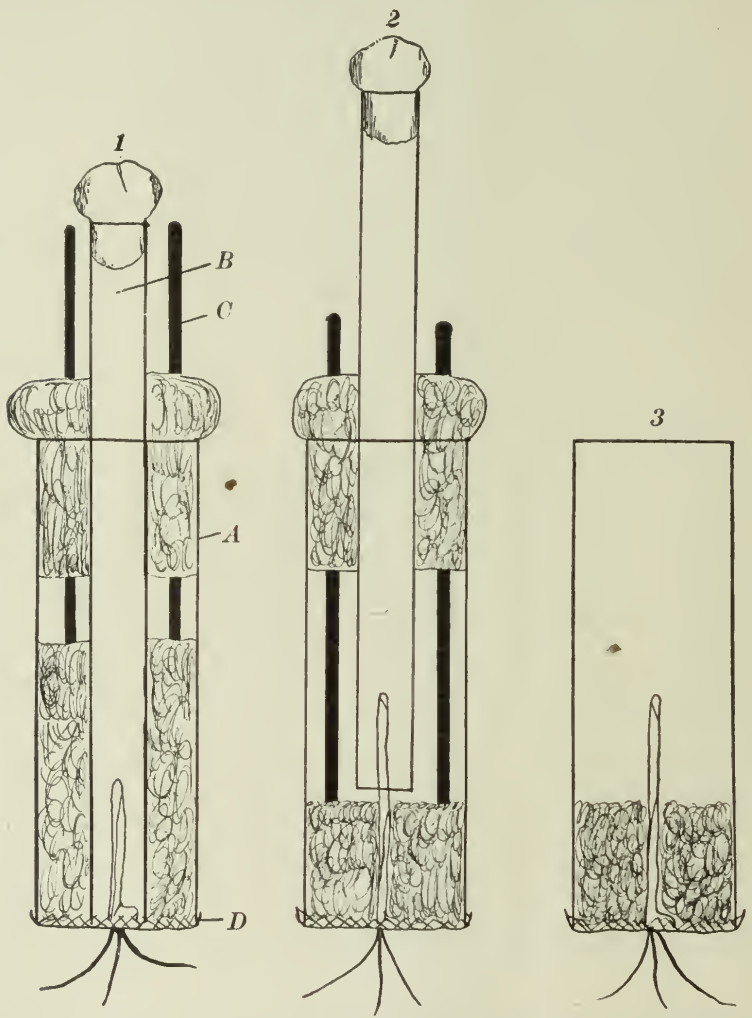

Fig. 45. Apparatus for growing seedlings under sterile conditions (After Schulow)

$A$, glass cylinder; $B$, glass tube $1 \mathrm{~cm}$. in diameter; $C$, glass rods ; $D$, wire net; 1 , arrangement at start; 2, arrangement after three to four days; 3 , arrangement after six to eight days

at 2 atmospheres steam pressure. After the vessel is cool, seal all stoppers with a wax prepared by melting together equal weights of beeswax and rosin.

The apparatus is now ready for planting. In order to do this under conditions as free as possible from all infection, carry the pots to inoculation room or to some place where the air is quiet and free 
from dust. Remove the cotton plug from the top of the inner glass tube (Fig. 45, B) and, using sterilized forceps, transfer the seeds germinated under sterile conditions to the apparatus, allowing them to drop down the inner tube on to the wire netting (Fig. 45, D).

When the young shoot appears after six to eight days, the inner tube $B$ should be slightly raised and the rods $C, C$ used to push the lower mass of cotton gently but firmly around the base of the shoot. as shown in Fig. 45, 2. Finally the tube $B$, rods $C, C$, and the upper mass of cotton are removed, leaving the seedling as shown in Fig. $45,3$. 


\section{APPENDIX B}

\section{HANDLING STOCK CULTURES}

Those in charge of a bacteriological laboratory will have need of stock cultures of the organisms commonly used. These cultures may be obtained from isolations made at the laboratory or may be obtained from other laboratories. In America bacteriologists obtain many of their cultures from fellow bacteriologists and also from such institutions as the laboratory of the American Museum of Natural History, and the firm of Parke, Daris and Co. of Detroit. In Europe Kral's laboratory in Prag is a convenient and prompt source of supply.

It should always be remembered that mistakes sometimes occur, and that contaminations are liable in transit. Therefore a culture received from another source should be cultivated for a time on media which will demonstrate its critical characters, before it finds its place in the collection of stock cultures.

The standard beef-peptone agar appears to be best suited for stock cultures of most organisms. It is put into rather large test tubes 18 by $175 \mathrm{~mm}$., which are (arefully plugged with deep plugs and slanted after sterilization.

After inoculation the tubes should be kept in a cool, dry place where there is not much fluctuation of temperature. A special room should be constructed where possible. It should not be built against an outside wall and should be entered by one tightly closing door. The room should contain plain cupboards which can easily be cleaned and are closed by tightly fitting doors. The cupboard shelves should be far enough apart so that the cotton plugs will not rub the shelf above as they are removed from the cupboard.

Transfers to newly prepared sterile tubes of media should be made every six or eight weeks. The length of time that a culture retains its vitality depends largely upon the temperature at which it is kept. If it is kept between $10^{\circ}$ and $15^{\circ} \mathrm{C}$., transfers once in ten to twelve weeks may suffice.

The old cultures should in every case be kept until one is certain that the transfer has grown and is pure. If contaminations appear, one may go back to the old culture and pour plates in order to reisolate pure cultures. 


\section{APPENDIX C}

\section{MAKING PERMANENT PREPARATIONS}

A supply of demonstration material is very useful for class instruction and for general publicity work. If colonies of organisms in pure culture are desired, there is nothing better than the Soyka flask. The medium, when hard, can be inoculated with a needle at the center and will produce a good colony. After growth begins and the agar has dried somewhat, the cotton plug can be burned off and the mouth of the flask sealed with red sealing wax. The flask may then be mounted in one of the special holders in which there is displayed a microphotograph or authentic drawing of individual bacteria of the species exhibited. Specimens prepared in this way will stand much rough handling and will endure for several years.

The Soyka-flask method is chiefly useful for pure-culture colonies or when work can be planned in advance. Teachers are well aware of the fact that many instructive examples arise in the progress of the daily work, and that such specimens are extremely valuable if properly preserved. A method is therefore desirable which will allow the preservation of cultures in test tubes and Petri dishes. Hastings ${ }^{1}$ has described a very satisfactory method in which glycerin agar is used. The method consists in pouring over the surface of the plates to be preserved some glycerin agar, which is prepared by mixing equal quantities of 2 per cent agar and glycerin. In preparing the glycerin agar the ordinary thread agar should be washed in tap water for two or three days. A 2 per cent solution of the washed agar in distilled water is made and carefully filtered through paper. An equal volume of glycerin is added to this solution. No sterilization is necessary, because the medium is dense enough to prevent the growth of bacteria and molds.

When one wishes to preserve an ordinary plate culture containing an agar medium, a small quantity of glycerin agar is melted, cooled to about $45^{\circ} \mathrm{C}$, and carefully poured over the surface of the plate culture. The glycerin agar solidifies and forms a firm protective layer over the surface of the plate. The larger part of the water will evaporate, but the glycerin, being hygroscopic, holds enough to 
prevent shrinking of the medium. The colonies preserve their original form and appearance. The dishes can be cleaned in the ordinary way when their usefulness is over.

Gelatin plates can be preserved by this method if they are first subjected to the vapor of formaldehyde to harden the gelatin and to destroy the enzymes which cause liquefication.

Another method for preserving Petri-dish cultures is by use of a sealing mixture. When the agar has become somewhat dried, invert the dish and pour melted paraffin into the crevice between the dish and the margin of the lid. 


\section{APPENDIX D}

\section{THE INOCULATING CHAMBER}

In every laboratory where much careful work is to be done an inoculating chamber is necessary. This is usually a closet large enough for a person to enter, although chambers are also made into which the operator thrusts only his arms. The closet type (Fig. 19) is usually preferred. It is 4 or $5 \mathrm{ft}$. square and at least $7 \mathrm{ft}$. high. One or two windows should be provided, to give plenty of light. The door should fit tightly and be provided with a spring which will keep it closed. The interior of the closet should be lined with some material which can be easily cleansed with a damp cloth; linoleum serves the purpose well. Near the top of the closet the wall should have an opening for ventilation. A hole 15 in. square may be fitted with a frame which is covered with a fine wire screen and one or two thicknesses of cheesecloth or a thin layer of absorbent cotton. This filtering layer of cloth or cotton should be renewed frequently, as it becomes filled with dust.

Before making inoculations in the closet, the walls, floor, ceiling, and shelf should be wiped with a cloth wrung out of $1: 1000$ solution of mercuric bicloride solution (for method of preparation see Exercise 132), or 3 per cent formalin.

The inoculating closet is not a good place to store stock cultures. The only shelf it should contain is the work shelf, on which there should be a gas burner for sterilizing the inoculating needles. 


\section{APPENDIX E}

\section{THE TITRATION OF BOUILLON}

After cooking the ingredients, the amount of water lost by evaporation should be restored. Stir for a moment, then pipette out $5 \mathrm{cc}$. into a porcelain evaporating dish. Add $20 \mathrm{ce}$. distilled water and boil over a flame for three minutes. Add a few drops of phenolphthalein.

Fill a burette with a one-twentieth normal sodium hydrate solution and place the porcelain dish beneath the pincheock of the burette. Run in the alkaline solution, stirring the bouillon with a glass rod, until a permanent, faint pink color is obtained. Read off the amount of alkali used. Titrate two other $\tilde{5}$-ce. samples in the same way. If the amounts of alkali used for each of the three samples are reasonably close together, average them and record this figure as the amount of $\mathrm{N} / 20$ alkali necessary to neutralize 5 cc. of bouillon. Compute the amount necessary to neutralize the bouillon remaining in the flask.

The balance of the bouillon is then to be neutralized, but the addition of so much weak alkali would dilute the bouillon too much ; therefore it is better to use a normal solution of sodium hydrate, of which only one twentieth of the original computation is necessary.

Test the accuracy of the work by pipetting out a small sample and adding a drop or two of phenolphthalein. If a faint pink color does not appear, the titration should be repeated.

For most bacteriological work it is best to have the medium definitely acid. This condition is obtained by adding a definite volume of normal hydrochloric acid, usually $0.5,1.0$, or $1.5 \mathrm{cc}$. per liter of medium. This is expressed as $+0.5,+1.0$, or +1.5 .

The reaction of the medium is usually expressed as plus or minus. A reaction expressed as +1 means that $1 \mathrm{cc}$. of normal alkali must be added to a liter of the culture medium in order to make it exactly neutral to phenolphthalein. In the same way, reaction expressed as -1 means that $1 \mathrm{cc}$. of normal acid must be added to bring 1 liter to the neutral point. It is essentia' that phenolphthalein be used as the indicator for this titration.

$A$ reaction of +1.0 is used for work in water and soil bacteriology ; +0.5 is better for many pathogenic organisms. 


\section{APPENDIX F}

\section{DETERMINATION OF AMMONIA}

For most bacteriological work with soils the ammonia is best determined after distillation with magnesium oxide. The analytical material is placed in a Kjeldahl or other flask suitable for distilling. Magnesium oxide is added to liberate the ammonia, and some shavings of paraffin to prevent frothing. The distilling flask is connected with a suitable condenser, the lower end of which dips into a measured amount of deci-normal acid in an Erlenmeyer flask.

Distillation is continued for a period varying with the amount of ammonia present, usually until $50 \mathrm{cc}$. or more of distillate has been collected. A few drops of methylrot or of cochineal are adderl, and the distillate is titrated with deci-normal alkali. The difference between the amount of alkali required to bring the solution to neutrality and the amount of acid taken represents the amount of ammonia distilled over. This difference multiplied by .0017 gives the grams of $\mathrm{NH}_{3}$ obtained.

If the amount of ammonia is small, it is better to use the wellknown Nessler reaction, as used in water analysis. The solutions for analysis must, however, be clear and colorless. Nessler's reagent is an alkaline solution of mercuric potassium iodide. The alkali of the reagent liberates the ammonia from its salts; if the concentration of the latter is considerable, a precipitate is formed, but if dilute, the compound remains in solution, giving a yellow color. The intensity of the color thus produced is proportional to the amount of ammonia present and is compared with that of a dilute standard ammonium chloride solution similarly treated. The substituted ammonias give a similar precipitate and color with this reagent, and in some lines of work it might be necessary to take this fact into consideration.

\section{REAGENTS REQUIRED ${ }^{1}$}

1. Ammonia-free water. This may be prepared by redistilling the water of the laboratory after acidifying slightly with sulphuric acid. For colorimetric purposes it may be quickly prepared by adding

1 Adapted from Schreiner and Failyer, Bulletin No. 31, Bureau of Soils, U.S. Dept. Agr., 1906. 
sodium carbonate to ordinary distilled water until slightly alkaline, and boiling until about one fourth has evaporated. The residual water is ready for use when cool. Ammonia-free water is used in the preparation of the following reagents and wherever the contamination with ammonia would influence the result.

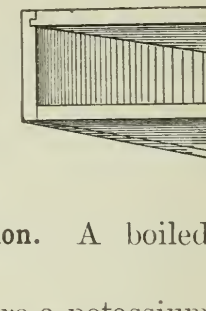

3. Nessler's reagent. Prepare a potassium iodide solution by dissolving $35 \mathrm{~g}$. in 100 ('c. of water, and a mercuric chloride solution by dissolving $17 \mathrm{~g}$. in $300 \mathrm{ce}$. of water. Heat may be applied, to hasten the solution of the mercuric chloride, but the liquid must be cooled before it is userl. The mercuric chloride solution is added to the potassium iodide solution until the precipitate of red mercuric iodide ceases to redissolve. The solution is then diluted to 1 liter with a 20 per cent solution of sodium hydroxide. Then add more of the mercuric chloride solution until a slight permanent precipitate again forms. Allow this to settle, keeping it in a well-stoppered bottle and drawing off small quantities into another bottle from time to time as required for the tests. The reagent should have a light yellow color; if colorless, more mercuric chloride must be added. Its sensitiveness should be tested from time to time with a very dilute solution of ammonium chloride.

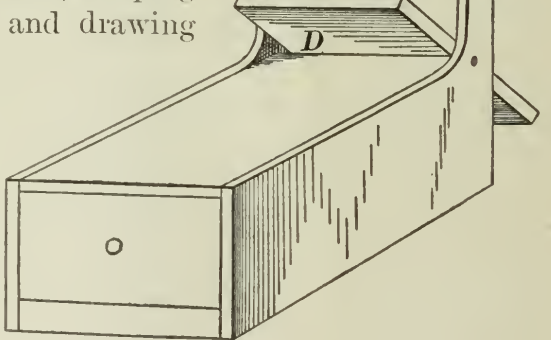

FIg. 46. The Schreiner Colorimeter $A, A$, immersion tubes ; $B$, graduated tubes; $C$, clamps; $D$, reflector; $E$, mirror

4. Standard ammonium chloride solution. 1)issolve $0.7405 \mathrm{~g}$. of pure ammonium chloride in ammonia-free water and dilute to 1 liter. Dilute $10 \mathrm{ce}$. of this stronger solution to $500 \mathrm{ce}$. This 
constitutes the standard ammonium chloride solution, and each cubic centimeter contains $0.005 \mathrm{mg}$. of $\mathrm{NH}_{4}$.

5. Standard colorimetric solution. This may be prepared by diluting $10 \mathrm{cc}$. of the standard ammonium chloride solution (4) to about 90 cc., adding 4 cc. of Nessler's reagent (3) and diluting to $100 \mathrm{cc}$. This standard should be prepared simultaneously with the development of the color in the solutions to be tested. This colorimetric standard contains 0.5 part of $\mathrm{NH}_{4}$ per million.

\section{ANALYTICAL PROCESS}

If the solution be colorless and free from salts which interfere with the reagents, the determinations can be made without previous distillation; otherwise it will be necessary to distill a measured quantity of the solution after it has been made alkaline with sodium carbonate. The flask and condenser should be rinsed with ammoniafree water. The condenser must be kept quite cold, with the end dipping into a little ammonia-free water at the start. The distillate is made up to a definite volume. The distillation has the advantage of concentrating the ammonia in the case of very weak solutions.

First test a small amount of the solution, to ascertain the dilution necessary to get a good color for comparison. This may be done by adding some of the Nessler reagent (3) to a few cubic centimeters of the solution in a test tube. If a precipitate forms, it will be necessary to dilute the solution and again test a small sample. The color of the solution should be a light shade of pure yellow. If it has a deep yellow or reddish tint, it is too strong to be used direct, and further dilution is necessary.

For the determination of the ammonia the analytical solution is diluted to about 45 cc., 2 ce. of Nessler's reagent (3) is added, and sufficient water is added to make $50 \mathrm{cc}$. The standard colorimetric solution is prepared at the same time, and after fifteen minutes the comparison is made in the colorimeter or in Nessler tubes. 


\section{APPENDIX G}

\section{DETERMINATION OF NITRATE}

The nitrates, if present in small quantities, are best determined by means of the color produced by the action of phenoldisulphonic acid and making alkaline with ammonia.

Chlorides, when present in considerable quantities, interfere quite markedly with the determination of nitrates and must be previously removed. This is best accomplished by means of silver sulphate free from nitrates. This can be added in the solid form, thus avoiding dilution of the original solution.

\section{REAGENTS REQLIRED}

1. Phenoldisulphonic acid reagent. This is prepared by mixing $30 \mathrm{~g}$. of pure crystallized phenol with $37 \mathrm{~g}$. (20.1 cc.) of concentrated sulphuric acid (sp. gr. 1.84) and heating for six hours at $100^{\circ} \mathrm{C}$. by setting the lightly stoppered flask in boiling water.

The acid thus prepared may crystallize out on standing, especially during the cold season. It may be brought into solution by heat, but the addition of water to affect solution is to be avoided.

2. Ammonium hydroxide. Dilute strong ammonium hydroxide solution (sp. gr. 0.9) with an equal volume of water.

3. Standard nitrate solution. Dissolve $0.1631 \mathrm{~g}$. of pure, dry potassium nitrate in water and make up to 1 liter. Of this stronger solution 100 cc. are diluted to 1 liter. This constitutes the standard nitrate solution and contains 0.01 of a milligram of $\mathrm{NO}_{3}$ in each cubic centimeter.

4. Standard colorimetric solution. Evaporate $10 \mathrm{cc}$. of the standard nitrate solution (3) to dryness in a porcelain dish on a water or steam bath and treat as described under Analytical Process below, finally diluting the solution to $100 \mathrm{cc}$. This standard colorimetric solution has the strength of one part of $\mathrm{NO}_{3}$ per million.

${ }^{1}$ Adapted from Schreiner and Failyer, Bulletin No. 31, Bureau of Soils, U.S. Dept. Agr., 1906. 


\section{ANALYTICAL PROCESS}

Evaporate 50 cc. or other convenient quantity, depending upon the amount of nitrate present, to dryness in a porcelain dish on a water bath, removing the dish as soon as it is completely dry. Arld 1 ce. of the phenoldisulphonic acid reagent (1) and stir thoroughly with the rounded end of a glass rod so as to loosen the residue and bring the acid well in contact with every portion of it. The time of action on the nitrate should be about ten minutes. At the end of this time the acid is diluted with about $15 \mathrm{cc}$. of water and made alkaline with ammonium hydroxide (2), a yellow color being developed when the solution becomes alkaline. This is then diluted to $50 \mathrm{cc}$. or $100 \mathrm{cc}$. and compared in the colorimeter with the standard colorimetric solution (4). If the color is too intense for direct comparison with this standard, an aliquot portion mar be taken and diluted to definite volume and the strength of this determined. 


\section{APPENDIX H}

\section{DETERMINATION OF NITRITE}

The nitrite is best determined by means of Ilosvay's modification of Griess's test, which has the advantage that the color is more rapidly developed and the reagents are less liable to change. The red color produced is due to the action of the liberated nitrous acid on the sulphanilic acid, the resulting diazo-compound being in turn converted by the naphthylamine into azo-amidonaphthalenebenzenesulphonic acid.

\section{REAGENTS REQUIRED}

1. Sulphanilic acid solution. Dissolve $0.5 \mathrm{~g}$. of pure sulphanilic acid in 150 ce. of dilute acetic acid (sp. gri. 1.04).

2. Naphthylamine acetate solution. Boil $0.1 \mathrm{~g}$. of $\alpha$-naplithylamine in 20 ce. of water and strain through a well-washed plug of absorbent cotton into 180 ce. of acetic acid (sp. gr. 1.04).

3. Nitrite reagent. Mix equal volumes of the sulphanilic acid solution (1) and the naphthylamine acetate solution (2). This reagent is prepared in small quantities from time to time. If a reddish tint is developed on mixing the solutions, it indicates the presence of nitrites. In this case the reagent is treated with zinc dust, which destroys the color, and after removing the excess of zinc, it is ready for use.

4. Standard sodium nitrite solution. I issolve $0.0836 \mathrm{~g}$. of pure silver nitrite in water. Add a solution of pure sodium chloride until silver chloride ceases to be precipitated. The volume is then made up to 250 cc. and, after thorough shaking, allowed to stand in the dark until the precipitate has completely settled. Dilute 10 ce. of the supernatant liquid to 100 ce. with nitrite-free water. This standard must be kept in a well-stoppered bottle in the dark. Each cubic centimeter of this standard solution contains $0.01 \mathrm{mg}$. of $\mathrm{NO}_{2}$. The pure silver nitrite is prepared by adding to a hot concentrated solution of sixteen parts of silver nitrate a hot concentrated solution of ten parts of potassium nitrite. Allow to cool, and separate the mother 
liquor by filtration with a filter pump. The silver nitrite is redissolved in the smallest possible quantity of hot water, allowed to cool, and the crystal mass again separated by means of suction. The crystals are then quickly dried in a water bath and preserved in a tightly stoppered bottle in the dark.

5. Standard colorimetric solution. This may be prepared by diluting $10 \mathrm{cc}$. of the above standard sodium nitrite solution (4) to about $80 \mathrm{cc.}$, adding $16 \mathrm{cc}$. of the nitrite reagent (3) and making up to 100 cc. It must be prepared at the same time as the test solutions. This colorimetric standard has the strength of one part $\mathrm{NO}_{2}$ per million, and solutions of other strengths may be similarly prepared when necessary, using the same quantity of reagent.

\section{ANALYTICAL PROCESS}

Dilute a measured volume of the solution, if necessary, to about 40 cc., add 8 cc. of the nitrite reagent (3), and dilute to 50 cc. Develop the color of the standard solution at the same time. Allow the solutions to stand fifteen minutes and then determine their relative strengths in the colorimeter or by direct comparison by any of the other colorimetric procedures. 


\section{APPENDIX I \\ DETERMINATION OF NITRITES BY TROMMSDORF'S METHOD \\ This method has certain advantages, although it is not strictly quantitative. Some organic compounds interfere with the test.}

\section{REAGENTS REQUIRED}

1. Starch-iodide solution. Triturate $4 \mathrm{~g}$. of starch with $150 \mathrm{cc}$. of water in a porcelain mortar. Cook the starch water in a steam sterilizer or on a water bath. Dissolve $20 \mathrm{~g}$. of zinc chloride in $100 \mathrm{cc}$. of water and add to the boiling starch paste. Remove from the steam bath and allow the solution to stand until it becomes clear. Add $2 \mathrm{~g}$. of zinc iodide and dilute the solution to 1 liter. Filter. Keep in a glass-stoppered bottle in the dark.

\section{ANALYTICAL PROCESS}

Take 100 cc. of the solution to be analyzed, 3 cc. of the starch-iodide solution, and $1 \mathrm{cc}$. of dilute $(1: 3)$ sulphuric acid. After a few minutes a blue color appears. Develop the color at the same time in the standard nitrite solution as used for the Griess-Ilosvay method (see above). 


\section{APPENDIX J}

\section{DETERMINATION OF TOTAL NITROGEN BY A MODIFICATION OF KJELDAHL'S METHOD, TO INCLUDE THE NITROGEN OF NITRATES}

This method in some form is used by most chemists for the determination of the total nitrogen, and is useful in many ways in bacteriological work.

\section{REAGENTS REQUIRED}

1. Standard hydrochloric acid solution. For careful work the absolute strength of the solution may be determined by precipitation with silver nitrate and by weighing the silver chloride.

2. Standard sulphuric acid solution. For ordinary work half-normal acid is used, but for work where small amounts of nitrogen are involved, decinormal acid is better.

3. Sulphuric acid. This should be the strong acid, sp. g. 1.84, and should be free from nitrates and ammonium sulphate.

4. Zinc dust. This should be an impalpable powder. Granulated zinc or zinc filings will not answer.

5. Sodium thiosulphate.

6. Commercial salicylic acid.

7. Metallic mercury or mercuric oxide. If mercuric oxide is used it should be prepared in the wet way, but not from mercuric nitrate.

8. Potassium permanganate. This is used as a fine powder.

9. Granulated zinc or pumice stone. One of these substances should be added to the contents of the distillation flasks to prevent bumping.

10. Potassium sulphide solution. A 4 per cent solution of commercial potassium sulphide.

11. Sodium hydroxide solution. A saturated solution of sodium hydroxide free from nitrates.

12. An indicator. A solution of cochineal prepared by digesting and frequently agitating $3 \mathrm{~g}$. of pulverized cochineal in a mixture of $50 \mathrm{cc}$. of strong alcohol and $200 \mathrm{cc}$. of distilled water for a day or two at room temperature. The filtered solution is employed as an indicator. 


\section{APPARATUS REQUIRED}

1. Kjeldahl flasks for both digestion and distillation. These are flasks having a capacity of about 550 cc., made of hard, moderately thick, and well-annealed glass. When used for the distillation, the flasks are fitted with rubber stoppers and bulb tubes, as described under distillation flasks.

2. Kjeldahl digestion flasks. These are pear-shape, round-bottom flasks, made of hard, moderately thick, well-annealed glass and having a total capacity of about $250 \mathrm{cc}$. They are $22 \mathrm{~cm}$. long and have a maximum diameter of $6 \mathrm{~cm}$., tapering gradually to a long neck, which is $2 \mathrm{~cm}$. in diameter at the narrowest part and flared a little at the edge.

3. Distillation flasks. For distillation a flask, of ordinary shape, of about 550 cc. capacity may be used. It is fitted with a rubber stopper carrying a bulb tube to prevent the possibility of sodium hydrate being carried over mechanically during distillation. The bulbs may be about $3 \mathrm{~cm}$. in diameter, but the tubes are the same diameter as the condenser, with which they are comnected by a rubber tube.

\section{ANALYTICAL PROCESS}

Place from $0.7 \mathrm{~g}$. to $3.5 \mathrm{~g}$. of the substance to be analyzed in a Kjeldahl digestion flask; if soils are being analyzed, a 10-15 g. sample is necessary. Add 30 ce. of sulphuric acid containing $1 \mathrm{~g}$. of salicylic acid and shake until thoroughly mixed; then add 5 g. of crystallized sodium thiosulphate; or add to the substance $30 \mathrm{cc}$. of sulphuric acid containing $2 \mathrm{~g}$. of salicylic acid, then add gradually $2 \mathrm{~g}$. of zine dust, shaking the contents of the flask at the same time. Finally, place the flask on the stand for holding the digestion flasks, where it is heated over a low flame until all danger from frothing has passed. The heat is then raised until the acid boils briskly, and the boiling continued until white fumes no longer escape from the flask. This requires about five or ten minutes. Add approximately $0.7 \mathrm{~g}$. of mercuric oxide, or its equivalent in metallic mercury, and continue the boiling until the liquid in the flask is colorless or nearly so. In case the contents of the flask are likely to become solid before this point is reached, add $10 \mathrm{cc}$. more of sulphuric acid. Complete the oxidation by adding small amounts of potassium permanganate until, after shaking, the liquid has a permanent green or purple color. 
After cooling, dilute with about 200 cc. of water, add a few pieces of granulated zinc or pumice stone, if necessary in order to keep the contents of the flask from bumping, and add $25 \mathrm{cc}$. of potassium sulphide solution with shaking. Next add $50 \mathrm{cc}$. of the soda solution, or sufficient to make the reaction strongly alkaline, pouring it down the side of the flask so that it does not mix at once with the acid solution. Connect the flask with the condenser, mix the contents by shaking, and distill until all ammonia has passed over into the standard acid. The tip of the condenser should dip into a 300-ce. Erlenmeyer flask containing 20-40 cc. of standard acid and enough distilled water to make a depth of $1-2 \mathrm{~cm}$. The first $150 \mathrm{cc}$. of the distillate will generally contain all the ammonia. This operation usually requires from forty minutes to one hour and a half. The distillate is then titrated with standard alkali, using cochineal as the indicator. Each cubic centimeter of decinormal ammonia is equivalent to $1.4 \mathrm{mg}$. of nitrogen. 


\section{APPENDIX K \\ DETERMINATION OF REDUCING SUGARS}

\section{REAGENTS REQUIRED}

1. Copper sulphate solution. Dissolve $34.639 \mathrm{~g}$. of crystallized copper sulphate in water and dilute to $500 \mathrm{cc}$.

2. Alkaline tartrate solution. Dissolve $173 \mathrm{~g}$. of Rochelle salts and $125 \mathrm{~g}$. of potassium hydroxide in water and dilute to $500 \mathrm{ce}$.

\section{GRAVIMETRIC METHOD FOR THE DETERMINATION OF DEXTROSE (ALLIHN)}

Place $30 \mathrm{cc}$. of the copper solution, $30 \mathrm{cc}$. of the alkaline tartrate solution, and $60 \mathrm{cc}$. of water in a beaker and heat to boiling. Add $25 \mathrm{cc}$. of the solution of the material to be examined (which must be so prepared as not to contain more than $0.250 \mathrm{~g}$. of dextrose) and boil for two minutes.

Prepare an asbestos felt at least half a centimeter thick in the bottom of a Gooch crucible. Wash the asbestos thoroughly with water to remove small particles, then with $10 \mathrm{cc}$. of alcohol and $10 \mathrm{cc}$. of ether. Dry the crueible and contents thirty minutes in a water oven at the temperature of boiling water; cool and weigh.

Filter the precipitated cuprous oxide through the asbestos felt and wash thoroughly with hot water, then with $10 \mathrm{ce}$. of alcohol and finally with $10 \mathrm{cc}$. of ether. Dry the crucible and contents thirty minutes in a water oven at the temperature of boiling water; cool and weigh.

The weight of cuprous oxide multiplied by 0.8883 gives the weight of metallic copper. From either figure the corresponding weight of dextrose is found from the following table: 
ALLIHN'S TABLE FOR THE DETERMINATION OF DEXTROSE

\begin{tabular}{|c|c|c|c|c|c|c|c|c|c|c|c|}
\hline $\begin{array}{l}\text { Milli- } \\
\text { grams } \\
\text { of cop- } \\
\text { per }\end{array}$ & $\begin{array}{c}\text { Milli- } \\
\text { grams of } \\
\text { cuprous } \\
\text { oxide }\end{array}$ & $\begin{array}{c}\text { Milli- } \\
\text { grams } \\
\text { of dex- } \\
\text { trose }\end{array}$ & $\begin{array}{c}\text { Milli- } \\
\text { grams } \\
\text { of cop- } \\
\text { per }\end{array}$ & $\begin{array}{c}\text { Milli- } \\
\text { grams of } \\
\text { cuprous } \\
\text { oxide }\end{array}$ & $\begin{array}{c}\text { Milli- } \\
\text { grams } \\
\text { of dex- } \\
\text { trose }\end{array}$ & $\begin{array}{c}\text { Milli- } \\
\text { grams } \\
\text { of cop- } \\
\text { per }\end{array}$ & $\begin{array}{l}\text { Milli- } \\
\text { grams of } \\
\text { cuprous } \\
\text { oxide }\end{array}$ & $\begin{array}{l}\text { Milli- } \\
\text { grams } \\
\text { of dex- } \\
\text { trose }\end{array}$ & $\begin{array}{c}\text { Milli- } \\
\text { grams } \\
\text { of cop- } \\
\text { per }\end{array}$ & $\begin{array}{c}\text { Milli- } \\
\text { grams of } \\
\text { cuprous } \\
\text { oxide }\end{array}$ & $\begin{array}{l}\text { Milli- } \\
\text { grams } \\
\text { of dex- } \\
\text { trose }\end{array}$ \\
\hline 11 & 12.4 & 6.6 & 51 & 57.4 & 26.4 & 91 & 102.4 & 46.4 & 131 & 147.5 & 66.7 \\
\hline 12 & 13.5 & 7.1 & 52 & 58.5 & 26.9 & 92 & 103.6 & 46.9 & 132 & 148.6 & 67.2 \\
\hline 13 & 14.6 & 7.6 & 53 & 59.7 & 27.4 & 93 & 104.7 & 47.4 & 133 & 149.7 & 67.7 \\
\hline 14 & 15.8 & 8.1 & 54 & 60.8 & 27.9 & 94 & 105.8 & 47.9 & 134 & 150.9 & 68.2 \\
\hline 15 & 16.9 & 8.6 & 55 & 61.9 & 28.4 & 95 & 107.0 & 48.4 & 135 & 152.0 & 68.8 \\
\hline 16 & 18.0 & 9.0 & 56 & 63.0 & 28.8 & 96 & 108.1 & 48.9 & 136 & 153.1 & 69.3 \\
\hline 17 & 19.1 & 9.5 & 57 & 64.2 & 29.3 & 97 & 109.2 & 49.4 & 137 & 154.2 & 69.8 \\
\hline 18 & 20.3 & 10.0 & 58 & 65.3 & 29.8 & 98 & 110.3 & 49.9 & 138 & 155.4 & 70.3 \\
\hline 19 & 21.4 & 10.5 & 59 & 66.4 & 30.3 & 99 & 111.5 & 50.4 & 139 & 156.5 & 70.8 \\
\hline 20 & 22.5 & 11.0 & 60 & 67.6 & 30.8 & 100 & 112.6 & 50.9 & 140 & 157.6 & 71.3 \\
\hline 21 & 23.6 & 11.5 & 61 & 68.7 & 31.3 & 101 & & 51.4 & 141 & & 71.8 \\
\hline 22 & 24.8 & 12.0 & 62 & 69.8 & 31.8 & 102 & 114.8 & 51.9 & 142 & 159.9 & 72.3 \\
\hline 23 & 25.9 . & 12.5 & 63 & 70.9 & 32.3 & 103 & 116.0 & 52.4 & 143 & 161.0 & 72.9 \\
\hline 24 & 27.0 & 13.0 & 64 & 72.1 & 32.8 & 104 & 117.1 & 52.9 & 144 & 162.1 & 73.4 \\
\hline 25 & 28.1 & 13.5 & 65 & 73.2 & 33.3 & 105 & 118.2 & 53.5 & 145 & 163.2 & 73.9 \\
\hline 26 & 29.3 & 14.0 & 66 & 74.3 & 33.8 & 106 & 119.3 & 54.0 & 146 & 164.4 & 74.4 \\
\hline 27 & 30.4 & 14.5 & 67 & 75.4 & 34. & 107 & 120.5 & 54.5 & 147 & 165.5 & 74.9 \\
\hline 28 & 31.5 & 15.0 & 68 & 76.6 & 34.8 & 108 & 121.6 & 55.0 & 14 & 166.6 & 75.5 \\
\hline 29 & 32.7 & 15.5 & 69 & 77.7 & & 109 & 12 & 55.5 & 149 & 167.7 & 76.0 \\
\hline 30 & 33.8 & 16.0 & 70 & 78.8 & 35.8 & 110 & 123.8 & 56.0 & 150 & 168.9 & 76.5 \\
\hline 31 & 34.9 & 16.5 & 71 & " 79.9 & 36 & 11 & 12 & 56.5 & 151 & 170.0 & 77.0 \\
\hline 32 & 36.0 & 17.0 & 72 & 81.1 & & 112 & 126 & 57.0 & 152 & 171.1 & 77.5 \\
\hline 33 & 37.2 & 17.5 & 73 & 82.2 & 37.3 & 113 & 127.2 & 57.5 & 153 & 172.3 & 78.1 \\
\hline 34 & 38.3 & 18.0 & 74 & 83.3 & 37.8 & 114 & 128.3 & 58.0 & 154 & 173.4 & 78.6 \\
\hline 35 & 39.4 & 18.5 & 75 & 84.4 & 38.3 & 115 & 129.6 & 58.6 & 155 & 174.5 & 79.1 \\
\hline 36 & 40.5 & 18.9 & 76 & 85.6 & 38.8 & 116 & 130.6 & 59.1 & 156 & 175.6 & 79.6 \\
\hline 37 & & 19.4 & 77 & 86.7 & 39.3 & 117 & 131 & 59.6 & 157 & 176.8 & 80.1 \\
\hline 38 & & 19.9 & 78 & 87.8 & & 11 & & 60.1 & 158 & 177.9 & 80.7 \\
\hline 39 & & & 79 & 88.9 & & 11 & 134 & 60.6 & 159 & 179.0 & 81.2 \\
\hline 40 & 45.0 & 20.9 & 80 & 90.1 & 40.8 & 120 & 135.1 & 61.1 & 160 & 180.1 & 81.7 \\
\hline 41 & 46.2 & 21.4 & 81 & & & 12 & 136.2 & 61.6 & 161 & 181.3 & 82.2 \\
\hline 42 & & & & 92.3 & & 12 & & 62.1 & 162 & 182.4 & 82.7 \\
\hline 43 & 48.4 & 22.4 & 83 & 93.4 & & 123 & 138.5 & 62.6 & 163 & 183.5 & 83.3 \\
\hline 44 & 49.5 & 22.9 & 84 & 94.6 & 42.8 & 124 & 139.6 & 63.1 & 164 & 184.6 & 83.8 \\
\hline 45 & 50.7 & 23.4 & 85 & 95.7 & 43.4 & 125 & 140.7 & 63.7 & 165 & 185.8 & 84.3 \\
\hline 46 & & 23.9 & 86 & 96.8 & 43.9 & 126 & 141.9 & 64.2 & 166 & 186.9 & 84.8 \\
\hline 47 & 52.9 & 24.4 & 87 & 97.9 & 44.4 & 127 & & 64.7 & 167 & & 85.3 \\
\hline 48 & 54.0 & 24.9 & 88 & 99.1 & 44.9 & 128 & 144.1 & & 16 & 189.1 & 85.9 \\
\hline 49 & & 25.4 & 89 & 100.2 & & 129 & & $65 . \overline{7}$ & 169 & 190.3 & 86.4 \\
\hline 50 & 56.3 & 25.9 & 90 & 101.3 & 45.9 & 130 & 146.4 & 66.2 & 170 & 191.4 & 86.4 \\
\hline
\end{tabular}




\section{ALLIHN'S TABLE FOR THE DETERMINATION OF DEXTROSE (Contineted)}

\begin{tabular}{|c|c|c|c|c|c|c|c|c|c|c|c|}
\hline $\begin{array}{c}\text { Milli- } \\
\text { grams } \\
\text { of cop- } \\
\text { per }\end{array}$ & $\begin{array}{c}\text { Milli- } \\
\text { grams of } \\
\text { cuprous } \\
\text { oxide }\end{array}$ & $\begin{array}{c}\text { Milli- } \\
\text { grams } \\
\text { of dex- } \\
\text { trose }\end{array}$ & $\begin{array}{c}\text { Milli- } \\
\text { grams } \\
\text { of cop- } \\
\text { per }\end{array}$ & $\begin{array}{c}\text { YIilli- } \\
\text { grams of } \\
\text { cuprous } \\
\text { oxide }\end{array}$ & $\begin{array}{c}\text { Milli- } \\
\text { grams } \\
\text { of dex- } \\
\text { trose }\end{array}$ & $\begin{array}{l}\text { Mrilli- } \\
\text { grams } \\
\text { of cop- } \\
\text { per }\end{array}$ & $\begin{array}{c}\text { Mrilli- } \\
\text { grams of } \\
\text { cuprous } \\
\text { oxide }\end{array}$ & $\begin{array}{c}\text { Mrilli- } \\
\text { grams } \\
\text { of dex- } \\
\text { trose }\end{array}$ & $\begin{array}{c}\text { Milli- } \\
\text { grams } \\
\text { of cop- } \\
\text { per }\end{array}$ & $\begin{array}{c}\text { Milli- } \\
\text { grams of } \\
\text { cuprous } \\
\text { oxide }\end{array}$ & $\begin{array}{l}\text { Milli- } \\
\text { grams } \\
\text { of dex- } \\
\text { trose }\end{array}$ \\
\hline 171 & & .4 & 211 & 237.6 & 08.4 & 251 & 282.6 & 129.7 & 291 & 7.4 & 151.6 \\
\hline 172 & & & 212 & 238.7 & & 252 & & & 292 & & 152.1 \\
\hline 173 & 194.8 & 88.5 & 213 & 239.8 & 109.5 & 253 & 284.8 & 130.8 & 293 & & \\
\hline 174 & 195.9 & & 214 & 240 & 110.0 & 254 & 286.0 & & 294 & & \\
\hline 175 & 197.0 & 89 & 215 & 242.1 & 110.6 & 255 & 287.1 & 131.9 & 295 & 332.1 & 153.8 \\
\hline 176 & 198.1 & & 216 & 243.2 & 11.1 & 256 & 288.2 & 132.4 & 296 & 3.3 & 154.3 \\
\hline 177 & 199.3 & & 217 & 244.3 & 111.6 & 257 & 289.3 & & 297 & 4.4 & 154.9 \\
\hline 178 & 200.4 & 91.1 & 218 & 245. & & & & & & & \\
\hline 179 & 201. & 91. & 219 & 246 & & 259 & & & 299 & & \\
\hline 180 & 202.6 & 92.1 & 220 & 247.7 & 113.2 & 260 & 292.7 & 134.6 & 300 & 337.8 & 156.5 \\
\hline 181 & 03.8 & 92.6 & 221 & 248.7 & 113.7 & 261 & 293.8 & 13 & 301 & 3.9 & 157.1 \\
\hline 182 & 204.9 & 93.1 & 222 & 249.9 & 114. & 262 & 295.0 & & 302 & & 157.6 \\
\hline 183 & 206.0 & 93.7 & 223 & 251 & & 263 & & & 303 & & 158.2 \\
\hline 184 & 207.1 & & 224 & 252 & & 26 & & & & & 158.7 \\
\hline 185 & 208.3 & 94.7 & 225 & 253.3 & 115.9 & 265 & 298.3 & 137 & 305 & 343.4 & 159.3 \\
\hline 186 & 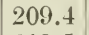 & & 226 & & 11 & 266 & & & 306 & & \\
\hline 187 & 210 & 95.7 & 227 & 6 & 116.9 & 267 & & & & & \\
\hline 188 & 211 & & 228 & & 11 & 268 & & & 308 & .8 & \\
\hline 189 & 212 & & 229 & 257 & 118 & & & & 309 & & \\
\hline 190 & 213.9 & 97.3 & 230 & 258.9 & 118.5 & 270 & 304.0 & 140.0 & 310 & 349.0 & 162.0 \\
\hline 19 & & 9 & 231 & 60.1 & 119.0 & 271 & & & 311 & & \\
\hline 192 & 16 & 9 & & & & & & & & & \\
\hline 193 & 217 & & 33 & 32.3 & 120 & 73 & & & 313 & .4 & 163.7 \\
\hline 194 & 218.4 & & & & 120 & 274 & & & 314 & & 164.2 \\
\hline 195 & 219.5 & 100.0 & 235 & 264.6 & 121.2 & 275 & 309.6 & 142.8 & 315 & 354.6 & 164.8 \\
\hline 19 & & & & & & 276 & & & 316 & & \\
\hline 19 & & & & & & & & & & & \\
\hline 198 & 9 & & & & & & & & & & \\
\hline 199 & 224.0 & & & & 123. & 279 & & 14 & 319 & & 167.0 \\
\hline 200 & 225.2 & 102.6 & 240 & 270.2 & 123.9 & 280 & 315.2 & 145.5 & 320 & 360.3 & 167.5 \\
\hline & & & & & & & & & & & \\
\hline & & & & & & & & & & & \\
\hline & 228.5 & & & & & & & & & & \\
\hline & 229.7 & & & & 126.0 & & & & & & \\
\hline 205 & 230.8 & 105.3 & 245 & 275.8 & 126.6 & 285 & 320.9 & 148.3 & 325 & 365.9 & 170.3 \\
\hline & & & & & & & & & & & \\
\hline & & & & & & & & & & & \\
\hline & & & & & & & & & & & \\
\hline 209 & & & & & & & & & & & \\
\hline 210 & 236.4 & 107.9 & 250 & 281.5 & 129.2 & 290 & 326.5 & 151.0 & 330 & 371.5 & 173.1 \\
\hline
\end{tabular}


ALLIHN'S TABLE FOR THE DETERMINATION OF DEXTROSE (Continued)

\begin{tabular}{|c|c|c|c|c|c|c|c|c|c|c|c|}
\hline $\begin{array}{c}\text { Milli- } \\
\text { grams } \\
\text { of cop- } \\
\text { per }\end{array}$ & $\begin{array}{c}\text { Milli- } \\
\text { grams of } \\
\text { cuprous } \\
\text { oxide }\end{array}$ & $\begin{array}{l}\text { Milli- } \\
\text { grams } \\
\text { of dex- } \\
\text { trose }\end{array}$ & $\begin{array}{c}\text { Nilli- } \\
\text { grams } \\
\text { of cop- } \\
\text { per }\end{array}$ & $\begin{array}{l}\text { Milli- } \\
\text { grams of } \\
\text { cuprous } \\
\text { oxide }\end{array}$ & $\begin{array}{c}\text { Milli- } \\
\text { grams } \\
\text { of dex- } \\
\text { trose }\end{array}$ & $\begin{array}{c}\text { Yilli- } \\
\text { grams } \\
\text { of cop- } \\
\text { per }\end{array}$ & \begin{tabular}{|c|} 
Milli- \\
grams of \\
cuprous \\
oxide
\end{tabular} & $\begin{array}{c}\text { Milli- } \\
\text { grams } \\
\text { of dex- } \\
\text { trose }\end{array}$ & $\begin{array}{c}\text { Milli- } \\
\text { grams } \\
\text { of cop- } \\
\text { per }\end{array}$ & $\begin{array}{c}\text { Milli- } \\
\text { grams of } \\
\text { cuprous } \\
\text { oxide }\end{array}$ & $\begin{array}{l}\text { Milli- } \\
\text { grams } \\
\text { of dex- } \\
\text { trose }\end{array}$ \\
\hline 331 & 372.7 & 73.7 & 366 & 12.1 & 193.4 & 401 & 451.5 & 213.5 & 436 & 490.9 & 233.9 \\
\hline 332 & 373.8 & 174.2 & 367 & 413.2 & 194.0 & 402 & 452.6 & 214.1 & 437 & 492.0 & 234.5 \\
\hline 333 & 374.9 & 174.8 & 368 & 414.3 & 194.6 & 403 & 453.7 & 214.6 & 438 & 493.1 & 235.1 \\
\hline 334 & 376.0 & 175.3 & 369 & 415.4 & 195.1 & 404 & 454.8 & 215.2 & 439 & 494.3 & 235.7 \\
\hline 335 & 377.2 & 175.9 & 370 & 416.6 & 195.7 & 405 & 456.0 & 215.8 & 440 & 495.4 & 236.3 \\
\hline 336 & 378.3 & 176.5 & 371 & 417.7 & 196.3 & 406 & 457.1 & 216.4 & 441 & 496.5 & 236.9 \\
\hline 337 & 379.4 & 177.0 & 372 & 418.8 & 196 & $40 \tau$ & 458.2 & 217.0 & 442 & 497.6 & 237.5 \\
\hline 338 & 380.5 & 177.6 & 373 & 420.0 & 197.4 & 408 & 459.4 & 217.5 & 443 & 498.8 & 238.1 \\
\hline 339 & 381.7 & 178.1 & 374 & 421.1 & 198.0 & 409 & 460.5 & 218.1 & 444 & 499.9 & 238.7 \\
\hline 340 & 382.8 & 178.7 & 375 & 422.2 & 198.6 & 410 & 461.6 & 218.7 & 445 & 501.0 & 239.3 \\
\hline 341 & 383.9 & 179.3 & 376 & 423.3 & 199.1 & 411 & 462.7 & 219.3 & 446 & 502.1 & 239.8 \\
\hline 342 & 385.0 & 179.8 & 377 & 424.5 & 19 & 412 & & 219.9 & 447 & 503.2 & 240.4 \\
\hline 343 & 386.2 & 180.4 & 378 & 425 & 200.3 & 413 & 465.0 & 220.4 & 448 & 504.4 & 241.0 \\
\hline 344 & $38 \pi .3$ & 180.9 & 379 & 426.7 & 200 & 414 & 466 & 221.0 & 44 & 505 & 241.6 \\
\hline 345 & 388.4 & 181.5 & 380 & 427.8 & 201.4 & 415 & 467.2 & 221.6 & 450 & 506.6 & 242.2 \\
\hline 346 & & 182.1 & 381 & 429.0 & 202.0 & 416 & 468.4 & 222.2 & 451 & 507.8 & 242.8 \\
\hline 347 & 390.7 & 182.6 & 382 & 430.1 & 202 & 417 & 469.5 & 222.8 & 452 & 508.9 & 243.4 \\
\hline 348 & 391.8 & 183.2 & 383 & 431.2 & 203 & 418 & 470.6 & 223.3 & 453 & 510.0 & 244.0 \\
\hline 349 & 392.9 & 183.7 & 384 & 432.3 & 203.7 & 419 & 471.8 & 223.9 & 454 & 511.1 & 244.6 \\
\hline 350 & 394.0 & 184.3 & 385 & 433.5 & 204.3 & 420 & 472.9 & 224.5 & 455 & 512.3 & 245.2 \\
\hline 351 & 395.2 & & 386 & & & 421 & 474 & 225. & 456 & 513.4 & 245.7 \\
\hline 352 & 396.3 & 185.4 & 387 & & 205 & 42 & 475.6 & 225.7 & 45 & 1.5 & 246.3 \\
\hline 353 & 397.4 & 186.0 & 388 & 436.8 & 206. & 423 & 476.2 & 226.3 & 458 & 15.6 & 246.9 \\
\hline 354 & 398.6 & 186.6 & 389 & 438.0 & 206.5 & 424 & 477.4 & 226.9 & 459 & 516.8 & 247.5 \\
\hline 355 & 399.7 & 187.2 & 390 & 439.1 & 207.1 & 425 & 478.5 & 227.5 & 460 & 517.9 & 248.1 \\
\hline 356 & & & & & & 426 & & & 461 & 519.0 & 248.7 \\
\hline 357 & 401.9 & 188.3 & 392 & 441.3 & 208.3 & 427 & & 228.6 & 462 & 520.1 & $24 ! 1.3$ \\
\hline 358 & 403.1 & 188.9 & 393 & 442.4 & 208.8 & 428 & 481.9 & 229.2 & 463 & 521.3 & 249.9 \\
\hline 359 & 404.2 & 189.4 & 394 & 443.6 & 209.4 & 429 & 483.0 & 229.8 & & & \\
\hline 360 & 405.3 & 190.0 & 395 & 444.7 & 210.0 & 430 & 484.1 & 230.4 & & & \\
\hline 361 & 406.4 & & 3 ! & & & & .3 & 23 & & & \\
\hline 362 & 407.6 & 191.1 & & & & 43 & .4 & & & & \\
\hline & & & & & 211.7 & 433 & & 232.2 & & & \\
\hline & & & 399 & 449.2 & 212.3 & 434 & 488.6 & 232.8 & & & \\
\hline 36.5 & 410.9 & 192.9 & 400 & 450.3 & 212.9 & 435 & 489.7 & 233.4 & & & \\
\hline
\end{tabular}




\section{GRAVIMETRIC METHOD OF DETERMINATION (DEFREN-O'SULLIVAN)}

For the determination of reducing sugars many prefer the method of Defren and O'Sullivan, because it is applicable to the determination not only of dextrose but also of maltose and lactose. ${ }^{1}$ Mix $15 \mathrm{cc}$. of the copper solution with $15 \mathrm{cc}$. of the alkaline tartrate in an Erlenmeyer flask, and add 50 cc. of distilled water. Place the flask and its contents in a boiling-water bath and allow them to remain five minutes. Then run rapidly from a burette into the hot liquor in the flask 25 cc. of the sugar solution to be tested (which should not contain more than $\frac{1}{2}$ per cent of reducing sugar). Allow the flask to remain in the boiling water just fifteen minutes after the addition of the sugar solution, remove, and, with the aid of a vacuum, filter the contents rapidly in a platinum or porcelain Gooch crucible containing a layer of prepared asbestos fiber about $1 \mathrm{~cm}$. thick, the Gooch, with the asbestos, having been previously ignited and weighed. The cuprous oxide precipitate is thoroughly washed with boiling distilled water till the water ceases to be alkaline.

Dry the Gooch with its contents in the oven, and finally heat to dull redness for fifteen minutes, during which time the red cuprous oxide is converted into the black cupric oxide. If a platinum Gooch is used (and this variety is preferable), it may be heated over the low flame of the burner. If the Gooch is of porcelain, considerable care must be taken to avoid cracking the crucible, the heat being increased cautiously. After oxidation as above, the crucible is transferred to a desiccator, cooled, and quickly weighed. From the milligrams of cupric oxide the milligrams of reducing sugar may be calculated (for a convenient table see Leach, loc. cit. p. 490).

1 See Leach, Food Inspection and Analysis, New York, 1907. 


\section{APPENDIX L}

\section{TITANIUM TRICHLORIDE SOLUTION: ITS PREPARATION AND STANDARDIZATION}

This reagent is useful for titrating methylene blue solutions. To prepare it, take :

Titanium trichloride (Merck) 15 per cent solution . . . . . 9 cc. Hydrochloric acid, concentrated . . . . . . . . . . 9 cc.

Boil this mixture on a steam bath until all the $\mathrm{H}_{2} \mathrm{~S}$ is expelled. Dilute with oxygen-free water to 3 liters, adding hydrochloric acid to slight excess. Keep the solution in a flask under carbon dioxide or hydrogen. When estimations are to be made, the burette should be filled quickly with the reagent and a little oil added to prevent contact at the top with atmospheric oxygen. The tip of the burette should dip a few centimeters below the surface of the liquid under titration.

Owing to almost unavoidable changes in the strength of the titanium solution, frequent standardization is necessary. For this purpose a solution of ferric chloride is used with potassium sulphocyanate as indicator. The titanium solution is added slowly until the test shows that the ferric chloride is reduced to ferrous. A standard iron solution is made by dissolving $2.9 \mathrm{~g} . \mathrm{FeCl}_{3}$ in $100 \mathrm{cc}$. water. This corresponds to $1 \mathrm{~g}$. Fe, and 1 cc. corresponds to $.01 \mathrm{~g}$. Fe. Not more than $10 \mathrm{cc}$. of this solution should be used for purposes of titration in estimating titanium samples. 


\section{APPENDIX M}

MEASLRES AND WEIGHTS-CONVERSION TABLES

A. METRIC TO ExGLISH

LENGTH

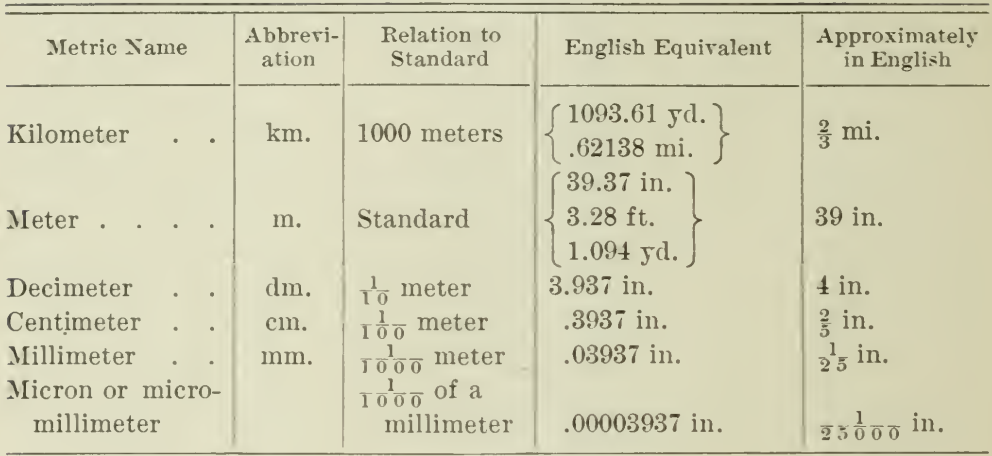

CAPACITY

\begin{tabular}{|c|c|c|c|c|}
\hline Liter . . & 1. & Standard & $\left\{\begin{array}{l}1.057 \text { C.S. qt. } \\
61.03 \text { cu. in. }\end{array}\right\}$ & $\begin{array}{l}1 \text { qt. U.S. } \\
\text { measure }\end{array}$ \\
\hline $\begin{array}{l}\text { Cubic centimeter } \\
\text { (Milliliter) }\end{array}$ & cc. & $\begin{array}{l}1000 \text { of a } \\
\text { liter }\end{array}$ & $\left\{\begin{array}{l}.001057 \text { U.S. qt. } \\
.06103 \text { cu. in. } \\
.031 \text { fluid ounce }\end{array}\right\}$ & $1000 \mathrm{qt}$. \\
\hline
\end{tabular}

WEIGHT

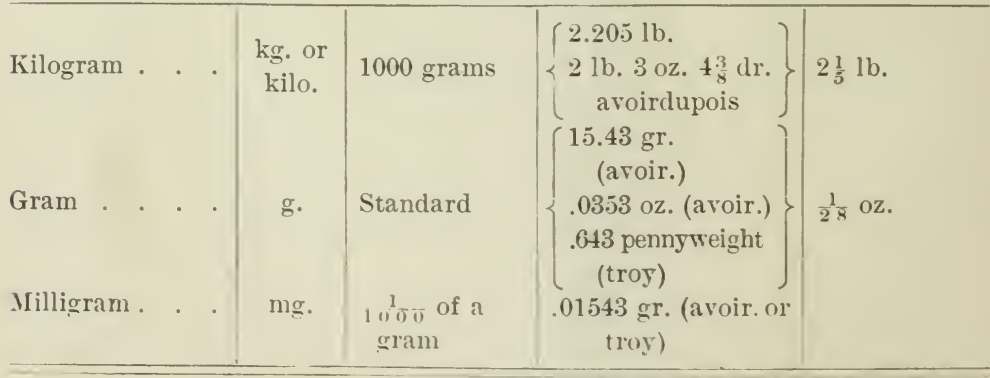


B. ENGLISH TO METRIC

Lengti

\begin{tabular}{|c|c|c|c|c|c|c|c|c|c|c|c|c|c|c|c|}
\hline \multicolumn{15}{|c|}{ English Name } & \multirow{5}{*}{$\begin{array}{c}\text { Metric Equivalent } \\
\begin{array}{c}1.609 \mathrm{~km} . \\
.914 \mathrm{~m} . \\
91.44 \mathrm{~cm}\end{array} \\
30.48 \mathrm{~cm} . \\
\left\{\begin{array}{c}2.54 \mathrm{~cm} . \\
25.40 \mathrm{~mm} .\end{array}\right.\end{array}$} \\
\hline Mile & · & & . . & . & . & . & - & - & - & - & - & . & . & . & \\
\hline Yard & $\cdot$ & $\cdot$ & . & . & - & . & . & - & - & - & . & - & . & . & \\
\hline Foot & . & . & . & . & . & . & . & . & - & - & . & . & . & . & \\
\hline Inch & . $\cdot$ & . . & · & . & . & . & . & . & - & - & . & . & . & . & \\
\hline \multicolumn{16}{|c|}{ Capacity } \\
\hline \multicolumn{15}{|c|}{ English Name } & Metric Equivalent \\
\hline Quart & $(\mathrm{U} . \mathrm{S})$. & ) & . & - & - & • & · & - & - & · & - & - & · & - & $\left\{\begin{array}{r}.946 \text { liters } \\
946.36 \mathrm{cu} . \mathrm{cm} .\end{array}\right.$ \\
\hline Pint & U.S.) & & . & . & . & . & . & . & . & . & . & . & . & . & $473.18 \mathrm{cu} . \mathrm{cm}$. \\
\hline Gill ( & U.S.) & . & . & . & . & . & . & . & . & . & . & . & . & . & $118.29 \mathrm{cu} . \mathrm{cm}$. \\
\hline Fluid & ounce & 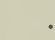 & . & . & . & . & . & . & . & . & . & . & . & . & $29.57 \mathrm{cu} . \mathrm{cm}$. \\
\hline Cubic & inch & . & . & . & . & . & . & . & . & . & . & . & . & . & $16.39 \mathrm{cu} . \mathrm{cm}$. \\
\hline \multicolumn{16}{|c|}{ WEIGHT } \\
\hline \multicolumn{15}{|c|}{ English Name } & Metric Equivalent \\
\hline Poun & (avoil & ir.) & & - & . & - & . & - & - & - & - & - & - & . & $\left\{\begin{array}{c}.4536 \mathrm{~kg} . \\
453.59 \mathrm{~g} .\end{array}\right.$ \\
\hline Ounc & (avoir & r.) & · & . & . & . & . & . & - & . & . & . & . & . & $\begin{array}{l}28.35 \mathrm{~g} . \\
\quad 0648 \mathrm{~g}\end{array}$ \\
\hline Grain & (avoir & r.) & . & . & . & . & . & - & - & - & • & - & . & . & $\left\{\begin{array}{r}.0648 \mathrm{~g} . \\
64.79 \mathrm{mg} .\end{array}\right.$ \\
\hline Oune & (troy) & & $\cdot$. & . & . & - & . & . & • & . & . & . & . & . & $31.103 \mathrm{~g}$. \\
\hline Penny & weight & & roy) & . & & & . & . & & • & . & . & . & . & $1.555 \mathrm{~g}$. \\
\hline Grain & (troy) & $(=$ & avoi & ir. $g$ & & & . & . & - & - & . & - & . & • & $\begin{array}{l}.0648 \mathrm{~g} . \\
64.80 \mathrm{mg} \text {. }\end{array}$ \\
\hline
\end{tabular}




\section{APPENDIX N}

\section{ALCOHOL TABLE MODIFIED FROM WINDISCH}

\begin{tabular}{|c|c|c|c|c|c|}
\hline $\begin{array}{l}\text { Specific } \\
\text { Gravity of } \\
\text { Distillate }\end{array}$ & $\begin{array}{l}\text { Per Cent of } \\
\text { Alcohol by } \\
\text { Weight }\end{array}$ & $\begin{array}{l}\text { Per Cent of } \\
\text { Alcohol by } \\
\text { Volume }\end{array}$ & $\begin{array}{c}\text { Specific } \\
\text { Gravity of } \\
\text { Distillate }\end{array}$ & $\begin{array}{l}\text { Per Cent of } \\
\text { Aleohol by } \\
\text { Weight }\end{array}$ & $\begin{array}{l}\text { Per Cent of } \\
\text { Alcohol by } \\
\text { Volume }\end{array}$ \\
\hline 1.0000 & 0.00 & 0.00 & 0.9908 & 5.20 & 6.55 \\
\hline 0.9998 & 0.11 & 0.13 & 6 & 5.32 & 6.71 \\
\hline 6 & 0.21 & 0.27 & 4 & 5.45 & 6.86 \\
\hline 4 & 0.32 & 0.40 & 2 & 5.57 & 7.02 \\
\hline 2 & 0.42 & 0.53 & 0 & 5.70 & -7.18 \\
\hline 0 & 0.53 & 0.67 & 0.9898 & 5.83 & 7.33 \\
\hline 0.9988 & 0.64 & 0.80 & 6 & 5.95 & 7.50 \\
\hline 6 & 0.74 & 0.93 & 4 & 6.08 & 7.66 \\
\hline 4 & 0.85 & 1.07 & 2 & 6.21 & 7.82 \\
\hline 2 & 0.96 & 1.20 & 0 & 6.34 & 7.99 \\
\hline 0 & 1.06 & 1.34 & 0.9888 & 6.47 & 8.15 \\
\hline 0.9978 & 1.17 & 1.48 & 6 & 6.59 & 8.31 \\
\hline 6 & 1.28 & 1.61 & 4 & 6.73 & 8.48 \\
\hline 4 & 1.39 & 1.75 & 2 & 6.88 & 8.64 \\
\hline 2 & 1.50 & 1.88 & 0 & 6.99 & 8.81 \\
\hline 0 & 1.60 & 2.02 & 0.9878 & 7.12 & 8.98 \\
\hline 0.9968 & 1.71 & 216 & 6 & 7.26 & 9.15 \\
\hline 6 & 1.82 & 2.30 & 4 & 7.39 & 9.32 \\
\hline 4 & 1.93 & 2.44 & 2 & 7.53 & 9.48 \\
\hline 2 & 2.04 & 2.58 & 0 & 7.66 & 9.66 \\
\hline 0 & 2.16 & 2.72 & 0.9868 & 7.80 & 9.83 \\
\hline 0.9958 & 2.27 & 2.86 & 6 & 7.94 & 10.00 \\
\hline 6 & 2.38 & 3.00 & 4 & 8.07 & 10.17 \\
\hline 4 & 2.49 & 3.14 & 2 & 8.21 & 10.35 \\
\hline 2 & 2.60 & 3.28 & 0 & 8.35 & 10.52 \\
\hline 0 & 2.72 & 3.42 & 0.9858 & 8.49 & 10.70 \\
\hline 0.9948 & 2.82 & 3.56 & 6 & 8.63 & 10.88 \\
\hline 6 & 2.94 & 3.71 & 4 & 8.77 & 11.05 \\
\hline 4 & 3.06 & 3.85 & 2 & 8.91 & 11.23 \\
\hline 2 & 3.17 & 4.00 & 0 & 9.06 & 11.41 \\
\hline 0 & 3.29 & 4.14 & 0.9848 & 9.20 & 11.59 \\
\hline 0.9938 & 3.40 & 4.29 & 6 & 9.34 & 11.77 \\
\hline 6 & 3.52 & 4.43 & 4 & 9.49 & 11.95 \\
\hline 4 & 3.64 & 4.58 & 2 & 9.63 & 12.14 \\
\hline 2 & 3.75 & 4.73 & 0 & 9.79 & 12.32 \\
\hline 0 & 3.87 & 4.88 & 0.9838 & 9.92 & 12.50 \\
\hline 0.9928 & 3.99 & 5.03 & 6 & 10.07 & 12.69 \\
\hline 6 & 4.11 & 5.18 & 4 & 10.22 & 12.88 \\
\hline 4 & 4.23 & 5.33 & 2 & 10.36 & 13.06 \\
\hline 2 & 4.35 & 5.48 & 0 & 10.52 & 13.25 \\
\hline 0 & 4.47 & 5.53 & 0.9828 & 10.66 & 13.44 \\
\hline 0.9918 & 4.59 & 5.78 & 6 & 10.81 & 13.63 \\
\hline 6 & 4.71 & 5.93 & 4 & 10.96 & 13.82 \\
\hline 4 & 4.83 & 6.09 & 2 & 11.12 & 14.01 \\
\hline 2 & 4.95 & 6.24 & 0 & 11.27 & 14.20 \\
\hline 0 & 5.08 & 6.40 & & & \\
\hline
\end{tabular}


ALCOHOL TABLE MODIFIED FROM WINDISCH (CONTINUEI)

\begin{tabular}{|c|c|c|c|c|c|}
\hline $\begin{array}{l}\text { Specific } \\
\text { Gravity of } \\
\text { Distillate }\end{array}$ & $\begin{array}{l}\text { Per Cent of } \\
\text { Alcohol by } \\
\text { Weight }\end{array}$ & $\begin{array}{l}\text { Per Cent of } \\
\text { Alcohol by } \\
\text { Volume }\end{array}$ & $\begin{array}{l}\text { Specific } \\
\text { (iravity of } \\
\text { Distillate }\end{array}$ & $\begin{array}{l}\text { Per Cent of } \\
\text { Aleohol by } \\
\text { Weight }\end{array}$ & $\begin{array}{l}\text { Per Cent of } \\
\text { Alcohol by } \\
\text { Volume }\end{array}$ \\
\hline 0.9818 & 11.42 & 14.39 & 0.9718 & 19.30 & 24.32 \\
\hline 6 & 11.57 & 14.58 & 6 & 19.45 & 24.51 \\
\hline 4 & 11.72 & 14.77 & 4 & 19.60 & 24.70 \\
\hline 2 & 11.88 & 14.97 & 2 & 19.76 & 24.89 \\
\hline 0 & 12.03 & 15.16 & 0 & 19.91 & 25.08 \\
\hline 0.9808 & 12.19 & 15.36 & 0.9708 & 20.06 & 25.27 \\
\hline 6 & 12.34 & 15.55 & 6 & 20.21 & 25.47 \\
\hline 4 & 12.50 & 15.75 & 4 & 20.36 & 25.66 \\
\hline 2 & 12.65 & 15.95 & 2 & 20.51 & 25.84 \\
\hline 0 & 12.81 & 16.14 & 0 & 20.66 & 26.03 \\
\hline 0.9798 & 12.97 & 16.34 & 0.9698 & 20.81 & 26.22 \\
\hline 6 & 13.13 & 16.54 & 6 & 20.96 & 26.41 \\
\hline 4 & 13.28 & 16.74 & 4 & 21.10 & 26.59 \\
\hline 2 & 13.44 & 16.94 & 2 & 21.25 & 26.78 \\
\hline 0 & 13.60 & 17.14 & 0 & 21.40 & 26.96 \\
\hline 0.9788 & 13.76 & 17.34 & 0.9688 & 21.54 & 27.14 \\
\hline 6 & 13.92 & 17.54 & 6 & 21.69 & 27.33 \\
\hline 4 & 14.08 & 17.74 & 4 & 21.83 & 27.51 \\
\hline 2 & 14.23 & 17.94 & 2 & 21.97 & 27.69 \\
\hline 0 & 14.39 & 18.14 & 0 & 22.12 & 27.87 \\
\hline 0.9778 & 14.55 & 18.34 & 0.9678 & 22.26 & 28.05 \\
\hline 6 & 14.71 & 18.54 & 6 & 22.40 & 28.23 \\
\hline 4 & 14.87 & 18.74 & 4 & 22.54 & 28.41 \\
\hline 2 & 15.03 & 18.94 & 2 & 22.68 & 28.59 \\
\hline 0 & 15.19 & 19.14 & 0 & 22.82 & 28.76 \\
\hline 0.9768 & 15.35 & 19.34 & 0.9668 & 22.96 & 28.94 \\
\hline 6 & 15.51 & 19.55 & 6 & 23.10 & 29.11 \\
\hline 4 & 15.67 & 19.75 & 4 & 23.24 & 29.29 \\
\hline 2 & 15.83 & 19.95 & 2 & 23.38 & 29.46 \\
\hline 0 & 15.99 & 20.15 & 0 & 23.52 & 29.64 \\
\hline 0.9758 & 16.15 & 20.35 & 0.9658 & 23.65 & 29.81 \\
\hline 6 & 16.31 & 20.55 & 6 & 23.79 & 29.98 \\
\hline 4 & 16.47 & 20.75 & 4 & 23.93 & 30.15 \\
\hline 2 & 16.63 & 20.96 & 2 & 24.06 & 30.32 \\
\hline 0 & 16.79 & 21.16 & 0 & 24.19 & 30.49 \\
\hline 0.9748 & 16.95 & 21.36 & 0.9648 & 24.33 & 30.66 \\
\hline 6 & 17.11 & 21.56 & 6 & 24.46 & 30.82 \\
\hline 4 & 17.27 & 21.76 & 4 & 24.59 & 30.99 \\
\hline 2 & 17.42 & 21.96 & 2 & 24.73 & 31.16 \\
\hline 0 & 17.58 & 22.16 & 0 & 24.85 & 31.32 \\
\hline 0.9738 & 17.74 & 22.35 & 0.9638 & 24.99 & 31.49 \\
\hline 6 & 17.90 & 22.55 & 6 & 25.12 & 31.65 \\
\hline 4 & 18.05 & 22.75 & 4 & 25.25 & 31.81 \\
\hline 2 & 18.21 & 22.95 & 2 & 25.37 & 31.98 \\
\hline 0 & 18.37 & 23.14 & 0 & 25.50 & 32.14 \\
\hline 0.9728 & 18.52 & 23.34 & 0.9628 & 25.63 & 32.30 \\
\hline 6 & 18.68 & 23.54 & 6 & 25.76 & 32.46 \\
\hline 4 & 18.84 & 23.73 & 4 & 25.88 & 32.62 \\
\hline 2 & 18.99 & 23.93 & 2 & 26.01 & 32.78 \\
\hline 0 & 19.14 & 24.12 & 0 & 26.13 & 32.93 \\
\hline
\end{tabular}




\section{APPENDIX O}

\section{COMPARISON OF FAHRENHEIT AND CENTIGRADE THERMOMETER SCALES}

\begin{tabular}{|c|c|c|c|c|c|c|c|}
\hline Fahr. & Cent. & Fahr. & Cent. & Fahr. & Cent. & Fahr. & Cent. \\
\hline 212 & 100 & 144 & 62.2 & 76 & 24.4 & 8 & -13.3 \\
\hline 210 & 98.9 & 142 & 61.1 & 74 & 23.3 & 6 & -14.4 \\
\hline 208 & 97.8 & 140 & 60.0 & 72 & 22.2 & 4 & -15.6 \\
\hline 206 & 96.7 & 138 & 58.9 & 70 & 21.1 & 2 & -16.7 \\
\hline 204 & 95.6 & 136 & 57.8 & 68 & 20.0 & 0 & -17.8 \\
\hline 202 & 94.4 & 134 & 56.7 & 66 & 18.9 & -2 & -18.9 \\
\hline 200 & 93.3 & 132 & 55.6 & 64 & 17.8 & -4 & -20.0 \\
\hline 198 & 92.2 & 130 & 54.4 & 62 & 16.7 & -6 & -21.1 \\
\hline 196 & 91.1 & 128 & 53.3 & 60 & 15.6 & -8 & -22.2 \\
\hline 194 & 90.0 & 126 & 52.2 & 58 & 14.4 & -10 & -23.3 \\
\hline 192 & 88.9 & 124 & 51.1 & 56 & 13.3 & -12 & -24.4 \\
\hline 190 & 87.8 & 122 & 50.0 & 54 & 12.2 & -14 & -25.6 \\
\hline 188 & 86.7 & 120 & 48.9 & 52 & 11.1 & -16 & -26.7 \\
\hline 186 & 85.6 & 118 & 47.8 & 50 & 10.0 & $\cdot-18$ & -27.8 \\
\hline 184 & 84.4 & 116 & 46.7 & 48 & 8.9 & -20 & -28.9 \\
\hline 182 & 83.3 & 114 & 45.6 & 46 & 7.8 & -22 & -30.0 \\
\hline 180 & 82.2 & 112 & 44.4 & 44 & 6.7 & -24 & -31.1 \\
\hline 178 & 81.1 & 110 & 43.3 & 42 & 5.6 & -26 & -32.2 \\
\hline 176 & 80.0 & 108 & 42.2 & 40 & 4.4 & -28 & -33.3 \\
\hline 174 & 78.9 & 106 & 41.1 & 38 & 3.3 & -30 & -34.4 \\
\hline 172 & 77.8 & 104 & 40.0 & 36 & 2.2 & -32 & -35.6 \\
\hline 170 & 76.7 & 102 & 38.9 & 34 & 1.1 & -34 & -36.7 \\
\hline 168 & 75.6 & 100 & 37.8 & 32 & 0.0 & -36 & -37.8 \\
\hline 166 & 74.4 & 98 & 36.7 & 30 & -1.1 & -38 & -38.9 \\
\hline 164 & 73.3 & 96 & 35.6 & 28 & -2.2 & -40 & -40.0 \\
\hline 162 & 72.2 & 94 & 34.4 & 26 & -3.3 & -42 & -41.1 \\
\hline 160 & 71.1 & 92 & 33.3 & 24 & -4.4 & -44 & -42.2 \\
\hline 158 & 70.0 & 90 & 32.2 & 22 & -5.6 & -46 & -43.3 \\
\hline 156 & 68.9 & 88 & 31.1 & 20 & -6.7 & -48 & -44.4 \\
\hline 154 & 67.8 & 86 & 30.0 & 18 & -7.8 & -50 & -45.6 \\
\hline 152 & 66.7 & 84 & 28.9 & 16 & -8.9 & -52 & -46.7 \\
\hline 150 & 65.6 & 82 & 27.8 & 14 & -10.0 & -54 & -47.8 \\
\hline 148 & 64.4 & 80 & 26.7 & 12 & -11.1 & -56 & -48.9 \\
\hline 146 & 63.3 & 78 & 25.6 & 10 & -12.2 & & \\
\hline
\end{tabular}

To change Centigrade to Fahrenheit: $\left(\right.$ C. $\left.\times \frac{9}{5}\right)+32=$ F. For example, to find the equivalent of $10^{\circ} \mathrm{C}$., $\left(10^{\circ} \times \frac{9}{5}\right)+32=50^{\circ} \mathrm{F}$.

To change Fahrenheit to Centigrade: $\left(\right.$ F. $\left.-32^{\circ}\right) \times \frac{5}{8}=$ C. For example, to reduce $50^{\circ} \mathrm{F}$. to Centigrade, $\left(50^{\circ}-32^{\circ}\right) \times \frac{5}{9}=10^{\circ} \mathrm{C}$; and $-40^{\circ} \mathrm{F}$. to Centigrade, $\left(-40^{\circ}-32^{\circ}\right)=-72^{\circ}$, whence $-72^{\circ} \times \frac{5}{3}=-40^{\circ} \mathrm{C}$. 


\section{APPENDIX P}

\section{THE DESCRIPTIVE CHART OF THE SOCIETY OF AMERICAN BACTERIOLOGISTS}

The identification of species of bacteria is rendered much more certain if one uses the chart prepared by the above-mentioned society. This chart enumerates practically all characters of bacteria which have a differential value when the organisms are grown upon media prepared according to the standard methods of the American Public Health Association as adopted in 1905.

Copies of this chart, in form suitable for use in the laboratory, are supplied at a nominal price by the. Secretary of the Society of American Bacteriologists.

\section{DESCRIPTIVE ('HART - SOCIETY OF AMERICAN BACTERIOLOGISTS}

Prepared by F. D. Chester, F. P. Gorhay, Erwix F. Smith, Commutee ox Methods of Inentification of Bacterial Species. Ixdorsed iy the Society for General Use at the Axxual Meetixg, Dec. 31, 1907

\section{DETAILED FEATURES}

(Note. Underscore required terms)

\section{Monphologi (1)}

1. Vegetative cells, medium used

temp. age days.

Form, round, short rods, long rods, short chains, long chains, filaments. commas, short spirals, long spirals, clostridium, cuneate, clavate, curved.

Limits of size. Size of majority

Ends, rounded, truncate, concave.

Agar hanging block $\left\{\begin{array}{l}\text { Orientation (grouping) .............................................. } \\ \text { Chains (number of elements) } \\ \text { Short chains, long chains. } \\ \text { Orientation of chains, parallel, irregular. }\end{array}\right.$

2. Sporangia, medium used temp.

Form, elliptical, short rods, spindled, clavate, dmumsticks. 
Limits of size Size of majority..

Agar hanging block $\left\{\begin{array}{l}\text { Orientation (grouping) } \ldots \ldots \ldots \ldots . . . . \\ \text { Chains (number of elements) ........... } \\ \text { Orientation of chains, parallel, irregular. }\end{array}\right.$

Location of endospores, central, polar

\section{Endospores}

Form, round, elliptical, elongated.

Limits of size. Size of majority.

Wall, thick, thin.

Sporangium wall, adherent, not adherent.

Germination, equatorial, oblique, polar, bipolar, by stretching.

4. Flagella, No......... Attachment, polar, bipolar, peritrichiate. How stained

5. Capsules, present on .

6. Zoöglœa, Pseudozoöglna.

7. Involution forms, on in........ days at........ ${ }^{\circ} \mathrm{C}$.

8. Staining reactions

1:10 watery fuchsin, gentian violet, carbol-fuchsin, Löfler's alkaline methylene blue.

Special stains

Gram

Glycogen

Fat.

Acid-fast

Neisser

\section{Agar stroke}

\section{Cultural Featires (2)}

Growth, invisible, scanty, moderate, abundant.

Form of growth, filiform, echinulate, beaded, spreading, plumose, arborescent, rhizoid.

Elevation of growth, flat, effuse, raised, convex.

Luster, glistening, dull, cretaceous.

'Topography, smooth, contoured, rugose, vermucose.

Optical characters, opaque, translucent, opalescent, iridescent.

Chromogenesis (7),

Odor, absent, decided, resembling

Consistency, slimy, butyrous, viscid, membranous, coriaceous, brittle.

Medium, grayed, browned, reddened, blued, greened.

\section{Potato}

Growth, scanty, moderute, abundant, transient, persistent.

Form of growth, filiform, echinulate, beaded, spreading, plumose, arborescent, rhizoid.

Elevation of growth, flat, effuse, raised, convex.

Luster, glistening, dull, cretaceous.

Topography, smooth, contoured, rugose, verrucose.

Chromogenesis ( 7$)$, Pigment in water, insoluble, soluble; other solvents,

Odor, absent, decided, resembling

Consistency, slimy, butyrous, viscid, membranous, corirceous, brittle.

Medium, grayed, browned, reddened, blued, yreened. 


\section{Löfler's blood sełum}

Stroke, invisible, scanty, moderate, abundant.

Form of growth, filiform, echinulate, beaded, spreading, plumose, arborescent, rhizoid.

Elevation of growth, flat, effuse, raised, convex.

Luster, glistening, dull, cretaceous.

Topography, smooth, contoured, rugose, verrucose.

Chromogenesis (7),

Medium, grayed, browned, reddened, blued, greened. Liquefaction begins in ........... days, complete in ........... days.

\section{Agar stab}

Growth, uniform, best at top, best at bottom; surface growth scanty, abundant; restricted, widespread.

Line of puncture, filiform, beaded, papillate, villous, plumose, arborescent; liquefaction.

\section{Gelatin stab}

Growth, uniform, best at top, best at bottom.

Line of puncture, filiform, beaded, papillate, villous, plumose, arborescent.

Liquefaction, crateriform, napiform, infundibuliform, saccate, stratiform ; begins in days, complete in days.

Medium, fluorescent, browned

\section{Nutrient broth}

Surface growth; ring, pellicle, flocculent, membranous, none.

Clouding, slight, moderate, strong; transient, persistent ; none; fluid turbid.

Odor, absent, decided, resembling

Sediment, compact, flocculent, granular, flaky, viscid on agitation, abundant, scant.

\section{Milk}

Clearing without coagulation.

Coagulation, prompt, delayed, absent.

Extrusion of whey begins in days.

Coagulum, slowly peptonized, rapidly peptonized.

Peptonization begins on ........... day, complete on ........... day.

Reaction, 1 day ............, 2 days............. 4 days 10 days 20 days

Consistency, slimy, viscid, unchanged.

Medium, browned, reddened, blued, greened.

Lab ferment, present, absent.

8. Litmus milk

Acid, alkaline, acid then alkaline, no change.

Prompt reduction, no reduction, partial slow reduction.

\section{Gelatin colonies}

Growth, slow, rapid.

Form, punctiform, round, irregular, amœeboid, mycelioid, filamentous, rhizoid. Elevation, flat, effuse, raised, convex, pulvinate, crateriform (liquefying).

Edge, entire, undulate, lobate, erose, lacerate, fimbriate, filamentous, floccose, curled.

Liquefaction, cup, saucer, spreading. 
10. Agar colonies

Growth, slow, rapid, (temperature...................).

Form, punctiform, round, irregular, amoeboid, mycelioid, filamentous, rhizoid.

Surface, smooth, rough, concentrically ringed, radiate, striate.

Elevation, flat, effuse, raised, convex, pulvinate, umbonate.

Edge, entire, undulate, lobate, erose, lacerate, fimbriate, floccose, curled.

Internal structure, amorphous, finely granular, coarsely granular, grumose, filamentous, floccose, curled.

11. Starch jelly

Growth, scanty, copious.

Diastasic action, absent, feeble, profound.

Medium stained,

12. Silicate jelly (Fermi's solution)

Growth, copious, scanty, absent.

Medium stained,

13. Cohn's solution

Growth. copious, scanty, absent.

Medium, fluorescent, nonfluorescent.

14. Uschinsky's solution

Growth, copious, scanty, absent.

Fluirl, viscid, not viscid.

15. Sodium chloride in bouillon

Per cent inhibiting growth

16. Growth in bouillon over chloroform, unrestrained, feeble, absent.

17. Nitrogen

Obtained from peptone, asparagine, glycocoll, urea, ammonia salts, nitrogen.

18. Best media for long-continued growth

19. Quick tests for differential purposes

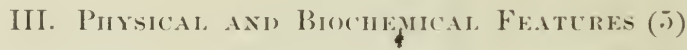

1. Fermentation tulues containing peptnne water or sugarfree bouillon and

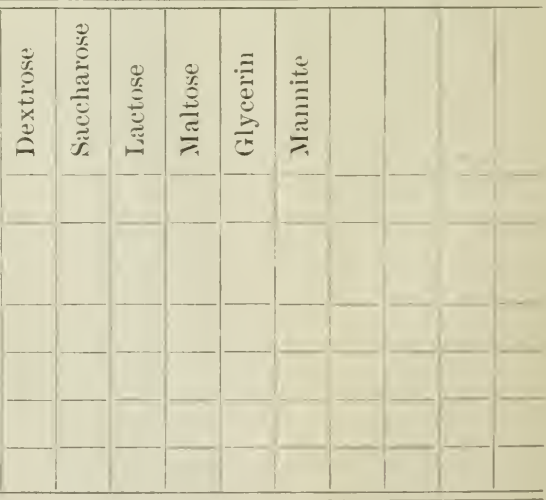

Growth in closed arm

Amount of acid produced in 1 day

Amount of acid produced in 2 days

Amount of acid produced in 4 days 
2. Ammonia production, feeble, moderate, strong, absent, masked by acids.

3. Nitrates in nitrate broth

Reduced, not reduced.

Presence of nitrites ammonia

Presence of nitrates free nitrogen

4. Indol production, feeble, moderate, strony.

5. Toleration of Acids, great, medium, slight.

Acids tested

6. Toleration of $\mathrm{NaOH}$, great, medium, slight.

7. Optimum reaction for growth in bouilon, stated in terms of Fuller's scale

8. Vitality on culture media, brief, moderate, long.

9. Temperature relations

Thermal death point (ten minutes exposure in nutrient broth when this is adapted to growth of organism), C.

Optimum temperature for growth.............. C. or best growth at $15^{\circ} \mathrm{C}$, $20^{\circ} \mathrm{C}, 25^{\circ} \mathrm{C}, 30^{\circ} \mathrm{C}, 37^{\circ} \mathrm{C}, 40^{\circ} \mathrm{C}, 50^{\circ} \mathrm{C}, 60^{\circ} \mathrm{C}$.

Maximum temperature for growth, ................

Minimum temperature for growth, ..............

10. Killed readily by drying; resistant to drying.

11. Per cent killed by freezing (salt and crushed ice or liquid air)

12. Sunlight, exposure on ice in thinly sown agar plates, one-half plate covered (time fifteen minutes), sensitive, not sensitive.

Per cent killed

13. Acids produced.

14. Alkalies produced

15. Alcohols

16. Ferments, pepsin, trypsin, diastase, invertase, pectase, cytase, tyrosinase, oxidase, peroxidase, lipase, catalase, glucase, galactase, lab, etc.

17. Crystals formed

18. Effect of germicides

\begin{tabular}{l|l|l|l|l|l|l|l|l|}
\hline Substance & Method user & & \\
\hline
\end{tabular}




\section{PATHOGENiCITY}

\section{Pathogenic to animals}

Insects, crustaceans, fishes, reptiles; birds, mice, rats, guinea pigs, rabbits, dogs, cats, sheep, goats, cattle, horses, monkeys, man.

\section{Pathogenic to plants}

3. Toxins, soluble, endotoxins.

4. Non-toxin-forming.

5. Immunity bactericidal.

6. Immunity nonbactericidal.

7. Loss of virulence on culture media, prompt, gradual, not observed in months.

(1) The morphological characters shall be determined and described from growths obtained upon at least one solid medium (nutrient agar) and in at least one liquid medium (nutrient broth). Growths at $35^{\circ} \mathrm{C}$ shall be in general not older than twentyfour to forty-eight hours, and growths at $20^{\circ} \mathrm{C}$ not older than forty-eight to serentytwo hours. To secure uniformity in cultures, in all cases preliminary cultivation shall be practiced as described in the revised Report of the Committee on Standard Methods of the Laboratory Section of the American Public Health Association, 1905.

(2) The observation of cultural and biochemical features shall cover a period of at least fifteen days and frequently longer, and shall be made according to the revised Standard Methods above referred to. All media shall be made according to the same Standard Methods.

(3) Gelatin-stab cultures shall be held for six weeks, to determine liquefaction.

(4) Ammonia and indol tests shall be made at end of tenth day, nitrite tests at end of fifth day.

(5) Titrate with $\mathrm{N} / 20 \mathrm{NaOH}$, using plenolphthalein as an indicator; make titrations at same times from blank. The lifference gives the amount of acid produced.

The titration should be done after boiling, to drive off any $\mathrm{CO}_{2}$ present in the culture.

(6) Generic nomenclature shall begin with the year 1872 (Cohn's first important paper).

Species nomenclature shall begin with the year 1880 (Koch's discovery of the poured-plate method for the separation of organisms).

(7) Chromogenesis shall be recorded in standard color terms. 


\section{BRIEF CHARACTERIZATION}

Mark + or 0 , and when two terms occur on a line, erase the one which does not apply, unless both apply.

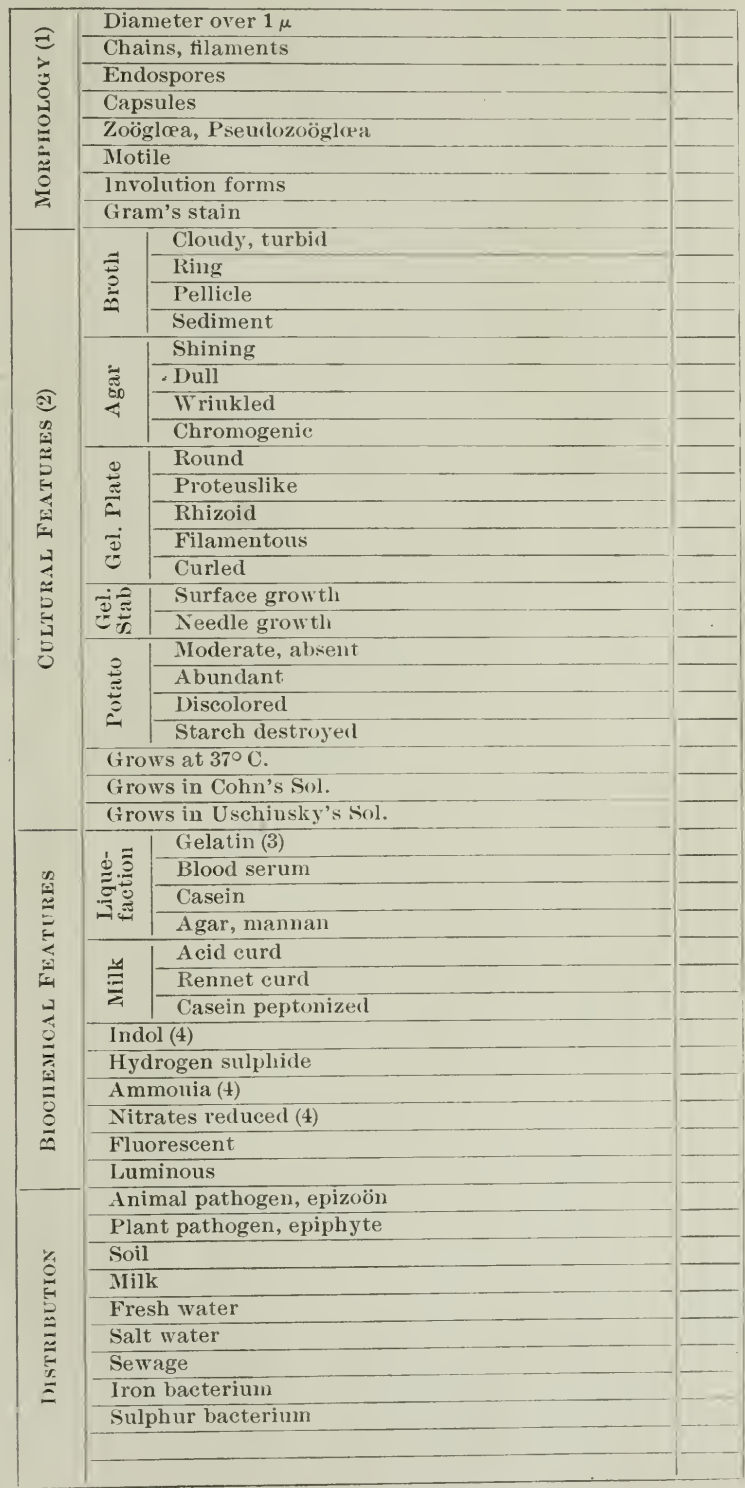




\section{GLOSSARY OF TERMS}

Agar hanging block, a small block of nutrient agar cut from a poured plate and placed on a cover glass, the surface next the glass having been first touched with a loop from a young fluid culture or with a dilution from the same. It is examined upside down, the same as a hanging drop.

Amœboid, assuming various shapes, like an amœba.

Amorphous, without visible differentiation in structure.

Arborescent, a branched, treelike growth.

Beaded, in stab or stroke, disjointed or semiconfluent colonies along the line of inoculation.

Brief, a few days, a week.

Brittle, growth dry, friable under the platinum needle.

Bullate, growth rising in convex prominences, like a blistered surface.

Butyrous, growth of a butterlike consistency.

Chains, short chains, composed of 2 to 8 elements; long chains, composed of more than 8 elements.

Ciliate, having fine. hairlike extensions, like cilia.

Cloudy, said of fluid cultures which do not contain pseudozoöglœæ.

Coagulation, the separation of casein from whey in milk. This may take place quickly or slowly, and as the result either of the formation of an acid or of a lab ferment.

Contoured, an irregular, smoothly unclulating surface, like tlat of a relief map.

Convex, surface the segment of a circle, but flattened.

Coprophil, dung bacteria.

Coriaceous, growth tough, leathery, not yielding to the platinum needle.

Crateriform, round, depressed, due to the liquefaction of the medium.

Cretaceous, growth opaque and white, chalky.

Curled, composed of parallel chains in wayy strands, as in anthrax colonies.

Diastasic action (same as diastatic), conversion of starch into water-soluble substances by diastase.

Echinulate, in agar stroke, a growth along line of inoculation, with toothed or pointed margins; in stab cultures, growth beset with pointed outgrowths.

Effuse, growth thin, veily, unusually spreading.

Entire, sinooth, having a margin rlestitute of teeth or notches.

Erose, border irregularly toothed.

Filamentous, growth composerl of long, irregularly placed or interwoven filaments.

Filiform, in stroke or stab cultures a uniform growth along line of inoculation.

Fimbriate, border fringed with slender processes, larger than filaments.

Floccose, growth composed of short, curved chains, variously oriented.

Flocculent, said of fluids which contain pseudozoöglose, that is, small adherent masses of bacteria of various shapes and floating in the culture fluid.

Fluorescent, having one color by transmitted light and another by reflected light.

Gram's stain, a method of differential bleaching after gentian violet, methyl violet, etc. The + mark is to be given only when the bacteria are rleep blue or remain blue after counterstaining with Bismarck brown. 
Grumose, clotted.

Infundibuliform, form of a funnel or inverted cone.

Iridescent, like mother-of-pearl. The effect of very thin films.

Lacerate, having the margin cut into irregular segments, as if torn.

Lobate, border deeply·undulate, producing lobes (see Undulate).

Long, many weeks or months.

Maximum temperature, temperature above which growth does not take place.

Medium, several weeks.

Membranous, growth thin, coherent, like a membrane.

Minimum temperature, temperature below which growth does not take place.

Mycelioid, colonies having the radiately filamentous appearance of mold colonies.

Napiform, liquefaction with the form of a turnip.

Nitrogen requirements, the necessary nitrogenous food. This is determined by adding to nitrogen-free media the nitrogen compound to be tested.

Opalescent, resembling the color of an opal.

Optimum temperature, temperature at which growth is most rapid.

Pellicle, in fluid, bacterial growth either forming a continuous or an interrupted sheet over the fluid.

Peptonized, said of curds dissolved by trypsin.

Persistent, many weeks or months.

Plumose, a fleecy or feathery growth.

Pseudozoöglœæ, clumps of bacteria, not dissolving readily in water, arising from imperfect separation or more or less fusion of the components, but not having the degree of compactness and gelatinization seen in zoöglœæ.

Pulvinate, in the form of a cushion, decidedly convex.

Punctiform, very minute colonies, at the limit of natural vision.

Raised, growth thick, with abrupt or terraced edges.

Rapid, developing in twenty-four to forty-eight hours.

Repand, wrinkled.

Rhizoid, growth of an irregular-branched, or rootlike character, as in B. mycoides.

Ring (same as rim), growth at the upper margin of a liquid culture, adhering more or less closely to the glass.

Saccate, liquefaction the shape of an elongated sack, tubular, cylindrical.

Scum, floating islands of bacteria ; an interrupted pellicle or bacterial membrane.

Short, applied to time, a few days, a week.

Slow, requiring five or six days or more for development.

Sporangia, cells containing endospores.

Spreading, growth extending much beyond the line of inoculation, that is, several millimeters or more.

Stratiform, liquefying to the walls of the tube at the top and then proceeding downward horizontally.

Thermal death point, the degree of heat required to kill young fluid cultures of an organism exposed for ten minutes (in thin-walled test tubes of a diameter not exceeding $20 \mathrm{~mm}$.) in the thermal water bath. The water must be kept agitated, so that the temperature shall be uniform during the exposure. 
Transient, a few days.

Turbid, cloudy, with flocculent particles; cloudy plus flocculence.

Umbonate, having a buttonlike, raised center.

Undulate, border wavy, with shallow sinuses.

Vermiform contoured, growth like a mass of worms or intestinal coils.

Verrucose, growth wartlike, with wartlike prominences.

Villous, growth beset with hairlike extensions.

Viscid, growth follows the needle when touched and withdrawn; sediment, on shaking, rises as a coherent swirl.

Zoöglœæ, firm gelatinous masses of bacteria, one of the most typical examples of which is the Streptococcus mesenterioides of sugar vats (Leuconostoc mesenterioides), the bacterial chains being surrounded by an enormously thickened firm covering, inside of which there may be one or many groups of the bacteria.

\section{TABLE}

A Numerical System of Recording the Saliext Characters of AN Orgaxism. (Grote Number $)^{\mathrm{l}}$

$\begin{array}{cl}100 . & \text { Fndospores produced } \\ 10 . & \text { Fndospores not produced } \\ 20 . & \text { Aërobic (strict) } \\ 30 . & \text { Facultative anaërobic } \\ 1 . & \text { Gelatin liquefied } \\ 2 . & \text { Gelatin not liquefied } \\ 0.1 & \text { Acid and gas from dextrose } \\ 0.2 & \text { Acid without gas from dextrose } \\ 0.3 & \text { No acid from dextrose } \\ 0.4 & \text { No growth with dextrose } \\ .01 & \text { Acid and gas from lactose } \\ .02 & \text { Acid without gas from lactose } \\ .03 & \text { No acid from lactose } \\ .04 & \text { No growth with lactose } \\ .001 & \text { Acid and gas from saccharose } \\ .002 & \text { Acid without gas from saccharose } \\ .003 & \text { No acid fron saccharose } \\ .004 & \text { No growth with saccharose } \\ .0001 & \text { Nitrates reduced with evolution of gas } \\ .0002 & \text { Nitrates not reduced } \\ .0003 & \text { Nitrates reduced without gas formation } \\ .00001 & \text { Fluorescent } \\ .00002 & \text { Violet chromogens } \\ .00003 & \text { Blue chromogens } \\ .00004 & \text { Green chromogens } \\ .00005 & \text { Yellow chromogens } \\ & \end{array}$

${ }^{1}$ This system will be found useful as a quick method of showing close relationships inside the genus, but is not a sufficient characterization of any organisn. 


$\begin{array}{ll}.00006 & \text { Orange chromogens } \\ .00007 & \text { Red chromogens } \\ .00008 & \text { Brown chromogens } \\ .00009 & \text { Pink chromogens } \\ .00000 & \text { Nonchromogenic } \\ .000001 & \text { Diastasic action on potato starch, strong } \\ .000002 & \text { Diastasic action on potato starch, feeble } \\ .000003 & \text { Diastasic action on potato starch, absent } \\ .0000001 & \text { Acid and gas from glycerin } \\ .0000002 & \text { Acid without gas from glycerin } \\ .0000003 & \text { No acid from glycerin } \\ .0000004 & \text { No growth with glycerin }\end{array}$

The genus according to the system of Migula is given its proper symbol, which precedes the number thus $(6)$ :
Bacilles coli (Esch.) Mig.
becomes B. 222.111102
Bacilles alcaligexes Petr.
becomes B. 212.333102
Pseudomonas caypestris (Pam.) Sm. becomes Ps. 211.333151
Bactericy suicida Mig.
becomes Bact. 222.232203 



\section{INDEX}

Agar, nutrient, 6 ; sterilization of, 126 ; synthetic, 61

Agar-agar, 6

Agar slant, 10

Air, bacteria of, 48

Alcohol table, 162

Aldehyde-reductase, 83

Allihn's method for deternination of sugars, 154

Ammonia, determination of, 143

Ammonification by soil bacteria, 62,63

Amylolytic action, 114

Anaërobic bacteria, 30, 58

Anthrax, 92

Arsenic, detection of, 114

Ashby's solution, 28

Aspergillus, 5, 111, 114

Atmospheric dust, 48

Autoclave, 13 ; temperature of, 14,119

Azotobacter, 67, 68; medium for, 28

Bacillus amylobacter, 72

Bacillus amylovorus, 88

Bacillus anthracis, 93

Bacillus campestris, 89

Bacillus carotovorus, 89

Bacillus coli, 54, 56, 57

Bacillus cyanogenus, 86

Bacillus denitrificans, $66,67,73$

Bacillus fluorescens liquefaciens, 50, 66,67

Bacillus Hartlebii, 66, 67

Bacillus lactis aërogenes, 82, 85

Bacillus lactis viscosus, 86

Bacillus mycoides, 72

Bacillus prodigiosus, 50

Bacillus proteus vulgaris, 57

Bacillus pyocyaneus, $66,67,95$

Bacillus radicicola, $68,70,71,73$

Bacillus subtilis, 50, 85

Bacillus tuberculosis, 95

Bacillus vulgatus, 72

Bacterium lactis-acidi, 84

Bacteroids, production of, 70

Beef extract, 6

Berkefeld filters, 121

Bile medium, 25, 26

Black rot of cabbage, 89
Blight of pome fruits, 88

Blood poisoning, 96

Blood serum, 128

Blue milk, 86

Body cells in milk, 77, 78

Bouillon, 9 ; glucose-forınate, 24 ; glycerin, 27 ; iron, 26 ; lead, 26 ; neutral red, 25, 55; phenol, 25; sugar, 24 ; sulphindigotate, 30 ; titration of, 142

Bread dough, 105

Brownian movement, 4

Carbol fuchsin (Ziehl), 33

Catalase in milk, 79

Cellulose decomposition by bacteria, 58,59

Chamberland filter, 121

Chart, descriptive, 165

Cider, 107

Clostridia, 2

Colonies, 45, 47

Colorimeter, Schreiner's, 144

Colostrum, 79

Cotton plugs, 9

Cover-glass forceps, 34

Cultural characters, 43

Cultural features, descriptive terms, 166-168

Czapek's solution, 30

Defren-O'Sullivan method for determination of sugar, 158

Dematium, 112

Descriptive terms, for cultural features, 166 ; for morphology, 165

Differential staining, 37

Diseases of man and animals, 91

Diseases of plants, 87

Disinfectants, 18 ; preparation of, 92

Drying, effect upon bacteria, 18

Dunhain's solution, 25, 57

Enriching cultures, 56

Enzymes, 21

Fecal bacteria, 54

Fermentation, 97 ; of bread dough, 105; of cider, 107 ; organisms of, 97 ; of vinegar, 108; of wine, 107 
Fermentation test for milk, 81

Fermentation tube, 25

Filtering apparatus, 122

Filtration, 121

Fractional sterilization, 13, 14

Fuchsin, 33

Gelatin, 6 ; nutrient, 10 ; sterilization of, 126

Gentian violet, 34

Giltay and Aberson's solution, 26

Glossary of terms, 172-174

Glucose-formate bouillon, 24

Gram's iodine solution, 37,67

Gram's stain, 37

Green pus, 95

Heat, effect upon growth, 17

Heyden-Nährstoff agar, 2i, 61

Hot-air sterilizer, 15

Infection threads, 69

Inflammation, 96

Inoculating chamber, 141

Inoculating needles, 21

Inoculating room, 39

Invertase, 101

Isolation methods, 38

Kjeldahl method, 151

Koch, Robert, 6 ; postulates of, 91

Leeuwenhoek, 1

Light, effect upon growth, 16

Litmus milk, 23

Litmus whey, 23

Litmus-lactose agar, 24

Litmus-lactose gelatin, 24

Measures, conversion tables, 160

Methylene blue, 33, 66, 83

Micrococcus candicans, 50

Microscope, 3

Microspira tyrogena, 86

Milk, acidity of, 80 ; bacteria of, 73 ; contamination of, 74 ; as a culture medium, 23; germicilal action of, 78 ; organisms in, 75 ; reducing action of, 82 ; sterilization of, 127

Mold cultures, 113

Molds, amylolytic action of, 114 ; peptonizing action of, 114

Mordants, 32

Morphology, 41; descriptive terms, $165-166$

Motility, 4

Mucor, 108
Negeli's solution, 29

Nessler's reagent, 144

Neutral red broth, 25,55

Neutralization of media, 10

Nitrate, determination of, 146

Nitrate formation, 64,65

Nitrate-forming organisms, medium for, 29

Nitrification, 65

Nitrite, determination of (GriessIlosvay), 148; (Trommsdorf), 150

Nitrite formation, 64

Nitrite-forming organisms, medium for, 29

Nitrite reagent, 148

Nitrogen, determination of, 151 ; fixation by nonsymbiotic organisms, 67 ; fixation by symbiotic organisms, 68 ; relation of soil bacteria to, 62

Nitrogen-free media, 28

Novy jar, 30

Numerical nomenclature, 174

Nutrition, j

Occurrence of bacteria, 1

Oidium lactis, 87

Oxygen, relation to aërobes, 16

Pasteurization, 84, 120

Pectinase, 90

P'enicillium, 110, 114

l'eptonizing action of molds, 114

Permanent preparations, 139

Petri dishes, 16, 125

Phenol bouillon, 25

Phenoldisulphonic acid reagent, 146

Physical and biochemical features, (lescriptive terms, 168

P'hysiological salt solution, 32

Poisons, stimulation by, 113

Potato gelatin, 27

P'otatoes used for cultures, 11

P'seudomonas Stewartii, 89

Reductase, 83

Root tubercles, 69, 71

Ropy milk, 86

Roux tube, 11

Saccharomyces, 98

Sake, 111

Sarcina lutea, 50

Seeds, sterilization of, 131

Septicemia, 96

Sewage bacteria, 55

Sewage streptococci, 55

Snow, bacteria in, 55

Soft rot of vegetables, 89 
Soil, ammonification in, 63 ; bacteria of, 59 ; changes due to heating, 129 ; nitrification in, 65; sampling, 60 ; sterilization of, 128

Sporangium, 109

Spores, 2

Stab cultures, 22

Staining methods, 34

Stains, capsule, 36 ; contrast, 35 ; flagella, 36 ; Gram's, 37 ; spore, 36 Starch-iodide solution, 150

Sterilization, 12, 115; by chemicals, 115; by filtration, 121 ; by heat, 117 ; by steam, 118,119 ; by ultra-violet light, 124 ; technique of, 125

Stimulation, 113

Stock cultures, 138

Streptococcus pyogenes, 96

Sugar bouillion, 24

Sugar gelatin, 24

Sugars, determination of, 154, 158

Sulphates, reduction by bacteria, 71

Titanium chloride, standardization of, 159

Torula, 112
'Total nitrogen, deternination of, 151

'Tuberculin, 94

Tuberculosis, 94

Tyndallization, 13

Tyndall's method, 13

Van Delden's solution, 27

Vinegar, fermentation of, 108

Water, bacteria of, 51,55 ; collecting samples, 51

Water blanks, 32

Water cultures under sterile conditions, 134

Weights, conversion tables, 160

Whey agar, 23

Wilt of sweet corn, 89

Wine, 107

Yeast, 98 ; spore formation in, 99

Ziehl-Neelson stain, 38

Zoöglœa, 4

Zymase, 102

Zymin, 103 



\section{UNIVERSITY OF CALIFORNIA}

MEDICAL SCHOOL LIBRARY

\section{THIS BOOK IS DUE ON THE LAST DATE}

\section{STAMPED BELOW}

Books not returned on time are subject to a fine of $50 \mathrm{c}$ per volume after the third day overdue, increasing to $\$ 1.00$ per volume after the sixth day. Books not in demand may be renewed if application is made before expiration of loan period. 


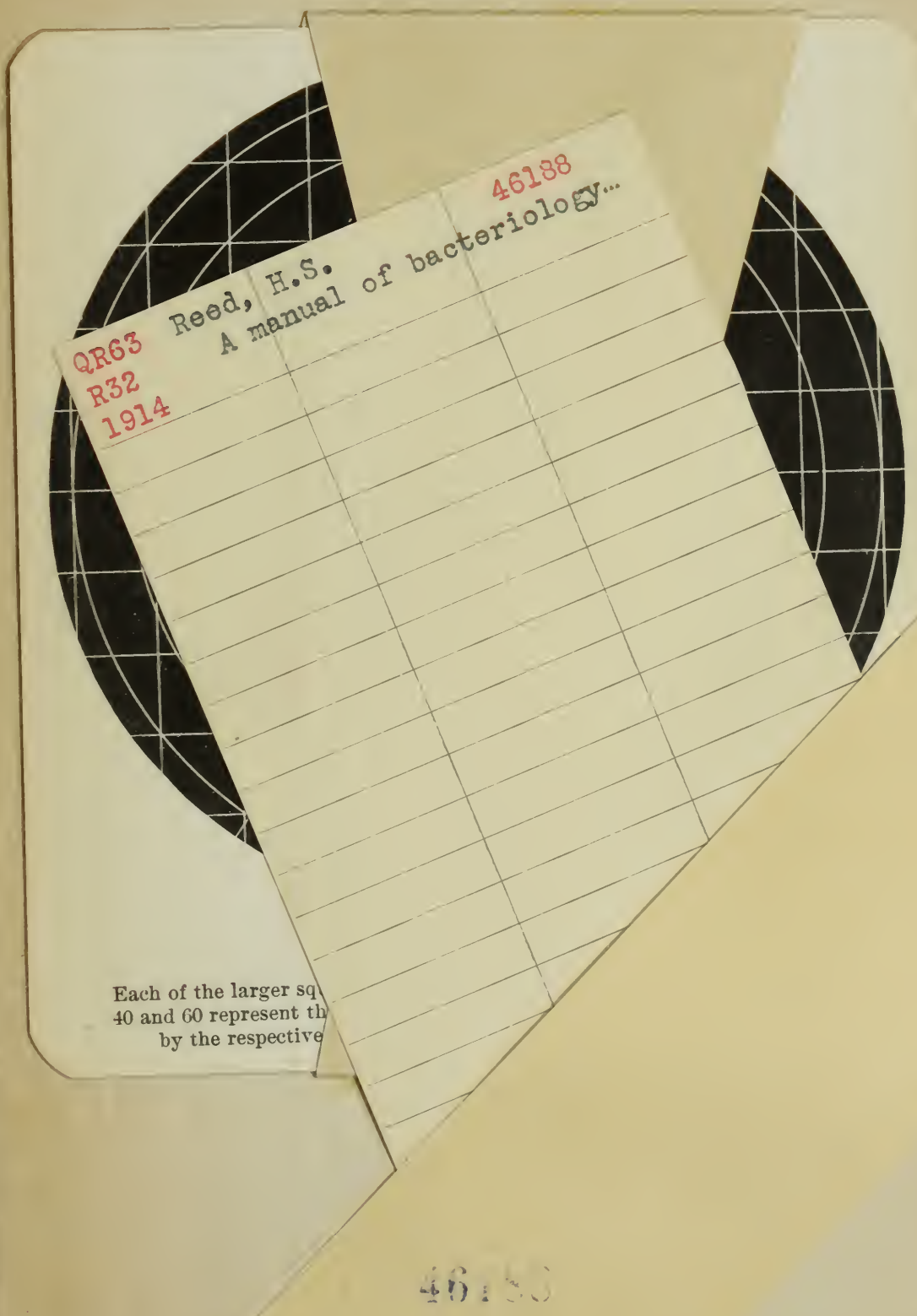


